Brigitte Grande, Edgar Grande, Udo Hahn (Hg.)

Zivilgesellschaft in der Bundesrepublik Deutschland

Edition Politik | Band 111 
Brigitte Grande (M.A.) ist Kulturberaterin und Vorsitzende des Freundeskreises der Evangelischen Akademie Tutzing.

Edgar Grande (Prof. Dr.) ist Gründungsdirektor des Zentrums für Zivilgesellschaftsforschung am Wissenschaftszentrum für Sozialforschung Berlin (WZB) und war bis 2017 Professor für Vergleichende Politikwissenschaft am Geschwister-Scholl-Institut für Politikwissenschaft der Ludwig-Maximilians-Universität München.

Udo Hahn ist Pfarrer und Direktor der Evangelischen Akademie Tutzing. 
Brigitte Grande, Edgar Grande, Udo Hahn (Hg.)

\section{Zivilgesellschaft in der Bundesrepublik Deutschland}

Aufbrüche, Umbrüche, Ausblicke 
Diese Open-Access-Publikation wurde durch den Publikationsfonds der LeibnizGemeinschaft und das Wissenschaftszentrum Berlin für Sozialforschung gefördert.

\section{Bibliografische Information der Deutschen Nationalbibliothek}

Die Deutsche Nationalbibliothek verzeichnet diese Publikation in der Deutschen Nationalbibliografie; detaillierte bibliografische Daten sind im Internet über http://dnb.d-nb.de abrufbar.

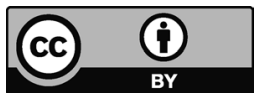

Dieses Werk ist lizenziert unter der Creative Commons Attribution 4.0 Lizenz (BY). Diese Lizenz erlaubt unter Voraussetzung der Namensnennung des Urhebers die Bearbeitung, Vervielfältigung und Verbreitung des Materials in jedem Format oder Medium für beliebige Zwecke, auch kommerziell. (Lizenztext:

https://creativecommons.org/licenses/by/4.o/deed.de)

Die Bedingungen der Creative-Commons-Lizenz gelten nur für Originalmaterial. Die Wiederverwendung von Material aus anderen Quellen (gekennzeichnet mit Quellenangabe) wie z.B. Schaubilder, Abbildungen, Fotos und Textauszüge erfordert ggf. weitere Nutzungsgenehmigungen durch den jeweiligen Rechteinhaber.

\section{Erschienen $2021 \mathrm{im}$ transcript Verlag, Bielefeld (๖) Brigitte Grande, Edgar Grande, Udo Hahn (Hg.)}

Umschlaggestaltung: Kordula Röckenhaus, Bielefeld Druck: Majuskel Medienproduktion $\mathrm{GmbH}$, Wetzlar

Print-ISBN 978-3-8376-5654-1

PDF-ISBN 978-3-8394-5654-5

https://doi.org/10.14361/9783839456545

Gedruckt auf alterungsbeständigem Papier mit chlorfrei gebleichtem Zellstoff. Besuchen Sie uns im Internet: $h$ ttps://www.transcript-verlag.de Unsere aktuelle Vorschau finden Sie unter www.transcript-verlag.de/vorschau-download 


\section{Inhalt}

Vorwort 9

\section{Einführung}

Wie wichtig ist die Zivilgesellschaft?

Einführende Bemerkungen

Edgar Grande

Geschichte der Zivilgesellschaft

in der Bundesrepublik Deutschland

Manfred G. Schmidt

Aufbrüche I:

Zivilgesellschaft und Wiederaufbau

Gewerkschaften als zivilgesellschaftliche Akteure

in der Bundesrepublik

Wolfgang Schroeder

Umbrüche I:

Politischer Protest und Demokratisierung

Neue Konflikte und neue soziale Bewegungen in Deutschland

Dieter Rucht 
Zivilgesellschaft und Demokratie

Die Perspektive der Aktivistin

Christine Scheel.

\section{Aufbrüche II:}

\section{Zivilgesellschaft und Wiedervereinigung}

Politischer Protest und Zivilgesellschaft im deutschen Transformationsprozess

Wolfgang Thierse im Gespräch mit Udo Hahn.... 87

Umbrüche II:

Migration und die neuen Bürgerbewegungen

in Deutschland

Migrationsgesellschaft und Zivilgesellschaft

Hans Vorländer.

Zivilgesellschaft in der Migrationsgesellschaft

Die Geschichte von "Asyl im Oberland «

Julia Poweleit

\section{Umbrüche III:}

Corona als Herausforderung für die Zivilgesellschaft

Was wird aus dem harten Kern?

Auswirkungen der Corona-Krise auf das Engagement

für Geflüchtete

Clara van den Berg, Edgar Grande, Swen Hutter

Ehrenamt und freiwilliges Engagement in der Corona-Krise

Thomas Röbke im Gespräch mit dem Bayerischen Bündnis für Toleranz. 141 
Corona als Herausforderung für Kirchen und Bildungsarbeit

Ein Essay

Udo Hahn

\section{Ausblicke:}

Perspektiven der Zivilgesellschaft in Deutschland

Rechtspopulismus und organisierte Zivilgesellschaft

Wolfgang Schroeder, Samuel Greef, Jennifer Ten Elsen, Lukas Heller.

Entwicklungen und Herausforderungen

der Zivilgesellschaft in Deutschland

Edgar Grande 165

Autorinnen und Autoren 183 



\section{Vorwort}

Der vorliegende Band ist das Ergebnis einer gelungenen Kooperation zwischen Wissenschaft und Zivilgesellschaft, dem Zentrum für Zivilgesellschaftsforschung am Wissenschaftszentrum für Sozialforschung Berlin (WZB) und der Evangelischen Akademie Tutzing und ihrem Freundeskreis. Das Zentrum für Zivilgesellschaftsforschung ist eine junge Einrichtung. Es wurde 2017 gemeinsam vom Wissenschaftszentrum Berlin und der Freien Universität Berlin gegründet und hat eine doppelte Zielsetzung. Zum einen soll mit dieser neuen Einrichtung die Zivilgesellschaftsforschung in Deutschland gefördert und längerfristig in ihrer ganzen Breite erschlossen werden; zum anderen soll dadurch die Vernetzung von Wissenschaft, Zivilgesellschaft und Politik gestärkt werden.

Die Evangelische Akademie Tutzing und ihr Freundeskreis sind etablierte und anerkannte zivilgesellschaftliche Institutionen. Seit 1947 ist die Akademie bundesweit Impulsgeber für Politik, Wirtschaft, Kultur, Wissenschaft, Medien und Kirche. Ihr Auftrag ist es, Meinungsbildung zu ermöglichen, Wissen in Orientierung zu verwandeln, die Zivilgesellschaft zu fördern und die Demokratie zu stärken.

In diesem Auftrag wird die Akademie von einem Freundeskreis unterstützt, der 1949 im Schloss Tutzing gegründet wurde - im selben Jahr wie die Bundesrepublik. Der Freundeskreis der Evangelischen Akademie Tutzing tritt mit einer Vielzahl von Kultur- und Bildungsveranstaltungen in Erscheinung. In vielen bayerischen Städten sind lokale Freundeskreise aktiv, um die Bildungsidee der Akademie weiter zu tragen. Etwa 1100 Bürgerinnen und Bürger in ganz Bayern engagieren sich dort als ehrenamtliche Mitglieder: organisieren, diskutieren, netzwerken - und bilden Zivilgesellschaft. Landesbischof Prof. Dr. Heinrich Bedford Strohm bezeichnet sie als »Multiplikatoren einer Diskussionskultur, in der das Argument gilt, das sorgfältige Abwägen seinen 
Stellenwert hat und unterschiedliche Positionen als bereichernd erlebt werden «.

Das 70-jährige Jubiläum des Freundeskreises der Evangelischen Akademie Tutzing war Anlass für eine gemeinsame Tagung, die die 70-jährige Geschichte der Bundesrepublik Revue passieren ließ und fragte, wie bürgerschaftliches Engagement die politische und gesellschaftliche Entwicklung unseres Landes mitgestaltete. Die Tagung trug den Titel: »Aufbrüche, Umbrüche, Ausblicke: Zivilgesellschaft in der Bundesrepublik Deutschland « und fand vom 14. bis 16. Juni 2019 im Schloss Tutzing statt. Gemeinsam mit Wissenschaftlern und bürgerschaftlichen Akteuren ${ }^{1}$ nahm die Tagung die entscheidenden Aufbrüche und Umbrüche in der Geschichte der Bundesrepublik in den Blick: Wiederaufbau und Wiedervereinigung, Demokratisierung und Migrationsgesellschaft. Wir wollten wissen, vor welchen Herausforderungen die Bundesrepublik in diesen Phasen stand, welche Konflikte die Gesellschaft prägten und welche Rolle die Zivilgesellschaft spielte.

Der Blick nach vorn am Ende der Tagung hat vor allem eines deutlich gemacht: Angesichts des schwächer werdenden gesellschaftlichen Zusammenhalts in unserem Land und der weltweiten Bedrohung freier demokratischer Gesellschaften bleibt es wichtig, dass Bürgerinnen und Bürger Debatten führen zur Zukunft unserer Gesellschaft und sich für eine stabile demokratische Gesellschaftsordnung engagieren. Die Bildungsarbeit Evangelischer Akademien als Foren für kontroverse gesellschaftliche Debatten, für wissenschaftliche Expertise und den Dialog zwischen Politik und Zivilgesellschaft wird wichtiger denn je.

Der vorliegende Band basiert auf der Tutzinger Tagung, er versteht sich aber nicht als Tagungsdokumentation. Ausgehend von der Konzeption der Tagung wurden weitere Beiträge aufgenommen, um das Bild abzurunden und aktuellen Entwicklungen Rechnung zu tragen. Das gilt insbesondere für die Auswirkungen der Corona-Krise, die zweifellos eine gewaltige Herausforderung für die deutsche Gesellschaft, auch für die Zivilgesellschaft, darstellt.

Berlin und Tutzing

Brigitte Grande, Edgar Grande und Udo Hahn

$1 \quad$ Mit Nennung der männlichen Funktionsbezeichnung ist in den Beiträgen dieses Bandes, sofern nicht anders gekennzeichnet, immer auch die weibliche Form mitgemeint. 
Einführung 



\section{Wie wichtig ist die Zivilgesellschaft? Einführende Bemerkungen}

Edgar Grande

Die Geschichte der Bundesrepublik ist auch eine Geschichte ihrer Zivilgesellschaft. In den markanten Entwicklungsphasen der Bundesrepublik spielten zivilgesellschaftliche Akteure und Bewegungen eine maßgebliche Rolle. Diese Grundannahme des vorliegenden Bandes möchte ich im Folgenden in drei Schritten konkretisieren. Zunächst werde ich erläutern, was wir unter Zivilgesellschaft verstehen. Zweitens werde ich begründen, weshalb es sinnvoll und angemessen ist, einen Zusammenhang zwischen der Geschichte der Bundesrepublik und der Zivilgesellschaft in Deutschland herzustellen. Schließlich werde ich der Frage nachgehen, wer nach diesem Verständnis zur Zivilgesellschaft gehört - und wer nicht. Abschließend werde ich kurz erläutern, wie diese Grundüberlegungen in der Konzeption des Bandes umgesetzt werden.

Was verstehen wir unter Zivilgesellschaft? Der Begriff hat bekanntlich eine lange Geschichte (vgl. Kocka 2001), er ist aber kein etablierter Begriff der politischen Systemlehre. Im Stichwortverzeichnis des Standardwerks zum politischen System Deutschlands von Manfred G. Schmidt finden wir den Begriff nicht (vgl. Schmidt 2016). Der Begriff der »Zivilgesellschaft« wurde bekanntlich erst in den 1990er Jahren im Zusammenhang mit den Bürgerbewegungen in Osteuropa wiederbelebt und hat seither auch in Deutschland größere Verbreitung gefunden (vgl. Adloff 2005). Der Begriff ist auch nicht unumstritten. Einige bevorzugen stattdessen den Begriff»Bürgergesellschaft« oder sie sprechen allgemein von »bürgerschaftlichem Engagement« (vgl. Enquete-Kommission 2002; Dahrendorf 2003). Im Grunde genommen beschreiben aber alle diese Begriffe das gleiche, nämlich die freiwilligen $\mathrm{Zu}$ sammenschlüsse, das freiwillige Engagement der Bürger als Bürger jenseits von Staat, Markt und Privatsphäre. In diesem Verständnis zeichnet sich Zivilgesellschaft durch eine große Vielfalt von Organisations- und Handlungs- 
formen und durch eine große Bandbreite von Handlungsbereichen aus. Das Spektrum reicht vom Non-Profit-Sektor, also dem nicht-gewinnorientierten wirtschaftlichen Handeln, über die vielfältigen Formen des ehrenamtlichen Engagements in Verbänden, Vereinen und Initiativen bis hin zur politischen Beteiligung, zu politischem Protest und zu sozialen Bewegungen. Dieses Verständnis von Zivilgesellschaft liegt allen Beiträgen des vorliegenden Bandes $\mathrm{zu}$ Grunde.

Die Zivilgesellschaft in diesem Sinne besitzt eine eigene Handlungslogik und sie steht in einem eigentümlichen Spannungsverhältnis sowohl zur Wirtschaft als auch zum Staat. Sie ist weder das eine noch das andere, sie muss sich zu beiden Bereichen positionieren und gegen Vereinnahmungsversuche behaupten. Wichtige Debatten zum bürgerschaftlichen Engagement in Deutschland drehen sich um dieses Spannungsverhältnis. Das gilt für die Debatte um die "Monetarisierung« des Ehrenamtes, in der es im Kern um das Verhältnis der Zivilgesellschaft zur gewinnorientierten Wirtschaft geht. Aber auch das Verhältnis der Zivilgesellschaft zum Staat ist immer wieder Anlass von Kontroversen. Hier geht es insbesondere um die Eigenständigkeit der Zivilgesellschaft und die Gefahr ihrer »Instrumentalisierung« durch den Staat einerseits, ihren Substanzverlust durch die »Professionalisierung« ehrenamtlicher Tätigkeit andererseits.

Wer gehört nun aber konkret zur Zivilgesellschaft? Die österreichische Tageszeitung »Der Standard« hat auf diese Frage unlängst eine aufschlussreiche Antwort gegeben: »Flüchtlingshelfer, Protestversammler, politische Aktivisten, Umweltschützer - sie zählen zur Zivilgesellschaft und springen ein, wenn Parteien und Staat versagen « (Standard, 30.09.2018). In dieser Antwort zeigt sich ein zwar aktuelles, aber doch sehr enges, von starken normativen Vorannahmen und Erwartungen geprägtes Verständnis von Zivilgesellschaft. Darin gilt die Zivilgesellschaft per Definition als gemeinwohlorientiert, dem politischen Protest werden umstandslos emanzipatorische Wirkungen zugeschrieben und politische Beteiligung gilt eindeutig als demokratiefördernd. Die Zivilgesellschaft gilt nach diesem Verständnis als "gelungene Gesellschaft« (Blinkert/Klie 2018).

Ist das so? Bei genauerer Betrachtung zeigt sich, dass in der Zivilgesellschaft die Pluralität, das gesamte Spektrum von Werten, Zielen, Akteuren und Handlungsformen in einer Gesellschaft zum Ausdruck kommt. Das schließt mit ein, dass auch die Zivilgesellschaft ihre Schattenseiten haben kann, ob das lokale Initiativgruppen sind, in denen die Eigeninteressen von Anwohnern dominieren, sei es gegen neue Straßen, gegen Mobilfunkmasten, gegen 
Windräder oder anderes mehr, oder ob das nationalistische und ausländerfeindliche Proteste wie Pegida sind. Die »schmutzige Seite« (Geiges et al. 2015) der Zivilgesellschaft zeigt sich an vielen Stellen und sie ist kein neues Phänomen. Sheri Berman (2003) hat am Beispiel der Weimarer Republik herausgearbeitet, dass zivilgesellschaftliche Vereinigungen auch von den Gegnern der Demokratie zu ihrer Abschaffung genutzt werden können. Deshalb sollte das Untersuchungsfeld der Zivilgesellschaftsforschung nicht durch zu starke normative Vorannahmen begrenzt werden. Nur so kann die Zivilgesellschaft in allen ihren Erscheinungsformen und in ihrer ganzen Widersprüchlichkeit erfasst werden. Wie wichtig das ist, zeigt Hans Vorländer (in diesem Band) in seinem Beitrag, aus dem deutlich wird, dass die Zivilgesellschaft in Deutschland derzeit gespalten ist und mehrere ganz unterschiedliche Gesichter hat.

Daraus folgt auch, dass die "Zivilgesellschaft« nicht nur ein Akteur oder ein Netzwerk von Akteuren ist, sondern dass sie auch eine Arena, ein Kampfplatz sein kann, wo unterschiedliche Ziele, Interessen und Wertvorstellungen aufeinanderprallen; wo gesellschaftliche Konflikte ausgetragen - und im besten Fall auch beigelegt werden.

Was hat die Zivilgesellschaft in diesem Verständnis mit der Geschichte der Bundesrepublik zu tun? Im siebzigsten Jubiläumsjahr der Bundesrepublik wurde Vieles und von Vielen gefeiert. Im Mittelpunkt standen die Verfassung, das Grundgesetz, und die Verfassungsorgane, nicht zuletzt das Bundesverfassungsgericht als oberster Hüter der Verfassung. In Feierstunden und Festreden wurde zu Recht betont, dass für eine »geglückte Demokratie« (Wolfrum 2006) eine gute Verfassung und gute Verfassungsorgane von größter Bedeutung sind. Aber inzwischen ist hinlänglich bekannt, dass es auf Verfassungen und politische Institutionen alleine nicht ankommt.

Als Kronzeugen für diese Einsicht möchte ich keinen Vertreter der politikwissenschaftlichen Systemlehre heranziehen, für die die Distanz zum Staat ohnehin konstitutiv ist, sondern einen der bekanntesten (und umstrittensten) konservativen Staatslehrer in Deutschland, Ernst Forsthoff. In der konservativen Staatslehre nimmt der Staat bekanntlich eine herausgehobene Stellung ein und sie besitzt deshalb eine besondere Empfindlichkeit - mitunter auch Überempfindlichkeit - für alle gesellschaftlichen und politischen Kräfte und Entwicklungen, die die Stellung des Staates zu gefährden drohen.

Die Erfolgsgeschichte der Bundesrepublik war für die konservative Staatslehre von Beginn an höchst irritierend. Auf das Provisorium, das nach dem Zweiten Weltkrieg in Deutschland entstanden ist, traf keines der klassischen Merkmale der Staatlichkeit in vollem Umfang zu. Die Staatsgewalt war 
eingeschränkt, das Staatsgebiet war unklar, das Staatsvolk war geteilt. Die außerordentlichen Leistungen der neuen Bundesrepublik - insbesondere das unerwartete "Wirtschaftswunder« - lassen sich, so Forsthoff, mit den klassischen Attributen von Staatlichkeit nicht überzeugend erklären. Offensichtlich waren für die wirtschaftlichen, politischen und gesellschaftlichen Erfolge der neuen Republik andere Faktoren verantwortlich - aber welche? Forsthoff hat versucht, auf diese Frage 1960 in einem noch heute lesenswerten kleinen Aufsatz in der Zeitschrift "Merkur« eine Antwort zu geben. Für ihn bestand das "Erstaunliche, unerwartet Neuartige der Entwicklung [...] seit 1945 darin, daß es die Gesellschaft war, die sich wesentlich aus eigener Kraft regeneriert hat.« (Forsthoff 1960, S. 810; meine Hervorhebung). Es sind die durch »die Selbstorganisation der Gesellschaft formierten Kräfte« (ebd., S. 811), die aus seiner Sicht für die Erfolgsgeschichte der Bundesrepublik in den Anfangsjahren verantwortlich sind. Auch wenn er selbst den Begriff nicht verwendet, so lautet Forsthoffs These im Kern, dass es gerade auf die organisierte Zivilgesellschaft in dieser Phase der Geschichte der Bundesrepublik angekommen ist.

Daran sollte sich in der Folgezeit nichts ändern. Der ZEIT-Journalist Gunter Hofmann behauptete mehr als vierzig Jahre später in seiner "Anatomie« der Bundesrepublik: »Die Bundesrepublik regiert sich weitgehend selbst. Sie ist zur Zivilgesellschaft geworden, auf die man sich im Zweifel mehr verlassen kann als auf ihre Politik« (Hofmann 2004). Es kann dahingestellt bleiben, ob diese Aussage tatsächlich zutrifft. Entscheidend ist, dass es gute Gründe gibt, bei der Würdigung der Erfolgsgeschichte der Bundesrepublik der Zivilgesellschaft eine besondere Bedeutung beizumessen.

Aber geht es dabei wirklich um die Zivilgesellschaft in unserem Verständnis? Forsthoff selbst verwendet den Begriff nicht, bei ihm ist von Parteien und Verbänden, insbesondere den Verbänden des Wirtschaftslebens, die Rede. Diese haben in den Nachkriegsjahrzehnten das Bild der organisierten Zivilgesellschaft in Deutschland geprägt. Die bundesdeutsche Gesellschaft war und ist eine »organisierte Gesellschaft«. Renate Mayntz hat das im Klassiker der deutschen Organisationssoziologie, ihrem erstmals 1963 erschienenen Buch "Soziologie der Organisation" prägnant formuliert: Die "gegenwärtige Gesellschaft«, ist gekennzeichnet »durch vielfaches Organisieren und durch eine große Zahl von komplexen, zweckbewußt und rational aufgebauten sozialen Gebilden« (Mayntz 1963, S. 7). Diese Organisationen sind notwendig und unentrinnbar. Auch wenn man nicht Mitglied einer Organisation ist, ganz ent- 
ziehen kann man sich ihrer Wirkungsmacht nicht. In allen Lebensbereichen ist man von ihrer Existenz und ihrem Funktionieren abhängig.

Beide, Forsthoff wie Mayntz, hatten wohl kaum »Protestversammler, politische Aktivisten, Umweltschützer« vor Augen, als sie die Bedeutung der Organisations- und Selbstorganisationsfähigkeit der Bundesrepublik in ihrer Gründungsphase betonten. Die Beiträge dieses Bandes zeigen aber auch, dass das Verständnis von Zivilgesellschaft wandelbar ist - und dass es sich in der Geschichte der Bundesrepublik auch gewandelt hat. Die Umbruchphasen, die im Mittelpunkt dieses Bandes stehen, sind auch Umbruchphasen im Verständnis und Selbstverständnis der Zivilgesellschaft in Deutschland. Das gilt für die normativen Erwartungen an das bürgerschaftliche Engagement, es gilt aber auch für die Grenzziehungen zu Staat und Wirtschaft. Dabei zeigt sich, dass Abgrenzungen immer wieder in Frage gestellt, verändert und aufgehoben werden. Am Beispiel der Gewerkschaften und Kirchen wird dies besonders deutlich. Beide finden sich in der oben genannten Umschreibung nicht wieder. Aber Wolfgang Schroeder (in diesem Band) betont in seinem Beitrag zu Recht, dass die deutschen Gewerkschaften sich immer auch als gesellschaftspolitischer Akteur verstanden haben, wenngleich sich der Stellenwert gesellschaftspolitischer Ziele und Aktivitäten für sie im Laufe der Zeit verändert hat. Die Frage ist dann nicht mehr, ob Gewerkschaften Teil der Zivilgesellschaft sind, sondern in welchem Maße sie dies sind - und diese Frage muss für die jeweiligen Entwicklungsphasen der Bundesrepublik wohl unterschiedlich beantwortet werden. Ähnliches gilt für die Kirchen, die sich ständig im Spannungsfeld zwischen seelsorgerischen Aufgaben und gesellschaftspolitischer Verantwortung befanden - und derzeit wieder in besonderer Weise finden, wie Udo Hahn (in diesem Band) in seinem Beitrag betont. All das legt nahe, nicht von der Zivilgesellschaft als einer mehr oder weniger festen Größe zu sprechen, sondern auch von Zivilgesellschaftlichkeit als einer Variablen, deren Umfang und Zusammensetzung sich ständig verändert - und die von den Akteuren und Organisationen selbst (durchaus strategisch) verändert werden kann.

Kurz gesagt: Die Zivilgesellschaft hat viele Gesichter und wir werden in diesem Band einige dieser Gesichter zeigen. Weil sie aber so viele Gesichter hat, waren wir gezwungen, eine Auswahl zu treffen. Die Zivilgesellschaft kann hier nicht in allen ihren Facetten präsentiert werden. Dieser Band will kein Handbuch der Zivilgesellschaft sein. Wir haben vielmehr versucht, in der Konzeption dieses Bandes mehrere Anliegen miteinander zu verbinden. Auf der einen Seite sollen durchaus eine gewisse Breite und Vielfalt der Zi- 
vilgesellschaft aufgezeigt werden und dies soll zugleich mit der Geschichte der Bundesrepublik verbunden werden. Wir beabsichtigen damit aber auch nicht, eine alternative Geschichte der Bundesrepublik zu präsentieren. Wir wollen die Rolle der Zivilgesellschaft und ihren Wandel vielmehr exemplarisch für markante Entwicklungsphasen der Bundesrepublik behandeln: Dazu zählen die Jahre des Wiederaufbaus, die Phase der Demokratisierung der 6oer und 7oer Jahre, die deutsche Wiedervereinigung, der gesellschaftliche Wandel hin zu einer Migrationsgesellschaft und die jüngste Zäsur durch die CoronaPandemie. Jede dieser Phasen war geprägt von zivilgesellschaftlichen Organisationen und bürgerschaftlichem Engagement: den großen Industriegewerkschaften, den neuen sozialen Bewegungen, der Bürgerbewegung in der DDR, den Helferinitiativen in der sogenannten Flüchtlingskrise, aber auch den Protestbewegungen gegen Einwanderung und gegen die Maßnahmen zur Bekämpfung der Corona-Pandemie. $\mathrm{Zu}$ jeder dieser Phasen haben wir in diesem Band einen Themenblock vorgesehen, der die Rolle der Zivilgesellschaft in den Aufbruch- und Umbruchphasen in der Geschichte der Bundesrepublik behandelt. Diese Schwerpunktsetzung mag an manchen Stellen willkürlich erscheinen. Sie findet sich auch nur bedingt in den Phaseneinteilungen einschlägiger historischer Gesamtdarstellungen zur deutschen Geschichte im 20. Jahrhundert wieder (vgl. z.B. Herbert 2014). Aber bekanntlich steckt hinter jeder Periodisierung eine absichtsvolle Willkür. Entscheidend ist, dass es mit ihrer Hilfe gelingt, interessante Einblicke und Erkenntnisse zu gewinnen und wir hoffen, dass die in diesem Band gewählte Phaseneinteilung das leisten wird.

Wir werden aber nicht nur zurückblicken, wir wollen auch nach vorne blicken. Der letzte Teil dieses Bandes wird sich mit den Zukunftsperspektiven der Zivilgesellschaft beschäftigen. Vor welchen Herausforderungen steht die Zivilgesellschaft in Deutschland? Und was kann, was muss getan werden, damit die Zivilgesellschaft diese Herausforderungen bewältigen kann?

Bei der Beschäftigung mit all diesen Fragen werden ganz unterschiedlichen Perspektiven kombiniert. Das Spektrum der Autoren umfasst sowohl Wissenschaftler, als auch Aktivisten und Praktiker aus Politik und Zivilgesellschaft. Die Vielfalt der Themenschwerpunkte, Herangehensweisen und Argumente der einzelnen Beiträge zeigt gerade in der Zusammenschau eindrucksvoll, dass die Zivilgesellschaft die Bundesrepublik entscheidend geprägt hat - und dass die großen Herausforderungen, vor denen sie steht, ohne eine starke Zivilgesellschaft nicht bewältigt werden können. 


\section{Literaturhinweise}

Adloff, Frank (2005): Zivilgesellschaft. Frankfurt a.M.: Campus.

Berman, Sheri (2003): Civil Society and the Collapse of the Weimar Republic. In: World Politics, 49(3), S. 401-429.

Blinkert, Baldo/Klie, Thomas (2018): Zivilgesellschaftliches Engagement in Deutschland und Europa. In: Klie, Thomas/Klie, Anne Wiebke (Hg.), Engagement und Zivilgesellschaft. Wiesbaden: Springer VS, S. 339- 424.

Dahrendorf, Ralf (2003): Die Krisen der Demokratie. München: C.H. Beck.

Enquete-Kommission (2002): Bericht der Enquete-Kommission »Zukunft des Bürgerschaftlichen Engagements«: Bürgerschaftliches Engagement: auf dem Weg in eine zukunftsfähige Bürgergesellschaft. Deutscher Bundestag, 14. Wahlperiode, Drucksache 14/8900.

Forsthoff, Ernst (1960): Die Bundesrepublik Deutschland. Umrisse einer Realanalyse. In: MERKUR, 14(9), S. 807-821.

Geiges, Lars/Marg, Stine/Walter, Franz (2015): Pegida. Die schmutzige Seite der Zivilgesellschaft? Bielefeld: transcript.

Herbert, Ulrich (2014): Geschichte Deutschlands im 20. Jahrhundert. München: C.H. Beck.

Hofmann, Gunter, 2004: Abschiede, Anfänge. Die Bundesrepublik - eine Anatomie. München: Piper.

Kocka, Jürgen (2001): Zivilgesellschaft. Zum Konzept und seiner sozialgeschichtlichen Verwendung. In: Kocka, Jürgen/Nolte, Paul/Randeria, Shalini/Reichardt, Sven, Neues über Zivilgesellschaft. Aus historisch-sozialwissenschaftlichem Blickwinkel. Discussion Paper Po1-801. Berlin: WZB, S. 4-21.

Schmidt, Manfred G. (2016): Das politische System Deutschlands, 3. Auflage. München: C.H. Beck.

Wolfrum, Edgar (2006): Die geglückte Demokratie. Geschichte der Bundesrepublik Deutschland von ihren Anfängen bis zur Gegenwart, 2. Auflage. Stuttgart: Klett-Cotta. 



\title{
Geschichte der Zivilgesellschaft in der Bundesrepublik Deutschland
}

\author{
Manfred G. Schmidt
}

Der folgende Beitrag gibt einen Überblick über die Geschichte der Zivilgesellschaft in der Bundesrepublik Deutschland. Er beginnt mit der Zivilgesellschaft im Jahr 2019. Daran schließt sich ein zweifacher Blick zurück an: $\mathrm{Zu}$ nächst bis in die 1970er und 1980er Jahre, anschließend bis in die Frühphase der Bundesrepublik Deutschland und die Jahre vor ihrer Gründung. Im Anschluss daran werden die Schubkräfte der Zivilgesellschaft erörtert, ihre Wirkungen diskutiert und die deutsche Zivilgesellschaft im internationalen Vergleich porträtiert. Offene Fragen der Beobachtung und Bewertung der Zivilgesellschaft beschließen den Beitrag.

\section{Zivilgesellschaft heute}

»Zivilgesellschaft« ist ein Begriff der politischen und der wissenschaftlichen Sprache für einen besonderen Bereich moderner Gesellschaften. ${ }^{1}$ Er hat zwei Bedeutungsvarianten: Er ist ein wertender (»normativer«) Begriff der politischen Sprache einerseits und ein auf Fakten bezogener (»empirischer«) Begriff der Beschreibung andererseits. Als ein wertender Begriff meint Zivilgesellschaft ein Erneuerungsprojekt, ein Erneuerungsprojekt menschlichen Zusammenlebens in der Tradition der Aufklärung (Kocka 2006; Kocka et al. 2001). In diesem Begriffsverständnis sind die Spuren seiner Vorgeschichte in

»Zivilgesellschaft« ist im Übrigen auch ein Theorieprogramm, das im Unterschied zur marxistischen Politischen Ökonomie und im Gegensatz zur klassisch-soziologischen Ungleichheitsforschung vor allem die »Anerkennungs-« und die »Teilhabegerechtigkeit«erörtert, nicht, jedenfalls nicht primär, die »Verteilungsgerechtigkeit« (vgl. hierzu vor allem Kocka 2006). 
Lateinamerika und Osteuropa nachweisbar. Zivilgesellschaft war ursprünglich in Lateinamerika in den 1970er Jahren ein Kampfbegriff der Opposition gegen den autoritären Staat und seine Wirtschaft. In Mittel- und Osteuropa wurde "Zivilgesellschaft« dann in den 1980er Jahren ein Erneuerungsbegriff der Opposition gegen den von marxistisch-leninistischen Parteien dominierten Staatssozialismus. Wer dieser Bedeutung auch heute folgt, definiert die Zivilgesellschaft als ein Erneuerungsprojekt. Jürgen Kocka (2006) beispielsweise wertet die Zivilgesellschaft als ein »nicht eingelöstes Zukunftsprojekt menschlichen Zusammenlebens in der Tradition der Aufklärung « rechtsstaatlich, demokratisch und wohlhabend. Eine ähnliche Sicht findet sich bei Klaus von Beyme (2006, S. 259-269). Eine kritische Distanz nimmt Ottmann (2017, S. 365f.) ein. Ottmann zeigt, dass in der Rede von der Zivilgesellschaft recht »verschiedene Vorstellungen vom guten Leben« zum Zuge kommen können.

Der Begriff »Zivilgesellschaft« bezeichnet vor diesem Hintergrund alle Organisationen und Bewegungen, die sich auszeichnen durch

- freiwillige Mitgliedschaft

- eine Position zwischen Staat, Markt und Privatsphäre

- öffentliche Aktivität

- ziviles (nicht-militärisches) und gesetzesverträgliches Tun und Lassen

- sowie Streben nach »öffentlichen Gütern« - oft im Sinne der Tradition der Aufklärung.

Wer gehört zur Zivilgesellschaft in diesem Verständnis? Nach geläufiger Auffassung zählen als ihre Mitglieder insbesondere

- Vereine,

- Verbände,

- soziale Bewegungen, auch Protestbewegungen,

- Bürgerinitiativen und

- Stiftungen.

Je nach engem oder weitem Begriffsverständnis werden Religionsgemeinschaften sowie bisweilen politische Parteien ebenfalls zur Zivilgesellschaft gezählt. Die Zivilgesellschaftlichkeit der Religionsgemeinschaften ist umstritten, weil in ihnen das Prinzip der durch Beitritt erlangten freiwilligen Mitgliedschaft in der Regel nicht gegeben ist. Die Parteien werden aufgrund ihrer 
Staatsnähe meist nicht oder nur am Rande als »zivilgesellschaftlich« gewertet.

Die Zivilgesellschaft vereint eine Vielzahl unterschiedlicher Organisationen. $\mathrm{Zu}$ ihr gehören ein umfänglicher nichtpolitischer Teil und ein politischer Sektor. Der nichtpolitische Teil umfasst größtenteils Massenorganisationen wie Sportvereine, Wandervereine und Vereine des Musikwesens - kurz: „Freizeitorganisationen«. Zum politisch engagierten Teil der Zivilgesellschaft gehören vor allem die Organisationen und Bewegungen, die nach politischem Einfluss streben - in der Öffentlichkeit und auf die Regierungspolitik. An Interessenverbände, soziale Bewegungen, politische Protestbewegungen und andere Kollektive ist dabei vor allem gedacht.

Wie groß ist die Zivilgesellschaft in Deutschland? Nach eigenen Angaben ist die Zivilgesellschaft mittlerweile eine Millionen zählende Wachstumsbranche. Allein die Zahl der zu ihr gerechneten Organisationen beispielsweise ist eindrucksvoll - 605.000 Vereine wurden 2017 in Deutschland gezählt, so berichtet der vom Bundesamt für Statistik herausgegebene Datenreport 2018 (S. 374). Beachtlich ist auch die Zahl der zivilgesellschaftlichen Interessenverbände. Allein der sogenannten Lobbyliste nach zu urteilen - sie enthält die offiziell registrierten und damit beim Parlament und bei der Regierung anhörungsberechtigten Verbände - gibt es derzeit mehr als 2300 Verbände.

Die Zahl der Mitwirkenden an der Zivilgesellschaft ist ebenfalls eindrucksvoll - trotz der Bandbreite der hierzu vorliegenden Informationen. Höchstzahlen berichtet der per Telefoninterviews durchgeführte Freiwilligensurvey 2014. Ihm zufolge haben 44 Prozent der über 16-Jährigen »Zivilengagement « (Alscher et al. 2018, S. 377). ${ }^{2}$ Hierbei werden allerdings Mitwirkende mit regelmäßiger und seltener Beteiligung zusammengezählt. Strengere Messungen signalisieren niedrigere Beteiligungswerte. Weniger als die Hälfte - 19 Prozent der mindestens 16-Jährigen - ermittelt das Sozioökonomische Panel für »regelmäßiges Engagement«, das als »mindestens einmal pro Monat « definiert ist (Alscher et al. 2018, S. 376). Und erheblich kleinere Mitgliederzahlen signalisiert zudem die "aktive Mitgliedschaft/Eh-

2 Zur Datenbasis: Seit Ende 2011 liegt die wissenschaftliche Leitung des Freiwilligensurveys beim Deutschen Zentrum für Altersfragen (DZA). Die Daten aller Erhebungsjahre sowie ausführliches Dokumentationsmaterial stehen Nutzerinnen und Nutzern für die wissenschaftliche Forschung über das Forschungsdatenzentrum des DZA zur Verfügung. 
renamt«-Statistik des ALLBUS (der Allgemeinen Bevölkerungsumfrage der Sozialwissenschaften).

Nach Mitgliederzahlen zu urteilen überragt der nichtpolitische Teil der Zivilgesellschaft den politischen Bereich - und zwar zunehmend (Weßels 2018, S. 355). Die größten Mitgliedschaften verzeichnen die Sportvereine, sodann Vereine, die sich der Kultur bzw. der Musik widmen und sonstige »Hobbyvereine«. Noch eindrucksvoller wird der Vorrang der nichtpolitischen Zivilgesellschaft vor der politischen, wenn auch die Religionsgemeinschaften mitgezählt werden.

Die volkswirtschaftliche Bedeutung der Zivilgesellschaft ist schwer $\mathrm{zu}$ schätzen, weil der Großteil ihrer Aktivitäten monetär nicht vergütet ist. Einfacher ist die Ermittlung der Zahl der Beschäftigten im wirtschaftsstärkeren Kern der Zivilgesellschaft, dem sogenannten »Non-Profit-Sektor« (im Sinne jenes Sektors, der weder Staat noch Markt ist) und von dort aus die Finanzierungsbasis. Die Zahl der sozialversicherungspflichtigen Beschäftigten beträgt nach Schätzungen von Adloff (2013, S. 915), der aus diversen Quellen berichtet, rund 2,3 Millionen (2007). Das sind 5,3 Prozent der Gesamtbeschäftigung in Deutschland. Diese lag damals - 2007 - bei 43,3 Millionen Erwerbspersonen, davon waren 39,654 Millionen Erwerbstätige (Datenreport 2008, S. 111). Die Finanzierung dieses Sektors basiert zu rund zwei Dritteln $(64,3 \%)$ auf Zuwendungen aus öffentlichen Haushalten, auf Gebühren und Spenden (vgl. Adloff 2013, S. 915). Die Staatsferne der Zivilgesellschaft ist mithin relativer Art.

\section{Stationen der Zivilgesellschaft seit den 1970er Jahren}

Seit wann spielt die Zivilgesellschaft in der Bundesrepublik Deutschland eine nennenswerte Rolle? Seit den 1970er und 1980er Jahren, sagen viele Beobachter. Sie haben dabei vor allem den politischen Teil der Zivilgesellschaft im Blick. Tatsächlich erregen neue politische Organisationen und politische Bewegungen der Zivilgesellschaft in diesen Jahrzehnten viel Aufsehen - und finden sich seit den 1980er Jahren vor allem mit den »Grünen« und dem linken Flügel der SPD auch im Deutschen Bundestag vertreten. Als besonders auffällige Organisationen der Zivilgesellschaft zählen dabei vor allem

- die seit Mitte der 1970er Jahre besonders sichtbare Anti-AtomkraftBewegung, 
- die Ökologiebewegung,

- die Frauenbewegung und - vor allem -

- die Friedensbewegung, die insbesondere im Streit um die "NATONachrüstung " gegen die sowjetischen SS-20-Mittelstreckenraketen »die größte Protestmobilisierung in der alten $\mathrm{BRD}$ « wurde, so die Worte eines Historikers zur Geschichte des politischen Protestes in Deutschland (Gassert 2018, S. 159).

Für die 1970er und 1980er Jahre als Aufstiegsperiode der Zivilgesellschaft, insbesondere ihres politischen Teils, spricht auch ihr kräftiges Wachstum in dieser Zeit. Davon zeugen viele Indikatoren, die Zahl der Organisationen und der Mitglieder der Zivilgesellschaft beispielsweise, oder ihre Spender, Stiftungen, Themen und Tätigkeitsfelder, sowie ihre Tätigkeit in Notlagen wie in der Flüchtlingskrise von 2015, in der die ultraliberale Migrationspolitik der Bundesregierung und der Bundestagsopposition die Länder und Kommunen vor größte Herausforderungen bei der Unterbringungen und Versorgung der Flüchtlinge stellte. ${ }^{3}$

Seit den 1970er Jahren wächst die Zivilgesellschaft (jedenfalls den Trends zufolge), aber mit unterschiedlicher Geschwindigkeit. Besonders kräftig expandiert bis heute der »Freizeit-Sektor" der Zivilgesellschaft (Datenreport 2018, S. 354-355). Abnehmende Mitgliederzahlen hingegen berichten die Religionsgemeinschaften, die politischen Parteien und die Gewerkschaften, was Fachleute als Warnsignal deuten (Datenreport 2018; Weßels 2018; Niedermayer 2019).

Uneinheitlich verhält sich hingegen der politische Teil der Zivilgesellschaft: teils wächst, teils stagniert, teils schrumpft er. Die Anlässe und Ursachen sind jeweils verschieden. Viele Protestbewegungen waren nach dem Hoch der 1980er Jahre schwächer geworden, so die Friedens-, die Umweltund die Frauenbewegungen. Doch zu Ende gelangt sind die Protestbewegungen nicht. Protest gegen Globalisierung und gegen Rechtspopulismus und Widerstreben gegen die Migrationspolitik der Bundesregierung in der Flüchtlingskrise sind stärker als zuvor. Zudem bleibt der Protest gegen Nuklearrüstung und Atomkriegsgefahr eine Konstante (Gassert 2018, S. 209ff., S. 237ff., S. 79). Außerdem wecken neue Themen die Aufmerksamkeit der 
Öffentlichkeit. Das gilt namentlich für klimapolitische Themen, wie die Mobilisierungskraft der »Fridays for Future«- Bewegung zeigt, und für verkehrspolitische Streitfragen.

\section{Stationen der Zivilgesellschaft vor den 1970er Jahren}

Wer meint, die Zivilgesellschaft spiele erst seit den 1970er Jahren eine größere politische Rolle, unterschätzt ihr Gewicht vor den 1970ern: Vereine, Verbände und Protestbewegungen waren schon in den 1950er und 1960er Jahren lautstark vernehmbar - Religionsgemeinschaften ebenso und politische Parteien allemal.

Unterschätzt werden oft auch die Massenproteste gegen Hunger und währungsreformbedingte Teuerung schon vor 1949 (Gassert 2018). Am 12. November 1948 beispielsweise wurden in der Bizone 9 Millionen Beteiligte am 24-stündigen Generalstreik gegen Hungersnöte infolge der Währungsreform gezählt (Gassert 2018, S. 31). Ebenso unterschätzt werden oft die Proteste der »Besatzungsgeschädigten« gegen die militärische Okkupation Deutschlands; und unterschätzt werden zudem meist die Organisationen und der Protest der Kriegsopfer und der Vertriebenen, die die politische Landschaft der 1950er Jahre beeinflussten (Gassert 2018, S. 54f.). Sodann ist der heftige Konflikt um die Wiederbewaffnung und um die Nuklearrüstung von Flugzeugen der Bundeswehr zu bedenken.

Zudem entstanden neue Sorgen in den 1950er und 1960er Jahren. Viele Beobachter der politischen und wirtschaftlichen Lage befürchteten übermächtig werdende Interessenverbände. Davon zeugen allein die Titel einflussreicher Buchveröffentlichungen, von denen hier nur zwei erwähnt werden sollen: »Herrschaft der Verbände?« von Theodor Eschenburg ist einer von ihnen (Eschenburg 1955); und »Der Staat der Industriegesellschaft« von Ernst Forsthoff (Forsthoff 1971) ein zweiter. Mit dem »Staat der Industriegesellschaft» war gemeint, dass der Staat nur noch der Knecht oder die Magd der Industriegesellschaft sei, nicht länger ihr Herr.

Außerdem erlebt die Bundesrepublik in dieser Zeit heftige politische Oppositionsströmungen gegen die als »CDU-Staat « geschmähte politische Ordnung des Landes. Die Anlässe und Quellen der Kritik waren vielfältig. Doch besonders lautstark äußerten sich die oppositionellen Strömungen seitens der DGB-Gewerkschaften, der SPD und sozialliberal gestimmter bürgerlicher Wähler. Der Protest gegen den »CDU-Staat« hatte aber auch eine konfessio- 
nelle Komponente. Er dokumentiert das Widerstreben protestantischer und laizistischer Kreise gegen einen als stark »katholisch« eingeschätzten Staat (Gassert 2018, 82-83).

Wer die Anfänge der Zivilgesellschaft nur in den 1970ern sucht und dabei nur den Westen Deutschlands im Blick hat, erfasst nur einen Teil der zivilgesellschaftlichen Strömungen. Die Zivilgesellschaft spielte auch im Osten des geteilten Deutschlands, in der Deutschen Demokratischen Republik, eine Rolle. Die Aufstände vom 17. Juni 1953 gegen den SED-Staat sind dafür ein eindrucksvolles Zeichen aus den 1950er Jahren. Später - vor allem seit der zweiten Hälfte der 1970er und mehr noch in den 1980er Jahren - kamen DDR-interne Oppositionsströmungen gegen die allgegenwärtige Parteiherrschaft der SED hinzu.

\section{Schubkräfte der Zivilgesellschaft}

Welche Schubkräfte trieben die Zivilgesellschaft an? Vielerlei kam dabei zusammen. Die Massendemonstrationen vor 1949 standen im Zeichen von materieller Not und Repressionen in den Jahren der militärischen Besatzung. Diese Proteste hatten eine starke nationale Komponente - mit deutsch-nationaler Prägung.

Gänzlich andere Beweggründe bestimmten die in den 1950er Jahren aufbrechende Opposition gegen militärpolitische Vorhaben, angestachelt zunächst durch den Streit um die »Wiederbewaffnung und weiter geschürt von heftigen Auseinandersetzungen um die Nuklearbewaffnung. Eine kriegsmüde, zunehmend pazifistisch eingestellte Bevölkerung wandte sich von sicherheitspolitischen Anliegen der Abschreckung im Nuklearwaffenzeitalter $\mathrm{ab}$ - auch dies ein Kennzeichen einer von Kriegserschütterungen zutiefst geprägten »Kriegsfolgengesellschaft« (Naumann 2001).

Nichts aber wäre aus der Zivilgesellschaft in Deutschland geworden ohne den Wertewandel von den "materialistischen « zu den "postmaterialistischen Werten « (Inglehart 1997; Inglehart/Welzel 2005). Dieser Wertewandel wiederum war undenkbar ohne den steilen Wirtschaftsaufschwung in den 1950er, 1960er und frühen 1970er Jahren, ohne das Emporkommen einer »Konsumgesellschaft « (Gassert 2018), ohne den Ausbau des Bildungswesens und ohne den Aufstieg der Massenmedien, einschließlich der Fernsehprogramme, mit denen politische Anliegen sich wie ein Lauffeuer ausbreiten konnten. 
Gesetzliche Rahmenbedingungen kamen der Zivilgesellschaft ebenfalls zugute. Ohne die in der Verfassung verbriefte Versammlungsfreiheit (GG Art. 8) und das Recht, Vereine und Gesellschaften zu bilden (GG Art. 9), hätten ihr zentrale Stützen gefehlt. Und ohne die Förderung aus öffentlichen Geldern - sei es über direkte finanzielle Zuwendungen oder indirekte, wie Steuererleichterungen - hätten etliche zivilgesellschaftliche Organisationen nicht lange überlebt.

Schlussendlich ist die internationale Verflechtung ebenfalls eine Schubkraft für jenen Teil der Zivilgesellschaft geworden, der sich - hauptsächlich in Gestalt rechtspopulistischer Strömungen - gegen Globalisierung wendet, gegen Masseneinwanderung und gegen die Verlagerung vieler Kompetenzen auf inter- und transnationale Einrichtungen, wie die Europäische Union.

Gemeinhin wird dieser Teil der Zivilgesellschaft als »Zivilgesellschaft von rechts« eingestuft - im Unterschied zum Hauptstrom der »Zivilgesellschaft von links«, der überwiegend sozialliberal, grün und rot gefärbt ist. Genauer aber informiert die Einbettung der linken und der rechten Variante der Zivilgesellschaft in die »Konfliktlinien« der deutschen Gesellschaft - die Spaltungen in der Wählerschaft. Hier fallen eindeutige Zuordnungen auf.

- Bei der Staat-Markt-Spaltung - die klassische Links-Rechts-Konfliktlinie - ist die deutsche Zivilgesellschaft überwiegend mitte-links oder auf der linken Seite des politischen Spektrums positioniert.

- Bei der Spaltung zwischen religiöser und säkularer Wählerschaft ist sie im Kern säkular, profitiert aber von kräftiger Mitträgerschaft der Kirchen in humanitären und pazifistischen Anliegen.

- Bei den materialistischen und postmaterialistischen Wertorientierungen neigt der Großteil der Zivilgesellschaft zu postmaterialistischen oder gemischten, materialistisch und postmaterialistisch gepolten Positionen.

- Bei der Spaltung zwischen kosmopolitisch versus lokal oder national schließlich geriert sich die Zivilgesellschaft überwiegend international.

Soweit der dominante Teil der Zivilgesellschaft. Ein Teil der Zivilgesellschaft in Deutschland ist in den Konfliktlinien anders verankert, nämlich eher materialistisch und überwiegend national oder lokal ausgerichtet, so die rechtspopulistische Variante. 


\section{Wirkungen der Zivilgesellschaft}

Wie wirkt die Zivilgesellschaft und was bewirkt sie? Laut Selbstbeschreibung ihrer Fürsprecher ist der Wirkungsradius der Zivilgesellschaft sehr groß. Die Zivilgesellschaft wirke nach innen und nach außen: Sie sei sozial kohäsiv, schaffe Beteiligung, stärke die Selbsthilfe, bringe neue Themen in die Politik, trage bei zur Bildung neuer Einrichtungen - Umweltministerien beispielsweise oder Gleichstellungsstellen - und wirke als Instanz der politischen Kontrolle und der Warnung vor drohenden Gefahren (Speth 2018, S. 208-212).

Musterbeispiele großer, kohäsiver und demokratieförderlicher Wirkungen sehen die Fürsprecher der Zivilgesellschaft an vielen Stellen. Als Illustration sei ein einigermaßen repräsentatives Beispiel zitiert: eine Abhandlung von Thomas Meyer, einem Fachmann der Demokratieforschung, aus dem Jahre 2018. Die Zivilgesellschaft ist laut Meyer »die moralische Infrastruktur moderner Gesellschaften« (Meyer 2018, S. 145). Ihre Aktivitäten hätten wesentlich zur kulturellen Integration beigetragen und das »demokratische Potential des Gemeinwesens« »erhöht" (ebd., S. 146). ${ }^{4}$ Ihren sozialen Bewegungen seien »Erfolge« (ebd., S. 148) von historischer Bedeutung zuzuschreiben - »beim Abbau der atomaren Mittelstreckenraketen und der Überwindung der Kernenergie in Deutschland (ebd., S. 148). Zudem habe die Zivilgesellschaft einen »maßgeblichen Beitrag [...] bei der Bewältigung der Flüchtlingskrise 2015 « geleistet (ebd., S. 139).

Trifft das wirklich $\mathrm{zu}$ ? Ist die Zivilgesellschaft wirklich »die moralische Infrastruktur « und ein wesentlicher Motor - wenn nicht der wesentlichste - der kulturellen Integration, der Demokratisierung, beim Abbau atomarer Mittelstreckenraketen, auch der sowjetischen SS-2O - und beim Ausstieg aus der Kernenergie? Zweifel sind angebracht. Liegt hier nicht eine Überschätzung der Macht der Zivilgesellschaft vor? Wird ihre moralische Qualität nicht übertrieben? Und werden andererseits gegenteilige Sichtweisen nicht ebenso unterschätzt wie Streitigkeiten in der Zivilgesellschaft und Streit, den sie verursacht? $?^{5}$ Zudem wird die Binnenwirkung unterschätzt. Die Zivilgesellschaft

4 Dieses Argument spielt in der Lehre der Zivilgesellschaft seit Tocqueville (1835/40) eine wichtige Rolle. Eine robuste Zivilgesellschaft stärke die Demokratie. mein Hotel zu kommen, wenn ich an einer internationalen Tagung teilnehme«. 
habe eine starke »expressive Komponente«, so die Worte von Gassert (2018, S. 172) - und damit meint er eine bewegungsintern wichtige Selbstvergewisserung.

Zudem sind zwei Korrekturen fällig. Erstens: Die als >Erfolge` eingestuften Politikergebnisse wie der Atomausstieg sind Ergebnis komplexer Ursachenketten, in denen die Zivilgesellschaft nur ein Rädchen unter vielen ist, das sich obendrein nicht in der Regierungsmaschinerie dreht, sondern außerhalb derselben. Und zweitens: Vom Engagement in der Flüchtlingskrise bleibt bei genauerem Hinsehen ein weniger imposantes Bild übrig. Einerseits waren seit 2015 mindestens 32 Prozent der mindestens 16-Jährigen in der Flüchtlingskrise in irgendeiner Form engagiert. Andererseits erstreckte sich der größte Teil des Engagements auf Spenden (28 Prozent der mindestens 16-Jährigen). Erheblich kleiner war der Kreis, der Hilfe vor Ort leistete (wie insbesondere Sprachkurse oder Behördengänge) - auf diesen Kreis entfielen 6 Prozent der Befragten. Und 5 Prozent berichteten, an Protestmaßnahmen wie Demonstrationen teilgenommen zu haben (Alscher et al. 2018, S. 380).

\section{Internationaler Vergleich}

Wie steht Deutschlands Zivilgesellschaft im internationalen Vergleich da? Zwei besonders auffällige Befunde erwähne ich. Der erste Befund kommentiert die Stellung der Zivilgesellschaft in der religiösen Konfliktlinie. »Die europäische Zivilgesellschaft hat ein säkulares Gesicht, die amerikanische ist religiös gefärbt. «So heißt es in Sigrid Roßteutschers instruktiver Abhandlung über »Religion, Zivilgesellschaft, Demokratie« (Roßteutscher 2009). Das säkulare Gesicht kennzeichnet auch die Zivilgesellschaft in Deutschland.

Der zweite Befund platziert den deutschen Fall in drei Modellen der nationalstaatlichen Einbindung zivilgesellschaftlicher Organisationen: Ein »liberales«, ein »sozialdemokratisches« und ein »subsidiäres Modell« wird dabei unterschieden, so der Vorschlag von Annette Zimmer (2009). Im liberalen, vor allem in angelsächsischen Ländern anzutreffenden Modell, gilt die Zivilgesellschaft als weitgehend eigenständiger gesellschaftlicher Bereich. Der Kern des sozialdemokratischen, vorwiegend in Skandinavien beheimateten Modells, besteht aus Mitgliederorganisationen, die auf Wachstum und Inklusion angelegt sind, wie Parteien, Gewerkschaften und Vorfeldorganisationen der Arbeiterbewegung. Das subsidiäre, überwiegend in Zentral- und Südeuropa anzutreffende und durch die katholische Soziallehre beeinflusste Modell 
schließlich definiert Zivilgesellschaft »als vorrangig lokal verortete Solidargemeinschaft« (Zimmer 2009).

Deutschlands Zivilgesellschaft liegt, dieser Perspektive zufolge, in der Mitte zwischen dem subsidiären, dem sozialdemokratischen und dem liberalen Modell. Das ist eine interessante Einstufung, die allerdings die ökologisch-grüne Ausrichtung der deutschen Zivilgesellschaft ebenso unterschätzt wie ihre Prägung durch die Religionsgemeinschaften, insbesondere in humanitären und pazifistischen Anliegen.

\section{Offene Fragen}

Bei der Beobachtung und Bewertung der Zivilgesellschaft bleiben etliche Fragen offen. Klärungsbedarf besteht vor allem in folgenden Feldern:

- Wie wirkungsvoll ist die Zivilgesellschaft wirklich?

- Vertreter der Zivilgesellschaft haben oft hochgesteckte Ansprüche. Dem Gemeinwohl dienten sie, behaupten viele ihrer Mitwirkenden und ihrer Fürsprecher. Stimmt das? Ist derjenige, der gegen Globalisierung ankämpft, ein Vorkämpfer des Gemeinwohls? Und was ist mit den Strömungen der Zivilgesellschaft, die ihre Gegner am liebsten außer Landes weisen würden? Dient das dem Gemeinwohl?

- Ist die Zivilgesellschaft hinreichend legitimiert? Wenn ja: welche Legitimität ist das? Die traditionale? Die charismatische? Die legale? Oder die Output-Legitimität?

- Die Zivilgesellschaft ist nicht von den Wählern gewählt, beansprucht aber weitreichende Problemlösungen. Ist das akzeptabel?

- Schließlich: Wie steht es um die Zukunft der Zivilgesellschaft in einer Gesellschaft, die altert, was die Rekrutierung jüngerer Mitwirkender erschwert, und die sich weiter internationalisiert, was den politisch gestaltbaren nationalstaatlichen Raum verkleinert, wenn alles Übrige gleichbleibt?

\section{Literaturhinweise}

Adloff, Frank (2013): Vereine. In: Mau, Steffen/Schöneck, Nadine M. (Hg.), Handwörterbuch zur Gesellschaft Deutschlands Bd. 2. Wiesbaden: VSVerlag, S. 909-921. 
Alscher, Mareike/Priller, Eckhard/Burkhardt, Luise (2018): Zivilgesellschaftliches Engagement. In: Datenreport 2018, S. 373-382.

Erlinghagen, Marcel (2013): Ehrenamt. In: Mau, Steffen/Schöneck, Nadine M. (Hg.), Handwörterbuch zur Gesellschaft Deutschlands Bd. 1. Wiesbaden: VS-Verlag, S. 199-212.

Eschenburg, Theodor (1955): Herrschaft der Verbände? Stuttgart: Deutsche Verlagsanstalt.

Forschungsjournal Soziale Bewegungen, 2018. Themenheft »Zukunft der Demokratie«, 31. Jg., H.1-2, Berlin.

Forsthoff, Ernst (1971): Der Staat der Industriegesellschaft. München: C.H. Beck.

Gassert, Philipp (2018): Bewegte Gesellschaft. Deutsche Protestgeschichte seit 1945. Stuttgart: Kohlhammer.

Grande, Edgar (2018): Zivilgesellschaft, politischer Konflikt und soziale Bewegungen. In: Forschungsjournal Soziale Bewegungen, 31(1-2), S. 52-59.

Inglehart, Ronald (1997): Modernization and Postmodernization. Cultural, Economic and Political Change in 43 Societies. Princeton, NJ: Princeton University Press.

Inglehart, Ronald/Welzel, Christian (2005): Modernization, Cultural Change and Democracy. The Human Development Sequence. Cambridge: Cambridge University Press.

Kocka, Jürgen (2006): Zivilgesellschaft und soziale Ungleichheit aus historischer Perspektive. In: Rehberg, Karl-Siegbert (Hg.), Soziale Ungleichheit, kulturelle Unterschiede. Verhandlungen des 32. Kongresses der Deutschen Gesellschaft für Soziologie in München. Frankfurt a.M.: Campus, S. 131-143.

Kocka, Jürgen/Nolte, Paul/Randeria, Shalini/Reichardt, Sven (2001): Neues über Zivilgesellschaft. Aus historisch-sozialwissenschaftlichem Blickwinkel. Discussion Papers 01(801). Berlin: WZB.

Mau, Steffen/Schöneck, Nadine M., (Hg.) (2013): Handwörterbuch zur Gesellschaft Deutschlands, 3. Auflage. Wiesbaden: VS-Verlag.

Meyer, Thomas (2018): Migration, Religion und Zivilgesellschaft. In: Forschungsjournal Soziale Bewegungen, 31(1-2), S. 139-151.

Naumann, Klaus, (Hg.) (2001): Nachkrieg in Deutschland. Hamburg: HIS Verlag.

Niedermayer, Oskar (2019): Parteimitgliedschaften im Jahre 2018. In: Zeitschrift für Parlamentsfragen, 50(2), S. 385-410. 
Ottmann, Henning (2012): Geschichte des politischen Denkens: Band 4.2.: Das 20. Jahrhundert. Von der Kritischen Theorie bis zur Globalisierung. Stuttgart: J.B. Metzler.

Priller, Eckhard (2018): Wie offen ist die Zukunft der Zivilgesellschaft? Einflussfaktoren und Rahmenbedingungen. In: Forschungsjournal Soziale Bewegungen, 31(1-2), S. 189-194.

Roßteutscher, Sigrid (2009): Religion, Zivilgesellschaft, Demokratie. BadenBaden: Nomos.

Speth, Rudolf (2018): Zivilgesellschaftliche Watchdogs. In: Forschungsjournal Soziale Bewegungen, 31(1-2), S. 204-214.

Statistisches Bundesamt (Destatis) u.a. (Hg.).: Datenreport 2016. Bonn: Bundeszentrale für politische Bildung.

Statistisches Bundesamt (Destatis) u.a. (Hg.): Datenreport 2018. Bonn: Bundeszentrale für politische Bildung.

Strachwitz, Rupert Graf (2018): Position und Perspektiven der Zivilgesellschaft im internationalen Vergleich. In: Forschungsjournal Soziale Bewegungen, 31(1-2), S. 374-385.

Tocqueville, Alexis de (1981) [1835/1840]: De la Démocratie en Amérique, 2 Bd. Paris: GF Flammarion.

Von Beyme, Klaus (2006): Politische Theorien der Gegenwart, 8. Auflage. Wiesbaden: VS-Verlag.

Weßels, Bernhard (2018): Politische Integration und politisches Engagement. In: Statistisches Bundesamt (Destatis) u.a. (Hg.): Datenreport 2018. Bonn: Bundeszentrale für politische Bildung, S. 350-357.

Wolfrum, Edgar (2013): Rot-Grün an der Macht. Deutschland 1998-2005. München: C.H. Beck.

Zimmer, Annette (2009): Zivilgesellschaft und Demokratie: Drei Modelle zivilgesellschaftlicher Einbettung. In: Gesellschaft - Wirtschaft - Politik, 58(3), S. 397-406. 

Aufbrüche I:

Zivilgesellschaft und Wiederaufbau 



\section{Gewerkschaften als zivilgesellschaftliche Akteure in der Bundesrepublik}

Wolfgang Schroeder

Die Gewerkschaften gehören zu den erfolgreichsten sozial- und demokratiepolitischen Akteuren der Industriegesellschaften (Schroeder 2014). Sie hatten maßgeblichen Anteil daran, dass aus feudalen und autoritären Gesellschaften Demokratien wurden, in denen Arbeitnehmer soziale Teilhaberechte erhalten haben. Ihre Stellung und Einflussmöglichkeiten beruhten auf einer festen Verankerung sowohl im zivilgesellschaftlichen Sektor (Solidarorganisation mit gesamtgesellschaftlichem Anspruch), im politischen Sektor (Gewerkschaften als politischer Verband) als auch im Sektor der Interessenorganisationen (auf materielle Interessen/Umverteilung orientierter Arbeitsmarktakteur). Wo aber stehen die Gewerkschaften heute?

Auf dem Weg zum anerkannten und befestigten Akteur haben sich nicht nur die Umwelt- und Rahmenbedingungen gewerkschaftlicher Arbeit verändert, sondern auch die Gewerkschaften selbst. Dabei hat sich der Stellenwert zwischen den drei klassischen Funktionen der Gewerkschaften als Arbeitsmarktakteur, als Solidarorganisation und als politischer Verband verschoben.

Auch für die Gewerkschaften haben sich die Bedingungen ihres Handelns mit veränderten staatlichen, ökonomischen, sozialen und gesellschaftlichen Rahmenbedingungen gewandelt. Nicht nur die traditionellen sozialen Milieus, auf denen sich ihre Erfolge als sozial-, demokratie- und wirtschaftspolitische Akteure aufbauten, sind mit der Zeit erodiert. Auch Internationalisierung und Europäisierung verändern den Gestaltungsspielraum national(staatlich)er Akteure. Vor allem aber haben sich der Arbeitsmarkt und damit auch die Beschäftigungsverhältnisse weiterentwickelt. Das Normalarbeitsverhältnis befindet sich auf dem Rückzug und der Boden gewerkschaftlicher Organisationserfolge verliert mit zunehmender Ausweitung des Dienstleistungssektors an Bedeutung. Die "privilegierte Partnerschaft« zwischen den Gewerkschaften und der Sozialdemokratie ist 
nicht zuletzt seit Schröders »Agenda 2010« stark relativiert worden. Der Konflikt zwischen Arbeit und Kapital ist in den letzten Jahren in starkem Maße durch andere gesellschaftliche Konfliktlinien überlagert worden (Grande 2018). Damit stehen die Gewerkschaften vor vielfältigen Herausforderungen, denen sie sich stellen und aktiv begegnen müssen, um weiter als souveräner Akteur und nicht als Spielball gesellschaftlich-politischer Verhältnisse zu landen. Bezogen auf die Gewerkschaften konstatiert Dettling (2002, S. 7) zwei Gefahren, die Anpassung an gesellschaftliche Realitäten zu verpassen: Einerseits, indem die Gewerkschaften »sich selbst, ihren Traditionen und Strukturen treu bleiben, aber eines Tages nicht mehr in die Zeit und zu den Menschen passen «; andererseits, indem sie sich »nur noch anpassen, ihre Werte vergessen und mit der Zeit beliebig und austauschbar werden«.

In diesem Anpassungsprozess, so lautet der Vorwurf von gewerkschaftskritischer Seite, hätten die Gewerkschaften nicht nur ihren (Klassen-)Kampfcharakter zugunsten einer systemkonformen Institutionalisierung aufgegeben, sondern darüber hinaus sei ihre lebensweltliche Einbettung mit dem Verschwinden der klassischen Arbeitermilieus verloren gegangen. Sie waren nicht dazu in der Lage, sich an die veränderten Bedingungen am Arbeitsplatz, dem Wandel von Erwerbstätigkeit und neuen Formen der abhängigen Beschäftigung anzupassen. In der Folge erodiert(e) nicht nur ihre zivilgesellschaftliche Basis. Mit »straffer Organisierung«, »beträchtlichem Bürokratismus« und der »spektakulären Herausbildung großer Verwaltungsapparate« seien aus den Gewerkschaften mit der Zeit vielmehr reine Dienstleistungsorganisationen geworden. Die »Gewerkschaft als Versicherungsbetrieb« habe »selbstverständlich völlig den Charakter einer >Bewegung« verloren (Pirker 1965, S. 7f., 17).

Sind die Gewerkschaften tatsächlich erstarrt und haben somit endgültig den Anschluss verpasst? Wie ist es heute um die Gewerkschaften als »alte soziale Bewegung« bestellt? Ist das »Alte« nicht mehr nur ein zeitliches Unterscheidungsmerkmal zu den "neuen sozialen Bewegungen«, sondern Ausdruck einer veränderten Organisationsform, der jeglicher Bewegungscharakter abhandengekommen ist? Wie verhält es sich mit der sozial- und lebensweltlichen Einbettung der Gewerkschaften? Haben sie sich von umfassenden Solidarorganisationen hin zu reinen Versicherungsvereinen entwickelt?

Diese Fragen sind nicht neu, vielmehr begleiten sie die Entwicklung der deutschen Gewerkschaften seit den 1960er Jahren: In den 6oer Jahren fand eine Debatte um die Gewerkschaften als Versicherungsbetrieb statt (z.B. Pirker 1965); in den 8oer Jahren war die Rede vom »Scheitern der deutschen Arbeiter- 
bewegung« (Lucas-Busemann 1983) oder vom »Ende der Arbeiterbewegung in Deutschland? (Ebbinghaus u.a. 1984). Was ist aus den »das Selbstverständnis ihrer Mitglieder ursprünglich prägenden sozialkulturellen und politischen Inhalten, ihren spezifischen Solidar- und Kampfformen« (ebd., S. 11) geworden? Die Gewerkschaften haben sich verändert und werden sich auch weiterhin verändern müssen. Im Folgenden wird jedoch gezeigt, warum die Gewerkschaften trotz aller Wandlungsprozesse weiterhin zur Zivilgesellschaft gerechnet werden können und auch sollten. Sie sind mitnichten zum reinen Versicherungsverein verkommen, sondern vielmehr zu einem Teil verschiedener Welten geworden. Und trotz aller Probleme, sind sie auch weiterhin mehr als nur ein Akteur unter vielen.

\section{Gewerkschaften und Zivilgesellschaft}

Der Begriff der Zivilgesellschaft steht für Organisationen (Vereine, Verbände, Bürgerinitiativen etc.), die auf den Prinzipien von Selbstorganisation, gewaltfreier Konfliktbereitschaft und partikularinteressenübergreifenden Vertretung im Sinne des Gemeinwohls aufbauen. Diese Organisationen bilden einen »Dritten Sektor«, der zwischen Markt, Staat und Privatsphäre existiert (vgl. z.B. Priller/Zimmer 2000, S. 2f.).

Schubert (2007) unterscheidet in der intermediären Sphäre zwischen Gesellschaft und Staat vier Sektoren: den Sektor der auf materielle Umverteilung orientierten Interessenorganisationen, den auf Anerkennung ideeller Interessen orientierten weltanschaulichen Sektor, den Bereich politischer Gruppierungen und den zivilgesellschaftlichen Sektor. Die Gewerkschaften, als institutionalisierter Ausdruck selbstorganisierten, kollektiven Handelns von abhängig Beschäftigten, können als Teil der Zivilgesellschaft angesehen werden, stechen aber gleichwohl aus ihr hervor. Franz Neumann (1978) definierte bereits 1935 die drei klassischen Funktionen der Gewerkschaften. Ihre Aufgaben gehen weit über eine rein genossenschaftliche Funktion, durch die Gewerkschaften als Solidarorganisation Solidarität und gegenseitigen Sicherung offerieren, hinaus. In ihrer Markt- und Kartellfunktion erbringen sie als ökonomischer Verband zur Durchsetzung kollektiver Interessen eine arbeitsmarktpolitische Kampffunktion. Daneben sind Gewerkschaften aber immer auch politische Verbände, die versuchen, in ihrem und im Sinne ihrer Mitglieder, Einfluss auf das politische System zu nehmen. Damit lassen sich die Gewerkschaften sowohl im politischen Sektor, im Sektor der auf materielle 
Umverteilung orientierten Interessenorganisationen als auch in der zivilgesellschaftlichen Sphäre verorten.

In ihrer Funktion als Solidarorganisation richtet sich der Blick primär auf die eigene Mitgliedschaft, die Mitgliederentwicklung und das Verhältnis zwischen Organisation und Mitgliedschaft. Dabei können die Grenzen zwischen Gewerkschaften und Gemeinwohl als fließend definiert werden (vgl. Dettling 2002, S. 7). Aber auch in Hinsicht auf die übrigen Funktionen und den Gestaltungsanspruch der Gewerkschaften sind ihre Mitglieder existenziell wichtig. Sie stellen nicht nur durch ihre Beiträge die finanziellen Ressourcen, die die Gewerkschaften für ihr durchsetzungsorientiertes, konfliktorisches Handeln (Streik- und Aussperrungskasse) benötigen, sondern sichern auch das Quasi-Repräsentationsmonopol der Gewerkschaften auf der Einflussebene. Aufbauend auf dieser Repräsentativität, durch das System der Tarifautonomie im deutschen Modell der industriellen Beziehungen und die Inkorporierung der Gewerkschaften durch den Staat, fanden sich die Gewerkschaften in einer herausgehobenen und privilegierten Position wieder. Die DGBGewerkschaften verstanden und verstehen sich nicht nur als Sprachrohr ihrer Mitglieder, sondern gleichwohl als Interessenvertretung aller Arbeitnehmer. Ihre herausgehobene Stellung in der deutschen Verbändelandschaft basierte auf der großen Zahl ihrer Mitglieder und ihrer Durchsetzungsstärke. »Der Anspruch auf die Mitgestaltung von Staat und Gesellschaft gründete auf dem Selbstverständnis, nicht ein einfacher Interessenverband zu sein, sondern Träger der sozial- und wirtschaftspolitischen Willensbildung der Arbeitnehmer.« (Grebing 2007, S. 201)

Mit dem Anspruch, nicht nur die Interessen der Beschäftigten zu vertreten, sondern auch einen Beitrag zum Wohl der Gesellschaft zu leisten, »sind die Gewerkschaften seit jeher ein Stück der sich entwickelnden Zivilgesellschaft gewesen« (Kocka 2003, S. 613). Kocka (ebd.) sieht die Arbeiterbewegungen sogar als die »stärksten zivilgesellschaftlichen Bewegungen des 19. und 20. Jahrhunderts«. Er deutet damit aber gleichfalls an, dass sich heute die Zuordnung der Gewerkschaften zur zivilgesellschaftlichen Sphäre nicht mehr ohne weiteres aufrechterhalten ließe.

Wie hat sich das Verhältnis zwischen Gewerkschaften und Gesellschaft verändert? Was ist aus der lebensweltlichen Verankerung der Gewerkschaften geworden? Und sind die Gewerkschaften tatsächlich von einer Emanzipationsbewegung aller Erwerbstätigen zu einem Versicherungsverein und Schutzverband für privilegierte Stammbelegschaften geworden? 
Die Gewerkschaften hatten sich bis zum Beginn der nationalsozialistischen Herrschaft, aufbauend auf Formen kollektiv organisierter Selbsthilfe, zu milieu- und lebensweltlich verankerten und etablierten Akteuren der Arbeiterbewegung entwickelt. Ihre Strukturen und Einbettungsformen charakterisierten sie als umfassende Solidarorganisationen. Mit ihrem Anspruch, über die Interessen ihrer Mitglieder und die der Arbeitnehmer hinaus gesamtgesellschaftliche Anliegen zu vertreten, wurden nicht nur die Gewerkschaften als Organisation ein Teil der Zivilgesellschaft. Darüber hinaus haben die Gewerkschaften und die Arbeiterbewegung "große Bevölkerungsschichten, die Arbeiterklasse, das Proletariat, zum ersten Mal für die Zivilgesellschaft gewonnen« (Kocka 2003, S. 613).

\section{Veränderte Ausrichtung nach dem Zweiten Weltkrieg: Von der Solidarorganisation zum Tarifverband?}

Nach dem Ende des Zweiten Weltkriegs entstand mit der organisatorischen Neustrukturierung der deutschen Gewerkschaften ein Gewerkschaftssystem, das in den industriellen Beziehungen lange Zeit für eine außerordentliche Stabilität durch hohe Flächentarifbindung sorgte, sowie zu einer starken institutionellen Stellung der Gewerkschaften beitrug. »Beseelt waren die Vertreter der Arbeiterbewegung von dem Gedanken, die Spaltung der Weimarer Zeit, die zur Niederlage der Arbeiterbewegung beigetragen hatte, in Einheitsorganisationen zu überwinden.« (Schmidt 2007, S. 162) Ein Großteil der Spaltungen und Konkurrenten, die den gewerkschaftlichen Arm der Arbeiterbewegung charakterisierten, konnten mit der Neuausrichtung überwunden und integriert werden. ${ }^{1}$ Die großen Industrie- und Einheitsgewerkschaften im DGB, die gewissermaßen über ein Interessen- und Repräsentationsmonopol für alle Erwerbstätigen in den tarifvertraglich definierten Gestaltungsbereichen verfügen, wurden zu mitgliederstarken, bürokratisierten und professionalisierten Massenorganisationen. Diese Struktur führte zu einer großen Steuerungs- und Durchsetzungsfähigkeit der Gewerkschaften. Ihre Fähigkeit, wirtschaftliche Leistungssteigerung, soziale und demokratische Teilhabe sowie sozialen Frieden zu verbinden, ließ sie zu einem exponierten Akteur des »Modells Deutschland« werden und beförderte ihre Inkorporierung, 
Anerkennung und Befestigung innerhalb des politischen Systems der Bundesrepublik. Mit ihrer Integration in das wirtschaftliche und soziale Produktionssystem standen die Gewerkschaften jedoch vor einer zwiespältigen Ausrichtung, wie sie sich beispielsweise in der Frage »Gewerkschaften als Ordnungsfaktor oder als Gegenmacht?« (Grebing 1973, S. 393) widerspiegelte.

Bereits Ende der 1960 Jahre mehrten sich die Stimmen, die den Gewerkschaften, ob ihrer stagnierenden Mitgliederentwicklung und einem zunehmenden Funktionswandel, konstatierten, vom »Kampfbund zum Establishment« (Die ZEIT, 11.04.1969, S. 15) geworden zu sein. Der ehemalige Kampfverband Gewerkschaft hätte sich zunehmend $\mathrm{zu}$ einer reinen Service-Organisation für seine Mitglieder entwickelt und wäre somit zum »Versicherungsbetrieb« (Pirker 1965, S. 7) geworden.

»Die Cewerkschaften sind von der Höhe eines emanzipatorisch orientierten, proletarischen Klassenkampfverbandes herabgesunken zu einem Dienstleistungsbetrieb, zu einer Verkaufsagentur für Arbeitskraft, zu einem Unternehmen für Versicherungen aller Art, insbesondere für Streik- und Aussperrungs-Vollversicherung.«(Grebing 1973, S. 394)

Aus Sicht der Gewerkschaften habe man sich jedoch mit der veränderten Ausrichtung, dem Wegfall sozialistischer, »systemtranszendierender Aktionen« (Nickel 1973, S. 479) für einen dritten Weg zwischen »den Extrempositionen Ordnungsfaktor des Status quo einerseits und evolutionärem Kampfverband andererseits « entschieden (Vetter 1970). Als »organisierte Gegenmacht « wären die Gewerkschaften weiterhin ein notwendiger »Integrations- und Stabilisierungsfaktor« (Nickel 1973, S. 481) mit einer gesamtgesellschaftlichen Funktion und nicht ausschließlich eine Dienstleistungseinrichtung für Mitglieder.

Gleichzeitig wurde bereits in den 1970er Jahren diskutiert, ob die Gewerkschaften sich nicht selbst überflüssig gemacht hätten (vgl. Grebing 1973, S. 395), zumindest im Hinblick auf ihre Funktion als klassische Schutzmacht der Arbeiter gegenüber der willkürlichen Ausbeutung durch Unternehmer. Heute zählen die wichtigsten sozialen Forderungen, die an der Wiege der Gewerkschaften standen, zum sozialen und demokratischen Grundbestand der Bundesrepublik. Deshalb meinen manche, dass die Erfolgsgeschichte der Gewerkschaften auch einen Teil ihrer Schwierigkeiten ausmache. Denn in dem Maße, in dem die gewerkschaftlichen Forderungen zum Kernbestand des Sozial- und Rechtsstaates geworden sind, hätten die Gewerkschaften gleichsam an Funktion und Aufgabe eingebüßt. 
Ein umfassendes Verständnis über die Entwicklung und den Zustand der Gewerkschaften und ihr Verhältnis zur Zivilgesellschaft benötigt einen differenzierten Blick auf die Entwicklung in allen drei Feldern gewerkschaftlicher Aufgaben und der Gewerkschaften als Mitgliederorganisation.

\section{Solidarfunktion: Blütezeit und Niedergang der Gemeinwirtschaft}

In den ersten Jahrzehnten nach dem zweiten Weltkrieg wurden die gemeinwirtschaftlichen Unternehmungen der Gewerkschaften »im Rahmen einer nun einheitlicheren und daher auch machtvolleren Gewerkschaftsorganisation« (Hassel 2003, S. 19) weiter ausgebaut. Die Genossenschaftsbewegung erlebte ihre Blütezeit in den 1970er Jahren.

»Die DGB-Unternehmen können auf eine überaus expansive Entwicklung (Konzern-Bilanzsumme über 95 Milliarden DM) zurückblicken. So ist die Unternehmensgruppe >Neue Heimat` das größte europäische Bauträgerunternehmen, die gewerkschaftseigene Bank für Cemeinwirtschaft AC die viertgrößte überregionale Ceschäftsbank, die >Volksfürsorge Lebensversicherung $A G<$ nach der Zahl der Versicherungsverträge die größte deutsche Lebensversicherung, das >Beamtenheimstättenwerk die drittgrößte Bausparkasse und die >Co op AG < der größte Lebensmittelhändler in Westdeutschland.«(Niedenhoff 1982, S. 239)

Bereits 1958 schlossen sich die Gewerkschaftsbanken zur Bank für Gemeinwirtschaft (BfG) zusammen. Mehr als 100 Konsumgenossenschaften aus dem ganzen Bundesgebiet wurden 1969 zur Co op-Gruppe (später unter der Co op AG Holding) zusammengefasst. Sie verfügte 1978 über ein Aktienkapital von 150 Millionen DM. Neben Co op war es aber vor allem die »Neue Heimat«-Gruppe, die für die »organisatorische und finanzielle Konsolidierung der Gewerkschaften in den sechziger und siebziger Jahren « stand (Schneider 2000, S. 358). Die Wohnungsbaugenossenschaft verwaltete 1977 (mit einem Stammkapital von 60 Millionen DM) 320.000 eigene Wohnungen, 100.000 fremde Wohnungen und fast 90.000 gewerbliche Objekte. Als Gesellschafter der »Neuen Heimat « traten der DGB und die Einzelgewerkschaften auf. ${ }^{2}$ Diese gründeten 1974 die Beteiligungsgesellschaft für Gemeinwirtschaft AG 
(BGAG). Über diese drei großen gemeinwirtschaftlichen Unternehmen hinaus verantworteten die Gewerkschaften mit der »Volksfürsorge« Versicherungsgesellschaft einen Versicherungsdienstleister sowie mit »Gut-Reisen« ein Touristikunternehmen. ${ }^{3}$

Die vier großen gemeinwirtschaftlichen Unternehmen (BfG, Co op, Neue Heimat und Volksfürsorge) gehörten $\mathrm{zu}$ den 100 größten Unternehmen in Deutschland (vgl. Hassel 2003, S. 117). Neben Mitgliedsbeiträgen und gewerkschaftlichen Vermögenswerten bildete die Gemeinwirtschaft damit das dritte finanzielle Standbein der Gewerkschaften (vgl. Grebing 2007, S. 210). Der Ausbau und die Ausweitung der gemeinwirtschaftlichen Unternehmungen führte aber auch zu einer »Ablösung von ihren genossenschaftlichen Ursprüngen« und zu einer Angleichung an den privatwirtschaftlichen Unternehmenstypus. Dieses stellte die Gewerkschaften vor die Frage, wie sich ihre wirtschaftliche Tätigkeit mit ihrem »moralischen Anspruch « und ihrer »politischen Zielsetzung« vereinbaren ließe (Schneider 2000, S. 360).

Mit den 1980er Jahren begann das Ende der gewerkschaftlichen Gemeinwirtschaft. Das Erlahmen der Baukonjunktur brachte die »Neue Heimat« in Bedrängnis. Hinzu gesellten sich Fehlinvestitionen im großen Ausmaß, was die Rentabilität der Gemeinwirtschaft stark verringert und damit kurz- und mittelfristig die Vermögenswerte der Gewerkschaften bedrohte. Der Versuch, die nicht mehr rentablen Unternehmen abzustoßen, wurde überschattet von »einer ganzen Reihe von Beispielen von Fehlverhalten im obersten Management der Neuen Heimat und der Co-op Gruppe« (Hassel 2003, S. 117).

$\mathrm{Zu}$ dem Vertrauens- und Imageverlust, den die Gewerkschaften und der DGB hinnehmen mussten, kamen die finanziellen Ausfälle hinzu. Angesichts leerer Kassen beschlossen die Einzelgewerkschaften ein Sparprogramm für den DGB, das in den folgenden Jahren für den Dachverband einen »Rückzug aus der Fläche« bedeutete. Da der DGB, trotz Beteiligung der Einzelgewerkschaften an den gemeinwirtschaftlichen Unternehmungen, die Verantwortung für die Skandale übernehmen musste, war er darüber hinaus von einer »lang anhaltenden politischen Lähmung« betroffen (Schmidt 2007, S. 171).

Mit dem Niedergang der Gemeinwirtschaft verloren die Gewerkschaften den Teil ihrer Funktionalität als Solidarorganisation, der über die reine summe von 34,2 Milliarden DM. Bilanzsumme der BfC 1978: 35 Milliarden DM (Schneider 2000, S. 359). 
mitgliederbezogene Solidarität hinausreichte. Bezogen auf die innergewerkschaftliche Solidarität haben die Gewerkschaften ihre Angebote dagegen immer weiter ausgebaut. Mit dem Ausbau exklusiver Leistungen, die als selektive Nutzenanreize auf (potenzielle) Mitglieder wirken sollen, verstärken die Gewerkschaften ihr Dienstleistungsangebot. Mit Blick auf die weiteren gewerkschaftlichen Funktionen wird aber deutlich, dass sie damit noch lange nicht zum reinen Versicherungsverein geworden sind, auch wenn sie mit ihrem Angebot an das Sicherheitsbedürfnis ihrer Mitglieder theoretisch in neue Konkurrenzverhältnisse (zum Beispiel zu klassischen Versicherungen) eintreten (vgl. Schroeder/Keudel 2008, S. 16).

\section{Politische Funktion: Entwicklung des Wohlfahrtsstaates}

Mit Blick auf die Entwicklung des Wohlfahrtsstaates wird das gesellschaftspolitische Engagement der Gewerkschaften deutlich, das sie sichtlich von der Vertretung ausschließlich partikularer Interessen abgrenzt. Das Verhältnis der Gewerkschaften zum Sozialstaat ist dabei aber durchaus ambivalent. Zum einen hängt es von der Ausgestaltung der sozialstaatlichen Leistungen ab, welcher gestalterische Raum den Gewerkschaften für ihre eigenen Leistungsund Solidarangebote verbleibt (vgl. Schroeder/Keudel 2008, S. 16). Zum anderen sind die Gewerkschaften selbst prominenter Teil des deutschen Sozialstaates. Als institutionalisierte Organisationen sitzen Gewerkschaftsvertreter in den Verwaltungsräten der Sozialversicherungsträger.

Den Ausbau des deutschen Sozialstaates haben die Gewerkschaften mit »Forderungen, Vorschlägen und Mobilisierungskampagnen« entschieden mitgeprägt - in den 1980er Jahren auch in »einem eigentümlichen Gegensatz zu dem dezidiert antikapitalistischen Gestus« von Funktionären und Grundsatzprogrammen (Wiesenthal/Clasen 2003, S. 299f.). Als treibende Kraft des Auf-, Aus- und Umbaus des Sozialstaates kritisieren die Gewerkschaften gleichzeitig jedoch die negativen Wirkungen und Strukturen des deutschen Sozialstaates.

Auch wenn viele Forderungen der Gewerkschaften im Laufe ihrer Erfolgsgeschichte zum festen Bestandteil der sozialpolitischen Ausgestaltung der Bundesrepublik geworden sind, haben sie selbst in ihrer Funktion als politischer Akteur auf diesem Gebiet nicht ausgedient. Sie werden daran gemessen, ob und wie es ihnen gelingt, zeitgemäße Ziele und Inhalte zu entwickeln und durchzusetzen, die kompatibel sind mit dem jeweiligen Stand der sozialstaatlichen Entwicklung. Dazu gehört auch, das Niveau sozialstaatlicher 
Entwicklungen zu verteidigen bzw. weiter zu entwickeln - gerade in Zeiten knapper Kassen und dem Rückbau sozialstaatlicher Leistungen.

\section{Arbeitsmarktfunktion: Konzentration auf die Tarifpolitik}

Das Scheitern der gewerkschaftlichen Forderungen nach einer »Sozialisierung der Schlüsselindustrien und einem wirtschaftlichen Mitbestimmungsrecht für Betriebsräte « 1947, der erfolglose »Generalstreik gegen die negativen Auswirkungen der Währungsreform « 1948 und die Niederlage »im Streit um das Betriebsverfassungsgesetz « 1952 führten bei den Gewerkschaften zu einer veränderten Ausrichtung (Schmidt 2007, S. 164). Sozialistische und antikapitalistische Bestrebungen zur Neuordnung des deutschen Wirtschaftssystems verschwanden aus den Grundsatz- und Aktionsprogrammen zugunsten eines Bekenntnisses zur sozialen Markwirtschaft und damit einhergehend einer stärkeren Konzentration auf die Tarif-, Lohn- und Sozialpolitik. »In der historisch beispiellosen Wachstumsphase der fünfziger und früher sechziger Jahre bestanden sehr günstige Voraussetzungen für einen tarifpolitischen Erfolgskurs, der auf Einkommensverbesserung und Arbeitszeitverkürzungen pochte.« (Schönhoven 2003, S. 55)

»Die Ritualisierung der Tarifverhandlungen hat aus den Hoch-Zeiten der Repräsentation der Macht der Arbeiterklasse oder bescheidener: der Arbeitnehmerorganisationen, einst personifiziert in der kämpferischen Haltung der Arbeiterführer, nun den geschäftsmäßigen Schlagabtausch von Profis gemacht: die Spielregeln sind bekannt, das Ergebnis berechenbar, die Kulissengeräusche wie spontane Arbeitsniederlegung und Warnstreik - programmiert. Die Gewerkschaften sind ein stationäres System geworden, ihre Aktivitäten sind institutionell kanalisiert, der Bewegungscharakter ist fast verschwunden, nur noch wehmütige Erinnerung der Alten.« (Grebing 1977, S. 46)

Die Teilhabe der Arbeitnehmer am wirtschaftlichen Wachstum wurde für die Gewerkschaften zur neuen Priorität. Die Durchsetzung materieller Forderungen, neben Lohnerhöhungen auch Arbeitszeitverkürzungen und Urlaubszeitverlängerungen (z.B. der Kampf um die Lohnfortzahlung im Krankheitsfall 1957), trat in den Vordergrund und führte zu einem Abschmelzen der Solidarund der politischen Kampffunktion zugunsten eines auf Arbeitsmarkt und Tarifpolitik gerichteten Vorgehens. Damit verbunden war auf Seiten der Gewerkschaften zu Anfangs auch die Vorstellung, über Tarifverträge die Gesell- 
schaft verändern zu können. So wurde in den 1950er Jahren versucht, die Lohnpolitik »als Hebel der Umverteilungspolitik zu nutzen « (Schneider 2000, S. 285).

Das Wirtschaftswachstum der 1950er und 6oer Jahre eröffnete so große Verteilungsspielräume, dass die Gewerkschaften ihren neuen tarifpolitischen Schwerpunkt sehr erfolgreich umsetzen konnten. Damit forcierten sie nicht nur die Anerkennung der marktwirtschaftlichen Ordnung in der eigenen Organisation, sondern auch in großen Teilen der Bevölkerung. Zugleich wurde die Stellung der Gewerkschaften als Tarifakteur bestärkt, da sich für die Arbeitgeber zeigte, dass die Gewerkschaften als Ordnungsfaktor akzeptierund belastbar waren. Als umfassende Interessenverbände mussten die Gewerkschaften aber auch in der Tarifpolitik die Gesellschaft im Blick haben und die gesamtwirtschaftlichen Folgen ihres tarifpolitischen Handelns berücksichtigen. Beides beförderte die stärkere Institutionalisierung und Inkorporierung der Gewerkschaften und wirkte damit selbstverstärkend auf den Stellenwert der Tarifpolitik in der gewerkschaftlichen Arbeit. Mit dem »deutschen Modell« der Arbeitsbeziehungen, seinen zentralen Verhandlungen unter dem Prinzip der Tarifautonomie und daraus resultierenden verpflichtenden Tarifverträgen, wurden die dazu passgenauen Industrie- und Einheitsgewerkschaften zu etablierten und gefestigten Tarifakteuren. Unter der Ägide von sozial- und/oder konfliktpartnerschaftlichen Verhandlungen bekamen aber auch »Verträge Priorität vor Spontaneität und dezentraler Konfliktaustragung« (Wiesenthal/Clasen 2003, S. 299).

Heute stehen die Gewerkschaften auch in ihrem Kernfeld gewerkschaftlicher Politik vielfältigen Problemen gegenüber. Der Flächentarifvertrag verliert im Zuge von Dezentralisierung und Flexibilisierung an Bedeutung. Die betriebliche Ebene und Firmentarifverträge werden wichtiger. Damit werden die betrieblichen Akteure gestärkt, während die Gewerkschaften als tarifpolitische Akteure zusätzlich, durch die Unterbietungskonkurrenz christlicher Gewerkschaften und seit einigen Jahren durch den Überbietungswettbewerb spezialisierter Berufsgewerkschaften, unter Druck geraten (vgl. Schroeder et al. 2011).

Unabhängig von Veränderungen in Programmatik und Organisationsstruktur sowie den Verschiebungen in Aufgaben und Funktion der Gewerkschaften stehen sie immer noch in der Tradition der Arbeiterbewegung. Und auch mit ihrem tarifpolitischen Fokus sind sie »zur Durchsetzung ihrer Ziele immer wieder darauf angewiesen [...], neben der alltäglichen Verhandlungsroutine ihren Charakter als Bewegung zu reaktivieren« (Schmidt 
2007, S. 158). Insbesondere trifft dies im Zuge von Arbeitskampfmaßnahmen zu. (Warn)Streiks, Demonstrationen und andere Aktionen bedürfen einer Aktivierung und Mobilisierung der Mitglieder. "Zudem weckt der Streik Gefühle sowohl der Zusammengehörigkeit, der eigenen Stärke wie auch der Gegnerschaft, ja des Klassenbewusstseins und des Klassenhasses.« (Boll 2003, S. 493) Damit kommt dem Streik eine emotionale und soziale Bedeutung $\mathrm{zu}$, die über die kurzzeitige Mobilisierung von Arbeitnehmern für gewerkschaftliche Aktivitäten hinausreicht.

Die Streikaktivität in Deutschland fällt, auch auf Grund der Einbettung der Gewerkschaften in das politische System und die Etablierung eines sozialpartnerschaftlichen, verrechtlichten Typus der Arbeitsbeziehungen, im internationalen Vergleich niedrig aus. Nichtsdestotrotz waren die 1970er und der Beginn der 1980er Jahre von Streikaktionen (1968 auch in Kooperation mit der außerparlamentarischen Opposition) geprägt, nachdem die 1960er Jahre dank der wirtschaftlichen Prosperität eine »Dekade des sozialen Friedens« (Müller-Jentsch 1979, S. 39) gewesen waren. Neben der aktiven und expansiven Lohnpolitik oder dem Kampf um die 35-Stunden-Woche, bekam der tarifpolitische Schwerpunkt der Gewerkschaften mit der wirtschaftlichen Rezession eine neue Ausrichtung. Arbeitsplatzsicherung und Besitzstandwahrung wurden angesichts von Betriebsschließungen und Massenentlassungen wichtige Ziele gewerkschaftlicher Forderungen, die auch vermehrt zu Streiks führten (vgl. Boll/Kalass 2014, S. 535f.).

Die deutschen Gewerkschaften sind einerseits hoch institutionalisiert, rechtlich befestigt und ins politische System eingebettete Tarifakteure. Andererseits sind sie aber auch in der Lage, zumindest punktuell, als soziale Bewegung zu agieren. Dazu zählt nicht nur eine auch gesellschaftliche Mobilisierungsfähigkeit während der Tarifrunden, sondern auch eine politische Vetofähigkeit gegen sozial als ungerecht bewertete Regierungsoptionen (1996 gegen die Kürzungsgesetze oder 2000 gegen die Rentenpolitik), ihre Aktionspolitik gegen Rechts oder ihr gesellschaftspolitisches Engagement für Gerechtigkeit und Chancengleichheit.

\section{Gewerkschaften als Mitgliederorganisation}

Unmittelbar nach dem Zweiten Weltkrieg erlebten die deutschen Gewerkschaften einen derartigen Mitgliederzulauf, dass Beobachter gar vom »Wunder der Organisation«(Pirker 1960) sprachen. Anfang der 1950er Jahre wurden bereits ein Nettoorganisationsgrad (nur erwerbstätige Mitglieder) von 36 Pro- 
zent und ein Bruttoorganisationsgrad von etwa 40 Prozent erreicht (MüllerJentsch/Ittermann 2000, S. 91). Seit Mitte der 1950er bis Ende der 1960er Jahre sanken diese Werte auf etwa 30 Prozent ab. In den 1970er Jahren gelang es den Gewerkschaften trotz einer bereits damals einsetzenden Verschiebung zwischen und innerhalb der Branchen, dieses Niveau auszudehnen, indem sie das gewerbliche Arbeiterpotential stärker als zuvor integrierten und vermehrt auch Nicht-Erwerbstätige als Mitglieder aufnahmen (Rentner, Arbeitslose usw.).

Abbildung 1: Mitgliederzahlen und Organisationsgrad DGB-Gewerkschaften 19502017

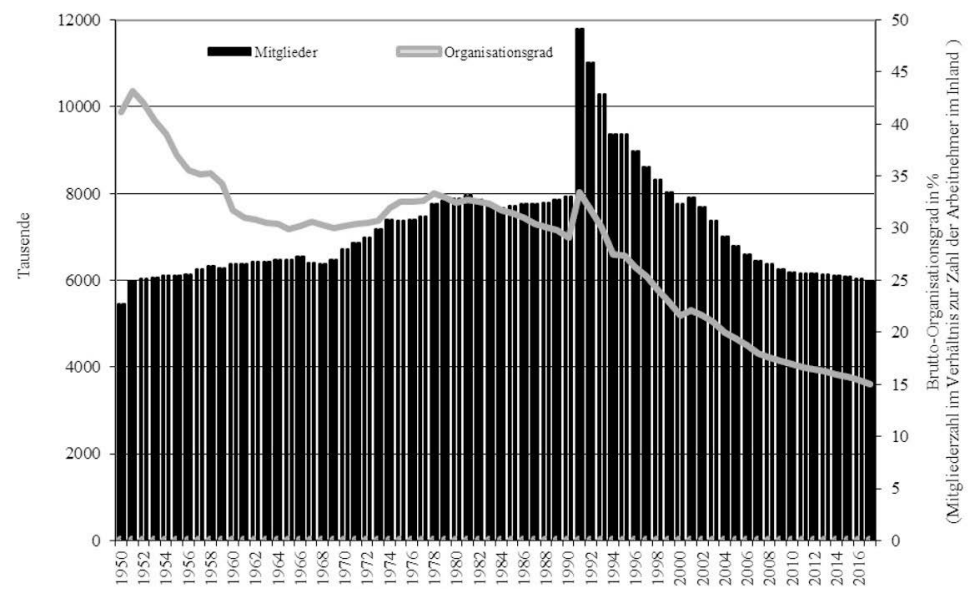

Quellen: DGB, Statistisches Bundesamt, Greef (2014)

Aus der Perspektive des sich veränderten Arbeitsmarktes war diese Mitgliederpolitik für die Folgezeit zu defensiv. Die bisher nicht ausreichende Umstellung der Gewerkschaften auf veränderte Formen von Erwerbstätigkeit, insbesondere Arbeitsformen jenseits des Normalarbeitsverhältnisses, schlägt sich in einem seither anhaltenden Mitgliederrückgang nieder. Mit dieser defensiven Mitgliederstrategie konnte keine Anpassung an die Arbeitsmarktdynamik erreicht werden. Diese drückt sich darin aus, dass sich die Beschäftigung im produzierenden Gewerbe drastisch reduzierte (von ca. 47 Prozent im 
Jahr 1970 auf etwa 23 Prozent 2017), während sie im Dienstleistungsbereich von 45 auf 73 Prozent anstieg.

Verschiedene Analysen gehen davon aus, dass die damit einhergehenden branchenbezogenen Verschiebungen in den letzten beiden Jahrzehnten für einen Großteil der Mitgliederverluste in den westeuropäischen Gewerkschaften verantwortlich sind (z.B. Ebbinghaus/Visser 1998). Während in den traditionell gewerkschaftlich gut organisierten Bereichen in den letzten Jahren Beschäftigung abgebaut wurde, erfolgte der Beschäftigungsaufbau genau in den Bereichen und bei den (Berufs-)Gruppen, die für Gewerkschaften bislang nur schwer ansprechbar waren. Dabei handelt es sich um Beschäftigte mit befristeten Arbeitsverträgen, Teilzeitarbeitnehmer und Leiharbeiter. Diese Beschäftigten arbeiten häufiger in kleinen und mittleren $\mathrm{Be}-$ trieben, sind höherer Unsicherheit ausgesetzt und müssen mobiler sein als die sogenannten Normalarbeitnehmer. Zu diesen Strukturveränderungen des Arbeitsmarktes, die weitreichende Anpassungsforderungen an die Gewerkschaften stellen, zählt auch die Zunahme der Frauenbeschäftigung: Mittlerweile ist die Erwerbstätigenquote der Frauen (Arbeitsagentur 2019, S. 9ff.) in Deutschland mit $72,1 \%$ die vierthöchste in der EU nach Schweden $(76,0 \%)$, den Niederlanden (72,8 \%) und Dänemark (72,6\%).

In Folge dieser Arbeitsmarktentwicklung und der defensiven Mitgliederpolitik der DGB-Gewerkschaften sank zwischen 1991 und 2017 ihr Organisationsgrad von etwa 36 auf 15 Prozent (Hassel/Schroeder 2018). Ein zentrales Problem besteht darin, dass die Kluft zwischen der Mitgliederstruktur der Gewerkschaften und der Arbeitsmarktstruktur gewachsen ist. Im Ergebnis führte dies zu einer anhaltenden Dominanz des gewerblichen männlichen Arbeiters in den Gewerkschaften, während die Angestellten, Frauen und Jugendlichen, gemessen an ihrer Präsenz auf dem Arbeitsmarkt, unterrepräsentiert sind. Der gewerkschaftliche Organisationsgrad liegt in Deutschland mit mittlerweile 15,7 Prozent unterhalb des Durchschnitts in der EU. Hinzu kommt, dass der Organisationsgrad von Männern mit 19,7 Prozent etwas überdurchschnittlich, der von Frauen mit knapp 11,3 Prozent deutlich geringer ausfällt. Der Abstand zwischen dem Männer- und Frauenanteil hat sich jedoch im Zeitverlauf reduziert. In vielen europäischen und insbesondere den nordischen Ländern sind Frauen häufiger gewerkschaftlich organisiert als Männer. Dies ist auf den höheren Beschäftigtenanteil von Frauen im staatlichen Dienstleistungssektor und die schwächere Bedeutung der Industrie, in der traditionell Männer dominieren, zurückzuführen. Die Gewerkschaftsmitglieder in Deutschland konzentrieren sich weiterhin auf den verarbeiten- 
den Sektor und den öffentlichen Dienst sowie auf größere Betriebe und bestimmte regionale Räume. Besonders schwach vertreten sind sie im Bereich des privaten Dienstleistungssektors.

Mit der nachlassenden Repräsentativität gewerkschaftlicher Mitgliedschaft laufen die Gewerkschaften Gefahr, mehr und mehr zur Interessenvertretung nur eines kleinen Teils der Arbeitnehmerschaft zu werden. Damit wird es für sie tendenziell schwieriger, nicht nur Partikularinteressen zu vertreten, sondern ihren gesamtgesellschaftlichen Anspruch aufrecht zu erhalten. Um die Kluft zwischen Mitglieder- und Arbeitsmarktstruktur abzubauen, ist deshalb ein Leitbildwandel erforderlich: Die Konzentration auf das Normalarbeitsverhältnis des männlichen Vollzeitbeschäftigten in der verarbeitenden, großbetrieblichen Industrie oder im Öffentlichen Dienst versperrt den Blick für andere Arbeitsformen und Arbeitssegmente. Es ist für die Gewerkschaften notwendig, die Interessenlage bisher nicht oder kaum beachteter Beschäftigtengruppen, wie Teilzeitbeschäftigte, Leiharbeiter oder Hochqualifizierte, hinsichtlich einer möglichen gewerkschaftlichen Organisierung besser $\mathrm{zu}$ identifizieren und genauer zu sondieren.

\section{Professionalisierung und Bürokratisierung}

Angesicht von Mitgliederrückgang und Effizienzdefiziten betreiben die Gewerkschaften in den letzten Jahrzehnten einen Umbau der verbandlichen Bürokratie mit dem Ziel einer kostenreduzierenden Optimierung aller Aktivitäten, die sich von der Organisationsentwicklung bis zur Budgetierung aller Aufgabenbereiche erstreckt. Bis 2002 waren aus den 17 Einzelgewerkschaften, die noch in den 1980er Jahren unter dem Dach des DGB existierten, durch Fusionen nur mehr acht Gewerkschaften übriggeblieben.

Zweitens betreiben sie eine Professionalisierung der gewerkschaftlichen Arbeit, die allerdings von einem starken Personalabbau begleitet wird. Mit dem Versuch, die gewerkschaftliche Arbeit auf das sogenannte »Kerngeschäft« zu konzentrieren, dessen Definition einer jeweils aktuell auszutarierenden und umstrittenen Neubestimmung unterliegt, verändert sich zugleich das Profil des Gewerkschaftsfunktionärs: Nicht mehr der reaktive Funktionär und politisch ambitionierte Generalist ist gefragt, sondern Funktionäre mit spezifischen Medien-, Klientel-, Fach- und Servicekompetenzen. Damit ziehen nicht nur marktwirtschaftliche Steuerungsmittel in die Gewerkschaftsorganisation ein, es kommt zudem auch zu einer Dezentralisierung der Binnenstrukturen. 
Die Implikationen können recht unterschiedlicher Art sein. Schon im erwähnten »Rückzug aus der Fläche« des DGB, der sich in der Schließung und Zusammenlegung der DGB-Kreise äußerte, sahen manche den Verlust der unmittelbaren Beziehungen zu den Mitgliedern und damit Anzeichen eines weiteren Umbaus von einer nur noch partiell existierenden Milieuorganisation zu einem Dienstleistungsapparat.

»Nachdrücklichen Verfechtern der Bedeutung der Gewerkschaften als im Prinzip emanzipatorische Kraft in der Cesellschaft muß es geradezu als ein Trauerspiel erscheinen, daß in der Außenwirkung die Gewerkschaften das Image gewinnen, Syndrom des Über-Kapitalismus zu sein: ein effizienter, moderner Dienstleistungsapparat, der durch die zunehmende Akademisierung seines mittleren Führungspersonals nach außen und gegenüber den Mitgliedern selbst die angsteinflößenden Züge superkapitalistischer Leistungsethik wie Härte, Fixigkeit, Cleverness, Eloquenz und den Anschein intellektueller Überlegenheit gewinnt. «(Grebing 1977, S. 46)

Tatsächlich impliziert die weitere Professionalisierung nicht nur die generelle Durchsetzung eines bestimmten Typs von Organisationspersonal, sondern möglicherweise auch die dominante Orientierung am Prinzip der Gewerkschaften als Versicherungsbetrieb. Dabei haben wir es jedoch mit einer Tendenz zu tun, die die Entwicklung der Gewerkschaften bereits seit ihren Anfängen begleitet.

Unter zivilgesellschaftlicher Perspektive wird mit der Bürokratisierung und funktionärsorientierten Struktur aber auch eine weitere Abkehr zivilgesellschaftlicher Prinzipien verbunden. Der Gewerkschaftsapparat wird durch bezahlte Funktionäre am Laufen gehalten und damit würden die Gewerkschaften immer weniger dem Prinzip der »Selbstorganisation « unterliegen. Gewerkschaftsarbeit sei für die Funktionäre schlicht Erwerbsarbeit (Kocka 2003, S. 613f.). Dem steht entgegen, dass Ehrenamt und Aktivitäten von Mitgliedern weiterhin für die gewerkschaftliche Arbeit vor Ort, in den Betrieben, bei Demonstrationen und Streiks unabdingbar sind. Und trotz aller Kritik an der Entpersönlichung beziehungsweise Versachlichung der Beziehungen zwischen Apparat und Mitgliedern ist nicht ausgemacht, dass der Weg der Professionalisierung und des Ausbaus von Dienstleistungen falsch ist. Denn der Mitgliederschwund der Gewerkschaften ist nicht darauf zurückzuführen, dass die mitgliederbezogenen Dienstleistungen zunehmen, sondern eher darauf, dass es den Gewerkschaften schwer fällt, substantielle Dienstleistungen anzubieten, die von den Beschäftigten als plausible Antwort auf ihre Nö- 
te angesichts unsicherer Arbeitsmarktstrukturen und Veränderungen sozialstaatlicher Leistungen bewertet werden. Der Ausbau des Dienstleistungsangebots kann demnach auch eine Chance sein, neue Mitglieder zu gewinnen und die Mitgliederbindung insgesamt zu stärken.

\section{Fazit: Was bleibt den Gewerkschaften für die Zukunft?}

Die organisatorische Stabilität, die die deutschen Gewerkschaften in den ersten Jahrzehnten der Bundesrepublik nach dem Ende des Zweiten Weltkrieges ausbildeten, erreichten sie als Einheits- und Industrie- beziehungsweise Branchengewerkschaften. Dabei hatten sie während der Zeit der deutschen Teilung eine zusätzliche Rolle als antikommunistische Integrationskraft. Als Kerninstitution des deutschen Modells und als Prototyp fordistischer Massengewerkschaft haben sie den bundesdeutschen Basiskonsens mitentwickelt und damit einen maßgeblichen Anteil daran, dass die soziale Marktwirtschaft zum Kern der Bonner Erfolgsstory wurde. Sie erlebten diese keynesianische Phase der fordistischen Massenproduktion als ihr eigenes goldenes Zeitalter, als selbstbewusster, öffentlich anerkannter und befestigter Akteur. Während die Gewerkschaften in dieser Hochzeit in politische Prozesse eingebunden waren und ihre Rolle als arbeitsmarktpolitscher Akteur weiter ausbauten, nahm der Stellenwert genossenschaftlicher Funktionen ab. Mit dieser veränderten Schwerpunktsetzung wandelten sich die Gewerkschaften zunehmend von umfassenden Solidarorganisationen zu Tarifverbänden.

Dieses goldene Zeitalter währte nicht ewig. Besonders schwer taten und tun sich die Gewerkschaften mit dem Wandel des Arbeitsmarktes und der Lebenslagen der Beschäftigten, deren lebensweltliche Orientierungen sich schon seit vielen Jahren nicht mehr in den Traditionen der deutschen Arbeiterbewegung bewegen. Milieuverluste und gesellschaftliche Individualisierungstendenzen, der Wandel betrieblicher Rationalisierung und der Formwandel von Erwerbsarbeit haben nicht nur neue, differenzierte Formen des betrieblichen Handelns sowie einen modifizierten Beschäftigtenhabitus befördert, sondern auch neue Vorstellungen von Organisationsloyalität und (gesamtgesellschaftlicher) Solidarität. Damit ist auch die »Vereinbarung von Mitgliederinteressen und Gemeinwohlorientierung [...] für die Gewerkschaften schwieriger geworden« (Kocka 2003, S. 616). Im Zuge der gesellschaftlichen Ausdifferenzierung, dem Wegbrechen gewerkschaftlicher Milieus, der »Institutionalisierung des Klassenkampfes« (Geiger 1949) 
und der Verschiebung zwischen Arbeitsmarkt- und Solidarfunktion der Gewerkschaften, ist diesen ein erheblicher Teil ihrer zivilgesellschaftlichen Verankerung verloren gegangen. Die Erosion ihrer zivilgesellschaftlichen Basis korrespondiert mit einem anhaltenden Mitgliederrückgang in Folge einer unzureichenden Anpassung an die veränderten Verhältnisse.

Aber auch wenn den Gewerkschaften oft beharrende und konservierende Eigenschaften attestiert wurden und werden, kann von einer völligen $\mathrm{Ab}$ kopplung gesellschaftlicher Entwicklungen nicht gesprochen werden. Ihre Organisationsbasis beruht weiterhin auf freiwilliger Mitgliedschaft und aktivem Ehrenamt. Trotz ihrer Integration in das politische und ökonomische System der Bundesrepublik sind sie nicht nur Teil des Kapitalismus, sondern zugleich auch dessen Kritiker, zuweilen mit systemalternativen und parallelgesellschaftlichen Optionen. Und nicht zuletzt haben sie weiterhin den Anspruch, nicht nur »pressure groups « für Arbeitsplatzbesitzende zu sein, sondern gesellschaftliche Prozesse in der gewerkschaftlichen Arbeit abzubilden, zu artikulieren und durchzusetzen. Sie versuchen ihre organisatorischen und ideenpolitischen Grundlagen auf die Herausforderungen des postindustriellen Kapitalismus einzustellen, um angesichts der neuen ökonomischen und technologischen Dimensionen des Postindustrialismus handlungsfähig zu bleiben. Die Gewerkschaften sind auch heute noch mehr als nur »Nachlassverwalter der alten Arbeiterbewegung« (Schönhoven 2003, S. 59). Da die defensive Expansionsstrategie der 1970er und 8oer Jahre keine Annäherung der gewerkschaftlichen Mitglieder- an die Arbeitsmarktstruktur förderte, sind heute gezielte Initiativen notwendig, die kontextspezifisch die neuen Arbeitsmarktsegmente ansprechen. Deshalb sind nicht nur neue Formen der Machtinszenierung notwendig, sondern auch eine aktive Veränderung der gewerkschaftlichen Organisation und ihrer nach innen und außen orientierten Kommunikationsfähigkeit.

Neue Formen der gewerkschaftlichen Mitgliedergewinnung, wie Organizing-Aktionen und Kampagnen, zeugen von einer Reaktivierung einzelner Elemente sozialer Bewegungen. Neue, projektbezogene Partizipationsformen erhöhen den Mitgliederbezug. Sie basieren auf einer stärkeren Einbindung von Mitgliedern vor Ort und der direkten Ansprache von Betroffenen. Die eigene Mitgliedschaft wird mobilisiert und potenzielle neue Mitglieder aktiv und systematisch angesprochen und einbezogen (vgl. z.B. Schroeder/Fuchs 2019). Die Gewerkschaften begeben sich damit wieder näher an die Lebens- und Arbeitswelt der Arbeitnehmer - ihrer Organisationsbasis. In Zusammenarbeit mit lokalen Akteuren und neuen sozialen Bewegungen 
übernehmen die Gewerkschaften ein stückweit deren Konzepte. Die Gewerkschaften sind somit weiterhin Teil verschiedener Welten oder intermediärer Sektoren. Sie sind Arbeitsmarktakteur (auf Umverteilung orientierte Vertretung materieller Interessen), politischer Verband, aber auch weiterhin Solidarorganisation mit gesamtgesellschaftlichem Anspruch. Davon zeugt auch der Versuch, die zivilgesellschaftliche Verankerung der Gewerkschaften wieder zu stärken. Eine Rückbesinnung und Stärkung ihrer Stellung im zivilgesellschaftlichen Sektor, wie die Revitalisierung von Elementen sozialer Bewegung, kann eine erfolgsversprechende Strategie für die Zukunft sein.

In diesem Prozess stehen die Gewerkschaften heute keinesfalls mehr am Anfang, denn sie können auf eine Reihe von Ressourcenentscheidungen, Initiativen und Aktivitäten aufbauen. Anknüpfungspunkte und erste Erfahrungen gibt es beispielsweise in dem Bereich partizipativer, öffentlichkeitsorientierter Formen der Mitgliedergewinnung im Bereich prekärer Beschäftigung. Unter Einbeziehung zivilgesellschaftlicher Akteure wurden US-amerikanische Organizing-Konzepte erfolgreich auf deutsche Verhältnisse angewandt. Das Vorgehen ist konfliktbereit, aber prinzipiell gewaltfrei. Und in Zusammenarbeit mit anderen Akteuren wird eine breite Öffentlichkeit einbezogen, um über partikulare Interessen hinaus gemeinwohlorientiert die Einhaltung von Prinzipien wie »Guter Arbeit« durchzusetzen. Damit ist die Gewerkschaftsarbeit wieder bei der Definition von Zivilgesellschaft angelangt.

\section{Literaturhinweise}

Bispinck, Reinhard/Schulten, Thorsten (2009): Re-Stabilisierung des deutschen Flächentarifvertragssystems. In: WSI-Mitteilungen, 4, S. 201-2009.

Boll, Friedhelm (2003): Streik und Aussperrung. In: Schroeder, Wolfgang/Weßels, Bernhard (Hg.), Die Gewerkschaften in Politik und Gesellschaft der Bundesrepublik Deutschland. Ein Handbuch. Wiesbaden: VSVerlag, S. 478-510.

Bromberg, Kirstin (2008): Verwaltungsapparat oder soziale Bewegung? Sozialweltliche Antworten auf die Frage, wie Gewerkschaften funktionieren. In: Haug, Christoph/Maier, Rudi/Schröder, Berit (Hg.), Kampf um Teilhabe. Akteure - Orte - Strategien. Hamburg: VSA, S. 222-235.

Bundesagentur für Arbeit (2019): Die Arbeitsmarktsituation von Frauen und Männern 2018. Nürnberg: BfA. 
Deppe, Frank (1984): Ende oder Zukunft der Arbeiterbewegung? Gewerkschaftspolitik nach der Wende. Eine kritische Bestandsaufnahme. Köln: Pahl-Rugenstein.

Dettling, Warnfried (2002): Gewerkschaften und Bürgergesellschaft. Anmerkungen zu einer schwierigen Beziehung. In: Forschungsjournal Neue Soziale Bewegungen, 15(2), S. 7-12.

Ebbinghaus, Rolf/Tiemann, Friedrich (Hg.) (1984): Das Ende der Arbeiterbewegung in Deutschland? Opladen: Westdeutscher Verlag.

Geiger, Theodor (1949): Die Klassengesellschaft im Schmelztiegel. Köln: Peter Lang.

Grande, Edgar (2018): Der Wandel politischer Konfliktlinien - Strategische Herausforderungen und Handlungsoptionen für Volksparteien. In: Mack, Winfried (Hg.), Zwischen Offenheit und Abschottung. Wie die Politik zurück in die Mitte findet. Freiburg: Herder, S. 17-43.

Grebing, Helga (1973): Gewerkschaften als Ordnungsfaktor oder als Gegenmacht? In: Gewerkschaftliche Monatshefte, 7, S. 393-400.

Grebing, Helga (1976): Gewerkschaften und Gesellschaft. In: Borsdorf, Ulrich/Hemmer, Hans O./Leminsky, Gerhard/Markmann, Heinz (Hg.), Gewerkschaftliche Politik: Reform aus Solidarität. Zum 60. Geburtstag von Heinz O. Vetter. Köln: Bund Verlag, S. 43-59.

Grebing, Helga (2007): Geschichte der deutschen Arbeiterbewegung. Von der Revolution 1848 bis ins 21. Jahrhundert. Berlin: Berliner Vorwärts Verlagsgesellschaft.

Greef, Samuel (2014): Gewerkschaften im Spiegel von Zahlen, Daten und Fakten. In: Schroeder, Wolfgang (Hg.), Handbuch Gewerkschaften in Deutschland. 2. Auflage (unter Mitarbeit von Samuel Greef). Wiesbaden: VS Verlag, S. 657-755.

Klönne, Arno/Reese, Harmut (1984): Die deutsche Gewerkschaftsbewegung. Von den Anfängen bis zur Gegenwart. Hamburg: VSA.

Kocka, Jürgen (2003): Gewerkschaften und Zivilgesellschaft - Dimensionen eines Konfliktverhältnisses. In: Gewerkschaftliche Monatshefte, 54(10/11), S. 610-616.

Lucas-Busemann, Erhard (1983): Vom Scheitern der deutschen Arbeiterbewegung, Basel: Stroemfeld/Roter Stern.

Müller-Jentsch, Walther (1979): Streiks und Streikbewegung in der Bundesrepublik 1950-1978. In: Bergmann, Joachim (Hg.), Beiträge zur Soziologie der Gewerkschaften. Frankfurt a.M.: Suhrkamp, S. 21-71. 
Müller-Jentsch, Walther/Ittermann, Peter (2000): Industrielle Beziehungen Daten, Zeitreihen, Trends 1950-1999. Frankfurt a.M.: Campus.

Nickel, Walter (1973): Zum gegenwärtigen Verhältnis von Arbeiterschaft und Gewerkschaft. In: Gewerkschaftliche Monatshefte, 8, S. 478-487.

Niedenhoff, Horst-Udo (1982): Gewerkschaftliche Gemeinwirtschaft als Teil der Wirtschaftsdemokratie. In: Schlaffke, Winfried (Hg.), Gewerkschaft und Gesellschaft. Entwicklungen, Inhalte und Strategien der Gewerkschaftspolitik. Köln: Deutscher Instituts-Verlag, S. 237-269.

Pirker, Theo (1965): Die Gewerkschaften als Versicherungsbetrieb. In: Horné, Alfred (Hg.), Zwischen Stillstand und Bewegung. Eine kritische Untersuchung über die Gewerkschaften in der modernen Industriegesellschaft. Frankfurt a.M.: EVA, S. 7-21.

Pirker, Theo (1984): Vom »Ende der Arbeiterbewegung«. In: Ebbinghaus, Rolf/Tiemann, Friedrich (Hg.), Das Ende der Arbeiterbewegung in Deutschland? Opladen: Westdeutscher Verlag, S. 39-51.

Priller, Eckhard/Zimmer, Annette (2000): Der Dritte Sektor in Deutschland - seine Perspektiven im neuen Millennium. Münsteraner Diskussionspapiere zum Nonprofit-Sektor Nr. 10, Münster.

Schmidt, Eberhard (2007): Arbeiterbewegung. In: Roth, Roland/Rucht, Dieter (Hg.), Handbuch der sozialen Bewegungen. Frankfurt a.M.: Campus, S. 158-186.

Schneider, Michael (2000): Kleine Geschichte der Gewerkschaften. Ihre Entwicklung in Deutschland von den Anfängen bis heute. 2. Auflage. Bonn: J.H. Dietz.

Schönhoven, Klaus (2003): Geschichte der deutschen Gewerkschaften: Phasen und Probleme. In: Schroeder, Wolfgang/Weßels, Bernhard (Hg.), Die Gewerkschaften in Politik und Gesellschaft der Bundesrepublik Deutschland. Ein Handbuch. Wiesbaden: VS-Verlag, S. 40-64.

Schroeder, Wolfgang (2004): Gewerkschaften als soziale Bewegung - soziale Bewegung in den Gewerkschaften in den Siebzigerjahren. In: Archiv für Sozialgeschichte, Bd. 44, S. 243-265.

Schroeder, Wolfgang (2008): SPD und Gewerkschaften: Vom Wandel einer privilegierten Partnerschaft. In: WSI-Mitteilungen, 5, S. 231-237.

Schroeder, Wolfgang/Keudel, Dorothea (2008): Strategische Akteure in drei Welten. Die deutschen Gewerkschaften im Spiegel der neueren Forschung. Study/edition der Hans-Böckler-Stiftung Nr. 127(219). Düsseldorf: Hans-Böckler-Stiftung. 
Schroeder, Wolfgang/Kalass, Viktoria/Greef, Samuel (2011): Berufsgewerkschaften in der Offensive. Vom Wandel des deutschen Gewerkschaftsmodells. Wiesbaden: VS-Verlag.

Schroeder, Wolfgang (Hg.) (2014): Handbuch Gewerkschaften in Deutschland. 2. Auflage (unter Mitarbeit von Samuel Greef). Wiesbaden: VS-Verlag.

Schroeder, Wolfgang/Fuchs, Stefan (2019): Neue Mitglieder für die Gewerkschaften. Mitgliederpolitik als neues Politikfeld der IG Metall. OBSArbeitsheft 97. Frankfurt: Otto-Brenner-Stiftung.

Schubert, Klaus (2007): Zivilgesellschaft aus der Sicht des Pragmatismus. Vortrag im Rahmen der Ringvorlesung zum Graduiertenkolleg »Zivilgesellschaftliche Verständigungsprozesse vom 19. Jahrhundert bis zur Gegenwart. Deutschland und die Niederlande im Vergleich« am 19. Juni 2007 im Haus der Niederlande, Münster.

Wiesenthal, Helmut/Clasen, Ralf (2003): Gewerkschaften in Politik und Gesellschaft: Von der Gestaltungsmacht zum Traditionswächter? In: Schroeder, Wolfgang/Weßels, Bernhard (Hg.), Die Gewerkschaften in Politik und Gesellschaft der Bundesrepublik Deutschland. Ein Handbuch. Wiesbaden: VS-Verlag, S. 296-322.

Zoll, Rainer (1976): Der Doppelcharakter der Gewerkschaften. Zur Aktualität der Marxschen Gewerkschaftstheorie. Frankfurt a.M.: Suhrkamp. 


\section{Umbrüche I: \\ Politischer Protest und Demokratisierung}





\title{
Neue Konflikte und neue soziale Bewegungen in Deutschland
}

\author{
Dieter Rucht
}

Der Begriff »soziale Bewegungen« ist vage und mehrdeutig, kann aber in einer typologischen und historisierenden Annäherung geschärft werden. Dies ist Ziel der beiden ersten Teile des vorliegenden Beitrags. Der dritte Teil wendet sich dem Konzept »Neuer sozialer Bewegungen« zu. Im vierten Teil werden diese Bewegungen im Rahmen politischer Konfliktlinien verortet, um anschließend (in Teil 5) die Wirkungen neuer sozialer Bewegungen einzuschätzen. Hier zeigen sich mit Blick auf mehrere Wirkungsdimensionen sehr unterschiedliche Effekte.

\section{Begriffsklärungen}

Soziale Bewegungen sind Teil eines weiter gespannten Handlungsfeldes diverser Akteure, für das sich der Begriff »Zivilgesellschaft« eingebürgert hat (vgl. dazu Grande in diesem Band). Ebenso wie im Falle der Zivilgesellschaft ist auch der Begriff »Soziale Bewegungen« unscharf; er wird zeit- und kontextspezifisch variiert und überschneidet sich mit Begriffen wie Protestbewegungen, politische Bewegungen, kulturelle Bewegungen, Protestkampagnen usw. Soziale Bewegungen sind umfassender als politische Bewegungen und zumal zeitlich und sachlich eng begrenzte politische Kampagnen. Obgleich soziale Bewegungen in ihrer konkreten Praxis oft kampagnenförmig agieren, ist ihr ideeller Fluchtpunkt letztlich die Gesamtgesellschaft samt deren Machtstrukturen und normativen Grundlagen. Zusammenfassend lassen sich soziale Bewegungen definieren als mobilisierte Netzwerke von Gruppen und Organisationen, die, gestützt auf eine kollektive Identität, grundlegenden gesellschaftlichen Wandel primär mit den Mitteln kollektiven und öffentlichen Protests herbeiführen oder verhindern wollen. Indem soziale Bewegungen sich auf 
ein umfassendes Konzept gesellschaftlicher Ordnung beziehen, ohne dieses schon im Einzelnen konkretisieren zu wollen oder zu können, ist es unabdingbar, sie in Relation zu einer gegebenen oder erstrebten Gesellschaftsformation zu interpretieren.

\section{Gesellschaftsformationen und Bewegungen}

Das von Karl Marx verwendete Konzept der Gesellschaftsformation setzt strukturell tief und somit jenseits der jeweiligen konkreten institutionellen Ausgestaltungen an. Marx unterscheidet auf der allgemeinsten Ebene zwischen Klassengesellschaften verschiedener Art einerseits und zwei Formen kommunistischer Gesellschaft andererseits, dem Urkommunismus und dem noch auf seine Verwirklichung harrenden Kommunismus in der Nachfolge des modernen Kapitalismus. Bewegungen begreift Marx in doppelter Weise als den Prozess des Wandels von Gesellschaftsformationen, aber auch als einen Typus kollektiver Akteure, die als antagonistische Klassen miteinander ringen. Nun muss man nicht Marx und seiner Vorstellung von der Wirkmacht klassengebundener revolutionärer Subjekte folgen, um dennoch anzuerkennen, dass soziale Bewegungen wesentlich zur Ablösung alter und Durchsetzung neuer Gesellschaftsformationen, etwa im Übergang von der Feudalgesellschaft zum modernen Kapitalismus, beigetragen haben. Bewegungen haben auch im Rahmen bestehender Gesellschaftsformationen deren qualitativen Wandel vorangetrieben, so zum Beispiel im Übergang vom liberalen zum organisierten Kapitalismus. In einer solch strukturorientierten Perspektive haben verschiedene Sozialwissenschaftler soziale Bewegungen zu Gesellschaftsformationen in Beziehung gesetzt, ohne dass die historischen Subjekte sich immer selbst so begriffen hätten. Drei Sichtweisen aus den Sozialwissenschaften, die zugleich einen Weg zum Konzept neuer sozialer Bewegungen eröffnen, seien nachfolgend genannt.

Der US-amerikanische Soziologe Ralph Turner (1969) hat in einem Aufsatz das Problem der Ungerechtigkeit als ein Leitkriterium angelegt, um mit Blick auf die vergangenen Jahrhunderte drei Arten fundamentaler Ungerechtigkeit und darauf bezogene Bewegungen zu identifizieren. Dies ist für die amerikanische und französische Revolution des späten 18. Jahrhunderts der Kampf um politische Teilhabe und Freiheitsrechte, also die Problematik des Ausschlusses; für die sozialistischen Bewegungen ist es die Fortsetzung des Ringens um Teilhabe und Ausschluss, nun aber in Verbindung mit dem Kern- 
problem der Armut; schließlich nennt Turner für die »new movements« oder "contemporary movements « den Wert und die Würde der Person und den Sinn für Identität, nun gerichtet auf das Kernproblem der Entfremdung.

Der französische Soziologe Alain Touraine setzte den Begriff soziale Bewegung, im Unterschied etwa zu politischen Organisationen, ganz kategorisch an und interpretierte soziale Bewegungen in Relation zu »Historizität «, d.h. dem Grundproblem einer jeweiligen gesellschaftlichen Entwicklungsstufe. Nach der vorangegangenen Agrargesellschaft und der Handelsgesellschaft begreift Touraine die Arbeiterbewegung als zentrale soziale Bewegung der industriellen Gesellschaft. In dieser ging es vorrangig um die Kontrolle über die Produktionsmittel. Nun, zu Beginn einer gesellschaftlichen Entwicklungsstufe, die er als postindustriell, technokratisch oder programmierte Gesellschaft bezeichnet, käme eine anti-technokratische Bewegung in Gang, deren Auftakt die Studentenbewegung der späten 1960er Jahre bildete. Dafür verwendete Touraine $(1968$; 1973) auch die Bezeichnung "neue soziale Bewegung« (im Singular!), wohingegen sein ehemaliger Schüler Alberto Melucci (1980) bewusst von einem Plural neuer sozialer Bewegungen ausging. Soziale Bewegungen, so auch die Bewegung vom Mai 1968, verstand Touraine als Klassenbewegungen. ${ }^{1}$ Daneben existierten periphere Bewegungen, die jedoch das Niveau von Historizität, also den Kernkonflikt einer gesellschaftlichen Formation, verfehlten.

Ein drittes Beispiel einer historisch orientierten Typologie sozialer Bewegungen bietet der deutsche Politikwissenschaftler Joachim Raschke (1985). Auch er unterscheidet drei Gesellschaftsphasen, denen er dann jeweils dominante Bewegungen mit ihren jeweiligen Merkmalen zuordnet (siehe Tabelle 1).

Die vorgestellten Typologien beruhen auf einem sehr groben Raster, das im Falle von Touraine und Raschke durch den Hinweis auf die Existenz von peripheren bzw. sekundären Bewegungen ergänzt wird. Insbesondere Raschke verengt die Bandbreite historisch bedeutsamer Bewegungen nicht auf das "progressive « Spektrum, sondern anerkennt die Existenz von bedeutsamen Gegenbewegungen, so die frühe konservative Bewegung in der vorindustriellen Phase sowie die neokonservative Bewegung und die nationalsozialistische Bewegung in der industriellen Phase. Für die nachindustrielle Phase vermerkt Raschke (noch) keine Gegenbewegung zu den neuen sozialen Bewegungen dem Satz: »Die Bewegung des Mai ist eine neue Form des Klassenkampfes. (Touraine 1968, S. 15; meine Übersetzung) 
(Raschke 1985, S. 111). Diese Leerstelle ist heute wohl durch rechtspopulistische und rechtsradikale Bewegungen besetzt worden.

Tabelle 1: Gesellschaftliche Entwicklungsphasen und korrespondierende Bewegungen

\begin{tabular}{|l|l|l|l|}
\hline $\begin{array}{l}\text { Gesellschafts- } \\
\text { phase }\end{array}$ & $\begin{array}{l}\text { Vorindustriell- } \\
\text { modernisierend } \\
1789-1840\end{array}$ & $\begin{array}{l}\text { Industriell } \\
1850 / 50-1960\end{array}$ & $\begin{array}{l}\text { Nachindustriell } \\
1960 / 70-\end{array}$ \\
\hline $\begin{array}{l}\text { Dominante } \\
\text { Bewegungen }\end{array}$ & $\begin{array}{l}\text { frühbürgerliche } \\
\text { Bewegungen }\end{array}$ & Arbeiterbewegung & $\begin{array}{l}\text { Neue soziale Bewe- } \\
\text { gungen }\end{array}$ \\
\hline $\begin{array}{l}\text { Aufsteigende } \\
\text { Großgruppe }\end{array}$ & Bürgertum & Arbeiterklasse & $\begin{array}{l}\text { Dienstleistungs- } \\
\text { intelligenz }\end{array}$ \\
\hline $\begin{array}{l}\text { Zentraler Pro- } \\
\text { blemkomplex }\end{array}$ & $\begin{array}{l}\text { Rechtsstaat und } \\
\text { Demokratie } \\
\text { (rechtl. u. polit. } \\
\text { Gleichheit) }\end{array}$ & $\begin{array}{l}\text { Wohlfahrtsstaat } \\
\text { (soziale Gleichheit) }\end{array}$ & $\begin{array}{l}\text { Soziokulturelle } \\
\text { Identität }\end{array}$ \\
\hline $\begin{array}{l}\text { Mobilisierungs- } \\
\text { typ }\end{array}$ & Ideelle Mobilisierung & $\begin{array}{l}\text { Organisations- } \\
\text { bestimmte } \\
\text { Mobilisierung }\end{array}$ & $\begin{array}{l}\text { Mobilisierung } \\
\text { projektorientierte }\end{array}$ \\
\hline
\end{tabular}

Quelle: Raschke (1985, S. 445)

Gemeinsam ist diesen drei Systematiken die Identifikation eines dominanten neuen Bewegungstypus in den (westlichen) Gegenwartsgesellschaften. Auf die Merkmale, Entwicklungen und Wirkungen dieser neuen Bewegungen konzentrieren sich die nachfolgenden Ausführungen.

\section{Merkmale der neuen sozialen Bewegungen}

Die in Frankreich und bald in anderen Ländern aufkommende Rede von den neuen sozialen Bewegungen bezeichnete nicht die Gesamtheit zeitgenössischer Bewegungen, sondern einen in inhaltlicher, sozialstruktureller, organisatorischer und strategischer Hinsicht distinkten Bewegungstypus. Dieser wurde auch nicht in Abgrenzung zu allen vorangegangenen Bewegungen bestimmt, sondern als angebliches Novum im Kontrast zu »alten « historischen Bewegungen mit progressiver Ausrichtung, namentlich der sozialistischen Arbeiterbewegung. Diese Entgegensetzung beruhte auf Stilisierungen des Alten und Neuen; sie spiegelte vor allem die Selbstwahrnehmung der neuen Bewegungen, wird aber deren tatsächlichen Entwicklungen und komplexen 
Konstellationen kaum gerecht. Insofern ist es geboten, neben der typologischen Entgegensetzung die weitaus differenziertere Realität zu betrachten.

In typologischer Perspektive lässt sich die Differenz von alten und neuen Bewegungen anhand einer Reihe von Dimensionen postulieren (vgl. Tabelle 2).

Tabelle 2: Merkmale alter und neuer sozialer Bewegungen

\begin{tabular}{|c|c|c|}
\hline Kriterium & Arbeiterbewegung & Neue soziale Bewegungen \\
\hline Themenfeld & $\begin{array}{l}\text { Produktionssphäre } \\
\text { Materielle Lebensbedingungen }\end{array}$ & $\begin{array}{l}\text { Reproduktionssphäre, } \\
\text { Lebensqualität }\end{array}$ \\
\hline $\begin{array}{l}\text { Gesellschafts- } \\
\text { entwurf }\end{array}$ & $\begin{array}{l}\text { Kommunismus/Sozialismus } \\
\text { demokratischer Sozialismus }\end{array}$ & $\begin{array}{l}\text { Sozialer Kapitalismus/demo- } \\
\text { kratischer Sozialismus }\end{array}$ \\
\hline Soziale Träger & Arbeiterschaft & $\begin{array}{l}\text { Gebildete Mittelschicht } \\
\text { (Humandienstleistende) }\end{array}$ \\
\hline Organisation & Straff, hierarchisch & Locker, dezentral \\
\hline $\begin{array}{l}\text { Strategische } \\
\text { Ausrichtung }\end{array}$ & Revolution Reformismus & Radikale Reform \\
\hline $\begin{array}{l}\text { Bevorzugte Pro- } \\
\text { testform }\end{array}$ & Streik, Kundgebung, Marsch & $\begin{array}{l}\text { Kundgebung, Marsch, Unter- } \\
\text { schriften, ziviler Ungehorsam }\end{array}$ \\
\hline
\end{tabular}

Der Begriff »Neue Soziale Bewegungen« (im Weiteren: NSB), der in Deutschland um 1980 aufkam, ist inspiriert von (aber nicht inhaltlich deckungsgleich mit) der Entgegensetzung von Alter Linken vs. Neuer Linken, die bereits in den 1950er Jahren in Großbritannien und dann anderswo übernommen wurde. Die Neue Linke, und mit ihr als Spätprodukt die Studentenbewegung in der zweiten Hälfte der 1960er Jahre, verstand sich einerseits in der revolutionären sozialistischen Traditionslinie. Andererseits grenzte sie sich von einer typisierten Alten Linken in mancher Hinsicht ab, so etwa der Hoffnung auf die Arbeiterschaft als dem alleinigen revolutionären Subjekt sowie der Präferenz für straffe und disziplinierte Organisationsformen einschließlich einer sozialistischen Bewegungspartei. Im Unterschied dazu war die Neue Linke sehr stark intellektuell geprägt und theorielastig, befürwortete Selbstentfaltung und Spontaneität in Abgrenzung zu hierarchischen Organisationsformen und rigiden Verhaltensnormen. In ihren Aktionsformen setzte die Neue Linke häufig auf das Mittel der Provokation.

Ein genauerer Blick auf die Alte und Neue Linke würde jedoch zu weitaus differenzierten Mustern führen und innerhalb beider Bewegungen bestimm- 
te Strömungen identifizieren (z.B. den historischen wie den zeitgenössischen Anarchismus), die durch keine markante ideologische Zäsur getrennt sind und somit den schroffen Dualismus alter und neuer sozialer Bewegungen in Frage stellen. Auch ist darauf hinzuweisen, dass dieser Dualismus vor allem in vielen Teilen Westeuropas intuitiv Sinn machte, während er in der DDR, in Mittel- und Osteuropa, in den USA und in manchen Ländern des globalen Südens auf erhebliche und empirisch durchaus begründete Vorbehalte stieß (z.B. Pichardo 1997). Zudem machten einzelne Historiker darauf aufmerksam, dass die Entgegensetzung von alten und neuen Bewegungen auf einem schiefen Vergleich beruhe, nämlich der stilisierten Spätphase der alten (sozialistischen) Bewegungen und der stilisierten Frühphase der neuen Bewegungen. Dagegen argumentierte beispielsweise Calhoun (1995, S. 204), dass die Bewegungen des frühen 19. Jahrhunderts und insbesondere die Arbeiterbewegung dieser Ära den heutigen neuen sozialen Bewegungen ähnlicher seien als die Bewegungen in der dazwischen liegenden Periode.

Es ist deshalb realitätsnäher, keine scharfe Zäsur im Entwicklungsgang progressiver Bewegungen zu unterstellen und darüber hinaus die neuen sozialen Bewegungen nicht statisch auf einen Typus bzw. eine Phase (insbesondere die Hochphase der enger gefassten Neuen Sozialen Bewegungen (NSB) einzufrieren, sondern eher von einer Überlagerung bzw. sich allmählich zeigenden Abfolge progressiver Bewegungen auszugehen, von denen die NSB lediglich eine Ausprägung darstellen.

Die enger und primär typologisch definierten NSB mit ihren nur lose verbundenen Themenschwerpunkten ${ }^{2}$ hatten ihre Hochphase in den 1970er und 8oer Jahren. In dieser Zeit entsprachen sie am ehesten dem postulierten Typus und auch der Selbstwahrnehmung der Bewegungsaktivisten. ${ }^{3}$ Davor und/oder danach, aber auch während dieser Hochphase, bestanden weitere sich als progressiv verstehende Strömungen, die vom typologischen Bild der NSB abwichen, aber in empirischer Sicht Schnittmengen mit dem Kern dieser Bewegungen aufwiesen (dazu Roth/Rucht 2008; Gassert 2018). Dazu gehören

Dazu gehören insbesondere die Themenbereiche Frieden und Abrüstung, Menschenund Bürgerrechte, Hunger und Elend in der Dritten Welt, Gleichstellung/Emanzipation von Frauen, Schwule und Lesben, Ökologie, Anti-Atomkraft sowie alternatives Leben und Wirtschaften.

Reichardt (2014), der eine umfangreiche Studie zum »linksalternativen Leben« im Umfeld der neuen sozialen Bewegungen vorgelegt hat, spricht mit Blick auf den Zeitraum von Mitte der 1970er bis Mitte der 1980er Jahre von einer "Stabilisierungs- und Konsolidierungsphase«, die dann an »milieuartiger Stabilität« verlor (Reichardt 2014, S. 875). 
Teile der Alten und Neuen Linken, die Ausläufer der Studentenbewegung in Gestalt sektiererischer kommunistischer Gruppen, der Linksterrorismus der 1970er und 1980er Jahre sowie eine Reihe von Bewegungen, die sich als weitere Generationen der neuen sozialen Bewegungen, jedenfalls als im weitesten Sinne jüngere "progressive« Bewegungen verstehen lassen. Diese Überlappungen und Abfolgen können hier nicht im Einzelnen beschrieben werden, aber sie sollen doch in einer schematischen Darstellung angedeutet werden (siehe Abbildung 1).

Abbildung 1: Abfolge progressiver Bewegungen

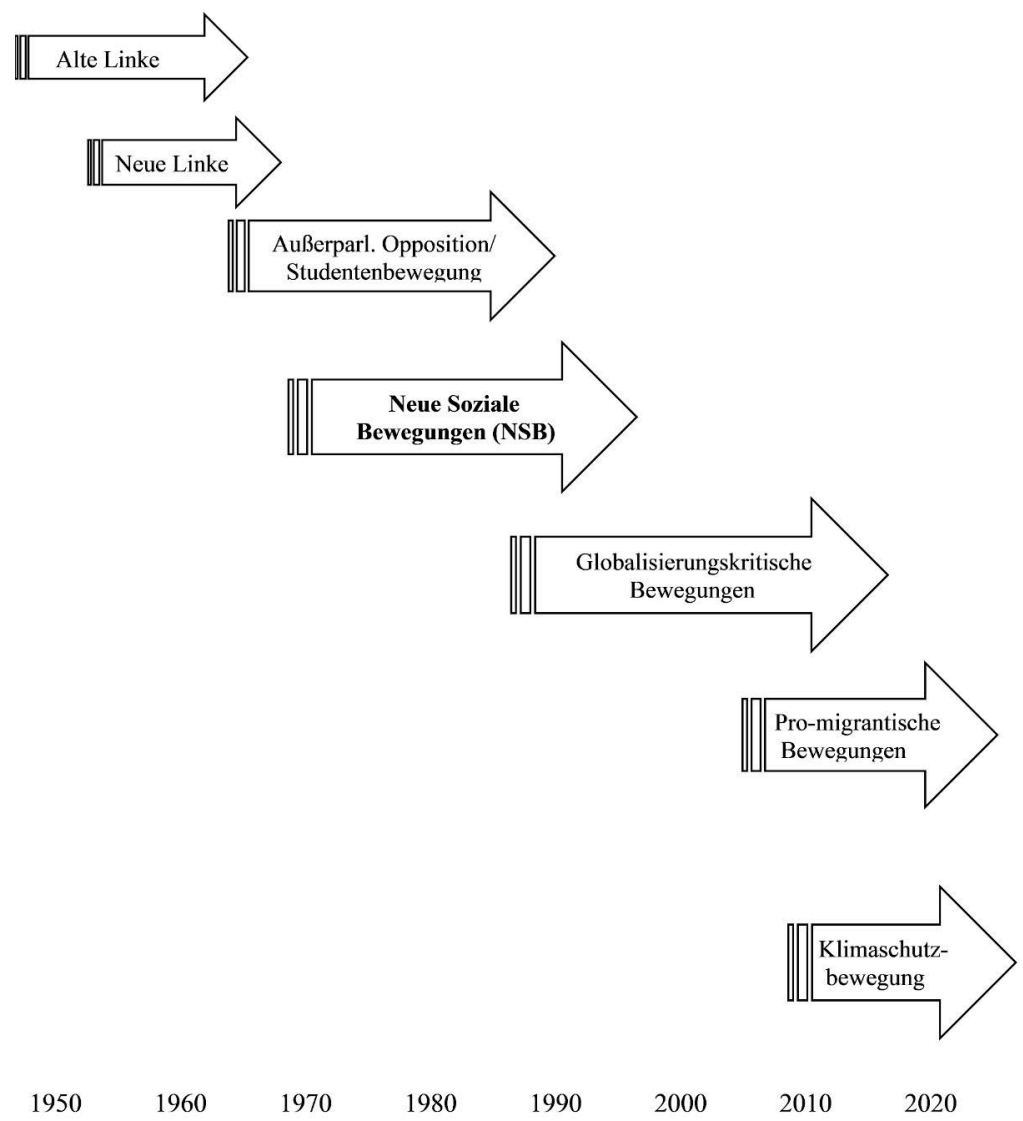


Die durch Rahmungen gesetzten Anfänge und Enden der jeweiligen Bewegungsgenerationen sind nicht als harte Grenzen zu verstehen. Zum Beispiel existieren Gruppierungen der Alten Linken bis heute fort und sind eingebettet in Bewegungskontexte wie die globalisierungskritischen Bewegungen, die insgesamt den neuen sozialen Bewegungen zuzurechnen sind. Auch lassen sich die Anfänge spezifischer progressiver Bewegungen oft weit zurückverfolgen. So begreift sich die heutige Frauenbewegung inzwischen als dritte oder vierte Generation einer traditionsreichen Bewegung, deren Anfänge bis in die Phase der Aufklärung zurück reichen. Ebenso sind die enger gefassten NSB nicht mit dem Ausklang der 1980er Jahre an ihr Ende gekommen, sondern fanden teilweise eine unmittelbare Fortsetzung in einer bestehenden Bewegung (so die Anti-Atomkraftbewegung mit ihrem neuen Aktionsschwerpunkt gegen die bis 2011 durchgeführten Castor-Transporte nach Gorleben) oder im Rahmen neuer Bewegungsgenerationen mit anders akzentuierten Themenschwerpunkten, so die globalisierungskritischen Bewegungen.

Sofern man das Etikett des »Neuen« innerhalb der genealogischen Linie progressiver Bewegungen ansetzen will, wäre somit eine Unterscheidung zu treffen zwischen einem weit gefassten Dachbegriff neuer sozialer Bewegungen, die mit der Neuen Linken in den 1950er Jahren Konturen gewinnen und bis heute anhalten, und einem engen Begriff Neuer Sozialer Bewegungen (NSB) mit einer Blütephase in den 1970er und 1980er Jahren. ${ }^{4}$ Von dieser Begrifflichkeit scharf abzugrenzen sind die Auftritte und Mobilisierungszyklen rechter Bewegungen, die teilweise ebenfalls das Adjektiv »neu«, etwa als »Neo-Nazis« oder - mit davon abweichender Bedeutung - als »Neue Rechte« zugeschrieben bekommen oder selbst beanspruchen. Rechtspopulistische und rechtsradikale Bewegungen sind die Antagonisten neuer (progressiver) sozialer Bewegungen. Deshalb sollte keinesfalls ein generischer Dachbegriff von neuen sozialen Bewegungen (oder NSB) in Abgrenzung zu historisch älteren Bewegungen jeglicher Ausrichtung verwendet werden - ein Dachbegriff, der die identitätsstiftende politische Differenz zwischen progressiven und rechten Bewegungen einebnen würde.

Der durchaus weit gefasste, aber auf das progressive Lager beschränkte Begriff neuer sozialer Bewegungen bedarf einer inhaltlichen Füllung seines

Nach den Protestereignisanalysen von Kriesi et al. $(1995$, S. 20) konnten in Deutschland in der Phase von 1975 bis 1989 knapp drei Viertel aller Proteste den NSB zugerechnet werden. Dies war der höchste Anteil im Vergleich zu den Niederlanden, der Schweiz und vor allem dem Schlusslicht Frankreich (36\%). 
gemeinsamen Nenners. Als "progressiv« können all jene Bewegungen und Kampagnen gefasst werden, die sich im weitesten Sinne den Zielen der Aufklärung und der individuellen wie gattungsbezogenen Emanzipationsidee verpflichtet fühlen. Das sind nicht exklusiv linke Bewegungen; auch bestimmte konservative Gruppen können sich diesen Idealen verschreiben. Die neuen Bewegungen im weiten Sinne zeichnen sich unter anderem dadurch aus, dass sie humanitäre und prodemokratische Positionen verfechten, kosmopolitisch orientiert sind, rigide Hierarchien ablehnen und in ihrer großen Mehrheit nicht über Strategien des radikalen Reformismus hinausgehen (dazu Roth 2018). Sozialstrukturell sind sie vorrangig in den gebildeten Mittelschichten (insbesondere im Humandienstleistungssektor) verankert und stehen damit in Distanz zu den kulturellen Werten und Prägungen des Milieus der einfachen Angestellten und der Arbeiterschaft. Vor diesem Hintergrund mag auch die auf den ersten Blick überraschende Einreihung der Klimaschutzbewegung, die nicht erst mit »Fridays for Future« ihren Anfang nahm, gerechtfertigt erscheinen. »Fridays for Future« entstammt nicht nur den gebildeten Mittelschichten (was auch auf einen kleineren Teil rechtspopulistischer Bewegung zutrifft), sondern kann inhaltlich als Verlängerung und Spezifizierung der in den 1970er Jahren aufgekommenen ökologisch orientierten Umweltbewegung verstanden werden.

\section{Neue Bewegungen und neue Konfliktlinien}

Die Arbeiterbewegung als dominante soziale Bewegung der zweiten Hälfte des 19. Jahrhunderts ${ }^{5}$ drohte mit ihrem revolutionären Drang die bürgerliche Gesellschaft zu sprengen. Entsprechend erschrocken reagierten die politischen und kulturellen Stützen dieser Gesellschaft mit ihrer Mischung aus kultureller Verachtung gegenüber dem »Pöbel«, der Pathologisierung der angeblich von einem »Herdentrieb« geleiteten »Massen«, der Repression und Kriminalisierung politischer Aktivitäten (u.a. Sozialistengesetze) und einer Strategie der Spaltung von Radikalen und Gemäßigten. Aus dieser dem Status quo verpflichteten Warte aus war Protest gleichbedeutend mit Unruhe und Aufruhr. Die zeitgenössische Zustandsbeschreibung des Zentralkonflikts wurde der Begriff soziale Bewegungen gleichgesetzt mit sozialistischen/kommunistischen Bewegungen. 
als eines Klassenkonflikts war durchaus zutreffend, auch wenn andere Konfliktlinien, z.B. Kirche vs. Staat, eine Rolle spielten.

Im Vergleich dazu ist die zeitgeschichtliche und gegenwärtige Grundkonstellation, soweit sie auch durch weit definierte neue soziale Bewegungen markiert wird, eine deutlich andere. Die potentielle Eingriffstiefe dieser Bewegungen ist geringer; politisch und kulturell sind die neuen sozialen Bewegungen zumindest in den kapitalistischen Ländern des globalen Nordens nicht an den Rändern, sondern eher mitten in der Gesellschaft zu verorten; kollektiver Protest wird im Allgemeinen nicht als Aufruhr, sondern als normaler Bestandteil demokratischer Konfliktaustragung verstanden; die Rede vom Klassenkampf wirkt angesichts der Differenziertheit sozialer Schichten und Milieus antiquiert; die heutigen sozialen Bewegungen erscheinen eher als eine spezifische Variante von "public interest groups« denn als pöbelnde oder systemsprengende »Massen«.

Dennoch sind die durch neue soziale Bewegungen markierten neuen Konflikte nicht als bloße Scharmützel zwischen Interessengruppen zu verstehen. Vielmehr stehen hinter den ganz konkreten Themen und Forderungen grundsätzliche Wertvorstellungen und Weltbilder, die, ganz im Sinne der in den 1960er Jahren formulierten politikwissenschaftlichen Konfliktlinientheorie (Lipset/Rokkan 1967), relativ stabile Trennlinien (»cleavages«) anzeigen, welche nicht nur auf der Ebene von Einstellungen, Meinungen und Wählerverhalten, sondern auch in konsolidierten Strukturen - Parteien, Verbände, soziale Bewegungen - ihren Niederschlag finden (vgl. Grande/Kriesi 2012). Von den alten Konflikten - Kapital vs. Arbeit, Stadt vs. Land, Zentrum vs. Peripherie, religiös vs. säkular - haben insbesondere die drei letztgenannten Konflikte an Bedeutung verloren. Doch zeigt sich neuerdings, dass die Konfliktachse Zentrum vs. Peripherie wieder an Bedeutung gewinnt. Aktuelle Beispiele dafür sind die Bewegung der Gelbwesten in Frankreich, aber auch die Verankerung rechtspopulistischer und rechtsradikaler Gruppen gerade in den dünn besiedelten und »abgehängten « Regionen Ostdeutschlands. Der Links/Rechts-Konflikt, der schon mehrfach als überholt erklärt wurde, besitzt nach wie vor eine starke Prägekraft. Er dient als ein grundlegendes politisches Orientierungsmuster, das es erlaubt, die Mehrzahl der Parteien und eine Fülle spezifischer Positionen einzuordnen. Wie die Umfrageforschung zeigt, wird die Links/Rechts-Achse auch von der überwiegenden Mehrheit der Bevölkerung als ein aussagekräftiges Instrument einer generalisierten politischen Selbstverortung akzeptiert. 
Gelegentliche Vorschläge, die heutige Konfliktsituation auf einen singulären Zentralkonflikt zu reduzieren, sind in der Konkurrenz um wissenschaftliche und mediale Aufmerksamkeit hilfreich, aber angesichts der Realität unterkomplex. Schon vor Jahrzehnten wurde zusätzlich zum Links/RechtsKonflikt die Konfliktdimension von Materialismus/Postmaterialismus als eine zweite strukturierende Konfliktachse ins Spiel gebracht (Inglehart 1977). Innerhalb eines durch beide Achsen gebildeten Feldes wurden die NSB zunächst als Ausdrucksform postmaterialistischer Werte, später überwiegend - und inhaltlich präziser - im Feld des linken Postmaterialismus verortet.

Auch angesichts der heutigen Problemlagen reicht es nicht aus, auf den Links/Rechts-Konflikt samt seinem Potential zu verweisen, neu aufkommende Themen allmählich zu absorbieren. Wenig überzeugend ist aber auch die gegenteilige Position, den Links/Rechts-Konflikt für weitgehend irrelevant zu erklären und an seiner Stelle einen singulären neuen Zentralkonflikt, beispielsweise den Gegensatz von Kosmopoliten und Kommunitaristen, ${ }^{6}$ in der Annahme zu postulieren, das parteipolitische Gefüge werde sich über kurz oder lang darauf ausrichten, indem etwa, bezogen auf Deutschland, AfD und Grüne zentrale Antipoden wären und sich alle anderen relevanten Parteien entsprechend positionieren müssten. Die Breite politischer Streitthemen lässt sich nur teilweise auf dieser Achse abbilden. Wir haben vielmehr von der Gleichzeitigkeit und auch partiellen Überlagerung mehrerer grundlegender Konfliktachsen auszugehen, deren jeweiliges Gewicht zeitspezifisch und regional erheblich variieren kann. Die heute mit der hoch politisierten Klimafrage anstehende Frage nach der Notwendigkeit harter ordnungspolitischer, fiskalischer und sonstiger Eingriffe erinnert an den traditionellen, mit dem Links/Rechts-Konflikt verbundenen Gegensatz von Staat vs. Markt und könnte längerfristig von dieser Konfliktlinie aufgesogen werden. Sie könnte sich aber auch zu einer weitgehend eigenständigen Konfliktlinie zwischen Befürwortern und Gegnern eines nachhaltigen Wirtschaftens und Konsumierens entwickeln.

6 Die Verwendung des Begriffs »Kommunitarismus« durch Wolfgang Merkel (2016) ist problematisch, insofern sie von der herkömmlichen Semantik des Begriffs Kommunitarismus erheblich abweicht. So würde sich etwa Amitai Etzioni (1993) als einer der wichtigsten Fürsprecher des Kommunitarismus dagegen verwahren, auf der Cegenseite des universalistischen und kosmopolitischen Lagers lokalisiert und in die Nähe von gemeinschaftstümelnden rechtspopulistischen Positionen gerückt zu werden. 
Mit Blick auf die genannten Konfliktachsen, die in ihrer Profilierung und ihrer relativen Bedeutung noch schwer abschätzbar sind, können die neuen sozialen Bewegungen in ihrer großen Mehrheit auf Seiten der postmaterialistischen, kosmopolitischen und auf Nachhaltigkeit gepolten Linken verortet werden, während eine Minderheit Nachhaltigkeitspolitik mit genuin konservativen politischen Positionen verbindet.

\section{Wirkungen der neuen sozialen Bewegungen}

Versucht man, die Wirkungen von sozialen Bewegungen zu bilanzieren, so wird meist ein zweifellos zentrales Kriterium, die Erreichung der erklärten Bewegungsziele (vorzugsweise in Verbindung mit messbaren Erfolgskriterien), herangezogen. Demgegenüber ist auf eine Reihe von weiteren Wirkungsdimensionen zu verweisen. Dazu zählen:

- der Wandel politischer Verfahren und Institutionen, der sich manchmal als indirekter Effekt aus vielen themenspezifischen Konfliktfeldern ergibt (z.B. die Erweiterung von Informations- und Klagerechten; Verfahren der Mitbestimmung und direkten Demokratie);

- der Wandel des Parteiensystems und der Regierungswechsel;

- schleichender oder auch abrupter Regime- und Systemwandel;

- Agenda-Setting in der breiten Öffentlichkeit;

- gesellschaftliche Aufklärung und Wertewandel;

- Veränderungen des Alltagsverhaltens und der Lebensstile;

- Wandel von Protestkultur und Protestgruppen (Organisationsformen, Konfliktstrategien, Protestrepertoires, Sozialisationseffekte, kollektives Gedächtnis, etc).

Für die neuen sozialen Bewegungen ergibt sich mit Blick auf die genannten Wirkungsdimensionen eine unterschiedliche Bilanz, die in einer alle Einzelheiten vernachlässigenden Form in Tabelle 3 festgehalten ist. 
Tabelle 3: Wirkungen der neuen sozialen Bewegungen in verschiedenen Sachdimensionen

\begin{tabular}{|l|l|l|}
\hline Wirkungsdimension & Allgemein & Spezifisch \\
\hline $\begin{array}{l}\text { Erklärte } \\
\text { Politikziele }\end{array}$ & Meist nur Teilerfolge & $\begin{array}{l}\text { Anti-Atom +++, Ökologie ++, Frau- } \\
\text { en ++, Clobaler Süden +-, } \\
\text { Schwule ++, Alternative Ökono- } \\
\text { mie +- }\end{array}$ \\
\hline $\begin{array}{l}\text { Politische Verfahren } \\
\text { und Institutionen }\end{array}$ & Ceringe Wirkungen & $\begin{array}{l}\text { Partielle Öffnung und Demokra- } \\
\text { tisierung, Bürgerentscheide und } \\
\text { Volksbegehren auf Landesebene, } \\
\text { Erweiterung der Auskunftsrechte } \\
\text { gegenüber Behörden, Etablie- } \\
\text { rung neuer Fachpolitiken } \\
\text { (z.B. Umweltpolitik) }\end{array}$ \\
\hline Regimewandel & Kein Effekt & $\begin{array}{l}\text { Mehrheitlich nicht beabsichtigt: } \\
\text { Linksradikale/Autonome -- }\end{array}$ \\
\hline $\begin{array}{l}\text { Wertewandel, } \\
\text { politische Kultur }\end{array}$ & Erhebliche Wirkungen & $\begin{array}{l}\text { Stärkung postmaterieller Wer- } \\
\text { te, kulturelle Pluralisierung, } \\
\text { Ich-Zentrierung }\end{array}$ \\
\hline Agenda setting & Erhebliche Wirkungen & $\begin{array}{l}\text { Erfolgreiches Agenda Setting in } \\
\text { Teilbereichen }\end{array}$ \\
\hline $\begin{array}{l}\text { Alltagsverhalten } \\
\text { der Bevölkerung } \\
\text { und Protest- }\end{array}$ & Partielle Wirkungen & $\begin{array}{l}\text { Sensibilisierung für Umweltfra- } \\
\text { gen, Probleme von Minderheiten, } \\
\text { Politischer Konsum (bei Minder- } \\
\text { heiten) }\end{array}$ \\
\hline & Erhebliche Wirkungen & $\begin{array}{l}\text { Nachhaltige Prägung der Bewe- } \\
\text { gungslandschaft; Aufbau relativ } \\
\text { stabiler Strukturen und Organisa- } \\
\text { tionen }\end{array}$ \\
\hline
\end{tabular}

Eine anders systematisierte Wirkungsbilanz der neuen sozialen Bewegungen ergibt sich mit Blick auf die Sphären des ökonomischen, politischen und sozio-kulturellen Systems (Tabelle 4). 
Tabelle 4: Wirkungen der neuen sozialen Bewegungen in drei gesellschaftlichen Teilbereichen

\begin{tabular}{|l|l|l|}
\hline Sphäre & Generell & Spezifisch \\
\hline $\begin{array}{l}\text { Ökonomisches } \\
\text { System }\end{array}$ & $\begin{array}{l}\text { Geringe Wirkungen, } \\
\text { keine grundlegende } \\
\text { Umgestaltung }\end{array}$ & $\begin{array}{l}\text { Umstrukturierung/Innovationen im Ener- } \\
\text { giebereich, Veränderungen im Konsumver- } \\
\text { halten, Blockade/Einschränkung einzel- } \\
\text { ner technisch-industrieller Projekte }\end{array}$ \\
\hline $\begin{array}{l}\text { Politisches } \\
\text { System }\end{array}$ & $\begin{array}{l}\text { Moderate Wirkun- } \\
\text { gen: mehr Partizipa- } \\
\text { tion, Flexibilisierung } \\
\text { von Strukturen }\end{array}$ & $\begin{array}{l}\text { Erweiterung von Anhörungs- und Mit- } \\
\text { wirkungsrechten (z.B. Planungswesen, } \\
\text { Verbandsklage), Erweiterung des Parteien- } \\
\text { systems (Grüne) }\end{array}$ \\
\hline Sozio-kulturelles & $\begin{array}{l}\text { Beträchtliche Wir- } \\
\text { kungen } \\
\text { Wertewandel (kultu- } \\
\text { relle Liberalisierung, } \\
\text { Postmaterialismus) } \\
\text { Stärkung von Zivil- } \\
\text { gesellschaft und bür- } \\
\text { gerschaftlichem } \\
\text { Selbstbewusstsein }\end{array}$ & $\begin{array}{l}\text { Abbau von Autoritätshörigkeit, } \\
\text { kulturelle Pluralisierung, } \\
\text { Gleichstellung von Frauen, } \\
\text { Entdiskriminierung von Schwulen und Les- } \\
\text { ben, Veränderung von Erziehungsstilen }\end{array}$ \\
\hline
\end{tabular}

Ein in der Bewegungsforschung meist vernachlässigter Aspekt der Wirkungsanalyse sind die nicht-intendierten Folgen des Bewegungshandelns, die sich sowohl auf der Ebene einzelner Individuen als auch auf gesamtgesellschaftlicher Ebene manifestieren können und teilweise erst im größeren zeitlichen Abstand sichtbar werden. Dazu gehören zum Beispiel die Folgen unrealistisch hoch angesetzter und deshalb verfehlter Ziele, was vormals hoch motivierte Aktivistinnen und Aktivisten frustrieren und zum Rückzug veranlassen kann. Auf systemischer Ebene können soziale Bewegungen, die eine gesellschaftliche Ordnung umwälzen wollen, durch ihre Kritik ungewollt dazu beitragen, diese Ordnung zu stabilisieren. So haben z.B. die neuen sozialen Bewegungen mit ihrer Wertschätzung von individueller Selbstbestimmung, Autonomie und Selbstoptimierung auch dazu beigetragen, den Boden für die Flexibilisierung von Arbeit und, weitergehend, den Erfolg neoliberaler Strategien zu bereiten. Zudem haben ihr kultureller Liberalismus und ihre kosmopolitische Grundhaltung ungewollt rechtspopulistische Abwehrbewegungen befördert. 


\section{Fazit}

Die neuen sozialen Bewegungen haben bestehende Konfliktlinien aufgeweicht und insgesamt eine weitere Differenzierung von Konfliktlinien befördert, aber scheinen auch eine neue Konfliktlinie zu markieren. Insbesondere deutet sich eine Profilierung des Konflikts zwischen progressivuniversalistischen Kräften, denen die neuen sozialen Bewegungen zuzurechnen sind, und rechtspopulistischen und rechtsradikalen Kräften an. Letztere treten für soziale und kulturelle Exklusion, für Nationalismus und Chauvinismus ein und sagen der »links-grün versifften« Republik den Kampf an. Anzeichen einer entsprechenden Polarisierung sind nicht zu übersehen.

In mancherlei Hinsicht sind die neuen sozialen Bewegungen zu einer geschichtsmächtigen Kraft geworden. Das gilt insbesondere für ihren Beitrag zur kulturellen Liberalisierung und demokratischen Öffnung einer Gesellschaft, die als frühe Bundesrepublik Deutschland noch deutliche Spuren einer »Obrigkeitsgesellschaft« aufwies (Greiffenhagen/Greiffenhagen 1979), deren Repräsentanten das Leitbild einer »formierten Gesellschaft« (Ludwig Erhard) ausriefen und deren stärkste Partei mit dem Slogan »keine Experimente« in Wahlkämpfe zog. Die neuen sozialen Bewegungen waren auch ein wesentlicher Faktor, um die Idee und Praxis von Zivilgesellschaft, und damit auch bürgerschaftlicher Mitverantwortung und gesellschaftlicher Selbststeuerung des Gemeinwesens, zu fördern (Rucht 2001; 2018). Zudem haben sie dazu beigetragen, politischen Protest zu konventionalisieren und ihn als ein »normales« Mittel politischer Interessenvertretung und Konfliktaustragung erscheinen zu lassen. ${ }^{7} \mathrm{Zu}$ ihrer Wirkungsbilanz gehört aber auch, dass diese Bewegungen nicht stark genug waren, um eine Reihe negativer sozialer und ökologischer Folgelasten ökonomischer Modernisierung zu verhindern. Darüber hinaus wurden sie ungewollt zu einem »Schmiermittel« für den flexibilisierten und globalisierten Kapitalismus.

So betitelte der US-Soziologe Amitai Etzioni sein 1970 erschienenes Buch mit »Demonstration Democracy«. Neidhardt und Rucht verwendeten in einem Konferenzbeitrag von 1991 und einem 1993 erschienenen Aufsatz den Begriff »Bewegungsgesellschaft«. 


\section{Literaturhinweise}

Calhoun, Craig (1995): »New Social Movements« of the Early Nineteenth Century. In: Mark Traugott (Hg.), Repertoires and Cycles of Collective Action. Durham and London: Duke University Press, S. 173-215.

Etzioni, Amitai (1970): Demonstration Democracy. New York et al.: Gordon and Breach.

Etzioni, Amitai (1993): The Spirit of Community. Rights, Responsibilities and the Communitarian Agenda. New York: Touchstone.

Gassert, Philipp (2018): Bewegte Gesellschaft. Deutsche Protestgeschichte seit 1945. Stuttgart: Kohlhammer.

Grande, Edgar/Kriesi, Hanspeter (2012): The Transformative Power of Globalization and the Structure of Political Conflict in Western Europe. In: Hanspeter Kriesi/Edgar Grande u.a., Political Conflict in Western Europe. Cambridge: Cambridge University Press, S. 3-35.

Greiffenhagen, Martin/Greiffenhagen, Sylvia (1979): Ein schwieriges Vaterland. Zur Politischen Kultur Deutschlands. München: List Verlag.

Inglehart, Ronald (1977): The Silent Revolution: Changing Values and Political Styles among Western Publics. Princeton: Princeton University Press.

Kriesi, Hanspeter/Koopmans, Ruud/Duyvendak, Jan Willem/Giugni, Marco G. (1995): New Social Movements in Western Europe: A Comparative Analysis. Minneapolis: University of Minnesota Press.

Lipset, Seymor M./Rokkan, Stein (1967): Cleavage Structures, Party Systems, and Voter Alignments: An Introduction. In: Seymor M. Lipset/Stein Rokkan (Hg.), Party Systems and Voter Alignments: Cross-National Perspectives. New York: Free Press, S. 1-64.

Melucci, Alberto (1980): The new social movements: A theoretical approach. In: Social Science Information, 19(2), S. 199-226.

Merkel, Wolfgang (2016): Bruchlinien. Kosmopolitismus, Kommunitarismus und die Demokratie. In: WZB-Mitteilungen, 154 (Dezember), S. 1-14.

Neidhardt, Friedhelm/Rucht, Dieter (1993): Auf dem Weg in die »Bewegungsgesellschaft«? Über die Stabilisierbarkeit sozialer Bewegungen. In: Soziale Welt, 44(3) S. 305-326.

Pichardo, Nelson A. (1997): New Social Movements: A Critical Review. In: Annual Review of Sociology, 23, S. 411-430.

Reichardt, Sven (2014): Authentizität und Gemeinschaft. Linksalternatives Leben in den siebziger und frühen achtziger Jahren. Frankfurt a.M.: Suhrkamp. 
Raschke, Joachim (1985): Soziale Bewegungen. Ein historisch-systematischer Grundriß. Frankfurt/New York: Campus.

Roth, Roland (2018): Radikaler Reformismus. Geschichte und Aktualität einer politischen Denkfigur. In: Ulrich Brand/Christoph Görg (Hg.), Zur Aktualität der Staatsform: Die materialistische Staatstheorie von Joachim Hirsch. Baden-Baden: Nomos, S. 219-240.

Roth, Roland/Rucht, Dieter (Hg.) (2008): Handbuch Soziale Bewegungen in Deutschland seit 1949. Frankfurt a.M.: Campus.

Rucht, Dieter (2001): Soziale Bewegungen als Signum demokratischer Bürgergesellschaft. In: Richard Münch/Claus Leggewie (Hg.), Demokratische Bürgergesellschaft. Frankfurt a.M: Suhrkamp, S. 321-336.

Rucht, Dieter (2018): Demokratisierung durch Bewegungen? Demokratisierung der Bewegungen? In: Forschungsjournal Soziale Bewegungen, 31(12), S. 40-51.

Touraine, Alain (1968): Le communisme utopique. Le movement de Mai 68. Paris: Seuil.

Touraine, Alain (1973): Production le la société. Paris: Seuil.

Turner, Ralph H. (1969): The theme of contemporary social movements. In: British Journal of Sociology, 20, S. 390-405. 



\title{
Zivilgesellschaft und Demokratie Die Perspektive der Aktivistin
}

\author{
Christine Scheel
}

Als Aktivistin seit Ende der 1970er Jahre möchte ich den abschließenden Gedanken von Dieter Rucht (in diesem Band) zur Bedeutung der Demokratie für die Zivilgesellschaft aufgreifen. Demokratie ist die Grundlage dafür, dass sich Zivilgesellschaft überhaupt herausbilden kann. Ohne diese Gegebenheit hätten wir in der Zivilgesellschaft in Bezug auf all die Gruppierungen und Initiativen, die sich organisiert haben - vor allem im Hinblick auf die 1970er und 1980er Jahre - nicht die Legitimität gehabt zu sagen, wir wollen in dieser demokratischen Gesellschaft Änderungen erwirken. Inhaltlich machten wir das fest an dem, was die Politik aus Sicht der gegründeten Initiativen falsch oder zu wenig umsetzte. Hierzu gehörte die Thematik Abrüstung und Frieden, die viele Menschen zu Sitzblockaden an geeigneten Standorten und Demonstrationen mit der Bildung von Menschenketten motivierte. In diesen Zeiten ging es darum, Gewalt gegen Frauen auch in der Ehe endlich ernster zu nehmen und gesetzgeberisch tätig zu werden. Seinerzeit wurde die Atompolitik mit dem Bau von Atomkraftwerken von den regierenden Parteien CDU/CSU/FDP, aber auch der SPD, noch als zukunftsweisend gesehen. Aktuell ist es die Klimapolitik und die Klimakrise, die vor allem auch junge Menschen wieder auf die Straße bringt mit dem Vorwurf an die Regierenden, zu wenig für eine zukunfts- und überlebensfähige Welt zu tun, die den nächsten Generationen eine gute Zukunft bietet. Es sind immer wieder große Themen, die viele Bürgerinnen und Bürger bewegen und neue Bewegungen in unserer Bürgergesellschaft heranwachsen lassen.

Ich bin jemand, die bereits in der Gründungsphase der GRÜNEN in Bürgerinitiativen und Bewegungen aktiv war und durch dieses Engagement, vor allem im Umweltbereich, aber auch frauenpolitisch bewegt, letztendlich in die parlamentarische Politik hineingegangen ist. 
Die meisten Organisationen, die es in den 7oer Jahren gab, haben sich institutionalisiert und so kam die Gründung einer neuen Partei, der GRÜNEN, überhaupt zustande. Fast alle sind aus der Antiatombewegung, aus der Frauenbewegung oder aus der Friedensbewegung gekommen, wobei die Übergänge der einzelnen Themen bei vielen fließend waren; geleitet von dem Anspruch, nicht nur auf der Straße Position zu beziehen, sondern auch in den Parlamenten. Dies führte natürlich auch an der einen oder anderen Stelle zu Konflikten. Das Protestgeschehen war vielfältig. Die Friedens- und Ökologiebewegung war machtorientiert und die Frauenbewegung kulturorientiert. Doch eine kollektive Identität hat den öffentlichen Protest hervorgebracht und eine Wirksamkeit entfaltet, die sich im politischen Raum niederschlug. Wohlwissend, dass die Gesetzgebung der Regierung obliegt und die Initiativarbeit lediglich in der Gesellschaft ihre Wirkung entfaltet, sind Aktivisten bei Landtags- und Bundestagswahlen angetreten um die Handlungsmöglichkeiten zu erweitern; andere sind bewusst in den Bewegungen geblieben, um den Druck aus der Gesellschaft heraus auf die politisch und in den Parlamenten Handelnden aufrecht zu erhalten. Der öffentliche Protest war in seiner Ausprägung und den Forderungen oft wesentlich radikaler, als dies die Kritiker z.B. der Atompolitik in den parlamentarischen Strukturen umsetzen konnten. So entstanden auch Brüche zwischen Handelnden in den Bewegungen und neu gewählten Politikern und Politikerinnen in den Parlamenten. Ein klassisches Beispiel war hierfür bundespolitisch die Geschwindigkeit des Ausstiegs aus der Atomenergie. Die einen wollten einen Sofortausstieg, die anderen waren in den Zwängen eines geregelten und rechtlich sinnvollen Ausstiegsszenarios mit der Schaffung notwendiger parlamentarischer Mehrheiten verhaftet.

Exemplarisch zeigen lässt sich dies an der Protestbewegung gegen die in den 1980er Jahren geplante Wiederaufbereitungsanlage für Kernbrennstoffe in Wackersdorf in Bayern. Die Planung der sogenannten WAA in der Oberpfalz wurde von der bayerischen Staatsregierung an diesem Ort forciert in der Hoffnung, dass sich in der relativ dünn besiedelten Region kein Widerstand entwickelt, sondern sich diese Planung als Garant für zukünftige Arbeitsplätze vor Ort erweisen wird. Ich selbst war bereits Anfang/Mitte der 1980er Jahre als Aktive in der Antiatombewegung bei Demonstrationen und dem Besuch des von Gegnern errichteten Hüttendorfs `Zeitzeugin ‘ im Umgang der Staatsgewalt mit der unliebsamen Protestbewegung. Bereits vor 1986, als die GRÜNEN erstmals in den bayerischen Landtag gewählt wurden und auch ich ein Mandat erlangte, gab es in Wackersdorf die Unterstützung des sich vor Ort, 
aus der örtlichen Bevölkerung heraus entwickelnden Protests durch immer mehr Menschen aus unterschiedlichsten Zusammenhängen.

Damals hat man dies in der bayerischen Landesregierung nicht wirklich ernst genommen. Es herrschte die Auffassung vor, dass ein paar Wenige anderer Meinung seien und dieser Widerstand sich nicht weiter auswachsen würde. Die Entwicklung des Widerstandes ist deshalb sehr interessant, da sie ihren Ursprung nicht in der bundesweiten Antiatombewegung hatte, sondern aus der lokalen Bevölkerung heraus entstand. Es war eine bürgerschaftliche Initiative, die sich erst regional gegründet hatte und daraufhin unterstützt wurde von Menschen aus der Antiatomkraftbewegung, die aus dem gesamten Bundesgebiet anreisten. Der Kreis der Gegner und Gegnerinnen wuchs weiter an und bundesweit mit großer Aufmerksamkeit verfolgte Demonstrationen und Kundgebungen fanden unter Teilnahme von vielen Menschen aus den Kirchen, dem kulturellen Leben, Jugendverbänden bis hin zu Landwirten und Bürgerinnen und Bürgern statt, die bis zu diesem Zeitpunkt noch niemals an einer Demonstration teilgenommen hatten. Es brach durch die Vereinigung bürgerschaftlicher Bewegungen und institutionalisierter Organisationen etwas auf, das der herrschenden Politik große Sorgen bereitete. Dadurch tauchte die Frage auf: Wie stark ist der Staat? Wie setzt die bayerische Staatsregierung ihr Vorhaben gegen die Interessen von so vielen Menschen um, die sich mit den Fragen der Atomenergie und deren Auswirkungen intensiv beschäftigt haben? Ich kann mich noch sehr gut an Polizeieinsätze erinnern, die für beide Seiten sehr belastend waren. Für die Polizisten und Polizistinnen mit ihren Einsatzbefehlen und die Demonstrierenden, die mit bürgerlichem Ungehorsam ihrer Position Ausdruck verliehen. Der Protest sollte von Seiten der Staatsgewalt klein gehalten und niedergedrückt werden. Berliner Sondereinsatzkommandos mit martialisch wirkender Ausstattung kamen genauso zum Einsatz wie Wasserwerfer und Tränengaseinsätze. Ziel des Innenministers war es, mit der Staatsmacht Angst zu verbreiten. Mit allen Konsequenzen: Körperverletzungen, reihenweise Verhaftungen waren das bittere Ergebnis. Rechtliche Verfahren, die zu gerichtlichen Auseinandersetzungen führten, kamen hinzu; und fehlerhafte Genehmigungsunterlagen konnten von Seiten der Anwälte des Widerstandes entlarvt werden.

Die Wirksamkeit dieser Entwicklung lag darin, dass in erster Linie das große und vielfältige Bündnis außerhalb der Politik, die gerichtliche Auseinandersetzung mit den Genehmigungsunterlagen, aber auch den Widerstand unterstützende Anträge und Anfragen von GRÜNEN und SPD im bayerischen Landtag gemeinsam dazu führten, dass sich die Umsetzung der WAA zeitlich 
immer weiter nach hinten verschob und die Betreiberfirmen das Vorhaben letztendlich aufgaben mit der Begründung, das Projekt sei zu teuer und zeitlich nicht kalkulierbar. Die bayerische Staatskanzlei und das Kabinett haben dann fast kein Wort mehr darüber verloren und viele gerichtliche Auseinandersetzungen fanden sehr schnell ein Ende.

Klar ist, dass es ohne dieses bürgerschaftliche Engagement nicht gelungen wäre, dieses - auch aus heutiger Sicht - >Wahnsinnsprojekt $<$ zu verhindern. Es gab diese kollektive Identität über alle Altersgruppen hinweg: Jung, alt, Familien mit kleinen Kindern und die Vielfalt der unterschiedlichsten Berufe. Interessant ist hierbei auch die Wirksamkeit einer bürgerschaftlichen Bewegung auf die Politik. Es ging nicht nur um die Ablehnung der geplanten Anlage, sondern sowohl auf der parlamentarischen Ebene, wie auch in der Bewegung um die Ausgestaltung und Anwendung des Polizeiaufgabengesetzes. Was hat die Polizei für Rechte und Pflichten? Wer verantwortet die Herangehensweise bei den Einsätzen? Es ging auch darum, welche chemischen Stoffe gegen Demonstrierende eingesetzt werden dürfen und ob dies überhaupt verhältnismäßig sein kann. Es ging um Fragen des Miteinanderumgehens und um Bemühungen, mit Mediationsgesprächen zu einer Deeskalation beizutragen. Das Geschehen hatte eine gesellschaftliche Dimension, die weit mehr beinhaltete, als die in Politik und Gesellschaft wahrgenommene Forderung nach dem Ausstieg aus der Atomenergie. Letztendlich ging es auch um das Verhältnis der Bürgerinnen und Bürger zu ihrem Staat.

Klar ist, dass es kein Atomausstiegsgesetz gegeben hätte, wenn die Antiatombewegung nicht weiter Druck auf die Politik ausgeübt hätte und die rot-grüne Bundesregierung in Berlin die Gesetzesgrundlage zum Ausstieg nicht auf den Weg gebracht hätte. In dieser Zeit haben etliche Pioniere und die Umweltbewegung eine andere Energieversorgung längst im Blick gehabt. So kam die Entwicklung zur Erzeugung von regenerativem Strom und Wärme aus der Gesellschaft heraus und wurde durch das Erneuerbare-EnergienGesetz beschleunigt. Kraftvolle Forderungen für eine dezentrale Versorgung mit den Erneuerbaren ließen viele Bürgergenossenschaften entstehen und führten letztendlich zu einer neuen Machtkonstellation. Nicht mehr die von der Regierung lange subventionierten Großkonzerne, sondern viele kleine Unternehmen haben mit ihren Investitionen eine neue Struktur geschaffen für eine wirklich nachhaltige Energieversorgung, bürgernah und ökologisch. Tausende neue Arbeitsplätze sind Jenseits der Atom- und Kohleindustrie entstanden. So ist es der Zivilgesellschaft gelungen, mit wirtschaftspolitischem 
und umweltpolitischem Know-how jahrzehntelange von der Politik gepflegte Machtstrukturen zu verändern.

Die sozio-kulturelle Frauenbewegung hat auch ihre Wirkung entfaltet und damit starken Einfluss auf die Politik ausgeübt. Nach dem Aufbruch in den 7oer Jahren kämpften viele Frauen bundesweit in der Frauenbewegung 25 Jahre lang, bis endlich der Protest für eine Reform des Sexualstrafrechts im deutschen Parlament durch eine Gesetzesänderung erfolgreich war. Im Jahr 1997 beschloss der Deutsche Bundestag, dass Vergewaltigung in der Ehe unter Strafe gestellt wird und der minderschwere Straftatbestand der Nötigung abgeschafft wird. Nur eine fraktionsübergreifende Frauenkoalition schaffte es, dass Fraueninteressen über das von Männern dominierte Parteiinteresse in Union und FDP gestellt wurden. Damit hat sich in der gesamten Gesellschaft etwas verändert und die Frauenbewegung der 70er bis zu den goer Jahren wurde nicht mehr nur auf das Thema des umstrittenen Paragraphen 218 zur Abtreibung reduziert. Es ging um die Rolle der Frauen in der Ehe und auch um den Aufbau einer Infrastruktur, um Frauen in Not durch Frauennotruftelefone und der Errichtung von Plätzen in Frauenhäusern zu helfen, in denen Frauen auch mit Kindern Hilfe bekommen konnten. Gleichzeitig verstärkten sich Forderungen nach gleicher Bezahlung von Männern und Frauen, aber auch die Forderung nach einer guten Kinderbetreuung, um Arbeit und Beruf besser vereinen zu können. Die Wirksamkeit dieser Bewegung führte in den Landesparlamenten und im Bundestag zu gesetzgeberischen Entscheidungen, die notwendigen Rahmenbedingungen zu schaffen. Leider wurde die Frauenbewegung medial viele Jahre lang auf die Abtreibungsdebatte um den Paragraphen 218 reduziert und die Vielfalt der frauenpolitischen Belange in den Medien wenig thematisiert.

Natürlich werden in den Medien Themen aufgegriffen, die provokative Aussagen beinhalten. Doch was eine soziale Bewegung leistet und die differenzierte ehrenamtliche Tätigkeit in Organisationen und Initiativen, das wird meistens viel zu wenig zur Kenntnis genommen und gewürdigt. Um den Bogen zurück zum politischen Protest und der Bedeutung Demokratie für die Zivilgesellschaft zu schlagen, möchte ich abschließend feststellen, dass die Demokratie die Auflehnung der Zivilgesellschaft braucht, um zu überleben. Ja, sie braucht sogar auch einen gewissen Ungehorsam. 



\section{Aufbrüche II:}

Zivilgesellschaft und Wiedervereinigung 



\section{Politischer Protest und Zivilgesellschaft im deutschen Transformationsprozess}

Wolfgang Thierse im Gespräch mit Udo Hahn

Udo Hahn: Herr Dr. Thierse, Sie sind in Breslau geboren und durch die Vertreibung ihrer Familie in Thüringen gelandet. Sie haben dort Abitur gemacht, Sie haben Schriftsetzer gelernt beim Thüringer Tageblatt in Weimar. Sie haben Germanistik und Kulturwissenschaften an der Humboldt-Universität zu Berlin studiert.

Wolfgang Thierse: Ich muss kurz unterbrechen - ich kenne mich ja: Wir waren in der DDR generell bescheiden. Wir haben nicht Wissenschaften im Plural studiert, sondern ich habe Kulturwissenschaft im Singular studiert.

Udo Hahn: Dann gab es ein Erlebnis, von dem ich gerne wüsste - und dafür unterbreche ich die Biografie - wie prägend es für die weitere Zeit für Sie war. Sie haben im Ministerium für Kultur gearbeitet in der Abteilung Bildende Kunst, und Sie waren dort entlassen worden weil - wie ich gelesen habe Sie sich weigerten, die Ausbürgerung des Liedermachers Wolf Biermann zu befürworten. Ein Akt von Zivilcourage, mutig in jedem Fall, wie kam es?

Wolfgang Thierse: Ich war lange an der Universität und irgendwann muss man sie verlassen. Und da habe ich wohl in einem Anfall von Leichtsinn ein Angebot angenommen, ins Kulturministerium der DDR zu gehen. Ich dachte, vielleicht kann man wirklich etwas ausrichten. Und das war nun nach eineinhalb Jahren zu Ende. Nach der Ausbürgerung von Biermann gab es ja - wie Sie wissen - eine Reihe von Prominenten, vor allem Schriftsteller der DDR, die das in einer öffentlich gewordenen Bittschrift kritisierten und die Parteiführung der SED, die Regierung, gebeten haben, diese Entscheidung zurückzunehmen. Diese Erklärung fand viele Unterstützer und die SED-Führung hat ihrerseits darauf reagiert mit der Organisation von Zustimmungserklärungen 
zu dieser Entscheidung. Man muss wissen, zum ersten Mal seit 1945 ist einem deutschen Staatsbürger die Staatsbürgerschaft aberkannt worden. Die DDR war ja ein Nachfolgestaat des Nazi-Staats, auch wenn immer so getan wurde, als hätte nur der Westen die Nachfolge angetreten. Es gab eine regelrechte Kampagne des »Neuen Deutschlands« und der anderen SED-Zeitungen. Die waren voll von Jubelerklärungen. Ich wurde aufgefordert, zu Künstlern zu gehen und sie um solche Jubelerklärungen zu bitten - und wenn sie das nicht machen, darüber zu berichten. Ich habe gesagt, das lehne ich ab, ich mache das nicht. Ich halte diese Entscheidung für einen kapitalen Fehler. Ich habe also nein gesagt und das hat zu meiner sofortigen Entlassung geführt.

Dazu noch eine Geschichte: Ich wurde zum Abteilungsleiter gerufen und der hat mir vorgehalten, was ich in den letzten Wochen alles gesagt habe. Das hatte eine Kollegin genauestens berichtet. Ich kam also von dem Gespräch mit meinem Abteilungsleiter, das mit meinem Rausschmiss geendet hatte, zurück und fragte die Kollegin, die mit mir im gemeinsamen Arbeitszimmer gesessen hatte: »Renate warum hast Du das gemacht? Warum hast Du über mich berichtet? Du weißt, dass ich ein streitlustiger Mensch bin, Du hättest mir alles ins Gesicht sagen können und dann hätten wir gestritten!« Dann kam die wörtliche Antwort: "Ach Wolfgang, als Mensch ist es mir schwer gefallen, aber als Genossin war es meine Pflicht." Das war ein ganz typischer DDRSatz. Das war die alltägliche Schizophrenie. Sie wusste ganz genau, dass sie etwas menschlich Unanständiges getan hatte, aber als SED-Genossin hatte sie es für ihre Pflicht gehalten.

Naja, so wurde ich von heute auf morgen entlassen und wusste nicht, wie es weitergeht. Ich bin dann anschließend zu einem uns bekannten Maler gegangen und habe mir aus Trotz ein Bild gekauft. Das hängt noch heute in unserem Wohnzimmer. Als der dann später hörte, was mit mir geschehen war, sagte er: »Wolfgang, hättest du mir doch was gesagt! Ich hätte es Dir sofort geschenkt! Und ich sagte »Nein, ich wollte das Bild kaufen! Nun erst recht! « Jetzt hängt es also in unserem Wohnzimmer - es ist eine wunderbare Zirkusszene. Also ganz passend.

Udo Hahn: Ich fahre kurz in der Biografie fort. Sie haben dann bis zur Wende als wissenschaftlicher Mitarbeiter an der Akademie der Wissenschaften der DDR gearbeitet, im Zentralinstitut für Literaturgeschichte. Sie haben sich in der Wendezeit zunächst dem Neuen Forum angeschlossen. Anfang 1990 sind Sie dann in die neugegründete SPD in der DDR eingetreten und sie haben in der SPD bis heute viele Aufgaben und Ämter wahrgenommen. In einer 
Biografie des Deutschlandfunks heißt es, Sie seien einer der erfolgreichsten ostdeutschen Politiker und einer der wenigen DDR-Bürgerrechtler, die es so weit nach oben geschafft haben - also aus der Wendezeit heraus Politik die letzten 30 Jahre im vereinten Deutschland gestaltet haben. Und, das fand ich besonders nett und ich bin gespannt wie sie darauf reagieren: Sie sind als engagierter Querulant bezeichnet worden. Das ist sicher etwas Liebevolles, aber finden Sie sich darin wieder?

Wolfgang Thierse: Nein. Wenn mir bescheinigt worden wäre, dass ich auch in der Politik eigensinnig geblieben bin, dann gefällt mir das. Querulant ist ja ambivalent. Und ich war nicht nur einfach ein Querulant, dann hätte ich nicht so lange stellvertretender Parteivorsitzender der SPD sein können. Ich hatte eine Menge anderer Funktionen in dieser Partei: Vorsitzender der Grundwertekommission, Vorsitzender des Kulturforums der Sozialdemokratie. Das macht man nicht, wenn man nur Querulant ist. Ich habe natürlich auch gelegentlich dem eigenen Kanzler widersprochen und anderen auch und so wird man halt zum `Querulanten<.

Udo Hahn: Herr Dr. Thierse, ich knüpfe nun an den Beitrag von Christine Scheel in diesem Band an, in dem sie sagt: »Ohne Demokratie gibt es keine Zivilgesellschaft.« Wie muss man sich eigentlich die DDR bis zur Wende vorstellen? Wir sprechen immer von der SED-Diktatur. Diktatur heißt eigentlich, da gibt es keine Zivilgesellschaft, da gibt es eine Partei, die das gesellschaftliche, politische und kulturelle Leben - und wir haben das ja eben gerade am Beispiel Wolf Biermann wahrgenommen - dominiert. Gab es doch so etwas wie Zivilgesellschaft? Wie würden Sie den Satz von Christine Scheel im Blick auf die DDR vor der Wende einordnen?

Wolfgang Thierse: Wenn man Zivilgesellschaft als positiv wertenden Begriff versteht im Sinne einer selbstbewussten Bürgerschaft, die fähig und willens ist zu selbstverantwortlichem Handeln, dann war es dem SED-Regime gelungen, eine solche Zivilgesellschaft fast vollständig zu zerstören. Genauso wie es dieser Arbeiterpartei - dieser sogenannten - gelungen ist, die Arbeiterklasse in der DDR fast vollständig zu entpolitisieren. Das sollte man wissen.

Das galt nicht für die Kirchen. Zwar sollte Religion bestenfalls Privatsache sein, aber die Kirchen blieben bzw. wurden Freiräume in einem unfreien Land. Und deswegen freut mich die historische Pointe, dass es die unterdrückten Kirchen waren, die eine solche Rolle bei der Überwindung des Re- 
gimes gespielt haben! Dass Christen die Religion eben nicht bloß ihre Privatsache sein lassen wollten, sondern daraus öffentliche politische Konsequenzen gezogen haben, und so wesentlich beigetragen haben zur Überwindung des Regimes! Es gab also in der DDR die Kirchen als einen Raum relativer Freiheit in einem unfreien Land. Das wurde dann deutlich sichtbarer in den 8oer Jahren, als sich Oppositionsgruppen bildeten, zunächst Zirkel eher geringer Größe, weil man vertraut miteinander umgehen können musste. Es gab die evangelischen und katholischen Studentengemeinden, die sehr wichtig waren. Es gab das demokratische Leben in der evangelischen Kirche: $\mathrm{Zu}$ den erstaunlichen Überraschungen für die Westdeutschen gehörte 1990 ja, dass der Vizepräsident der Volkskammer, Reinhard Höppner, den parlamentarischen Betrieb ziemlich souverän gehandhabt hat. Er hatte es gelernt, denn er war Synodenpräses. Da weiß man, wie man Versammlungen leitet. Das konnte man sonst in der DDR nirgendwo lernen. Und auch ich wurde ja - wenn ich das mit einer gewissen Ironie sagen darf - im Westen mit Erstaunen begrüßt. Ich erinnere mich an einen SPIEGEL-Artikel über mich: Da kommt einer aus der DDR und kann deutsch und ist der öffentlichen Rede mächtig. Das war offensichtlich etwas Überraschendes. Ich wunderte mich darüber und dachte, ich habe schließlich Germanistik studiert, dann werde man doch eine beträchtliche Beherrschung der nicht politischen deutschen Sprache draufhaben. Und nicht nur den politischen Jargon. Es fiel also auf, dass ich eine andere Sprache spreche als die westdeutschen Politiker. Auch für mich war eben die Studentengemeinde ein wichtiger Lernort gewesen.

Also, die Zivilgesellschaft war nicht vollständig ausradiert. Aber sie war nicht als eine öffentlich wirksame sichtbar. Es gehörte zu den Entwicklungen im Laufe der 8oer Jahre, dass die unterschiedlichen Zirkel des Überlebens, des widerständigen Denkens - Opposition, das ist ein so großes Wort - die zunächst getrennt waren, sich zu überschneiden begannen. Wo hat Stefan Heym gelesen, wo ist Stefan Krawczyk aufgetreten, wer hat begonnen, mit wem zu diskutieren? Da gab es ja auch Zirkel in der Wissenschaft, selbst bis in die SED hinein, Ideen einer Reform des Sozialismus. Und erst als die anfingen, sich zu begegnen, da wurde es gefährlich. Erst sehr spät im Vergleich etwa zu Polen: Solidarnosc war deshalb ein außerordentliches Phänomen, weil da eine wirkliche Gewerkschaft entstanden war, wo Intellektuelle sich mit den Arbeitern verbündeten, wo die großen Namen von Mazowiecki bis Geremek sich den sich organisierenden Arbeitern zur Verfügung stellten. In der DDR dagegen: Entpolitisierte Arbeiterklasse, die privatisierte. Ein typischer DDRSatz war: »Privat geht vor Katastrophe.« Das war ein Ausdruck der Entpoli- 
tisierung einer Mehrheit: Man wusste seit 1953, dass man nichts ausrichten konnte. Erst in den späten 8oer Jahren entstand eine andere Lage, wenn man so will eine Art von vorrevolutionärer Situation.

Udo Hahn: Herr Dr. Thierse, wann haben Sie gespürt oder erkannt, dass sich in der DDR grundlegende Veränderungen abzeichnen könnten? Gab es da ein Erlebnis oder eine Entwicklung, an dessen Ende Sie sagten, da kann etwas passieren?

Wolfgang Thierse: Ich will nicht Legendenbildungen erliegen. Sie wissen ja, dass der Zeitzeuge als der natürliche Feind der Historiker gilt. Denn wir Menschen sind so gestrickt, dass wir unmerklich oder bewusst ständig an unseren Erinnerungen arbeiten und daraus Mythen entstehen, auch individuelle. Ich versuche das zu vermeiden.

Wir haben in der DDR in einem eigentümlichen Zwiespalt gelebt. Dem Zwiespalt zwischen der offiziellen Wahrnehmung dessen, was die DDR war, den Propagandameldungen über die erfolgreiche Wirtschaft, teilweise überraschenderweise bestätigt vom Westen, der Respekt vor der DDR hatte. Eine Zeitlang hieß es, die DDR sei die zehnstärkste Industrienation der Welt. Wir staunten! In der DDR lebend! Das Echo der DDR-Propaganda wurde uns gewissermaßen vom Westen widergespiegelt. Das war die eine Wahrnehmung, die offizielle. Und dann die andere: Der eigene unmittelbare Lebensausschnitt, das Erlebnis einer Mangelwirtschaft und zugleich die Erfahrungen einer Notgemeinschaft gegen die Widrigkeiten des Alltags und des Mangels und der Bedrängnis und Bedrückung von oben. Wir hatten diese zwiespältige Wahrnehmung: Eigentlich kann das Ganze doch nicht mehr richtig funktionieren. So waren die unmittelbare Wahrnehmung, der eigene Lebensausschnitt und das, was wir von anderen Bekannten und Freunden hörten. Und andererseits das offiziell Geschilderte - es geht ja doch irgendwie weiter. Im Jahr 1989 wurden die unüberwindbaren Widersprüche sichtbarer.

Ein wichtiger Schritt war die Dokumentation der Fälschung der Kommunalwahl im Mai 1989. Wir wussten immer, die Wahlen sind Betrug, aber jetzt wurde es nachgewiesen von mutigen Menschen in Berlin, in Leipzig und in einer Reihe anderer Städte. Dann im Juni 1989 die Drohung aus Peking: Der glorreiche Egon Krenz war in Peking zu Besuch und hat mitgeteilt, dass die blutige Unterdrückung der Opposition auf dem Tiananmen-Platz ein notwendiger Schritt war. Wir wussten, der meint auch uns. Und dann im August/September 1989 die Welle der Ausreisenden. Ich werde nie vergessen, 
wie ich am Telefon einen westdeutschen Freund fast angeschrien habe (da merkte man die eigene Betroffenheit). Ich habe gesagt: Hör mal zu, es bleiben nicht nur die Faulen und Feigen und Unanständigen hier im Lande. Es war ein ungemeiner Druck: Da gingen so viele und man selber war immer noch da. Was für eine absurde Situation, dass man sich dafür rechtfertigen muss, dass man da ist, wo man lebt. Ich glaube nicht, dass Sie im Westen Deutschlands je eine solche Erfahrung gemacht haben.

Es ging mir im Herbst 1989 so, wie ganz vielen anderen: Ich hatte das dringende Gefühl, wenn ich jetzt nicht auf die Straße gehe und mitmische und dieses Land verändere, werde ich mich mein ganzes weiteres Leben lang vor mir selber und vor meinen Kindern schämen, die vielleicht auch irgendwann mal abhauen und nicht einfach so trotzig oder bequem oder überzeugt da bleiben.

Noch am 10. November habe ich nicht gewusst, wie lange die DDR weiter existieren wird. Die SED-Führung werde sich vielleicht verändern. Wir aber müssten erreichen, dass wir elementare Grundrechte erringen: Schluss mit dem Führungsanspruch der SED, unterschiedliche Parteien, also Reformen innerhalb der DDR. Und die Unsicherheit, ob die Sowjetunion das zulassen wird und ob es überhaupt diese Chance geben wird.

Ich will jedenfalls im Rückblick nicht behaupten, dass ich damals gewusst hätte, ob und wie schnell es mit der DDR zu Ende geht. Das emotionale Begreifen des Geschehens, der rasanten Entwicklungen, erfolgte Schritt für Schritt.

Udo Hahn: Jetzt sind wir dreißig Jahre weiter. Sie haben sich in vielen Vorträgen und Publikationen intensiv mit dem Thema Zivilgesellschaft beschäftigt. Wenn Sie jetzt nach drei Jahrzehnten sozusagen durch die Brille der Zivilgesellschaft die Entwicklungen beurteilen, wo stehen wir heute im Blick auf die ehemalige DDR, die neuen Bundesländer, Ostdeutschland?

Wolfgang Thierse: Nun gibt es ja, wie ich persönlich empfinde, eine eigentümlich beunruhigende Debatte über Ostdeutschland und auch unter Ostdeutschen. Da ist plötzlich davon die Rede, dass Ostdeutschland kolonisiert worden sei, von Demütigungserfahrungen und von vielem anderen. Ich rate zur Nüchternheit und beginne noch einmal mit einer Erinnerung. Die friedliche Revolution war - wie Revolutionen immer - etwas, was von einer Minderheit gemacht worden ist. Und da sie am Schluss erfolgreich war, war die Mehrheit deren Nutznießer. Sie war nicht nur eine friedliche Revolution, sie war 
auch und zugleich ein wirtschaftlicher, politischer und moralischer Zusammenbruch des SED-Regimes. Es war eine Minderheit, die diese Revolution initiiert hat. Und diese Minderheit ist bereits am 18. März 1990 abgestraft worden. Bis zum 9. November 1989 war die wichtigste Losung »Wir sind das Volk«: Wir bestreiten Euch den Anspruch, für uns zu reden, wir reden ab sofort für uns selber. Und $a b$ dem 9. November, ab dem Moment, wo eine Mehrheit der Ostdeutschen plötzlich in den Westen konnte, da wandelte sich die Losung in »Wir sind ein Volk«. Was war da passiert? Das ist eine wirkliche Programmänderung: Weg von demokratischen Reformen innerhalb der DDR, weg von Selbstermächtigung hin zu einem realistischen Ziel. Die Mehrheit der DDR-Bürger meinte nun, all das, was wir wollen - Grundrechte, Freiheit und Demokratie, Reisen, Wohlstand - das gibt's doch alles direkt nebenan, in dem anderen, größeren, erfolgreichen Teilstaat, auf den wir schon immer neidisch geblickt haben.

Mitte November gab es den Aufruf »Für unser Land«, im Wesentlichen formuliert von Christa Wolf im Auftrag des Neuen Forum. Dieser Aufruf ging herum zum Unterzeichnen und ich hatte damals schon das Gefühl, ich unterzeichne das nicht, ich glaube nicht, dass eine Mehrheit der DDR-Bürger sich erneut zum Material der nächsten real-sozialistischen oder nun vielleicht utopisch-sozialistischen oder demokratisch-sozialistischen Utopie machen lassen will. Das war mein Gefühl. Ich habe nicht unterschrieben. Der Entwurf war dann tot, als Egon Krenz ihn unterschrieben hatte. Und wenn ich einfügen darf: Wie ich den Ausdruck »Wende« hasse! Denn dieser Ausdruck stammte von Egon Krenz und bezeichnete seine Inthronisation als Generalsekretär der SED. »Wir haben die Wende eingeleitet«, sagte er in einer Fernsehansprache. Wir sahen das und Krenz redete uns an mit: "Liebe Genossinnen und Genossen ...«. Da dachte ich, der begreift nichts, denn auch wenn es zwei Millionen SED-Genossen waren, 15 Millionen waren es nicht! Dieser Ausdruck »Wende« schleppt sich fort, weil Kohl ihn übernommen hat und nun schleppen ihn alle weiter.

Stichwort Minderheit und Stimmungswechsel: Der 18. März 1990 und das Wahlergebnis, das war eine eindeutige Botschaft. Eine große Mehrheit der DDR-Bürger wollte so schnell wie möglich unter das rettende Dach der Bundesrepublik Deutschland. Daran erinnere ich heute meine Landsleute. Ihr wolltet das - wenn ihr heute enttäuscht seid! Ihr wolltet nicht, was unsere Freunde von Bündnis 90 und wir jungen Sozialdemokraten wollten, einen Prozess der Vereinigung von zwei, drei, vier Jahren, also Schritt für Schritt, Reform für Reform. Die Mehrheit wollte etwas ganz anderes. Zur Tempo- 
Beschleunigung des Jahres 1990 gehörte eben die Ungeduld der DDR-Bürger: »Kommt die D-Mark bleiben wir, kommt sie nicht dann gehen wir.« Dann kam der faktische wirtschaftliche Zusammenbruch der DDR-Wirtschaft, weil eine Mehrheit der DDR-Bürger nicht mehr die eigenen Produkte kaufte, sondern die West-Produkte haben wollte - ich sage das ohne Vorwurf, das kann man ja verstehen - und weil die Lieferketten in den Osten Europas plötzlich nicht mehr funktionierten. Und schließlich die außenpolitische Ungewissheit, ob, wann, wie lange, zu welchen Bedingungen Gorbatschow zustimmen würde zur Deutschen Einheit und zum weiteren Gang der Dinge. Das waren alles beschleunigende Faktoren, weshalb dann die Vereinigung eben vollzogen wurde als Beitritt zur Bundesrepublik. Entsprechend dem Willen der ganz großen Mehrheit. Ich betone das so, weil es noch heute Leute gibt, die das kritisieren und daraus Vorwürfe machen. Dann sage ich, könnt ihr machen, aber guckt hin, was damals tatsächlich die Situation war.

Es war eine Minderheit, die die »friedliche Revolution« ins Werk und auf demokratische Reformen gesetzt hat. Und vielleicht wirkt das bis heute nach. Eine Mehrheit wollte damals so schnell wie möglich unter das rettende Dach Westdeutschlands und wollte den Verheißungen glauben. Und Helmut Kohl hat dem deutschen Einigungsprozess eine Art patriarchale Prägung gegeben: »Ich nehme euch an die Hand und führe euch ins Wirtschaftswunderland«. Das war sein Gestus jedenfalls - und eine Mehrheit der DDR-Bürger wollte das glauben! So waren dann auch die Wahlergebnisse im März und Dezember 1990. Wenn man solche Erwartungen hat und so heftig an Versprechen glaubt, dann ist es nicht ganz so überraschend, dass mit unterschiedlicher Schnelligkeit die Enttäuschungen eintreten, die heute noch die Stimmungslage bei einem Teil der Ostdeutschen mitbestimmen. Wie heißt ein kleiner Buchtitel: »Integriert doch erst mal uns«. Er spiegelt genau das wider: Eine fortwirkende autoritäre Prägung. Wenn man die deutsche Geschichte beleuchtet - zwölf Jahre Nazizeit, vierzig Jahre DDR, die Unmöglichkeit, selbstbewusste Bürgerschaft zu leben - dann sage ich das ohne moralischen Vorwurf: Das wirkt nach. Und es verlängert die Einstellung, wie damals in der DDR, alles von denen da oben erwarten zu müssen. Und jetzt richtet sich die Erwartung und die Schuldzuweisung an »Die da oben« im Westen. Die Enttäuschungen, die da eintreten, weil eine Demokratie solche Erwartungen niemals befriedigen kann, die sind heftig. Hatte man die Hoffnungen bei zwei Wahlen zur CDU getragen, dann zur SPD, dann zur Linkspartei, so trägt ein Teil der Ostdeutschen seine Enttäuschungen nun zur AfD. Das ist gewiss etwas grobschlächtig formuliert, aber ich glaube, dass es einen solchen Zusammenhang gibt, der 
viel wichtiger ist, als die Behauptung, dass die AfD und die Stimmungslage durch ökonomische oder materielle Gründe bestimmt seien. Untersuchungen zeigen: Pegida und die AfD, das sind nicht die Ärmsten der Armen, das ist nicht die Masse der Arbeitslosen, sondern die mittlere Schicht, das mittlere Publikum. Die sind gar nicht unbedingt unter die Räder gekommen, aber deren Erwartungen sind nicht befriedigt worden. Das ist ein Teil des Konfliktes, in dem dann auch noch ein kultureller Konflikt ganz anderer Art steckt. Darüber müsste man noch gesondert reden.

Udo Hahn: Was heißt das jetzt für die Zivilgesellschaft in den neuen Bundesländern? Die Menschen, von denen sie gerade sprachen, gehören eigentlich zur Zielgruppe der Kirchen beispielsweise, sie verfügen über Bildungsabschlüsse, sie sind in der Lage, Argumente zu belegen und müssten eigentlich nicht jeder Parole oder jedem Slogan hinterherlaufen. Wie sollen wir also die Zivilgesellschaft im Moment einschätzen? Und die weitere Frage ist dann:Wie schauen wir auf unser Land insgesamt?

Wolfgang Thierse: Man wird oft gebeten, Ostdeutschland zu erklären, warum der Ostdeutsche so braun sei oder ob es sich tatsächlich um »Dunkeldeutschland« handele. Ich will zu erklären versuchen, warum es die Demokratie dort schwerer hat. Die Erfolgsgeschichte der Demokratie in der Bundesrepublik Deutschland verlief parallel zur wirtschaftlichen Erfolgsgeschichte. Das Ja zur Demokratie ist fundiert oder erleichtert worden durch den wirtschaftlichen Erfolg. Die Erfahrung war: Wirtschaftlicher Wohlstand und Demokratie passen zusammen! In Ostdeutschland muss das Ja zur Demokratie gesagt werden angesichts dramatischer Umbrüche, der Erfahrung von Arbeitslosigkeit oder der Angst davor, in einer Situation wirtschaftlicher, sozialer, moralischer Verunsicherung. Das ist eine grundlegend andere Situation. Gerade auch vor dem Hintergrund der Schwäche der Zivilgesellschaft. Jetzt kommt noch etwas hinzu: Wir sind gegenwärtig in einer Situation neuer, gleichzeitiger und dramatischer Veränderungen. Die Stichworte sind: Globalisierung, Entgrenzung und Beschleunigung der Welt und ihre Entwicklungen, die Flüchtlingsbewegung, in der die Globalisierung gewissermaßen personifiziert ist. Das Fremde und die Fremden rücken uns nahe! Die digitale Transformation. Die drängende ökologische Katastrophe, die eine radikale Veränderung unserer Lebensweise verlangt. Und dann noch die internationale Situation: Terrorismus, Gewalt, Konflikte. Insgesamt also eine bedrohlich erscheinende Dramatik von Veränderungen, die Ängste und Verunsicherung erzeugt. Und diese 
trifft in Ostdeutschland auf eine Bevölkerung, die noch nicht fertig ist mit der Bewältigung der dramatischen Veränderungen seit 1989/90!

Und jetzt soll sie die nächste Veränderungsphase verarbeiten. Das heißt, die Verunsicherung, die Ängste - oder wie ich es nenne - Entheimatungsängste, das ist dort viel dramatischer. Und damit ist auch die Sehnsucht viel heftiger nach den einfachen, schnellen Antworten. Nach den einfachen Botschaften. Nach der schnellen Lösung. Nach Erlösung. Und das ist die Stunde der Populisten. Deswegen ist die AfD erfolgreich. Sie verspricht. Sie nimmt Enttäuschungen auf. Sie verstärkt und instrumentalisiert Ärger und Wut. Sie bestätigt und bestärkt Abwehrängste gegen all diese Veränderungen.

Was dagegen zu tun ist, geht weit über die Politik hinaus. Politiker müssen viel besser erklären was sie tun. Politik muss selbst Demokratiearbeit leisten, also in der politischen Auseinandersetzung zugleich politische Bildung betreiben. Das ist so ziemlich das Gegenteil dessen, was Frau Merkel immer gemacht hat. Viel mehr werbend und erklärend agieren. Das ist ziemlich mühselig. Das zweite ist, dass dies eigentlich noch viel mehr Aufgabe der Bürgergesellschaft ist. Meine Erfahrung jedenfalls ist, dass das Gespräch zwischen Politikern und Bürgern immer darunter leidet, dass es durch ein Vorwurfs-Gefälle geprägt ist, durch sofortige Abwehr, durch Vorurteile gegen »die da oben«. »Der weiß nichts von mir, der begreift nicht.« Ich habe es erlebt: Da steht ein Bürger in einer Veranstaltung auf, formuliert eine ganze Kaskade von Vorwürfen gegen die Politik. Und wenn ich dann eine Antwort geben möchte und diskutieren will, dann hört der Fragende nicht zu oder geht raus. Der wollte nur seine Wut "gegen den da oben« artikulieren.

Trotzdem: Gespräche müssen geführt werden, unbedingt. Ich bin überzeugt davon, dass von Nachbar zu Nachbar, von Kollege zu Kollege ein versachlichendes Gespräch leichter zu führen ist. Und dass die Demokraten ein schönes Wort, das nicht von mir stammt, sondern von Bernhard Pörksen - dass die Demokraten »Hermeneuten der Wut« der anderen werden sollen. Hermeneuten der Wut: Was ängstigt euch, worüber bist Du wütend? So konkret wie möglich darüber reden. Das ist Sache der Zivilgesellschaft, das ist Zivilgesellschaft!

Ralf Dahrendorf hat 1990 eine Prognose abgegeben. Er sah folgenden Zeitbedarf voraus: Für die Einführung politischer Demokratie und rechtsstaatlicher Verhältnisse sechs Monate, für die Entwicklung einer funktionierenden Marktwirtschaft sechs Jahre, für die Entwicklung einer starken Zivilgesellschaft sechzig Jahre. Wir sind also durchaus noch im Zeitplan! 
Udo Hahn: Ich habe noch zwei Fragen: Zunächst eine, zu der ich ins Ausland schauen will. Wenn wir die Entwicklung in Ländern wie Ungarn oder Polen unter die Lupe nehmen, dann sehen wir, dass sich auch dort viel verändert hat, und dass dort das System der Medien unter Druck geraten ist, die Justiz und auch die Zivilgesellschaft. Und wenn man gegen diese drei Bereiche schießt, von denen man sagen kann, dass sie eine Demokratie konstituieren, dann weiß man eigentlich nicht so recht, was da noch übrigbleiben soll. Jetzt aus dem Ausland zurück nach Deutschland: Mein Eindruck ist, dass auch bei uns die Medien, der öffentlich-rechtliche Rundfunk, aber auch die Qualitätszeitungen und Nachrichtenmagazine von SPIEGEL oder FOCUS über die ZEIT, die Süddeutsche Zeitung und die FAZ, kritisch unter die Lupe genommen werden. Gegen die Justiz gibt es auch Bestrebungen und die Zivilgesellschaft ist dann das nächste Ziel. Man hört an einigen Stellen Forderungen wie die, der Bundeszentrale für politische Bildung das Geld am besten wegzunehmen, weil alles, was dort investiert wird, das braucht es eigentlich nicht. Wie bedrohlich ist aus Ihrer Sicht die Situation tatsächlich, und wer in der Zivilgesellschaft müsste sich jetzt alles mit anderen unterhaken?

Wolfgang Thierse: Jetzt haben wir ja, parteiisch wie wir sind, geradezu emphatisch über die Zivilgesellschaft gesprochen und damit indirekt Pegida und die AfD an den Rand gestellt, die natürlich auch zivilgesellschaftliche Erscheinungen bestimmter Art sind. Das muss man auch ernst nehmen. Auch darin kann man interessante Beobachtungen machen, dass die DDR und Ostdeutschland nun wirklich nicht ganz so homogen waren und sind. Der Unterschied etwa zwischen Leipzig und Dresden gerade in solchen Fragen ist riesig. Das sind ziemlich unterschiedliche Städte und das war auch zu DDR-Zeiten schon so. Ich werde nicht vergessen, in Dresden konnte man noch Reste eines alten Bürgertums erleben mit entsprechenden starken Kulturprägungen. Das gab es so in Leipzig nicht mehr und in Berlin auch nicht. Da gibt es untergründige Traditionen, die noch eine Rolle spielen.

Ich setze eine gewisse Hoffnung darauf, dass in Ostdeutschland, in den größeren Städten, in den Universitätsstädten zumal, eine neue deutsche Mischung entsteht. Wir haben ja schließlich nicht die Mauer vom Osten her eingedrückt, um unter uns zu bleiben! Also es ist schön, wenn die Wessis zu uns rüberkommen, was ja nicht alle gleichermaßen als so schön empfinden. In den Universitätsstädten entsteht etwas Neues, und damit entsteht eine Konfrontation zwischen dieser neuen Mischung und anderen, traditioneller 
geprägten Orten. Aber auch innerhalb dieser Orte kann man das beobachten, z.B. in Dresden, wo es ein ziemlich konservatives (auch AfD-gestimmtes) Bürgertum gibt, das dieses Grundgefühl hat: Jetzt werden wir fremd im eigenen Land. Es hat sich so viel verändert, was uns ausgemacht hat; was uns geholfen hat, die DDR zu überstehen. Und jetzt, wo wir das Sehnsuchtsziel erreicht haben, die Deutsche Einheit, wird uns das unter den Füßen weggezogen. Das ist eine ganz eigentümliche Stimmung. Und da sage ich wiederum, da hilft nur das Gespräch zwischen denen, die schon länger da sind, und den Hinzugekommenen. Ich weiß, wie schwierig das sein kann, weil Vorurteile aufeinandertreffen können. Das ist eine der großen Herausforderungen.

Sie haben auch nach den Medien gefragt. Das ist ohnehin verrückt, wenn man hört, dass es eine Zunahme derer gibt, die den seriösen Medien nicht mehr glauben: »Lügenpresse«. Das ist ein mediales Problem, durchaus auch eines Kulturkampfes, das ernst zu nehmen ist: Es gibt eben viele Ostdeutsche, die der Meinung sind, ihr Leben in der DDR und in den letzten dreißig Jahren, das was ihr Leben ausgemacht hat, das kommt gar nicht angemessen vor. Sie haben das Gefühl, dass sie vorurteilsbeladen beurteilt werden. Dagegen muss man anarbeiten, weil das inzwischen zu einem Opfermythos geworden ist, also durchaus eine Übertreibung. Aber die ostdeutsche Wahrnehmung, nicht fair und gerecht bewertet zu werden, habe ich schon Anfang der 9oer Jahre angesprochen und immer wieder wie ein politischer Wanderprediger gesagt: Ihr lieben Westdeutschen, ihr müsst deutlich und sichtbar und hörbar unterscheiden zwischen dem Urteil über das System - das gescheitert ist, das zusammengebrochen ist, da kann und muss das Urteil radikal und hart sein - und dem Urteil über die Menschen, die da gelebt haben. Mit diesem Urteil müsst ihr behutsam und differenziert umgehen. Und wir müssen reden miteinander. Ostdeutsche und Westdeutsche müssen sich wechselseitig ihre Lebensgeschichten erzählen. Da wird nämlich deutlich, dass die im Westen nicht nur Erfolgs- und Siegergeschichten hinter sich haben und wir im Osten nicht nur finstere Verräter- und Schurkengeschichten.

Solch vorsichtig-differenziertes Urteilen war aber eher die Ausnahme. Denn insgesamt, das wirkt nach, waren die goer Jahre bestimmt von der medialen Vermarktung der DDR-Biografien zu Skandalgeschichten von Feigheit und Verrat unter der Überschrift des Faszinosums Stasi. Und wenn ich, ich darf das personifizieren, wenn ich so einen Scharfrichter wie Hubertus Knabe, dessen Anliegen ich ja ganz gut nachvollziehen kann, im Fernsehen erlebe mit seinen harten Urteilen über DDR-Biografien, dann weiß ich, dass sich ganz viele Ostdeutsche gegen dessen Urteile wehren und damit einer 
selbstkritischen Betrachtung ihrer eigenen DDR-Biografien verweigern und die DDR plötzlich verteidigen, wie sie es zu DDR-Zeiten nie getan haben. Das war nach meiner Beobachtung die Wirkung von Hubertus Knabe, der lange Zeit Leiter der Gedenkstätte Stasi-Gefängnis Hohenschönhausen war und immer den Eindruck vermittelte, er hätte selbst in Bautzen gesessen. Dabei hat er schlicht eine westdeutsche Biografie, denn er war Sohn eines grünen Bundestagsabgeordneten.

Udo Hahn: Herr Dr. Thierse, ein wichtiges Thema ist der Wandel der Zivilgesellschaft. Als Teil der Zivilgesellschaft betrifft das die Gewerkschaften; aber die Parteien gehören im weitesten Sinne ja auch zur Zivilgesellschaft und hier vollzieht sich auch ein Wandel, von dem insbesondere die SPD betroffen ist. Wie nehmen Sie diesen Wandel, diese Veränderung, diesen Veränderungsdruck, unter dem die SPD im Augenblick steht, wahr?

Wolfgang Thierse: Also ich beherrsche mich und sage einen steilen Satz: Wer Parteien verachtet, gerade auch in Momenten ihrer Krise, verachtet Demokratie. Schauen wir in die Geschichte: So wichtig soziale Bewegungen sind und wohl auch der lebendigere Teil von Politik sein können - Bewegungen an die Stelle von Parteien zu setzen, das erscheint mir gefährlich. Die deutsche Erinnerung und der Blick in andere Länder sollten uns warnen. Es sollte um das Zusammenspiel von demokratischen Parteien und demokratischen zivilgesellschaftlichen Bewegungen gehen, das halte ich für richtig und notwendig. Das Zusammenwirken wird mit Sicherheit nicht ohne Widersprüche und Konflikte sein. Aber dass wir das Prinzip der repräsentativen Demokratie aufheben, ich kann nicht sehen, wie wir dadurch etwas gewinnen können. Wie wir diese repräsentative Demokratie verlebendigen können, wie die Parteien sich selber verändern, das ist die schwierige Herausforderung. Ich glaube auch nicht, dass die SPD darin ein spezifisches Problem hat. Das spezifische Problem der SPD ist ihre soziale und kulturelle Basis, die stärker erschüttert ist, stärker erodiert ist als die Basis der CDU, der anderen Volkspartei. Und bei den Grünen werden wir sehen, was daraus wird, wenn Robert Habeck mitteilt: Nein, Volkspartei wollen wir nicht werden, wir wollen Bündnispartei werden. Solche Art sprachliche Tricks liebe ich als Germanist und freue mich auf deren Erfolg in der Wirklichkeit.

Wolfgang Schroeder empfahl der SPD unlängst - das finde ich auch einen schönen Begriff - »Brückenpartei« zu werden. Darin steckt ein richtiger Gedanke: In einer zersplitterten, individualisierten, sich ständig verändern- 
den Gesellschaft ist die Basis von Großorganisationen erodiert und schwierig geworden. Das gilt für die Parteien, für Gewerkschaften, für Kirchen, für Sportverbände. Darauf muss man Antworten finden und das kann man nur in Experimenten. Und da sind wir unterwegs. Aber das Triumphgeschrei, das ich jeden Tag in der Zeitung lese, das Ende der Volksparteien sei da, dieses Triumphgeschrei mag ich nicht so sehr. Wir sind an einem Tiefpunkt und werden wohl noch durch ein etwas längeres, tieferes Tal gehen müssen. Das sehe ich auch, aber ich wünsche mir, dass es nicht abgrundtief ist. Wenn Sie mir diesen Wunsch verzeihen! 


\section{Umbrüche II: \\ Migration und die neuen Bürgerbewegungen \\ in Deutschland}





\title{
Migrationsgesellschaft und Zivilgesellschaft
}

\author{
Hans Vorländer
}

Wenn man aus Dresden kommt, so wie ich, dann lässt sich das Thema dieses Beitrags gut an einer Bewegung veranschaulichen, die im Herbst 2014 als Facebook-Gruppe begann, sodann über die Straßen der sächsischen Landeshauptstadt zog, innerhalb kürzester Zeit beträchtlich an Umfang zunahm und dabei starke nationale wie internationale Aufmerksamkeit gewann. Die Bewegung, die sich »Patriotische Europäer gegen die Islamisierung des Abendlandes« nannte, brachte Menschen auf die Straße, die offensichtlich gegen die Zuwanderung aus muslimischen Kulturkreisen Front machte. Aber das war nicht das einzige Motiv. Die Rufe »Volksverräter und »Lügenpresse« wiesen auch auf fundamentale Entfremdungserfahrungen mit dem politisch-medialen System der Bundesrepublik Deutschland hin. Pegida als in Bewegung gesetzte Zivilgesellschaft, als Wegbereiterin für den Aufstieg rechtspopulistischer und rechtsextremer Strömungen und Parteien - und als Auftakt zu einer politischen Polarisierung, die in der >Flüchtlingskrise vom Herbst 2015 einen Höhepunkt erreichte?

Pegida ist bis auf den heutigen Tag eine Protestbewegung geblieben, die öffentlich in Erscheinung tritt, die mittlerweile aber deutlich, auf etwa 1000 bis maximal 2000 Teilnehmer, geschrumpft ist - überwiegend handelt es sich um ältere Männer, zumeist aus dem Umland Dresdens, aus Ostsachsen oder Mittel- und Südsachsen oder aus den peripheren Stadtteilen Dresdens. Es ist das Ritual einer regelmäßigen Vergemeinschaftung sich abgehängt oder ausgegrenzt oder zurückgelassen fühlender Menschen geworden. Ein Pegidist sagte mir einmal: So wie andere sonntags in die Kirche gehen, so ist es meine Wallfahrt, am Montag zu Pegida zu fahren.

Pegida war am Beginn nicht nur eine Protestbewegung gegen Migration oder die »Islamisierung des Abendlandes«, von der man in Ostdeutschland ja ohnehin nur eine sehr vage Vorstellung hatte. Es war auch eine, etwas zugespitzt, nachholende Revolte gegen den Westen. Das zeigte sich auch in den 
ersten empirischen Befragungen. Denn es war nicht der Islam oder die Asyloder Integrationspolitik, die als Hauptmotive des Protestes genannt wurden, sondern es war die harsche Ablehnung von Politikern und Medien. Wenn man sich die Antworten auf die Fragen nach der Motivation genauer anschaute, dann ging es vornehmlich gegen die westlich dominierte Politik und die westlich dominierten Medien. Im Protest machten sich Entfremdungsphänomene bemerkbar, die als eine Auseinandersetzung um die Deutungshegemonie von Westvorstellungen und Ostbefindlichkeiten gedeutet werden konnten. Denn was in Ostdeutschland bis zum heutigen Tag zu reflexhafter Ablehnung führt, das sind als "Bevormundung " wahrgenommene Versuche aus dem Westen, den Ostdeutschen zu sagen, was sie zu denken und wie sie sich zu verhalten haben. Das sollte dann auch in der Auseinandersetzung um Pegida selbst sehr deutlich zum Ausdruck kommen, als sich eine Gegenbewegung etabliert hatte, die die »Weltoffenheit« Dresdens, Sachsens und Deutschlands gegen die offene Fremden- und Islamfeindlichkeit zu behaupten suchte. In den politischen Auseinandersetzungen und wissenschaftlichen Deutungen zu Pegida hat sich somit etwas - wie in einem Brennglas - zu erkennen gegeben, was nunmehr in den Fokus meiner Ausführungen rücken soll: die Spaltung der Zivilgesellschaft über die Migrationsfrage.

In welchem Verhältnis stehen Migrations- und Zivilgesellschaft zueinander? Was verstehen wir unter Migrationsgesellschaft? Und welche Rolle spielt die Zivilgesellschaft darin? Ich werde mich diesen Fragen in vier Schritten annähern. Dabei lautet die zentrale These, auch aus den Erkenntnissen zu Pegida herrührend, dass wir zumindest von zwei Zivilgesellschaften sprechen müssen, die sich an der Immigrationsfrage, aber nicht nur an ihr, scheiden. Die Migrationsfrage spaltet, sie führt zu Mobilisierung und $\mathrm{zu}$ Gegenmobilisierung; und die Migrationsfrage macht deshalb Foren und Arenen der Wiedergewinnung ziviler gesellschaftlicher Auseinandersetzung notwendig. Zunächst soll jedoch die Frage gestellt werden, was es bedeutet, eine Migrationsgesellschaft zu sein.

\section{Deutschland als Migrationsgesellschaft}

In einer Migrationsgesellschaft mit ihrer heterogenen Bevölkerungsstruktur wird beständig über Zugehörigkeit, über Anerkennung und Teilhabe von Einzelnen und Gruppen gestritten - und das in den verschiedensten gesellschaftlichen Bereichen: im Zugang zu Arbeits- und Wohnungsmärkten, im Bereich 
von Bildung und Ausbildung. Dazu gehören auch die öffentlichen Diskurse über Werte, Regeln und Mitgliedschaft in der politischen Gemeinschaft der Bürgerinnen und Bürger. Im Grunde werden also beständig die Fragen von Inklusion sowie $\mathrm{Ab}$ - und Ausgrenzung miteinander verhandelt. Hieraus entwickeln sich, vor allem in Zeiten schneller und hoher Zuwanderung, politische Konflikte, die sich zu verfestigten Spaltungslinien einer Gesellschaft auswachsen können, die soziale Milieus und Gruppierungen umgreifen. In den Migrationsgesellschaften der Gegenwart sind solche »cleavages« nicht nur in Deutschland zu beobachten. Dabei können ihnen durchaus unterschiedliche Ursachen - ökonomische, soziale, demographische - zugrunde liegen, doch zeigen Untersuchungen, dass Migrationsfragen, also die Auseinandersetzung über das Maß und die Zusammensetzung von $\mathrm{Zu}$ - und Abwanderung sowie über Zielrichtung und Maßnahmen der Integration, verschärfenden, katalysatorischen Charakter haben können. Durch sie werden schon bestehende Konfliktlinien sichtbar gemacht oder aber kulturell aufgeladen. Der Konkurrent um den Arbeitsplatz, die Wohnung oder die Sozialleistung wird beispielsweise - ethnisch - als der Türke oder - religiös - als der Muslim markiert. Wo es dann um solche Zuschreibungen geht, werden gesellschaftliche und politische Auseinandersetzungen »essentialistisch«: Religiöse, kulturelle, ethnische Identitätsbehauptungen konstruieren Mechanismen und Polarisierungen von Ein- und Ausschluss, von »wir« und die »anderen«.

Bei diesen Auseinandersetzungen geht es dann nicht mehr um rationale, zu Kompromissen führende Interessenausgleiche. Wo es um Identitäten, beziehungsweise um Identitätsbehauptungen geht, ist es schwer, in einem Prozess der Aushandlung das, was ich von mir oder meiner Gruppe denke, also mein oder ein kollektives Selbstverständnis, zur Disposition zu stellen. Über Identitäten lässt sich nicht verhandeln. Das ist genau der Zusammenhang, in dem Rechtspopulisten agieren, weil sie es verstehen, Migrationsfragen auf diese Weise identitätspolitisch aufzuladen, sie zu kulturalisieren, zu ethnisieren und zu Feindkonstruktionen zu schmieden. Der Rechtspopulismus ist in der Lage, eine Semantik anzubieten für scharfe, essentialistische Unterscheidungen, die dann zu diskursiven Eskalierungsspiralen führen können, wo ihnen, in sachlich berechtigter Weise, wenngleich oftmals in moralisierender Rhetorik, Identitätsbehauptungen anti-rassistischer oder anti-faschistischer Provenienz entgegengestellt werden.

Ist Deutschland eigentlich eine Migrationsgesellschaft? Das ist eine Frage, die gar nicht so leicht zu beantworten ist, wenn man sich den öffentlichen Diskurs anschaut. Lange Zeit ist das Faktum der Migration, vor allem der 
Zuwanderung, aus humanitären Gründen wie solcher der Arbeitssuche oder Arbeitsaufnahme, im öffentlichen Diskurs beschwiegen worden. Vielfach war von »Gastarbeitern« die Rede, von denen angenommen wurde, dass sie nach einiger Zeit das Land wieder verlassen. Das änderte sich erst im Jahr 1999, in dem ein neues Staatsangehörigkeitsgesetz verabschiedet wurde, das am 1. Januar 2000 in Kraft trat. Darin wurde zum ersten Mal anerkannt, dass diejenigen, die zugewandert sind und dauerhaft im Land zu verbleiben beabsichtigen, ein erleichtertes Recht auf Einbürgerung haben sollten; dabei ist das die Verleihung der Staatsbürgerschaft lange Zeit bestimmende Abstammungsprinzip, das ius sanguinis, durch das Geburtsortprinzip, das ius solis, ersetzt bzw. ergänzt worden. Das markierte einen ersten entscheidenden Paradigmenwechsel. Der zweite hat vor kurzer Zeit stattgefunden, nämlich bei den Beratungen zum Facharbeitereinwanderungsgesetz. Zum ersten Mal taucht hier der Begriff der »Einwanderung« zur Bezeichnung eines Gesetzes auf.

Gleichwohl muss natürlich festgehalten werden, dass Deutschland, genauer: Westdeutschland, eigentlich seit 1945/49 bereits verschiedene Wellen von Zuwanderung zu verzeichnen hatte. Zuerst zwölf Millionen Flüchtlinge aus den ehemaligen Ostgebieten Deutschlands, dazu aus der Sowjetischen Besatzungszone und der 1949 gegründeten DDR rund drei Millionen. Später kamen ca. fünf Millionen »Gastarbeiter« aus Italien, Spanien, Portugal, Griechenland, Jugoslawien und der Türkei hinzu. In den 1990er Jahren kamen aus Ostmitteleuropa, vor allem infolge der Auflösung der Sowjetunion und des Jugoslawienkrieges, etwa 2,5 Millionen Menschen nach Deutschland, als »Spätaussiedler«, als Asylbewerber oder zur Arbeitsaufnahme. Gerade als Reaktion hierauf und auf die ausländerfeindlichen Übergriffe, Morde (in Mölln und Solingen) und Protestaktionen (in Rostock-Lichtenhagen und Hoyerswerda) wurde das Asylrecht deutlich verschärft und durch das sogenannte »DublinAbkommen « das Problem der Zuwanderung aus Nicht-EU-Staaten an die Außengrenzen der EU, vor allem nach Italien und Griechenland, ausgelagert und damit unsichtbar zu machen versucht.

Deshalb kam es dann 2015 mit der sogenannten Flüchtlingskrise zu einer Schockerfahrung - denn eine Schockerfahrung war es, wenn man sich die damalige Situation noch einmal in Erinnerung ruft. Über 50 Prozent der befragten Bürgerinnen und Bürger stimmten der Aussage zu, dass es einen Kontrollverlust des Staates über die Zuwanderung gegeben habe; und etwa 50 Prozent verbanden mit der Migration vor allem sehr starke Sorgen, nicht zuletzt um den gesellschaftlichen Zusammenhalt. Das änderte sich wieder, aber die Mehrheit befürwortet nach wie vor eine Begrenzung der Zuwande- 
rung. Vor allem verschärfte sich der politische Diskurs, und der Widerstand gegen die Migrationspolitik der Bundesregierung und der im Bundestag vertretenen Parteien formierte sich in den sozialen Netzwerken, auf öffentlichen Plätzen und im Parteiensystem. Dabei wurden dort die Grenzen zwischen demokratisch legitimen Protest und physischer Gewaltausübung überschritten, wo es zu tätlichen Übergriffen auf Asylunterkünfte oder Migrantinnen und Migranten kam. Die Zahl politisch motivierter Gewalt stieg exponentiell an.

Insofern war die sogenannte Flüchtlingskrise des Jahres 2015 tatsächlich, wie Ivan Krastev formuliert hat, ein »9/11-Moment« - nicht nur für die Bundesrepublik Deutschland, doch kam es besonders hier zu einer scharfen Polarisierung in Gesellschaft und Politik. Damit ist auch zur zentralen Frage geworden, ob sich die Bundesrepublik Deutschland nun als eine Migrationsgesellschaft beschreiben will, in der politische Anerkennungs-, Zugehörigkeitsund Teilhabefragen kritisch und offen verhandelt werden, um politische Konzepte für Migration und Integration in demokratischer Weise zu entwerfen - oder ob sie sich an der Vorstellung einer vermeintlich durch Homogenität, Tradition und Herkunft geprägten »Leitkultur « zu orientieren gewillt ist, in der es vor allem Aufgabe der Zugewanderten ist, sich der wie auch immer zu definierenden »Mehrheitsgesellschaft « anzupassen. Am empirischen Befund einer Migrationsgesellschaft, die hohe $\mathrm{Zu}$ - und Abwanderung - auch aus und in den EU-Raum - zu verzeichnen hat und die nicht zuletzt aus demographischen Gründen auf Arbeitsmigration angewiesen ist, kann indes nach den Erfahrungen der letzten Jahre - und angesichts weltweiter Migrationsströme - kaum gezweifelt werden.

\section{Migration mobilisiert}

Migration mobilisiert, und das in zwei Richtungen. Zum einen mobilisiert sie in Form des zivilgesellschaftlichen Engagements, so in der Flüchtlingshilfe. Sie hat darüber hinaus zu einer Willkommens- und Anerkennungskultur beigetragen, die Deutschland in jenen Tagen und Wochen entwickelte. Auf der anderen Seite war gleichzeitig aber eine zunehmende Verhärtung derjenigen zu beobachten, die sich gegen die »Willkommenskultur«, gegen die Politik Angela Merkels, die Flüchtlingshilfe und die Zuwanderung positionierten.

Zum Engagement in der Flüchtlingshilfe wissen wir aus Forschungsprojekten etwas über den Umfang, die Motivation und die sozio-demographische Zusammensetzung der Beteiligung (siehe dazu auch die Beiträge von 
Poweleit und van den Berg et al. in diesem Band). Wir können davon ausgehen, dass sich etwa sieben bis acht Prozent der deutschen Bevölkerung sehr aktiv in der Flüchtlingshilfe beteiligt haben (dabei bleiben Geld- und Sachspenden unberücksichtigt), in Westdeutschland war das Engagement größer als in Ostdeutschland, und je höher der formale Bildungsgrad, desto höher war auch die Beteiligung. Engagiert haben sich viele zunächst in informellen Kontexten und damit nicht in Kirchen oder Wohlfahrtsverbänden. Davon haben 84 Prozent in einer Allensbach-Umfrage angegeben, das Motiv für ihr Engagement sei soziale Gerechtigkeit; 23 Prozent der Befragten führten an, sich dadurch am politischen Leben beteiligen zu wollen, und dies gerade in den schwierigen Wochen des Herbstes 2015. Gearbeitet haben die freiwilligen Helfer nach eigenen Angaben etwa 5 bis 6 Stunden in der Woche. 88 Prozent gaben an, sie hätten ein gutes Verhältnis zu den Flüchtlingen; aber: 28 Prozent sagten, dass sie angefeindet worden seien von anderen Mitgliedern der Bevölkerung oder aus ihrem sozialen Nahbereich.

Die ehrenamtliche Flüchtlingshilfe war sicherlich einer der wichtigsten Faktoren bei der Bewältigung der unmittelbaren Probleme bei Aufnahme und Versorgung von Geflüchteten, bei Fahrdiensten, in der Begleitung bei Gängen zu Ämtern, bei der sprachlichen Verständigung und bei der Betreuung sog. unbegleiteter minderjähriger Geflüchteter. Dabei hat sich auch, wie erste Studien zeigen, ein neues Verhältnis zwischen Zivilgesellschaft und der Verwaltung, vor allem auf kommunaler Ebene, herausgebildet. So lassen sich hier Muster einer »neuen Governance« im Bereich von Ersthilfe und Integrationsmaßnahmen beobachten. Zwischen den Ehrenamtsstrukturen der Zivilgesellschaft, der Wohlfahrtspflege und lokalen Verwaltungen hat sich ein sehr enges Koordinationsverhältnis herausgebildet, das für manche Kommunen eine ganz neue Erfahrung darstellt. In Ostdeutschland beispielsweise besaß man keine oder nur äußerst geringe Erfahrung, wie man in kurzer Zeit mit der Zuweisung einer hohen Zahl von Geflüchteten umgehen sollte. Das erklärt im Übrigen auch manche heftigen Gegenreaktionen in der ersten Zeit. Aber es hat dann doch sehr schnell auch in einigen, wenngleich nicht in allen Kommunen eine sehr aktive Zivilgesellschaft in Form von Helferkreisen gegeben, die mit den Kommunen Formen unterstützender Kooperation zu entwickeln wussten. Dadurch hat sich etwas verändert zwischen den zivilgesellschaftlichen Akteuren und den staatlichen administrativen Strukturen, vor allen Dingen auch die Anerkennung des freiwilligen Engagements durch die Kommunen. Dadurch ließen sich auch in präventiver Weise potenzielle Interessenkonflikte vermeiden. 
Interessant ist auch, wie groß das Engagement von Personen mit Migrationshintergrund ist. Hierzu gibt es auch einige wenige Studien. Zwei Aspekte sind vor allen Dingen wichtig. Zunächst gibt es einen markanten Unterschied: Personen mit Migrationshintergrund sind stärker in den eigenen Migranten-Communities engagiert. Sie arbeiten eher in informellen sozialen Netzwerken im Umfeld von Verwandtschaft und Nachbarschaft und in Bereichen der gegenseitigen Hilfe und Selbsthilfe in den jeweiligen ethnischen Gemeinschaften. Mit zunehmender Dauer des Aufenthaltes zeigt sich aber, zweitens, dass es eine große Bereitschaft gibt, sich auch außerhalb der eigenen ethnischen oder migrantischen Community zu engagieren. Migranten engagieren sich zunehmend in der Mehrheitsgesellschaft und in zentralen gesellschaftlichen Bereichen, so dass Grund zur Annahme besteht, dass es im Generationenverlauf, mit der zweiten Generation, im Hinblick auf das zivilgesellschaftliche Engagement Angleichungsprozesse im Verhalten zwischen der Bevölkerung mit und ohne Migrationshintergrund gibt.

\section{Spaltet Migration?}

Mein dritter Punkt beschäftigt sich mit der Frage: Spaltet Migration Gesellschaften? Sind Fluchtbewegungen die Ursache für politische Polarisierungen, wie sie in Deutschland zwischen einer »Willkommenskultur« hier und den Kritikern dort erkennbar geworden ist? Die Antwort ist komplex, auch wenn prima facie der Eindruck entstanden sein mochte, dass die Ereignisse vom Herbst 2015 die Verwerfungen in den Gesellschafen und zwischen den Staaten Europas bewirkt hätten. Unbestritten ist, dass infolge der sogenannten Flüchtlingskrise von 2015 der Rechtspopulismus in Deutschland, auch der Rechtsextremismus, an Terrain gewonnen haben und politisch motivierte Gewalt signifikant zugenommen hat. Das zeigt der Zugewinn an Stimmen für die AfD bei Landtags- und Bundestagswahlen, das belegen die Fallzahlen im Bereich von Hassgewalt, der Tätlichkeiten gegenüber Asylbewerberheimen, Flüchtlingen, Ausländern und vermeintlich »fremd « aussehenden Menschen in Deutschland. In Ostdeutschland sind die Zuwächse im Übrigen stärker ausgefallen als in Westdeutschland, wenngleich hier die offiziellen Statistiken für einige Bundesländer ebenfalls erschreckend hohe Zahlen ausweisen.

Des Weiteren ist ohne Frage infolge der Zuwanderung von 2015 der öffentliche Diskurs entschieden rauher geworden, haben sich Hass, Hetze und Herabwürdigung in den sozialen Netzwerken verbreitet. Zugleich hat Migra- 
tion nicht nur in Deutschland sondern auch in anderen europäischen Ländern zu Spaltungseffekten geführt. Ivan Krastev argumentiert, dass es eine neue Spaltung zwischen West/Nordeuropa auf der einen und Ost/Mitteleuropa auf der anderen Seite gibt. In der Tat hat sich bei der Frage der Verteilung und der Aufnahmequoten von Flüchtlingen in Ostmitteleuropa eine Resistenz gezeigt, die im Wesentlichen darauf zurückzuführen ist, dass Immigration vor allem aus Nicht-EU-Staaten in diesen Ländern abgelehnt wird. In den anderen EU-Staaten sieht das anders aus, aber auch dort war zwischenzeitlich, so in der Jahreswende 2015/16, die Skepsis gegenüber Zuwanderung größer geworden.

Wie kann man erklären, dass es zu diesen Mobilisierungen, Polarisierungen und Spaltungstendenzen gekommen ist? Eine Möglichkeit der Erklärung besteht darin anzunehmen, dass die Bevölkerung in toto skeptischer, gar ablehnend, gegenüber Einwanderung geworden ist und sich durch die sogenannte Flüchtlingskrise 2015 die Einstellungen gegenüber Migration erheblich zum Negativen hin verändert haben. Das aber ist nicht der Fall: Ausweislich der kontinuierlich erhobenen Daten des Eurobarometers sind seit 2015 die Einstellungen gegenüber Migration in den europäischen Staaten, auch in Deutschland, nicht negativer geworden. Im Gegenteil, sie sind gegenüber Flüchtlingen sogar positiver geworden. In den Eurobarometer-Daten gibt es jedoch einen kleinen Einbruch zu Beginn des Jahres 2016, da gehen die Zustimmungsraten etwas herunter. Aber dann steigen sie wieder, und sie sind heute höher als vor 2015. Gewiss, andere Befragungen lassen eine klare Tendenz erkennen, dass der Zuzug von Flüchtlingen in irgendeiner Weise zu begrenzen sei. Aber es ist kein Anwachsen xenophober oder islamophober Einstellungen zu registrieren. Etwas anderes gilt für Ost- und Mitteleuropa. In diesen Staaten wird vor allem die Einwanderung aus Nicht-EU-Staaten über Jahre konstant entschieden negativer beurteilt.

Es kann also, zumindest für die Staaten Nord-, West- und Südeuropas nicht an den Einstellungen der Bürger liegen. Hingegen liegt es - so meine These - an der Bedeutung des Themas Integration und Migration in der Öffentlichkeit. Das hängt sehr stark davon ab, wie die Medien solche Themen behandeln. Man kann beobachten, dass die Mediennennungen seit dem Herbst 2015 erheblich zugenommen haben. Und bei Befragungen nach dem wichtigsten politischen Thema stand Migration lange Zeit auf Platz eins. Das ist mittlerweile wieder etwas anders. Andere Themen wie Sicherheit, Bildung, Erziehung oder auch Arbeitsplätze spielen wieder eine größere Rolle. Aber ganz ist das Thema Migration nicht aus dem Fokus der Befragten verschwun- 
den. Wenn dieses Thema als so bedeutsam angesehen wird und eine so große Medienresonanz erzeugt wird, dann gibt es für politische Akteure, in diesem Fall rechtspopulistische oder rechtsextreme politische Parteien, eine günstige Gelegenheit, dieses Thema für sich zu nutzen, es zu skandalisieren und auf diese Weise Gefolgschaft zu mobilisieren. So wird man von einer Wirkungskette sprechen können: Die plötzliche, schnelle und große Fluchtbewegung des Herbstes 2015 hat dem Thema Migration in den Medien und in der Öffentlichkeit eine besondere Aufmerksamkeit verschafft - vor allem auch, weil es zuvor weitgehend sunsichtbar « geblieben war -, was es wiederum migrationsfeindlichen zivilgesellschaftlichen und politischen Akteuren leicht machte, mit der Migrationsfrage verbundenen Ängste, Befürchtungen und Ressentiments in Teilen der Bevölkerung zu mobilisieren.

Sicherlich wäre es verkehrt, in der Migration die Ursache für gesellschaftliche Spaltungen und politische Polarisierungen zu sehen. Migration aber ist ein Katalysator für den schnellen Aufstieg des Rechtspopulismus in den letzten Jahren gewesen. Und gleichzeitig hat die Migrationsthematik wie ein Brennglas gewirkt, in dem soziale Verwerfungen deutlicher sichtbar wurden: Erstens solche kultureller Natur, vor allem die Unterschiede zwischen urbanen, weltoffenen und liberalen Lebensformen auf der einen Seite und traditionellen, wertkonservativen und regional bestimmten Lebensstilen auf der anderen Seite; zweitens solche sozioökonomischer Natur, zwischen, grob formuliert, den Gewinnern und den Verlierern im Prozess von Globalisierung und Digitalisierung; und drittens schließlich solche zwischen junger Bevölkerung in verdichteten urbanen Räumen und einer immer älter werdenden Bevölkerung in den peripheren Regionen, die sich vielfach - so auch durch den öffentlichen Verkehr, die Gesundheitsversorgung oder staatliche Dienstleistungen - abgehängt fühlen. Dies sind nur Beispiele von strukturellen Spannungen, die sich diskursiv und politisch entladen haben und die wiederum zu einer Polarisierung zwischen sich verfestigenden Milieus führen - mit ganz unterschiedlichen Formen zivilgesellschaftlicher Aktivität.

\section{Wie kann man diese Spaltungen überwinden?}

So ohne weiteres lassen sich die gegenwärtig beobachtbaren Spannungen nicht beheben, deshalb geht es darum, sie einzuhegen. Das Entscheidende wird sein, eine zivilgesellschaftliche Streitkultur zu entwickeln - oder dort, wo sie (noch) vorhanden ist, zu erhalten und zu stärken. Es wird darum ge- 
hen müssen, mittels Dialogforen, demokratischen Aktions- und politischen Mediationsformen sowie dem Knüpfen von Netzwerkstrukturen Auswege aus den identitätspolitischen Schützengräben mit ihren Feindbildkonstruktionen und Angstszenarien zu finden. Ohne Toleranz, Respekt und Kooperationsbereitschaft lässt sich auf Dauer eine demokratische Gesellschaft der Vielfalt nicht aufrechterhalten. Die Gleichzeitigkeit von Solidarität und Empathie auf der einen Seite, und von Wut, Hass und Verachtung auf der anderen Seite, wie sie infolge der Ereignisse vom Herbst 2015 festzustellen war, hat Demokratie und Zivilgesellschaft in Deutschland einer harten Bewährungsprobe ausgesetzt.

\section{Literaturhinweise}

Bundesministerium für Familie, Senioren, Frauen und Jugend (BMFSFJ) (2017): Engagement in der Flüchtlingshilfe - Ergebnisbericht einer Untersuchung des Instituts für Demoskopie Allensbach. Berlin: BMFSFJ.

Dennison, James/Geddes, Anthony (2018): A Rising Tide? The Salience of Immigration and the Rise of Anti-Immigration Political Parties in Western Europe. In: The Political Quarterly, 90(1), S. 107-116.

Karakayali, Serhat (2018): Ehrenamtliches Engagement für Geflüchtete in Deutschland. IMIS (Institut für Migrationsforschung und Interkulturelle Studien), Flucht: Forschung und Transfer. State of Research Papier 09. Osnabrück: IMIS.

Klie, Thomas/Klie, Anna Wiebke (Hg.) (2018): Engagement und Zivilgesellschaft. Expertisen und Debatten zum Zweiten Engagementbericht. Wiesbaden: VS-Verlag.

Krastev, Ivan (2017): Europadämmerung. Berlin: Suhrkamp.

MIDEM (Mercator Forum Migration und Demokratie): Migration und Populismus. MIDEM Jahresbericht 2018. Hg. von Hans Vorländer, Dresden.

Vorländer, Hans/Herold, Maik/Schäller, Steven (2016): Pegida. Entwicklung, Zusammensetzung und Deutung einer Empörungsbewegung. Wiesbaden: VS-Verlag.

Vorländer, Hans/Herold, Maik/Schäller, Steven (2018): Pegida and New RightWing Populism in Germany. Cham: Palgrave Macmillan. 


\title{
Zivilgesellschaft in der Migrationsgesellschaft Die Geschichte von »Asyl im Oberland»
}

\author{
Julia Poweleit
}

Während der neuen Flüchtlingsbewegung um das Jahr 2015 gab es einige Aufund Umbrüche im zivilgesellschaftlichen Engagement. Um einen Einblick in aktuelle Formen des Engagements zu geben, wird hier die Geschichte von »Asyl im Oberland« vorgestellt. Das ist ein Beispiel aus der ehrenamtlichen Flüchtlingshilfe in Oberbayern, dem Landkreis Weilheim-Schongau, welche sich erst auf die konkrete Unterstützung vor Ort konzentrierte und später darüber hinaus auch überregionale Strukturen ausbildete.

Mit den ersten Geflüchteten, die in den Landkreis Weilheim-Schongau kamen, entstanden dort auch die ersten Asylhelferkreise. In jeder Gemeinde, in denen Geflüchtete untergebracht wurden, fanden sich spontan interessierte Menschen, die helfen wollten - zu Beginn sogar meist mehr als Flüchtlinge einer Gemeinde zugeteilt waren. Diese Unterstützerkreise setzten sich aus den unterschiedlichsten Menschen des Ortes zusammen, die sich vorher meist nicht oder nicht sehr gut kannten, sondern nur durch den gemeinsamen Wunsch, in dieser Situation zu helfen, verbunden waren. Viele der Helfer erzählten später, dass sie sich durch die ehrenamtliche Arbeit im Asylbereich selbst erst richtig in ihre Gemeinde und den Landkreis integriert hätten. Kennzeichen dieser Unterstützerkreise war zudem, dass diese häufig als loser Verbund agierten, ohne Rückbindung an eine Organisation, die Kirche, die Gemeinde oder einen Verein. Dies ermöglichte es ihnen, unbürokratisch, eigenverantwortlich und flexibel $\mathrm{zu}$ reagieren. Im Fokus dieser ersten Zeit stand die Unterstützung der Geflüchteten bei der ersten Orientierung in der neuen Lebenssituation durch das gegenseitige Kennenlernen, Unternehmungen in der Region, Begleitung bei Behördengängen, Organisieren alltäglicher Dinge (Internet, Kleidung, Fahrräder) sowie das Unterrichten der deutschen Sprache. 


\section{Neue Strukturen vor Ort}

Von Beginn an vernetzten sich die Helfer im Landkreis Weilheim-Schongau unter dem Namen »Asyl im Oberland«. Sie organisierten und strukturierten sich innerhalb des Landkreises, um für sich selbst Austauschplattformen zu schaffen und etablierten regelmäßige Treffen mit den zuständigen Behörden vor Ort. Sehr schnell arbeiteten sich die ehrenamtlichen Helfer in komplizierte Sachverhalte rund um das Thema Asyl ein - ihr Sachwissen war oftmals detaillierter als das der Hauptamtlichen, die sich aufgrund eines späteren Einstiegs erst in die verschiedenen Bereiche einarbeiten mussten. Das Internet ermöglichte den Ehrenamtlichen, sich schnell zu informieren und zu vernetzen - an hauptamtlichen Instanzen vorbei. So verfügten die Unterstützerkreise meist schneller über aktuelle Informationen als die zuständigen Behörden oder Kommunen.

Mit der Zeit zeigte sich, dass sich die Hilfe nicht, wie anfangs gedacht, auf eine erste Unterstützung in der »Not« beschränkte, sondern Wissen über verschiedene Bereiche des alltäglichen Lebens (wie Arbeit, Wohnen etc.) sowie spezifischeres Wissen über rechtliche Grundlagen des Asylrechts und der Sozialgesetzgebung gebraucht wurden. Zwar gab es bereits einige Stellen im Ausländeramt des Landratsamtes Weilheim-Schongau oder die Asylsozialund Migrationsberatung bei den Wohlfahrtsverbänden, die für diese Bereiche zuständig waren, jedoch konnten diese den Flüchtlingshelfern nicht die umfangreiche fachliche und zeitliche Unterstützung bieten, die diese gebraucht hätten.

Die Ehrenamtlichen von Asyl im Oberland initiierten 2016 deshalb ein Treffen mit den verschiedenen freien und staatlichen Trägern des Landkreises und forderten hauptamtliche Unterstützung für ihr Engagement. Als Ergebnis dieses Treffens wurden noch im selben Jahr zwei hauptamtliche Ehrenamtskoordinatorenstellen geschaffen, welche von der Herzogsägmühle (Innere Mission), dem Caritasverband Weilheim-Schongau, der Diakonie Oberland, dem Landkreis Weilheim-Schongau sowie aus Mitteln der bayerischen Staatsregierung finanziert wurden. Der Trägerverbund, zu dem sich die verschiedenen Träger bei diesen Treffen zusammenschlossen, war in Bayern ein einmaliges, beispielhaftes Konstrukt der guten Zusammenarbeit - ein Leuchtturmprojekt!

Neben diesen strukturellen Neuerungen auf der hauptamtlichen Seite suchten die Ehrenamtlichen auch einen Weg, sich selbst neu zu strukturieren. Inhaltlich waren sie meist sehr gut strukturiert durch einen ehrenamtlichen 
Koordinator, der die Kontakte verwaltete, zu regelmäßigen Treffen einlud und sich auf regelmäßigen Koordinatorentreffen mit den umliegenden Unterstützerkreisen vernetzte sowie durch die Helfer, die sich mehr und mehr auf einen der vielfältigen Bereiche spezialisierten, diesen organisierten und koordinierten.

Formell waren sie jedoch als loser Verbund engagierter Menschen immer wieder auf Kooperationen mit etablierten Organisationen angewiesen, wenn sie beispielsweise Räume anmieten oder Spenden verwalten wollten. Um ihre Autonomie zu stärken, ohne dabei selbst eine formale Struktur zu werden, gründeten die Helfer 2017 einen landkreisweiten Verein, den »Förderverein Asyl im Oberland e.V.«. So wurde es einerseits möglich, dass die Unterstützerkreise weiterhin als lose Vereinigung unbürokratisch und flexibel agierten, andererseits wurde somit der Handlungsspielraum vergrößert, da sie nun nicht länger auf Kooperationen angewiesen waren.

\section{Der Wind dreht sich, die Frage ist: Schaffen wir das?}

Dabei kristallisierte sich mehr und mehr die Notwendigkeit heraus, auch über die konkrete ehrenamtliche Arbeit vor Ort hinaus etwas zu bewirken, denn die Hilfe vor Ort bröckelte: überall traten Ehrenamtliche zurück. Viele waren von dem zeitlich und emotional intensiven Engagement in der Flüchtlingshilfe erschöpft, andere resignierten aufgrund der Situation, in der viele Geflüchtete sich befanden: Das lange Warten auf den Asylbescheid in einer Unterkunft, in der man sich meist zu viert ein Zimmer teilte, ohne gezielte Tätigkeit wegen mangelnder Arbeitserlaubnis und fehlenden Deutschkursen sowie die hinzukommende unsichere Zukunftsperspektive aufgrund des unbekannten Ausgangs des eigenen Asylverfahrens. Der wichtigste Grund für den Rückgang des Engagements war jedoch der Ärger über die bayerische Politik. Zwar wurde in Bayern manches Positive auf den Weg gebracht, wie beispielsweise die unbürokratische finanzielle Unterstützung der ehrenamtlichen Deutschkurse, die Abschaffung von Essenspaketen oder die Unterbringung in dezentralen Unterkünften. Dieses positive Klima, welches mit der »Wir schaffen das«Aussage der Bundeskanzlerin im Sommer 2015 verbunden wird, änderte sich schleichend, bis es sich schlagartig komplett drehte.

Auslöser dafür waren unter anderem Ereignisse wie die Silvesternacht in Köln, die sehr große mediale Aufmerksamkeit erhielt, sowie Berichte von bereits zu Beginn skeptischen Bürgern oder mittlerweile desillusionierten Hel- 
fern, die die Integration als gescheitert ansahen. Hinzu kam die zunehmende öffentliche Präsenz einer neuen Partei, der AfD, die diese einzelnen Ereignisse aufgriff, verallgemeinerte und als Grund für die Unzufriedenheit vieler Bürgern sah. Die bayerische Staatsregierung reagierte und verabschiedete neue Regelungen und Gesetze. Die Konsequenzen trafen vor allem die Asylsuchenden hart: Der ersehnte Familiennachzug wurde ausgesetzt, Arbeitsverbote erlassen, Ankerzentren geplant und vermehrte Abschiebungen wurden angekündigt. Zugleich wurde versucht, die Helferbewegung mithilfe einer neuen Organisationsstruktur und Beratungsrichtlinien für hauptamtliche Akteure zu transformieren, so dass die ehrenamtliche Arbeit nicht mehr nur unterstützt, sondern zudem gesteuert werden konnte. Viele der neu geschaffenen Stellen wurden dem Landratsamt unterstellt, aus Ehrenamtskoordinatoren wurden Integrationslotsen und aus ehrenamtlichen Flüchtlingshelfern ehrenamtliche Integrationsbegleiter. Viele Helfer fanden dies übergriffig und bezogen nun immer mehr öffentlich Stellung.

\section{3. Überregionale Vernetzung und Politisierung des Ehrenamtes}

Im Jahr 2015 lud Asyl im Oberland in Kooperation mit der Plattform www.asylhelfer.bayern alle umliegenden Unterstützerkreise zu einem gemeinsamen »Asylgipfel« in Weilheim ein - diese Austauschtreffen wurden etabliert und erweitert. Mittlerweile treffen sich nicht nur die oberbayerischen Helferkreise zwei Mal im Jahr - auch Ostbayern, Franken und Schwaben vernetzten sich auf ähnliche Weise. Höhepunkt dieser Treffen war am 3. Oktober 2018 der erste gesamtbayerische Asylgipfel der Helferkreise in München. ${ }^{1}$

Sie wurden sich der politischen Dimension ihrer Tätigkeit bewusst und traten zunehmend in Opposition zur bayerischen Staatsregierung. Auf dem dritten oberbayerischen Asylgipfel in Tutzing wurde die »Tutzinger Resolution « verfasst, welche Forderungen an die Politik beinhaltete. 2017 kamen 1000 Flüchtlingshelfer bei einer Sternfahrt nach München unter der Bavaria zusammen, um ihren Forderungen Nachdruck zu verleihen. Auch andere ehrenamtliche Verbände wurden aktiv. 2017 fand die erste Vollversammlung aller 
Flüchtlingshelfer auf dem Marienplatz in München statt, weitere öffentlichkeitswirksame Aktionen und Demonstrationen folgten.

Bald darauf wurden die ehrenamtlichen Organisatoren der bayerischen Asylgipfel zu Gesprächen in die zuständigen Landesministerien eingeladen, um die Forderungen der ehrenamtlichen Helfer zu besprechen. Diese Gespräche etablierten sich und mündeten in regelmäßigen Treffen der Helfer mit dem Innenministerium. Parallel dazu gründete sich auch ein bayerischer Landesverband der Flüchtlingshelfer (»Unser Veto«) als politischer Arm der Bewegung, dessen Vertreter an den Asylgipfeln sowie an den Gesprächen im Innenministerium teilnehmen und darüber hinaus regelmäßige Stellungnahmen verfassen und Informationen gebündelt weiterleiten.

Dabei sehen sich die ehrenamtlichen Flüchtlingshelfer nicht nur als Vermittler, die ihre Erfahrung und Expertise von der Basis in Gesprächen mit der Regierung einbringen, sie nehmen gleichzeitig auch eine kontrollierende Funktion ein. So brachten die Ehrenamtlichen auf dem vierten oberbayerischen Asylgipfel im Sommer 2017 eine Normenkontrollklage gegen die überhöhten Unterkunftsgebühren, welche die Geflüchteten zahlen sollten, auf den Weg. Auf Bitten der Asylgipfelorganisatoren beauftragte der bayerische Flüchtlingsrat einen Anwalt, der Klage gegen die bayerische Staatsregierung einreichte. Am 16. Mai 2018 wurde der Klage stattgegeben, die Regierung musste ihre Bescheide zurückziehen und für die Zukunft neu berechnen.

Auf dem ersten gesamtbayerischen Asylgipfel der Helferkreise kurz vor der bayerischen Landtagswahl im Oktober 2018 erarbeiteten die Helfer Handlungsempfehlungen an die neue Regierung, welche sie dieser nach der Wahl überreichten und in weiteren Treffen mit dem Innenministerium besprachen.

\section{Zivilgesellschaftliches Engagement - eine Chance für unsere Gesellschaft?}

Die hier dargestellte Geschichte ist ein Beispiel dafür, wie innerhalb kurzer Zeit eine neue zivilgesellschaftliche Bewegung entstehen kann und sich über mehrere Jahre selbstorganisiert und außerhalb bestehender Strukturen engagiert. Die Flüchtlingshelferbewegung etablierte in den letzten Jahren ehrenamtliche, autarke Strukturen, die mittlerweile bis in die Regierungsebene reichen. Dies geht weit über die anfängliche Motivation, Geflüchteten zu helfen, hinaus. Trotz Herausforderungen und auch Rückschlägen, denen sich 
die Helfer aufgrund der politischen und gesellschaftlichen Veränderungen in dieser Zeit, gegenübersahen, blieben die Helfer vor Ort und damit die ganze Bewegung aktiv. So konnten auch immer wieder Erfolge verzeichnet werden.

In diesem Beispiel wird ein Bild von einer starken, engagierten Zivilgesellschaft skizziert, die sich aktiv in die Gestaltung der politischen und gesellschaftlichen Verhältnisse miteinbringen möchte und die bereit ist, Verantwortung zu übernehmen. Ziel weiterer Entwicklungen darf deshalb nicht sein, zivilgesellschaftliches Engagement in professionelle Strukturen zu überführen, sondern vielmehr das offene, rebellische, friedliche und kreative Engagement der Bürger zuzulassen, denn hierin liegt der Kern einer demokratischen Gesellschaft. 


\section{Umbrüche III: \\ Corona als Herausforderung \\ für die Zivilgesellschaft}





\section{Was wird aus dem harten Kern? Auswirkungen der Corona-Krise auf das Engagement für Geflüchtete}

Clara van den Berg, Edgar Grande, Swen Hutter

\section{Einleitung: Krisen und Katastrophen als Sternstunden der Zivilgesellschaft?}

Katastrophen und Krisen sind immer eine Herausforderung für die Zivilgesellschaft. ${ }^{1}$ Sie führen zu unvorhergesehenen Notlagen und bringen neue Formen der Hilfsbedürftigkeit hervor. In solchen Notsituationen ist nicht nur der Staat gefordert, darin zeigen sich auch die spontane Hilfsbereitschaft und die Solidarität der Bürger. Diese Solidarität lässt sich nicht anordnen, sie beruht auf dem sozialen Kapital einer Gesellschaft, also den Beziehungsnetzwerken, in die die Menschen eingebunden sind, und dem Vertrauen, das sie ihren Mitbürgern und den öffentlichen Institutionen entgegenbringen (vgl. Putnam 1993). Gerade in Katastrophen und Krisen zeigt sich die große Bedeutung des sozialen Kapitals und die Stärke der Zivilgesellschaft besonders deutlich aber auch deren Grenzen.

In der Corona-Pandemie spielte die Zivilgesellschaft von Beginn an eine wichtige Rolle. Nach dem Lockdown im März 2020 waren mannigfaltige Formen des solidarischen Engagements und der spontanen gegenseitigen Hilfe zu beobachten. Die Zivilgesellschaft stärkte solidarisches Verhalten, sie unterstützte Hilfsbedürftige bei der Bewältigung von Notlagen, sie vernetzte die Bürger, sie artikulierte aber auch Kritik und machte auf Missstände aufmerksam (vgl. Springer 2020). In einer repräsentativen Umfrage der Universität Konstanz gaben im April und Mai 2020 rund die Hälfte der Befragten an, 
anderen Menschen geholfen zu haben. Zugleich belief sich der Anteil derjenigen, die Unterstützung durch andere Menschen erhalten hatten, auf etwa 16 Prozent (Koos/Bertogg 2020, S. 3).

Katastrophen und Krisen können die Zivilgesellschaft aber auch schwächen (vgl. Wang und Ganapati 2018). Diese Ambivalenz zeigte sich in der Corona-Krise besonders deutlich. Sie hat die Bürger nicht nur aktiviert, sie hat die Möglichkeiten des bürgerschaftlichen Engagements auch erheblich eingeschränkt - und es ist zu befürchten, dass einige dieser Einschränkungen noch längere Zeit weiter bestehen werden. Aufgrund der Maßnahmen zur Eindämmung der Pandemie sind weite Teile der Zivilgesellschaft monatelang zum Stillstand gekommen. Die Beschränkungen des öffentlichen Lebens, die zur Bekämpfung der Corona-Pandemie eingeführt wurden, haben drastisch vor Augen geführt, dass der Zugang zum öffentlichen Raum und die Möglichkeit des gemeinsamen Handelns vor Ort für das bürgerschaftliche Engagement unverzichtbar sind. Die Nationale Akademie der Wissenschaften Leopoldina kam in ihrer Stellungnahme vom 13. April 2020 zum Ergebnis:

»Die aktuellen Maßnahmen zur Verlangsamung der Ansteckungen führen [...] zu einer empfindlichen Schwächung der Zivilgesellschaft. [...] Die Aktivitäten der Vereine - von den Sport- und Kulturvereinen über Freundes- und Fördervereine bis zu den Basisorganisationen des politischen und kirchlichen Lebens - sind größtenteils eingestellt. Große Bereiche der organisierten Zivilgesellschaft existieren aktuell lediglich in digital geknüpften Netzwerken in geschrumpfter Form.«

Wird sich die Zivilgesellschaft von den Folgen dieser Kontaktbeschränkungen wieder erholen, oder ist zu befürchten, dass das Engagement dadurch nachhaltig geschwächt wird? Wir gehen dieser Frage am Beispiel des ehrenamtlichen Engagements mit und für Geflüchtete in Deutschland nach. Die freiwilligen Hilfsangebote für Geflüchtete waren von den Kontaktbeschränkungen, die zur Eindämmung der Pandemie beschlossen wurden, in besonderer Weise betroffen. Die neue "Bürgerbewegung«, die in diesem Bereich im Herbst 2015 entstanden war, »lebt von der persönlichen Begegnung zwischen Einheimischen und Geflüchteten « (Schiffauer 2017, S. 21). Sie ist deshalb in ihren Handlungsmöglichkeiten durch Kontaktverbote und den begrenzten Zugang zum öffentlichen Raum erheblich eingeschränkt.

Welche Auswirkungen hat die Corona-Krise auf die Strukturen und Formen des Engagements mit und für Geflüchtete, die sich nach 2015 herausgebildet haben? In diesem Beitrag möchten wir erste Antworten auf diese 
Frage geben. Als empirische Grundlage dienen uns qualitative Interviews mit neun freiwillig in Vereinen und Initiativen Engagierten, drei hauptamtlichen Ehrenamtskoordinatoren und einer Integrationsbeauftragten. Sowohl die Ehren- als auch die Hauptamtlichen verfügen in ihrer Stadt über einen umfassenden Einblick in das Geflüchtetenengagement und haben dort mehrheitlich auch die Entwicklung des Engagements seit 2015 aktiv gestaltet. Die semi-strukturierten Interviews zu den Auswirkungen der Corona-Krise wurden zwischen April und August 2020 telefonisch durchgeführt. Wir ergänzen diese Interviews stellenweise um Auszüge aus der lokalen und nationalen Presseberichterstattung. Zudem können wir uns auf vier Interviews stützen, die wir kurz vor Beginn der Pandemie im Rahmen eines laufenden Verbundprojekts zur nachhaltigen Wirkung von bürgerschaftlichem Engagement mit und für Geflüchtete geführt haben. ${ }^{2}$

Unsere Ausführungen konzentrieren sich auf ausgewählte Mittelstädte in drei Bundesländern (Bayern, Baden-Württemberg und Brandenburg). Diese Auswahl kann zwar keine Repräsentativität beanspruchen, auf diese Weise können aber dennoch wichtige regionale und landespolitische Unterschiede berücksichtigt werden. So war die bayrische Engagementlandschaft in der Geflüchtetenhilfe in den vergangenen Jahren durch eine Vielzahl an aktiven, lokalen Helferkreisen gekennzeichnet, die sich seit 2015 mit einer zunehmend restriktiveren Asylpolitik der Landesregierung konfrontiert sahen (siehe dazu auch den Beitrag von Poweleit in diesem Band). Im Unterschied dazu zeichnet sich Baden-Württemberg durch eine stärkere staatliche Förderung und öffentliche Anerkennung des Geflüchtetenengagements aus. Auch das Engagement in Brandenburg ist von einer weniger restriktiven Landespolitik geprägt, traf jedoch im Jahr 2015 auf eine teilweise politisierte Zivilgesellschaft, die in einigen Teilen des Bundeslandes Konflikte zwischen Gegnern einer offenen Asylpolitik und Unterstützern sichtbar machte (siehe HeinrichBöll-Stiftung 2016).

2 Das Projekt »Die aktivierte Zivilgesellschaft - Eine Analyse der nachhaltigen Wirkung von bürgerschaftlichem Engagement auf Sozialkapital und Cemeinwohl« ist ein Verbundvorhaben, an dem das Deutsche Zentrum für Integrations- und Migrationsforschung (DeZIM; Projektkoordinator), das Institut für Migrationsforschung und Interkulturelle Studien an der Universität Osnabrück (IMIS) und das Zentrum für Zivilgesellschaftsforschung am Wissenschaftszentrum Berlin für Sozialforschung (WZB) beteiligt sind. Es wird durch das Bundesministerium für Bildung und Forschung (BMBF) im Rahmen der Förderlinie »Teilhabe und Cemeinwohl« gefördert. Weitere Informationen finden sich auf der Projektwebsite www.aktivzivil.de. 
Die folgende Analyse erfolgt in drei Schritten. Im ersten Schritt beschreiben wir, in welcher Verfassung die Zivilgesellschaft im Bereich der Geflüchtetenhilfe vor der Corona-Pandemie war. Im zweiten Schritt untersuchen wir die unmittelbaren Auswirkungen der Corona-Krise auf das Engagement in diesem Bereich; und im letzten Schritt beschäftigen wir uns mit den längerfristigen Folgen der Beschränkungen auf das Engagement mit und für Geflüchtete.

\section{2. "Nur noch der harte Kern «: Zivilgesellschaftliches Engagement mit und für Geflüchtete vor der Corona-Pandemie}

Die Auswirkungen von Krisen und Katastrophen auf die Zivilgesellschaft hängen auch von deren Zustand, nicht zuletzt von der Stärke des vorhandenen sozialen Kapitals ab. Deshalb ist es wichtig zu wissen, in welcher Verfassung die Zivilgesellschaft im Bereich des Engagements mit und für Geflüchtete vor der Corona-Pandemie war. Im Folgenden geben wir einen kurzen Überblick über die Rolle der Zivilgesellschaft in der Geflüchtetenhilfe, ihre Aktivierung im Sommer 2015 und ihre weitere Entwicklung bis zum Frühjahr 2020.

Das öffentliche Bild der Geflüchtetenhilfe in Deutschland wird vor allem geprägt von der starken Aktivierung der Bürger und ihrer spontanen Hilfsbereitschaft in den Anfangsjahren, insbesondere im Spätsommer 2015. Die Bilder von hunderten Menschen, die am Münchner Hauptbahnhof warteten, um die Neuankömmlinge willkommen zu heißen, gingen um die Welt. Diese spontane Solidarität mit den Menschen, die vor allem aus Konfliktgebieten über die sogenannte Balkanroute nach Westeuropa flohen, gilt in der deutschen Zivilgesellschaft als beispiellos (Schiffauer 2018, S. 29). Nicht umsonst wird diese Zeit auch als »Herbst der Solidarität« bezeichnet.

Nach den Ergebnissen des Sozio-Oekonomischen Panels (SOEP) waren in den Jahren 2015 und 2016 knapp ein Drittel (32 \%) der deutschen Bevölkerung in mindestens einem der erfragten Bereiche mit und für Geflüchtete aktiv. Die große Mehrheit beteiligte sich mit Geld- und Sachspenden (28\%). Einen kleineren Teil machte das persönliche Engagement vor Ort (6\%) sowie die Beteiligung an Unterschriftenaktionen oder Demonstrationen (5\%) aus (vgl. Alscher et al. 2018, S. 380). Schiffauer (2017, S. 13) schätzte, dass sich in dieser Zeit über fünf Millionen Bürger in ca. 15.000 Projekten und Initiativen engagierten. 
Viele der neu gebildeten Projekte und Initiativen unterscheiden sich bewusst vom Engagement in Vereinen. Im Vergleich zum traditionellen Ehrenamt kennzeichnet das Engagement mit und für Geflüchtete laut einer Studie von Hamann et al. (2016:8) eine starke basisdemokratische Selbstorganisation mit flachen Hierarchien. Exemplarisch zeigt sich dies bei den Unterstützerkreisen in Oberbayern. Diese Unterstützerkreise sind unter anderem gekennzeichnet durch: Diversität unter den Netzwerkmitgliedern, flache Hierarchien, wenig Kontrolle, große Dynamik, Eigenverantwortlichkeit, Spontanität und Flexibilität (vgl. Herrmann 2018, S. 9). »Letztendlich«, so das Fazit der Studie von Hermann (2018, S 10), „verbindet nur eine Mailliste diese Menschen«. In diesen Organisationsstrukturen zeigt sich der allgemeine Strukturwandel der Zivilgesellschaft, der dadurch gekennzeichnet ist, dass feste, dauerhafte Bindungen an Vereine, Verbände und Parteien an Bedeutung verlieren, während gleichzeitig neue, flexiblere Formen des Engagements entstehen (vgl. Enquetekommission 2002).

Ein differenzierter Blick auf die Engagementlandschaft im Bereich Flucht und Migration zeigt, dass der Aktivierungsschub auch die formelle Zivilgesellschaft erfasste. So ist um 2015 ein Teil des ehrenamtlichen Engagements innerhalb von bestehenden Vereinen, Verbänden und Kirchengemeinden entstanden. Diese erweiterten etwa im Sport- und Kulturbereich häufig ihre üblichen Leistungen und Angebote, um so auch Geflüchtete miteinzubeziehen (vgl. Aumüller 2016, S. 4; Priemer et al. 2017, S. 38ff.).

Bereits 2016 reagierten allerdings viele Initiativen und Vereine auf Veränderungen im Bereich der Geflüchtetenhilfe mit einer Verlagerung und Neuausrichtung der Tätigkeitsbereiche und Themenfelder (vgl. Institut für Demoskopie Allensbach 2017, S. 15ff.). Ging es in der Anfangsphase vorwiegend um die Überwindung der drängendsten Versorgungs- und Unterbringungsprobleme, sind im Jahr 2016 eher Fragen der Bleibeperspektive und Integration von Geflüchteten in den Vordergrund gerückt. Ein immer größerer Umfang des Engagements entfiel auf Behördengänge, um bei Asylanträgen oder der Wohnungssuche zu unterstützen. Eine Untersuchung der Willkommensinitiativen in Brandenburg zeigt, dass dort viele Ehrenamtliche informell die Funktion von Integrationsbegleitern übernahmen (Lemmermeier/Gartz 2018, S. 4).

Ein wichtiges Merkmal der weiteren Entwicklung ist der starke Rückgang des Engagements. Die Einschätzung Schiffauers (2017, S. 13), dass sich das Engagement »sowohl in Hinsicht auf Qualität als auch auf Quantität seit dem Herbst 2015 auf hohem Niveau stabilisiert« habe, bestätigt sich in der 
Folgezeit nicht. Spätestens im Jahr 2017 begann die »neue Bürgerbewegung« zu schrumpfen. Am Beispiel Oberbayerns lässt sich dies wiederum exemplarisch zeigen. Dort entstanden allein im Landkreis Weilheim-Schongau bis 201528 Unterstützerkreise zur Betreuung von Geflüchteten. Bereits im Jahr 2017 nahm die Zahl der darin aktiven Helfer von 900 auf 660 ab. Bezogen auf die einzelnen Unterstützerkreise hieß dies:

»Von durchschnittlich 50 Teilnehmern der ersten Unterstützerkreistreffen, engagierten sich dann tatsächlich etwa 25 . Aus verschiedenen Cründen beendeten etwa 10 ihren Einsatz für Flüchtlinge nach ein bis zwei Jahren. Zurück blieben 10 Engagierte und 5 Unterstützer auf Abruf.« (Herrmann 2018, S. 18)

Die Gründe für den Rückgang an Ehrenamtlichen sind vielfältig und bisher noch nicht ausreichend erforscht. Er hatte nur bedingt etwas damit zu tun, dass die Zahl der Geflüchteten zurückging und die drängendsten Versorgungs- und Unterbringungsprobleme gemeistert waren (vgl. Erler et al. 2018, S. 12). Vorliegende Untersuchungen wie die Engagement-Studie des Allensbach Instituts (2017, S. 38) sowie eine Studie zur Entwicklung und Nachhaltigkeit von Willkommensinitiativen von Gesemann et al. (2019, S. 34ff.) deuten darauf hin, dass Schwierigkeiten mit Behörden sowie eine Überforderung mit der Freiwilligenarbeit bei einigen Ehrenamtlichen Frustration und Enttäuschung ausgelöst haben. Der Eindruck, dass die bestehenden rechtlichen und bürokratischen Hürden die erfolgreiche Integration von Geflüchteten beeinträchtigen und ihr Einsatz nicht zu den erhofften Erfolgen führt, sorgte sowohl unter den freiwillig Engagierten als auch unter den Geflüchteten für erhebliche Frustration. Ein Befragter in der Studie von Herrmann (2018, S. 21) bringt diese Frustration der Helfer prägnant zum Ausdruck: »Wir wollten mit den Flüchtlingen kochen und essen, Feste vorbereiten, Ausflüge machen. Dafür ist gar keine Zeit mehr. Nur noch Formulare ausfüllen und Behördengänge!«. Im Fall der oberbayerischen Unterstützerkreise kommt ein weiterer Faktor hinzu: Die zunehmend restriktivere Asylpolitik der bayerischen Landeregierung seit Dezember 2016. Die Studie von Herrmann kam Ende des Jahres $2017 \mathrm{zu}$ einem eindeutigen Ergebnis: "Hauptgrund, sich nicht mehr für Geflüchtete einzusetzen, ist mit Abstand der Ärger über die bayerische (Flüchtlings-)Politik.«(Hermann 2018, S. 28)

Die Fallstudie von Hermann (2018) hat auch gezeigt, dass unter den weiterhin aktiven Helfern eine erhebliche Frustration besteht: 
»Vielen Unterstützern macht dieses Ehrenamt gar nicht mehr wirklich Freude. Das wäre aber zu erwarten gewesen, denn natürlich soll das Ehrenamt Spaß machen, einen emotional positiv stärken. Warum engagiert man sich sonst im Sportverein, in der Blaskapelle, in der kirchlichen Jugendgruppe, beim Heimat- und Trachtenverein? Mehr als die Hälfte der etwa 600 Ehrenamtlichen im Landkreis ist eher frustriert als erfreut in ihrem Ehrenamt. Kombiniert mit dem teilweise überaus großen zeitlichen Engagement ist die Gefahr des Ausgebranntseins, das Gefühl der Überforderung sehr groß. [...] Nur knapp 10 Prozent erfahren rundum Freude in der Unterstützung der Geflüchteten.«(Hermann 2018, S. 24)

Daran hat sich in der Folgezeit wenig geändert. Auch die Ergebnisse unserer eigenen Studie machen deutlich, dass in Baden-Württemberg und Bayern viele freiwillig Engagierte schon vor Ausbruch der Pandemie auf Grund der strengen Asylpolitik und der mangelnden Erfolge in diesem Bereich frustriert und überfordert waren (E3, $\mathrm{E}_{5}^{3}$ ). Besonders die oftmals vergeblichen Bemühungen um Arbeitsgenehmigungen und die Beschaffung von Wohnraum für Geflüchtete haben zu einer Resignation unter vielen Beteiligten geführt.

»Viele Ehrenamtliche sind auf Crund der politischen Gegebenheiten frustriert, denn bei den Hauptthemen für Geflüchtete in Esslingen - Wohnen und Arbeit - können die Ehrenamtlichen nicht mehr weiterhelfen. Es besteht eine große Hoffnungslosigkeit unter den Ehrenamtlichen, denn es gibt wenig Möglichkeiten, Arbeitsgenehmigungen zu erwirken und auch sehr wenig, aber teuren Wohnraum, der für Ceflüchtete nicht in Frage kommt.«(Ehrenamtliche 3, Baden-Württemberg)

Laut einem Engagierten aus Bayern, der durch seine Netzwerkarbeit seit Jahren mit zahlreichen bayerischen »Helferkreisen« in Kontakt steht, verbessert sich die Lebenssituation vieler Geflüchteter kaum; allenfalls bei Menschen, die einen positiven Asylbescheid und die Arbeitserlaubnis erhalten. Zahlreiche Geflüchtete würden vergeblich auf ein Ergebnis im Asylverfahren warten oder einen negativen Bescheid immer wieder anfechten.

»Zu Anfang hatten viele Ehrenamtliche das Gefühl, dass sie in Bayern politisch noch etwas erreichen können [...]. Nun ist seit 2018 eine Resignation und Hoffnungslosigkeit unter den Ehrenamtlichen und Geflüchteten eingetreten.«(E5, Bayern) 
Diesen Eindruck teilt auch einer unserer Interviewpartner aus Brandenburg, der verdeutlicht wie zentral die politische Unterstützung auf kommunaler und bundespolitischer Ebene für die Zivilgesellschaft sein kann.

»Es ist unklar, warum das Engagement eingebrochen ist, doch liegt dies vermutlich zum einen an der Überforderung der Ehrenamtlichen und zum anderen an der mangelnden Unterstützung der Zivilgesellschaft. Die Kehrtwende in der Asylpolitik der Bundesregierung hat auch dazu geführt, dass sich Ehrenamtliche entmutigt fühlten. Merkel hatte zunächst eine schützende Hand über die Ehrenamtlichen gehalten, doch danach standen tausende Ehrenamtliche im Regen.«(E13, Brandenburg)

Der Rückzug aus dem Engagement für und mit Geflüchteten hat sich bis 2020 fortgesetzt. Viele Unterstützerkreise bestanden Anfang des Jahres 2020, vor dem Einsetzen der Corona-Pandemie, daher nur noch aus einem harten Kern an freiwillig engagierten Personen. Hinsichtlich des Fortbestands der Initiativen und Netzwerke selbst kommen Gesemann et al. (2019, S. 17) zu dem Ergebnis, dass etwa die Hälfte der 137 befragten Initiativen ihren Fortbestand als gesichert und $17 \%$ als anwachsend einschätzen. Die Ergebnisse machen jedoch auch deutlich, dass ein Viertel der Initiativen ihre Entwicklung als rückläufig und $7 \%$ sogar als bedroht sieht. Exemplarisch zeigt sich die Konzentration auf den harten Kern im Landkreis Weilheim-Schongau. Zwar bestanden dort im Frühjahr 2020 noch 27 der 28 Unterstützerkreise. Aber: »Manchmal sind sie schon sehr geschrumpft, dass man nicht mehr unbedingt von Kreisen reden kann, sondern vielleicht von Pärchen« (E14).

Insgesamt lässt sich basierend auf ersten Studien und unseren eigenen Interviews festhalten, dass sich die Zivilgesellschaft zur Unterstützung Geflüchteter bereits vor der Corona-Krise sowohl qualitativ als auch quantitativ gewandelt hatte. Während die Phase der Aktivierung im Sommer und Herbst 2015 durch Nothilfe und erste Betreuungsangebote für Geflüchtete gekennzeichnet war, rückten anschließend Aufgaben der längerfristigen Betreuung und Unterstützung bei Integrationsfragen in den Vordergrund. Gleichzeitig ist das Aktivierungsniveau deutlich gesunken. Vielerorts ist das freiwillige Engagement »auf einen harten Kern« (E6) geschrumpft. Die zunehmende Bürokratisierung der Unterstützungstätigkeiten und die schwierige Zusammenarbeit mit Behörden haben zudem zu einer erheblichen Frustration unter den weiterhin aktiven Engagierten geführt. 


\section{Das eingeschränkte Engagement mit und für Geflüchtete in Zeiten von Corona}

Die Corona-Krise »traf« daher auf ein geschwächtes, aber weiterhin vielfältiges zivilgesellschaftliches Engagement mit und für Geflüchtete. Im Großteil der Initiativen und Netzwerke engagierte sich ein deutlich kleinerer Kreis an Helfern mit großem Einsatz in einer Vielzahl von Tätigkeitsbereichen. Wie wirkte sich nun die Corona-Krise auf das lokale Engagement in der Geflüchtetenhilfe aus? Um diese Frage zu beantworten, stellt dieser Beitrag auf Grundlage der Interviews und ergänzenden Presseberichte in einem ersten Schritt die unmittelbar spürbaren Konsequenzen vor. Diese beziehen sich im Wesentlichen auf den Einbruch des Engagements aufgrund von Kontaktbeschränkungen und der Vorsicht der Engagierten, die zu den Risikogruppen zählen. In einem zweiten Schritt richten wir den Blick auf den Umgang mit der Pandemie sowie die möglichen langfristigen Folgen für das Geflüchtetenengagement.

In unseren Interviews wird sehr deutlich, dass die eingeführten Kontaktbeschränkungen zu Beginn der Pandemie das Engagement mit und für Geflüchtete sehr stark beeinträchtigten. Die Folgen werden besonders an den Besuchsverboten in den Asylunterkünften sichtbar, die häufig einen zentralen Ort für das Engagement darstellen (E1, E2). So bringt es eine der Interviewten aus Bayern auf den Punkt: »Es war unheimlich schwierig, weil der Zutritt zu den Unterkünften verboten war.«(E7). Laut einer Interviewten aus BadenWürttemberg haben die Maßnahmen im öffentlichen Raum das Engagement gänzlich »lahmgelegt« (E2). Diese Grundstimmung spiegelt sich in fast allen unseren Interviews wider: das Zugangsverbot in den Asylunterkünften stellte das größte Hindernis für die Ehrenamtlichen dar (E1, E2, E3, E4, E5, E6, E7, E8, E12). Durch den Verlust des persönlichen Kontakts mit Geflüchteten und des zentralen Orts der Begegnung fehlten den Ehrenamtlichen zwei wesentliche Grundlagen für ihr Engagement.

»Zu Anfang der Maßnahmen im März kam es zu einer totalen Pause. Da die Unterkünfte geschlossen waren, fand für einige Monate kein Engagement mehr statt.«(E12, Brandenburg)

Die Zugangsverbote zu den Aufnahmeeinrichtungen und Sammelunterkünften für Geflüchtete wurden nicht zuletzt mit dem hohen Ansteckungsrisiko für die Bewohner begründet. Aufgrund der Enge in den Unterkünften ist es dort kaum möglich, die gebotenen Abstands- und Hygieneregeln einzuhalten. 
In einer größeren Zahl von Unterkünften gab es Infektionsfälle; im badenwürttembergischen Ellwangen steckten sich in der dortigen Landeserstaufnahmestelle beispielsweise mehr als die Hälfte der 600 Bewohner und mehr als 30 Beschäftigte mit dem COVID-19-Virus an. Einer Studie der Universität Bielefeld zufolge lag das Ansteckungsrisiko für Bewohner von Aufnahmeeinrichtungen und Sammelunterkünften bei 17 Prozent (vgl. Uhlmann 2020, S. 14). Gerade für die Geflüchteten war diese Form der kollektiven Quarantäne besonders belastend, denn »der psychosoziale Stress ist für Menschen, die möglicherweise traumatisiert, verunsichert und in Sorge sind, besonders groß« (Michael Knipper, zitiert nach Uhlmann 2020: 14). Zugespitzt formuliert: In der ersten Phase der Corona-Krise war die Hilfsbedürftigkeit der Geflüchteten besonders groß - und die Möglichkeiten der Helfer, sie zu unterstützen, besonders gering.

Hinzu kommt, dass die Mehrheit der freiwillig Engagierten auf Grund ihres Alters in der aktuellen Corona-Pandemie zur Risikogruppe gehört. Da die Gruppe der über 60-Jährigen in den befragten Initiativen meist den größten Teil der Ehrenamtlichen ausmacht, haben viele Engagierte speziell im Frühjahr 2020 direkte gemeinschaftliche Kontakte gemieden (E1, E2, E3, E4, E5, E6, E7, E8).

»Da viele der Ehrenamtlichen über 50 bis 60 Jahre oder Rentner sind, hat sich die Mehrheit der Ehrenamtlichen aus dem persönlichen Kontakt mit Geflüchteten zurückgezogen.«(E1, Baden-Württemberg)

»Die Kontaktbeschränkungen haben dazu geführt, dass viele Ehrenamtliche sich komplett zurückgezogen haben. Viele ältere Ehrenamtliche sind auf Grund ihres Alters vorsichtig und nehmen weder an Treffen mit Ehrenamtlichen teil, noch besuchen sie die Unterkünfte. Es wird kaum möglich sein, diese Ehrenamtlichen wieder zu mobilisieren.«(E5, Bayern)

Zusammenfassend deuten unsere qualitativen Interviews darauf hin, dass sowohl die eingeschränkten Besuchsregelungen in den Unterkünften als auch die Vorsicht der älteren Ehrenamtlichen die Bedingungen für das Geflüchtetenengagement stark erschweren. Eine Ausnahme unter den analysierten Fällen stellen zwei Initiativen und ein Verein in Brandenburg dar, die einen niedrigeren Altersdurchschnitt der Engagierten aufweisen (E12, E11). Laut einer Interviewten hat eine Brandenburger Initiative neue Freiwillige dazugewonnen, die durch die Einschränkungen des öffentlichen Lebens mehr Austausch in ihrer Nachbarschaft wünschten. 
»Ich habe nicht den Eindruck, dass sich Ehrenamtliche aus der Initiative zurückziehen. Eher im Gegenteil, denn viele Ehrenamtliche fühlen sich durch die Corona-Beschränkungen ein wenig abgeschnitten und möchten so vor Ort aktiver sein.«(E11, Brandenburg)

Als Folge der Corona-Beschränkungen haben nach zehn von zwölf Interviewten viele Angebote für Geflüchtete, wie Sprach- und Begegnungscafés, interkulturelle Treffs und Deutschkurse, pausiert (E1, E2, E3, E4, E5, E7, E8, E9, E11, E12). Während einige interkulturelle Cafés in Bayern laut einer Ehrenamtlichen (E7) im Juli 2020 langsam wieder geöffnet haben, sind diese Treffpunkte nach Auskunft von mehreren Befragten in ihrer Region weiterhin stillgelegt (E1, E3, E4, E5). Da zu erwarten war, dass die Pandemie trotz der stetigen Öffnung des öffentlichen Raums auch die zweite Jahreshälfte 2020 und darüber hinaus bestimmen wird, verhalten sich viele Ehrenamtliche zum Zeitpunkt unserer Interviews noch vorsichtig. Sie suchen vielfach (noch) nicht den persönlichen Austausch mit anderen Ehrenamtlichen und Geflüchteten, sondern halten sich weiterhin zurück (E1, E3, E5, E7, E8). Eine Freiwilligenkoordinatorin aus Baden-Württemberg (E1) weist zudem darauf hin, dass nicht nur Asylunterkünfte und Cafés schließen mussten, sondern auch »wichtige Infrastruktur « wie Stadtbibliotheken und andere Orte der Begegnung (u.a. Mehrgenerationenhäuser oder Familienzentren). Bei der Unterstützung Geflüchteter werden an diesen Orten häufig die kostenlosen Räumlichkeiten für ehrenamtliche Deutschkurse oder Angebote für Familien und Kinder genutzt. Sie gehören somit vielerorts zur sozialen Infrastruktur und dienen als Begegnungs- und Austauschraum.

Aus den Interviews geht außerdem hervor, dass sich einige Ehrenamtliche im Sommer 2020 wieder untereinander und gemeinsam mit Geflüchteten in Gärten oder öffentlichen Parks zusammengefunden haben. Es ist aber noch ungeklärt, ob und wie diese Aktivitäten wieder in die Innenräume verlegt werden können (E1, E4, E5, E7, E8). Dies kommt in der folgenden Aussage einer Ehrenamtlichen aus Baden-Württemberg zum Ausdruck:

»Bei gutem Wetter haben die Ehrenamtlichen erste Angebote, wie Sprachkurse und das Begegnungscafé, im Freien organisiert; dies wird jedoch im Herbst problematisch. Feste und andere Veranstaltungen, die zur festen Routine gehören, wie zum Beispiel das Sommerfest, mussten abgesagt werden.«(E4, Baden-Württemberg) 
Inwiefern konnten digitale Kommunikationsmittel den Verlust an persönlichen Kontakten und analogen Orten der Vernetzung ausgleichen? Aus den Interviews geht hervor, dass sich fast alle Initiativen und Vereine im Februar und März 2020 spontan auf die neue Situation eingerichtet haben. Insgesamt neun von zwölf Befragten berichten in den Interviews, wie sie ihre Kommunikation auf Telefon und digitale Nachrichtendienste (wie WhatsApp oder Telegram) umgestellt haben, um die persönlichen Verbindungen zu erhalten (E1, E2, E3, E4, E6, E8, E9, E11, E12).

»Die Helfer, die persönlich mit den Geflüchteten in Kontakt stehen, konnten die Unterkünfte für einige Monate nicht mehr besuchen. Über WhatsApp und Telefonate wurde nur bedingt Kontakt gehalten.«(E6, Bayern)

Auch ein Blick in die Presseberichterstattung zwischen März und Juni 2020 zeigt, dass sich diese Tendenzen zur digitalen Kommunikation in vielen deutschen Städten beobachten ließen (u.a. Süddeutsche Zeitung, 10.04.2020; Allgemeine Zeitung, 03.04.2020; Nordbayern, 06.04.2020; Süddeutsche Zeitung, 15.06.2020). Während diese Umstellung zunächst Hoffnungen weckte, dass das Engagement mit digitalen Medien in ähnlicher Weise weitergeführt werden könnte, zeigen die Interviews, dass diese den Verlust des persönlichen Miteinanders nicht ausgleichen konnten. Eine Ehrenamtliche aus Bayern (E7) bestätigt, dass digitale Wege der Kommunikation keinesfalls einen Ersatz für die gewohnten Treffen darstellen: "Es ist schwierig den Kontakt mittels digitaler Medien aufrechtzuerhalten, denn dieser kann die persönliche Begegnung nicht ersetzen."

Der Mediendienst Integration weist in einem Lagebericht von Mitte Juni ebenfalls darauf hin, dass die Arbeit mit und für Geflüchtete ohne persönliche Kontakte große Hürden überwinden muss. Eine Vielzahl an Angeboten, wie medizinische und psychotherapeutische Hilfe oder rechtliche Beratungen wurden demnach stark zurückgefahren - eine digitale und telefonische Unterstützung könne die persönliche Begegnung nicht ersetzen. Dieser Eindruck wird auch in einem Großteil unserer Interviews in Bayern, BadenWürttemberg und Brandenburg vermittelt, in denen häufig schon zu Beginn des Gesprächs darauf hingewiesen wird, dass das Engagement in den ersten Monaten der Pandemie fast gänzlich ruhen musste (E1, E2, E3, E4, E5, E6, E7, E8, E12). Zudem verweist ein Ehrenamtlicher auf die mangelnde digitale Infrastruktur in den Unterkünften. 
»Da es in dezentralen Unterkünften kein Internet gibt und die Geflüchteten auf ihren Handys kaum an Lernangeboten teilnehmen können, wurden Deutsch- und Integrationskurse seit März nicht mehr angeboten.« (E5, Bayern)

Die zitierten Aussagen verdeutlichen, dass sich in dieser Zeit wenige Möglichkeiten eröffnet haben, auf persönlicher Ebene Beziehungen zu Geflüchteten $\mathrm{zu}$ pflegen und zu verfestigen. Wie eingangs beschrieben, sind jedoch gerade die sozialen Beziehungen zwischen Geflüchteten und Ehrenamtlichen eine wesentliche Bedingung für das Engagement im lokalen Rahmen.

\section{Wie geht es weiter? Langfristige Auswirkungen der Corona-Krise auf das Engagement mit und für Geflüchtete}

Wie wirken sich die beschriebenen Entwicklungen auf das künftige Engagement mit und für Geflüchtete in Deutschland aus? In welcher Weise verstärkt es die beschriebenen Trends des Rückgangs und Tätigkeitswandels in diesem Bereich? Basierend auf den geführten Interviews skizzieren wir im Folgenden mögliche Entwicklungsperspektiven aus Sicht der befragten Ehrenamtlichen und Hauptamtlichen.

Zunächst geben die vorliegenden Befunde Anlass zu der Annahme, dass das Geflüchtetenengagement durch die Corona-Krise weiter geschwächt wird. Die Krise könnte in diesem Bereich des zivilgesellschaftlichen Engagements einen weiteren Demobilisierungsschub bewirken. Diese Befürchtung äußern einige der Interviewten. Vor allem die Befragten aus Bayern und Baden-Württemberg beschreiben den Zustand der Geflüchtetenhilfe seit Beginn der Pandemie bis zum August 2020 als äußerst schwierig (E1, E2, E3, E4, E5, E8). Da das Engagement in vielen Städten und Gemeinden im Frühjahr 2020 für einige Monate vollkommen zum Erliegen gekommen ist, äußern mehrere Interviewpartner die Sorge, dass einige der Engagierten Corona als Gelegenheit sehen, um sich dauerhaft zurückziehen (E1, E2, E3, E5, E7, E12).

»Ich befürchte [...], dass einige Ehrenamtliche nach Corona nicht mehr zurückkommen und das Ehrenamt aufgeben. Gründe dafür sind Überforderung, Frustration, fehlende Anerkennung ihres Engagements, und eine Überlastung.« (hauptamtliche Ehrenamtskoordinatorin 2, BadenWürttemberg) 
Wichtig hierbei ist, dass die Corona-Krise zwar der Anlass für den Rückzug aus dem Engagement sein mag, aber nicht die Ursache. Das folgende Zitat aus der Studie von Hermann (2018, S 1) dürfte die Motivationslage einiger Helfer in den vergangenen Jahren gut auf den Punkt bringen: "Hätte ich gewusst, was auf mich zukommt, hätte ich vor zwei Jahren die Flüchtlingsarbeit nicht begonnen. Jetzt einfach aufhören geht aber auch nicht«. Mit Corona scheint sich dies geändert zu haben. Eine hauptamtliche Ehrenamtskoordinatorin aus BadenWürttemberg befürchtet, dass einige Freiwillige ihr Engagement aufgeben: »Hier ist die Corona-Pandemie der Aufhänger für einige Ehrenamtliche über einen Ausstieg nachzudenken. Es bleibt insgesamt eine Verunsicherung: >Kann ich das noch?" (E2). Viele Ehrenamtliche haben die Zeit der Kontaktverbote und der sozialen Distanzierung genutzt, "um sich auszuruhen, aber auch um ihr Engagement ganz grundsätzlich zu überdenken« (E2). Eine andere Befragte schätzt die Situation wie folgt ein: »Die Gelegenheit, mit dem Engagement aufzuhören, ist jetzt besonders günstig«(E2). Aus Bayern berichtet ein Ehrenamtlicher, der mit einer großen Zahl von Helferkreisen in Kontakt steht, dass einige Initiativen ihr Engagement im Frühjahr 2020 vollständig beendet haben: "Ein paar Helferkreise in Bayern standen schon vor Corona kurz vor dem Ende und haben sich im Verlauf der letzten Monate ganz aufgelöst.«(E5) In diesen Fällen bestätigt sich die Befürchtung, dass die Corona-Beschränkungen zu einer weiteren Schwächung und einem Rückgang des Engagements führen können.

Die dominante Leseart, dass das Engagement mit und für Geflüchtete durch die Corona-Krise weiter geschwächt wird, wird allerdings nicht von allen Befragten geteilt. Andere Akteure betonen eher, dass es sich bei den Ehrenamtlichen, die sich in ihren Städten in den Initiativen und Vereinen engagieren, ohnehin nur noch um den »harten Kern« handelt (E6, E10, E12). Dieser Kern an Engagierten würde sich auch zukünftig in der Geflüchtetenhilfe einsetzen und, so die Befragten, es sich aufgrund der aktuellen Situation kaum anders überlegen. Eine Interviewpartnerin aus Brandenburg (E12) führt zudem an, dass ihr Verein die ersten Monate der Pandemie verwendet hat, um Aktivitäten zu überdenken, die ehrenamtliche Arbeit umzustrukturieren und neue Projekte anzuschieben. Für diese zukunftsgerichteten Strategiefragen sei vorher kaum Zeit gewesen. Dieser Interpretation der Krise als Reflexionsbzw. Regenerationsphase schließt sich auch eine hauptamtliche Ehrenamtskoordinatorin aus Baden-Württemberg (E2) an, die darauf hinweist, dass sich die Ehrenamtlichen »mal von ihrem Engagement ausruhen " möchten, und sie sich gut vorstellen könne, dass einige Freiwillige in dieser Zeit Kraft und Energie für ihr Ehrenamt gesammelt hätten. 
Neben der Demobilisierungs- und Regenerationsperspektive legen andere Aussagen der Interviewten eine mögliche Neuausrichtung des Engagements nahe. Während die Nutzung des öffentlichen Raums zwischenzeitlich stark eingeschränkt war und das gewohnte Engagement gewissermaßen stillstand, haben sich einige Initiativen und Vereine neue Betätigungsfelder erschlossen. Zwei Entwicklungen konnten wir in diesem Bereich feststellen.

Zum einen setzten sich einige Initiativen und Unterstützerkreise für Menschen ein, die von der Pandemie und den Einschränkungen zu deren Bekämpfung stark betroffen waren. So sammelten freiwillig Engagierte laut zweier Befragter (E2, E7) Laptop- und Computerspenden für Schüler, die während des Homeschoolings auf verbesserte technische Ausstattung angewiesen waren. Zudem schufen verschiedene Gruppen Einkaufsdienste für Risikogruppen. Zwei Befragte aus Baden-Württemberg und Brandenburg (E1, E11) berichten, dass sich im Frühjahr viele Engagierte bereit erklärten, Einkäufe für ältere Menschen und solchen mit Vorerkrankungen zu erledigen. Diese Beispiele decken sich auch mit den von uns recherchierten Presseberichten. Demnach haben Initiativen der Geflüchtetenhilfe in verschiedenen Städten neue Angebote wie Einkaufsdienste geschaffen oder kostenlose Alltagsmasken für Mitbürger genäht (u.a. vgl. Süddeutsche Zeitung, 01.06.2020; Märkische Allgemeine Online, 16.04.2020; Stuttgarter Zeitung, 06.06.2020; Deutsche Welle, 02.05.2020). In Erkrath bei Düsseldorf schloss sich beispielsweise eine Geflüchteten-Initiative dem neu gegründeten Nachbarschaftsbündnis »Corona« an, um die lokale Tafel zu unterstützen. Diese hatte im März kurzfristig aus Vorsicht geschlossen, um ihre älteren Engagierten nicht zu gefährden. Um die Angebote der Tafel weiter am Leben $\mathrm{zu}$ halten, schuf das Bündnis mit rund 40 Beteiligten ein Ersatzangebot für die Lebensmittelausgabe (vgl. Garcia 2020).

Zum anderen wird in mehreren Interviews ersichtlich, dass vor allem Ehrenamtliche aus Bayern und Baden-Württemberg im Verlauf des letzten Jahres begonnen haben, sich vermehrt mit der Situation von Geflüchteten auf den griechischen Inseln und in der Türkei zu beschäftigen (E3, E4, E5, E6, E7). Im Zuge dessen haben sich einige der Initiativen dazu entschieden, das Städtebündnis der Seebrückenbewegung "Sicherer Hafen« zu unterstützen. Für die Planung dieses Projekts stand laut den Interviewten gerade während des pausierenden Engagements vor Ort in den letzten Monaten mehr Zeit zur Verfügung: »Seit Corona haben die Ehrenamtlichen wieder mehr Zeit sich für die Initiative der Seebrücke sSichere Häfen einzusetzen." (E6, Bayern). In Oberbayern beispielsweise haben sich verschiedene Helferkreise einem breiteren Bündnis 
angeschlossen, das versucht, die Städte in ihren Landkreisen $\mathrm{zu}$ »sicheren Häfen « zu machen (E6, E7). Auch in Baden-Württemberg gibt es laut zwei Interviewten vergleichbare Bestrebungen (E3, E4). Während das primäre Ziel nicht darin besteht, dem Rückgang an Engagierten entgegenzuwirken, besteht unter einigen Befragten dennoch die Hoffnung, dass sich diese Reorientierung positiv auf das Engagement der lokalen Helferkreise und Initiativen auswirkt.

\section{Schlussfolgerungen}

Die Corona-Pandemie hat die bereits bestehenden Probleme und Herausforderungen der Zivilgesellschaft im Bereich des Engagements mit und für Geflüchtete in besonderer Weise sichtbar gemacht. Das Engagement war schon vor der Corona-Pandemie auf einen harten Kern von Ehrenamtlichen geschrumpft - und dieser Kern wird nun an manchen Orten in seinem Bestand gefährdet. Die Ergebnisse unserer qualitativen Interviews zur derzeitigen Situation der Geflüchtetenhilfe in der Corona-Krise lassen sich in drei (vorläufigen) Befunden zusammenfassen. Erstens: Durch das Zugangsverbot in den Asylunterkünften und dem eingeschränkten Kontakt zwischen Unterstützern und Geflüchteten ist die wichtigste Grundlage für das Geflüchtetenengagement zunächst gänzlich weggebrochen. Zweitens: Da eine Mehrheit der Ehrenamtlichen auf Grund ihres höheren Alters zur Risikogruppe zählt, treffen viele Beteiligte Vorsichtsmaßnahmen und pausieren ihr Engagement aus Sorge vor einer Erkrankung. Drittens: Die Nutzung von digitalen Kommunikationswegen hat zwar dazu beigetragen, dass bestehende Kontakte auf einem Mindestmaß erhalten werden können, sie scheint jedoch nicht geeignet zu sein, um den Verlust von persönlichen Kontakten und gewohnten Treffen auszugleichen.

Hinsichtlich der Entwicklungsperspektiven des zivilgesellschaftlichen Engagements mit und für Geflüchtete zeichnen unsere Interviews ein eher pessimistisches Bild. Die Feststellung, dass in diesem Bereich »die Bereitschaft zu helfen ungebrochen ist " (Springer 2020, S. 170), kann durch unsere Befunde nicht bestätigt werden. Viele der Befragten äußern die Sorge, dass die Corona-Krise das Engagement nachhaltig schwächen bzw. ganz zum Erliegen bringen wird. Grund für den Rückzug ist aber zumeist nicht der erzwungene Stillstand des Engagements, sondern eine bereits zuvor bestehende Erschöpfung und Frustration bei den Engagierten. Zugespitzt formuliert: Der bereits vor der Pandemie auf den »harten Kern« zusammen- 
geschrumpfte Kreis an Engagierten ist an einigen Orten in seiner Substanz gefährdet. Neben dieser häufig geäußerten Befürchtung zur weiteren Entwicklung des Engagements im Bereich der Geflüchtetenhilfe skizzierten unsere Befragten allerdings auch andere Perspektiven. Diese manchenorts bereits erkennbaren Tendenzen deuten auf das Beharrungsvermögen der noch Aktiven und eine Neuausrichtung des Engagements hin.

Aufgrund der Dynamik und Unsicherheit der momentanen Situation können unsere Ergebnisse und Thesen zur Entwicklung der Zivilgesellschaft in diesem Bereich allerdings nur vorläufigen Charakter haben. Die Unterschiede zwischen den Bundesländern Bayern, Baden-Württemberg und Brandenburg deuten zudem an, dass die Zusammensetzung und Altersstruktur der Engagierten sowie deren bisherigen Erfahrungen mit der Politik vor Ort wichtige Bedingungen dafür sind, wie viel und welche Art von Engagement die Herausforderungen der Corona-Krise überstehen wird.

\section{Literaturhinweise}

Alscher, Mareike/Priller, Eckhard/Burkhardt, Luisa (2018): Zivilgesellschaftliches Engagement. In: Datenreport 2018, https:/www.destatis.de/DE/Se rvice/Statistik-Campus/Datenreport/Downloads/datenreport-2018-kap9.pdf?_blob=publicationFile (20.09.19).

Aumüller, Jutta (2016): Flüchtlingszuwanderung und bürgerschaftliches Engagement. In: Betrifft: Bürgergesellschaft 42. Berlin: Friedrich-EbertStiftung.

Enquete-Kommission (2002): Bericht der Enquete-Kommission »Zukunft des Bürgerschaftlichen Engagements«: Bürgerschaftliches Engagement: auf dem Weg in eine zukunftsfähige Bürgergesellschaft. Deutscher Bundestag, 14. Wahlperiode, Drucksache 14/8900.

Erler, Wolfgang/Prytula, Andrea/Grotheer, Angela (2018): »Ausbildung und Arbeit für Flüchtlinge? Ohne die Freiwilligen können Sie das vergessen!«. Über bürgerschaftliches Engagement zur Unterstützung der Arbeitsmarktintegration. Gütersloh: Bertelsmann Stiftung.

Friedrich, Dorothea: Die Folgen der Corona-Krise für Flüchtlinge. Die nächste Krise. In: Süddeutsche Zeitung, 10.04.2020; https://www.suedd eutsche.de/muenchen/dachau/die-folgen-der-corona-krise-fuer-fluechtl inge-die-naechste-krise-1.4874004 (20.08.2020). 
Gesemann, Frank/Seidel, Alexander/Mayer, Margit (2019): Entwicklung und Nachhaltigkeit von Willkommensinitiativen. Berlin: DESI - Institut für Demokratische Entwicklung und Soziale Integration.

Garcia, Ria (2020): Nachbarschaftshilfe Corona springt für die Tafel ein. In: Erkrath Jetzt, 31.03.2020; https://www.erkrath.jetzt/nachbarschaftshilfecorona-springt-fuer-die-tafel-ein/?cn-reloaded=1 (19.08.2020).

Goebel, Fabian (2020): Helfern fehlt der direkte Kontakt. Corona Verordnung schränkt die Arbeit der Flüchtlingshilfe ein. In: Allgemeine Zeitung, 03.04.2020; https:/www.allgemeine-zeitung.de/lokales/alzey/vg-wo errstadt/saulheim/corona-krise-erschwert-fluchtlingshilfe_21501660 (20.08.2020).

Hamann, Ulrike/Karakayali, Serhat/Wallis, Mira/Höfler/Leif Jannis (2016): Koordinationsmodelle und Herausforderungen ehrenamtlicher Flüchtlingshilfe in den Kommunen. Qualitative Studie des Berliner Instituts für empirische Integrations- und Migrationsforschung. Gütersloh: Bertelsmann Stiftung.

Heinrich Böll Stiftung (2016): Übersicht zur Flüchtlingspolitik in den Bundesländern. Online verfügbar unter: https://www.boell.de/de/fluech tlingspolitik-baden-wuerttemberg; https://www.boell.de/de/fluechtlings politik-bayern; https://www.boell.de/de/fluechtlingspolitik-brandenburg (31.08.2020).

Herrmann, Jost (2018): 5 Jahre »Asyl im Oberland«. Zur Situation der Ehrenamtlichen Flüchtlingshelfer, https://www.asylimoberland.de/fileadmin/ user_upload/uk_ueberregional/Newsletter/2018-3-1/Situation_der_Helfe rkreise_7.3.2018.pdf (18.08.2020).

Hoben, A. (2020): Helfen hilft. In: Süddeutsche Zeitung, Nr. 66, 19.03.2020, Ri.

Institut für Demoskopie Allensbach (2017): Engagement in der Flüchtlingskrise. Ergebnisbericht für das Bundesministerium für Familie, Senioren, Frauen und Jugend, https://www.bmfsfj.de/blob/122010/d35ec9bf4a94 oea49283485db4625aaf/engagement-in-der-fluechtlingshilfe-data.pdf (20.07.2020).

Koos, Sebastian/Bertogg, Ariane (2020): Lokale Solidarität während der Corona-Krise: Wer gibt und wer erhält informelle Hilfe in Deutschland? Cluster of Excellence »The Politics of Inequality«: Konstanz, www.nbnresolving.de/urn:nbn:de:bsz:352-2-15cxzwli6uvge7 (21.08.2020). 
Landsberg, Torsten (2020): Masken nähen in Berliner Initiative. In: Deutsche Welle, 02.05.2020; https:/www.dw.com/de/flüchtlinge-helfen-inder-corona-krise/a-53303303 (19.08.2020).

Lemmermeier, Doris/Gartz, Manfred (2017): Integration machen Menschen. Aktuelle Situation des Ehrenamts in der Flüchtlingshilfe im Land Brandenburg, https://msgiv.brandenburg.de/msgiv/de/service/publikationen / detail/ 11-03-2018-integration-machen-menschen-aktuelle-situationdes-ehrenamts-in-der-fluechtlingshilfe-im (02.08.2020).

Mediendienst Integration (2020): Wie Corona die Flüchtlingsinitiativen beeinflusst, 19.06.2020; https://mediendienst-integration.de/artikel/wie-co rona-die-fluechtlingsinitiativen-beeinflusst.html (31.08.2020)

o.A.: Coronavirus in München. Hilfsangebote und Initiativen. In: Süddeutsche Zeitung, 01.06.2020; https://www.sueddeutsche.de/muenchen/coro na-muenchen-hilfe-initiativen-1.4850255 (19.08.2020).

o.A.: Kaum Privatsphäre. Flüchtlinge trifft die Corona-Krise schwer. In: Nordbayern, 06.04.2020; https://www.nordbayern.de/region/nuernberg /kaum-privatsphare-fluchtlinge-trifft-die-corona-krise-schwer-1.999994 5 (20.08.2020).

o.A.: Maskennähen in Jüteborg. In: Märkische Allgemeine Zeitung, 16.04.2020, https://www.maz-online.de/Lokales/Teltow-Flaeming/Ju eterbog/Jueterbogs-Fluechtlinge-naehen-Mund-Nase-Masken-fuer-Erst aufnahmeeinrichtung (19.08.2020).

Priemer, Jana/Krimmer, Holger/Labigne, Anael (2017): Vielfalt verstehen. Zusammenhalt stärken. ZiviZ-Survey 2017. Berlin: Stifterverband.

Putnam, Robert (1993): Making democracy work: civic traditions in modern Italy. Princeton, N.J.: Princeton University Press.

Schiffauer, Werner (2018): Die civil society als feine Kunst betrachtet. In: Schiffauer, Werner/Eilert, Anne/Rudloff, Marlene (Hg.), So schaffen wir das - eine Zivilgesellschaft im Aufbruch. Bedingungen für die nachhaltige Projektarbeit mit Geflüchteten. Eine Bilanz. Bielefeld: transcript, S. 9-31. Schiffauer, Werner (2017): Einleitung: Eine neue Bürgerbewegung. In: Schiffauer, Werner/Eilert, Anne/Rudloff, Marlene (Hg.), So schaffen wir das eine Zivilgesellschaft im Aufbruch. 90 wegweisende Projekte mit Geflüchteten. Bielefeld: transcript, S. 13-34.

Springer, Cornelia (2020): Zivilgesellschaft in der Verantwortung. Drei Spannungsfelder von Solidarität in der Krise. In: Volkmer, Michael/Werner, Karin (Hg.), Die Corona-Gesellschaft. Bielefeld: transcript, S. 167-176. 
Ströbele, Torsten (2020): Alltagsmasken in Stuttgart. In: Stuttgarter Zeitung, 06.06.2020; https://www.stuttgarter-zeitung.de/inhalt.coronav irus-fluechtlinge-sorgen-fuer-mehr-schutz.73a1edc1-47e7-41cc-bf3a-58a5 784bige4.html (19.08.2020).

Uhlmann, Berit (2020): Blinder Fleck im Infektionsschutz. In: Süddeutsche Zeitung, 2. Juni 2020, S. 14.

Wang, Lili/Ganapati, Nazife Emel (2018): Disasters and Social Capital: Exploring the Impact of Hurricane Katrina on Gulf Coast Counties. In: Social Science Quarterly, 99 (1), S. 296-312.

Wejsada, Sabine (2020): Integration mit Hindernissen. In: Süddeutsche Zeitung, 15.06.2020; http:/www.sueddeutsche.de/muenchen/landk reismuenchen/oberschleissheim-coronakrise-integration-1.4937092 (20.08.2020). 


\section{Ehrenamt und freiwilliges Engagement in der Corona-Krise}

Thomas Röbke im Gespräch mit dem Bayerischen Bündnis für Toleranz

Bayerisches Bündnis für Toleranz: Ehrenamtliches und freiwilliges Engagement leben in hohem Maße von der Begegnung zwischen Menschen. ${ }^{1}$ Vor welche Herausforderungen stellt die Corona-Krise das Ehrenamt und das freiwillige Engagement? Fördert die Krise möglicherweise sogar die Solidarität und den Zusammenhalt in der Gesellschaft?

Thomas Röbke: Mit netten Leuten zusammenkommen ist eines der wichtigsten Motive, weswegen sich Menschen ehrenamtlich engagieren. In der CoronaKrise hat das natürlich sehr gelitten. Vereine konnten nicht spielen, Kulturinitiativen keine Konzerte durchführen, viele Gruppen physisch nicht zusammenkommen. Unsere Netzwerkpartner haben diese Krisenzeit in vielen Fällen wirklich als Krise erlebt. Selbsthilfegruppen, die auf persönliche Nähe angewiesen sind, können das auch nicht durch Online-Meetings wettmachen. Ebenso ergeht es unseren Seniorenbüros mit ihren Besuchsdiensten in Altenheimen. Das geht einfach nicht mehr. Und weil es in vielen Altenheimen kein W-Lan gibt, lässt sich das auch nicht durch virtuelle Nähe kompensieren. Unsere Mütter- und Familienzentren fragen sich von Tag zu Tag, ob sie öffnen können oder schließen müssen. Natürlich sind Ehrenamtliche, die sich für andere Menschen einsetzen auch besonders verantwortungsbewusst. Aber wir alle empfinden Lockerungen als einen großen Segen und hoffen auf mehr.

Ob die Krise auch Solidarität hervorgerufen hat? Sicher! Es gab spontan viel Nachbarschaftshilfe, die etwa von unseren Freiwilligenzentren organisiert wurde. Aber es wurden auch die Brüche in unserer Gesellschaft sichtbar. Wenn wir uns alle auf unruhiger See befinden, so sind doch einige auf komfortablen Yachten, aber viele in kleinen Booten und manche können sich nur 
mühsam über Wasser halten. Die werden dann stärker durchgerüttelt und sind größeren Gefahren ausgesetzt. Viele Bildungspatenschaften mit Kindern aus armen Haushalten mussten beispielsweise eingestellt werden, weil diese gar nicht die Ausrüstung für eine Online-Betreuung zuhause haben. Die Krise hat die soziale Ungleichheit in unserer Gesellschaft sichtbarer gemacht, vielleicht sogar vertieft. Es wäre schön, wenn wir daraus Konsequenzen ziehen und mehr in soziale Gerechtigkeit und sozialen Zusammenhalt investieren würden.

Bayerisches Bündnis für Toleranz: Entwickeln sich durch den Verlust von persönlicher Begegnung und Nähe neue Formen der Anteilnahme? Und erlebt freiwilliges Engagement einen Innovationsschub? Nehmen Sie eine Veränderung im Verhältnis der Generationen wahr?

Thomas Röbke: Ob aus der Pandemie-Zeit mehr Empathie und Solidarität erwachsen werden? Das kann man heute noch nicht beurteilen. Man kann es nur hoffen. Vielleicht wird auch mehr Menschen bewusst, was wirklich im Leben zählt. Schön war beispielsweise zu sehen, wie viele Tafelprojekte, die ihre Arbeit zurückfahren mussten, weil die Ehrenamtlichen der Risikogruppe der Älteren angehören, spontan von jungen Menschen weitergeführt wurden. Durch die Umstellung auf Online-Fortbildungen konnten oft mehr Teilnehmende erreicht werden als bei den vor der Pandemie üblichen Präsenzveranstaltungen. Der »Digital Social Summit«, der 2020 das zweite Mal Online stattgefunden hat, hatte beispielsweise über tausend Teilnehmende. Bei der Präsenzveranstaltung im Jahr zuvor waren es dreihundert. Die Arbeitsweisen haben sich auch im bürgerschaftlichen Engagement in kurzer Zeit radikal verändert. Virtuelle Fortbildungen und Treffen sind jetzt für viele selbstverständlich. Aber bestimmte Gruppen sind ausgeschlossen, zum Beispiel viele ältere Menschen. Die Jungen sind schon in die digitale Technik hineingeboren. Und gewisse Ermüdungserscheinungen sind unübersehbar und viele sehnen sich nach echten Begegnungen. Wahrscheinlich wird eine gemischte Kultur Online-Offline bleiben. Denn viele wollen die neue Technik auch nicht mehr missen. Kollaborative Arbeitsformen im Internet, gemeinsame OnlineTreffen und -Fortbildungen etc.

Bayerisches Bündnis für Toleranz: Neben der Gastronomie- und Tourismusbranche trifft das Veranstaltungs- und Kontaktverbot der letzten Wochen den soziokulturellen Bereich besonders hart. Welche Angebote und Hilfen bieten Sie 
an? Und wie bleiben Sie derzeit mit Freiwilligenagenturen, Bürgerstiftungen, Familienzentren, Ausländer- und Integrationsbeiräten, soziokulturellen Zentren, Seniorenbüros in Kontakt?

Thomas Röbke: Viele ehrenamtlich geführte Vereine und Spielstätten sind auf Veranstaltungseinnahmen angewiesen. Staatliche Unterstützungsprogramme aber greifen im Ehrenamt nur ungenügend, weil es auch schwierig ist, den Ausfall finanziell genau darzustellen und zu beziffern oder existenzielle Bedrohung nachzuweisen. Beantragungswege für Unterstützungen sind für Ehrenamtliche oft zu bürokratisch. Einzelne Bundesländer wie RheinlandPfalz haben schnell ehrenamtlichen Vereinen mit Soforthilfen unter die Arme gegriffen. Auch wir haben uns an die Politik in Bayern gewandt und auf die besondere Problematik des Ehrenamtes hingewiesen, das einfach unbürokratische Hilfen braucht. Dabei geht es ja auch nicht um die großen Summen, die beispielsweise derzeit als Kurzarbeitergeld ausgezahlt werden. Im Kultur- und Sportbereich ist jetzt ja einiges in die Wege geleitet. Auch das bayerische Digitalministerium überlegt geeignete Hilfen für Vereine. Es gibt nun die Deutsche Stiftung für Engagement und Ehrenamt, die gerade ein Förderprogramm für die Unterstützung des Ehrenamts mit digitalen Werkzeugen ausgeschrieben hat. Das kleine Team der jungen Stiftung wurden mit 12.500 Anträgen förmlich überrannt. Das zeigt das Ausmaß des Bedarfs. Bei den letzten »Krisen« wie der Flutkatastrophe 2002 oder der starken Zuwanderung von Flüchtlingen 2015 wurde das bürgerschaftliche Engagement politisch über den grünen Klee gelobt. Wobei man manchmal vollmundig versprach, wie der damalige Bundeskanzler Schröder in der Fluthilfe, das bürgerschaftliche Engagement massiv zu fördern, weil es so wichtig oder: systemrelevant ist. Viel ist da freilich nicht herausgekommen. Diesmal scheint, so ist der Eindruck unserer Netzwerkpartner, das Ehrenamt politisch und medial gar nicht so recht vorzukommen. Wenn aber die Krise eines gezeigt hat: Gesellschaften, in denen der soziale Zusammenhalt besser funktioniert und die ein vertrauensvolles Verhältnis zu ihren Mitmenschen haben, kommen besser durch diese schwierigen Zeiten. Selbstverantwortung und Verantwortung für andere zu übernehmen bedingen einander. Daher muss es jetzt endlich auch eine verlässliche und nachhaltige Infrastrukturförderung des bürgerschaftlichen Engagements geben. An jedem Ort müssen gut ausgestattete Freiwilligenzentren selbstverständlich sein, Vereine brauchen Fortbildungen und eine zeitgemäße digitale Ausstattung. Und dennoch: Sich endlich wie- 
144 Thomas Röbke im Gespräch mit dem Bayerischen Bündnis für Toleranz

der »in echt« treffen zu können, wie wir in Franken sagen, ist immer eine Wohltat. 


\section{Corona als Herausforderung für Kirchen und Bildungsarbeit Ein Essay}

Udo Hahn

Was prägt eine Gesellschaft im Kern? Und wie lässt sich die an sich komplexe Realität beschreiben - besser noch: auf den Punkt bzw. den Begriff bringen? Dazu gibt es in der sozialwissenschaftlichen Literatur zahlreiche Deutungsangebote. Eine Charakterisierung wie etwa »Wissensgesellschaft» unterstreicht den Stellenwert von Wissen und Information (Informationsgesellschaft) und Bildung (Bildungsgesellschaft) z.B. für sozialen Aufstieg, Wohlstand und dauerhaften Frieden. "Mediengesellschaft « wiederum deutet an, wie Kommunikationstechnologien zur Information, Bildung und Unterhaltung von Menschen beitragen. »Erlebnis-« oder »Spaßgesellschaft« unterstreicht, welchen Wert Genuss und individuelles Erleben haben; »Freizeitgesellschaft«, dass der Einzelne künftig womöglich weniger arbeiten und mehr freie Zeit (Freizeit) haben wird. Der von Ulrich Beck 1986 geprägte Begriff »Risikogesellschaft« betont, dass die Menschen immer stärker unsichtbaren Bedrohungen ausgesetzt sind, die der technische Fortschritt hervorbringt. Diese Risiken der industriellen Moderne können alle Individuen treffen, unabhängig von ihrem Status.

Mit der Risikogesellschaft lässt sich der Begriff »Disruption«verknüpfen. Er leitet sich aus dem Englischen »to disrupt «ab, was so viel bedeutet wie: stören, unterbrechen, spalten, sprengen, zerreißen, zerstören, aufbrechen. Der Wirtschaftswissenschaftler Clayton Christensen hat 1997 die Theorie der Disruption entwickelt. Demnach wird jedes noch so erfolgreiche und etablierte Unternehmen eines Tages von einer existenzraubenden Revolution bedroht. Wenn es um die Digitalisierung geht - etwa um Sharing Economy, das Internet der Dinge -, wird dieses Buzzword bemüht, um auf die (bevorstehende) Zerstörung etablierter Strukturen durch und für innovative Geschäftsideen 
und -modelle hinzuweisen. 2015 wurde Disruption zum »Wirtschaftswort des Jahres« gekürt. Seither hat es in alle Bereiche des Lebens Eingang gefunden.

Risikogesellschaft, Disruption - es ist naheliegend, die seit Anfang 2020 die ganze Welt in Atem haltende Corona-Pandemie mit diesen beiden Begriffen zu verbinden und die Frage zu stellen, ob die Menschen unter dem Corona-Vorzeichen eine Disruption bisher nicht vorstellbarer Art erleben und Risiken ausgesetzt sind, welche die globalisierte Welt und jeden Einzelnen in einer ebenfalls zuvor nicht vorstellbaren Weise herausfordern. Zugespitzt formuliert: Worauf ist Verlass? Was ist noch sicher?

Eine komplexe Welt verlangt, dass wir in Zusammenhängen denken und mit Unsicherheiten leben lernen. Diese Anforderung stellte sich den Menschen zu allen Zeiten. Dabei haben die Entwicklungen der letzten dreißig, vierzig Jahre gezeigt, dass - jedenfalls in bestimmten Teilen der Welt - Freiheit, Frieden, Demokratie, Wohlstand für eine stabile Ordnung sorgen können. Andererseits signalisieren Klimawandel, Finanzmarktkrise, Terror, Vertreibung, Flucht, wieder erstarkender Nationalismus, Rassismus und Antisemitismus, dass sicher Geglaubtes nicht dauerhaft sicher bleiben muss. Dies zeigen auch die Debatten über die Frage, wie robust Gesellschaften sein müssen, was Resilienz und Emergenz begünstigt und wie die Bereitschaft, Unsicherheiten zu akzeptieren sich mit der Bereitschaft verbinden lässt, aus Fehlentwicklungen zu lernen.

Die vielleicht verblüffendste Feststellung im Zusammenhang mit der Corona-Krise war, dass Wirtschaft und Gesellschaft durch einen Lockdown - verbunden mit Ausgangssperren und Kontaktbeschränkungen - in einer Weise zum Stillstand gebracht werden konnten, wie dies bislang für unvorstellbar gehalten wurde. Die Ausrufung des Katastrophenfalls, massive Eingriffe des Staates auf der Basis des Infektionsschutzgesetzes, Regieren mit Rechtsverordnungen - auf dieser Grundlage ruhen die Beschränkungen des öffentlichen Lebens, die für notwendig erachtet wurden, um die CoronaPandemie einzudämmen bzw. wirksam zu bekämpfen. Bis ein Impfstoff die Gewähr bietet, zu einem Miteinander zurückzukehren, wie es die Menschen vor Corona gewohnt waren. Unter welchen Rahmenbedingungen dieses neue Miteinander erfolgt, bleibt jedoch abzuwarten.

Die Kirchen sind Teil einer Gesellschaft, die sich verändert - und in der sich auch die Kirchen verändern. Die demographische Entwicklung führt dazu, dass die Zahl der Kirchenmitglieder rückläufig ist. Diese Entwicklung erlebt durch eine anhaltend hohe Austrittsbereitschaft immer dann zusätzlich 
Auftrieb, wenn das Erscheinungsbild der Kirchen in der Öffentlichkeit Anlass zur Kritik bietet. Ein aktuelles Beispiel ist der Missbrauchsskandal.

In der Phase des Lockdowns im Frühjahr 2020 waren auch die Kirchen geschlossen und es durften keine Gottesdienste stattfinden. Die Kirchen haben dies akzeptiert und wollten ihre Bereitschaft, diese Schließung hinzunehmen, auch als Beitrag zur Eindämmung der Pandemie verstanden wissen. In der Öffentlichkeit gab es dazu eine kontroverse Debatte, aufgehängt an der Frage, warum Baumärkte öffnen dürfen, Kirchen aber nicht. Im Herbst-Lockdown sind die Kirchen von der Schließung ausgenommen worden. In der gesellschaftlichen Debatte mehrten sich Stimmen, die von den Kirchen einen freiwilligen Verzicht verlangten und diese Vorzugsbehandlung in Frage stellten. An diesem Beispiel deutet sich an, dass die Rolle und Bedeutung der Kirchen für das Gemeinwesen nicht einfach schon feststeht, sondern im Diskurs immer wieder neu vergewissert bzw. geklärt werden muss.

Kirchliche Aktivitäten sind auch unter Corona-Bedingungen möglich. Der viel zitierte Digitalisierungsschub wirkt auch hier. Dabei handelt es sich um eine intensivere Nutzung technischer Möglichkeiten, die es zuvor schon gab. Diese waren aber nicht oder nur unzureichend genutzt worden - mangels Ressourcen (fehlendes Geld, Personal und Knowhow); oder weil Kirche sich dezidiert als Synonym für persönliche Begegnung und somit personale Kommunikation versteht. Kann dies nicht geschehen, dann entstehen und wachsen auch in der Kirche (neue) mediale Kommunikationsformen.

Unter dem Titel »Hinaus ins Weite - Kirche auf gutem Grund« hat die Evangelische Kirche in Deutschland (EKD) im November 2020 »Zwölf Leitsätze zur Zukunft einer aufgeschlossenen Kirche« beschlossen - auf ihrer jährlichen Tagung, die erstmals virtuell stattfinden musste. Erarbeitet wurden diese Leitsätze von einem »Z-Team«. Z steht dabei für Zukunft. Ein erster Entwurf mit elf Leitsätzen war in den Monaten zuvor kontrovers diskutiert worden. In der evangelischen Kirche ist es üblich, von Zeit zu Zeit Zukunftsstrategien vorzulegen - wie etwa das Impulspapier »Kirche der Freiheit« aus dem Jahr 2006. Insbesondere die Devise, gegen den Trend wachsen zu wollen, hatte damals Kritik hervorgerufen. Ein weiterer Einwand lautete, die Kirche orientiere sich zu sehr an Profit-Unternehmen und versuche, auf die Glaubenskrise mit Strukturveränderungen zu reagieren.

Gleichwohl sind Strukturveränderungen notwendig, da die Ressourcen der Kirche zurückgehen. Mit ihren zwölf Leitsätzen unternimmt die EKD den Versuch, Strukturelles und Inhaltliches miteinander zu verbinden. Die möglichen Auswirkungen von Corona in die Überlegungen mit einzubeziehen, 
darum bemüht sich das Papier. Es darf als mutiger Versuch einer kirchlichen Zeitansage gewertet werden.

Was sind die Besonderheiten? Und wie sind sie zu verstehen? "Hinaus ins Weite - das Motto bezieht sich auf einen Vers im Alten Testament - 2. Sam. 22,20 - und ist programmatisch zu verstehen. Es »bedeutet Offenheit, nicht Rückzug«. Mit anderen Worten: »Die Kirche muss daher in der Gesellschaft präsent, spürbar, wahrnehmbar bleiben.«Und:»Als Kirche der Freiheit bejahen wir eine plurale Gesellschaft.«

Auffällig ist, dass dem Thema Bildung besondere Bedeutung beigemessen wird. Wörtlich: »Kirchlicher Bildungsarbeit kommt dabei zentrale Bedeutung zu.« Dass Kirche und Bildung aufs Engste zusammengehören und dies seit der Reformation Martin Luthers zur DNA der evangelischen Kirche gehört, das wurde schon in vielen kirchlichen Verlautbarungen betont, wie etwa in der Orientierungshilfe des Rates der EKD aus dem Jahr 2009 unter dem Titel »Kirche und Bildung. Herausforderungen, Grundsätze und Perspektivem evangelischer Bildungsverantwortung und kirchlichen Bildungshandelns«. Bislang ist ein solcher Akzent aber zumeist nur auf Papiere beschränkt geblieben, in denen es ausschließlich um Bildung ging. In anderen Verlautbarungen wird das kirchliche Kernhandeln meist ausschließlich auf Gottesdienst, Verkündigung, Seelsorge und Diakonie konzentriert. Bildung hat zwar auch in den zwölf Leitsätzen keinen eigenen Abschnitt erhalten. Da es als Querschnittsaufgabe nunmehr wahrgenommen wurde, ist dies nicht erforderlich. Die eigentliche Bedeutung des Zukunftspapiers der EKD liegt darin, Bildung endlich auf die Ebene mit Verkündigung, Seelsorge und Diakonie gehoben zu haben. Dabei wird ebenso anerkannt, dass Bildungsorte Orte geistlicher Erneuerung sind. Und es finden sich Ausführungen, die bislang üblicherweise nur in Bildungspapieren vorkamen: »Bildung stärkt nach evangelischem Verständnis die Persönlichkeit und befördert Dialogfähigkeit und eigenständiges Urteilen.«

Dass die Kirche von der Digitalisierung profitiert, kommt in dem Bekenntnis »Wir wollen digitale Kirche werden« zum Ausdruck. Dieses Ziel soll dadurch erreicht werden, dass Kirche selbst im digitalen Raum zu Hause ist, sich für digitale Lösungen einsetzt, um Menschen besser zusammenzubringen und zu erreichen, aber auch, um als Kirche besser und leichter erreichbar zu sein. Dabei setzt die EKD auf »hybride Lösungen«, die analoge und digitale Elemente verbinden. 
Bildung und Digitalisierung - diese beiden Themen sind im Lichte der Corona-Pandemie noch einmal gesondert zu betrachten und auch in ihrem Zusammenhang.

Die Notwendigkeit von Bildung wird ohne Zweifel in unserer Gesellschaft anerkannt - als Voraussetzung für soziale, wirtschaftliche, kulturelle und gesellschaftliche Teilhabe im umfassendsten Sinn. Soweit besteht Konsens, wenn allgemein über Bildung gesprochen wird. Mit der durchaus sinnvollen Aufteilung in schulische und außerschulische Angebote verbindet sich jedoch eine Bewertung, die gerade unter Corona-Bedingungen kritikwürdig ist. Demnach hat schulische Bildung (Kindergärten, Schulen, Hochschulen) einen höheren Stellenwert als die außerschulische (Erwachsenenbildung im weitesten Sinne). Der eine Bereich soll unter allen Umständen offenbleiben bzw. offengehalten werden, der andere wird - wie Kunst und Kultur - der Freizeit zugeordnet, kann also geschlossen werden bzw. bleiben. Und dass es dafür auch Rettungsschirme braucht, war eine späte Einsicht. Ob die Bildungs- und Kulturlandschaft nach Corona so vital ist, wie sie einmal war, wird man sehen.

Was noch hinzukommt: Die außerschulische Bildung wird ihrerseits noch einmal unterteilt in berufliche Fortbildung (muss weiter möglich sein) und Bildungsangebote, die nicht verzweckt sind (werden geschlossen, sind also derzeit - nicht nötig).

Die Kirchen haben in ihren Beiträgen zur Bildungsdebatte stets Tendenzen einer Verkürzung von Bildung widersprochen, die rein funktionale Erfordernisse betonen. »Oberstes Maß der Bildung müssen der Eigenwert und die eigene Würde jedes einzelnen Menschen sein, in der Kirche selbst, aber auch in anderen Bereichen der Gesellschaft «, heißt es in dem EKD-Papier »Kirche und Bildung«.

Jenseits von Schulpflicht und Bildungszertifikaten sind non-formale und informelle Bildungsprozesse nicht weniger wichtig. Ganz im Gegenteil! Orientierung und Orientierungswissen erst sind der Schlüssel zur Selbstbildung des Menschen in den verschiedenen Phasen seines Lebenslaufs. Sie sind von anderer - nicht minderer - Qualität als das Verfügungswissen (Sachwissen/Handlungs-Know-how).

Persönlichkeitsbildung, kulturelle Bildung, gesellschaftspolitische Bildung und Verantwortung - dies sind die Merkmale außerschulischer Bildung mit ihren Angeboten lebenslangen und lebensbegleitenden Lernens. Diese Angebote sind essentiell, fundamental, existentiell und keinesfalls Freizeitbeschäftigungen, die verzichtbar sind. 
Dies zu unterstreichen war auch schon vor Corona wichtig. Denn Fortbildung, die ausschließlich dazu dient, Erfordernissen in Wirtschaft und Industrie zu entsprechen, reduziert Menschen darauf, funktionieren zu sollen bzw. zu müssen. Dies widerspricht klar einem Bildungsansatz, der den ganzen Menschen in den Blick nimmt.

Die Digitalisierung fordert gleichermaßen die schulische wie die außerschulische Bildungsarbeit heraus. Corona hat gezeigt, dass die technischen Voraussetzungen für Homeschooling (Schule zu Hause) gar nicht gegeben sind - weder in der Schule noch im privaten Bereich. Nicht nur die Ressourcen (technische Ausstattung u.a.) fehlen, sondern auch die Professionalisierung der Lehrenden ist unzureichend.

Was aber vor allem beunruhigen muss, sind die ungleichen Teilhabechancen. Das Versprechen der Digitalisierung - mehr Teilhabe bzw. Teilhabe für die bislang Benachteiligten - ist erst noch einzulösen. Dabei liegen die Vorteile der Digitalisierung auf der Hand: ungeahnte Lernmöglichkeiten, flexible Zugriffsmöglichkeiten. Um diese Potentiale nutzen zu können, braucht es entsprechende Anstrengungen, gleiche Teilhabechancen $\mathrm{zu}$ gewährleisten. Andernfalls profitieren die ohnehin schon besser Gebildeten und die Bildungsschere geht weiter auseinander.

Und was mindestens so wichtig erscheint: Es braucht einen kritischen Diskurs über die gesellschaftlichen Folgen der Digitalisierung. E-Learning, Homeoffice, Videokonferenz - damit ist noch keine methodisch-didaktische oder organisatorische Nutzung digitaler Medien gegeben. Wenn Digitales zur Normalität wird, dann ist zum rechten Gebrauch auch die Entwicklung alternativer, nichtdigitalisierter (Bildungs- und Freizeit)Angebote erforderlich. Denn: »Alles wirkliche Leben ist Begegnung.« Dieser viel zitierte Satz des jüdischen Religionsphilosophen Martin Buber hat auch und gerade in CoronaZeiten nichts von seiner Bedeutung eingebüßt. Der Wert der persönlichen Begegnung hat an Gewicht gewonnen. Wie wichtig er ist, hat Buber in unmittelbarem Anschluss ausgeführt - eine Mahnung für heute und für die $\mathrm{Zu}$ kunft: »Wenn wir aufhören, uns zu begegnen, ist es, als hörten wir auf zu atmen.«

Bildung und Begegnung, Kunst und Kultur - das ist unverzichtbar für die Weiterentwicklung jedes Einzelnen wie der gesamten Gesellschaft. Kultur und politische Bildung haben ihr je eigenes Profil, aber sie sind die Foren und das Lebenselixier der Zivilgesellschaft. Ohne sie fehlt das fürs Leben und Überleben Notwendige. 
Die Corona-Krise stellt unser Zusammenleben, Politik, Gesellschaft, Wirtschaft, Kultur, Medien - schlicht alles in Frage. Haben wir es mit einer zerstörerischen Disruption zu tun? Oder reichen die Ressourcen für eine Weiterentwicklung, die sich am Gemeinwohl und an den Bedürfnissen vieler und nicht am Gewinn für wenige orientiert? Bildung heißt: Menschen befähigen, die Zukunft selbst zu gestalten. Hierin lag schon immer ein kraftvoller Impuls für eine Veränderung zum Besseren. Damit er auch gegenwärtig und zukünftig wirksam werden kann, braucht es die bewusste Verständigung und Vergewisserung in Politik und Gesellschaft. Wird diese nicht gesucht bzw. die Entwicklung dem freien Spiel der Kräfte überlassen, besteht die Gefahr, dass Bewährtes und Unverzichtbares unwiederbringlich zerstört wird.

\section{Literaturhinweise}

Evangelische Kirche in Deutschland (2020): »Hinaus ins Weite - Kirche auf gutem Grund«. Zwölf Leitsätze zur Zukunft einer aufgeschlossenen Kirche, https://www.ekd.de/ekd_de/ds_doc/Hinaus-ins-Weite-Kirche-aufgutem-Grund-Zwoelf-Leitsaetze-zur-Zukunft-einer-aufgeschlossenenKirche.pdf (16.11.2020)

Kirchenamt der EKD (Hg.) (2009): Kirche und Bildung. Herausforderungen, Grundsätze und Perspektiven evangelischer Bildungsverantwortung und kirchlichen Bildungshandelns. Eine Orientierungshilfe des Rates der Evangelischen Kirche in Deutschland, Hannover, https://www.ekd.de/ek d_de/ds_doc/kirche_und_bildung.pdf (16.11.2020)

Evangelisch-Lutherische Kirche in Bayern (Hg.) (2016): Horizonte weiten Bildungslandschaften gestalten. Bildungskonzept für die EvangelischLutherische Kirche in Bayern, mit ausführlichen Literaturhinweisen, https://www.rpz-heilsbronn.de/Dateien/Amtliche-Verlautbarungen /bildungskonzept_elkb.pdf (16.11.2020) 



\section{Ausblicke:}

Perspektiven der Zivilgesellschaft in Deutschland 



\section{Rechtspopulismus und organisierte Zivilgesellschaft}

Wolfgang Schroeder, Samuel Greef, Jennifer Ten Elsen, Lukas Heller

\section{Einleitung}

Die etablierten zivilgesellschaftlichen Organisationen als elementare Bestandteile der Bürgergesellschaft und einer pluralen Demokratie wurden in den letzten Jahren zunehmend durch rechtspopulistische Aktivitäten und Gruppen herausgefordert. ${ }^{1}$ Dazu zählen die Mobilisierungen von Pegida, das Werben »Alternativer Gewerkschaften« um Betriebsratssitze, die rassistischen Interventionen in der »Özil-Debatte« im Rahmen der Fußballweltmeisterschaft 2018, die Diskurse um die Einladung von AfD-Vertretern zu den Kirchentagen oder der Versuch antidemokratischer Kräfte, die Veranstaltungen gegen die Corona-Politik der Regierung für eine rechtspopulistische Agenda $\mathrm{zu}$ instrumentalisieren. Schließlich hat auch die AfD (2019: 36) die organisierte Zivilgesellschaft als wichtigen Raum für sich erkannt und versucht sich »mit einem Marsch durch die Organisationen« systematisch in verschiedenen Bereichen der Zivilgesellschaft $\mathrm{zu}$ platzieren. Ihr Ziel ist es, "sich stärker in der Bürgergesellschaft zu verankern«, um ein politisches Vorfeld zu etablieren. Diese Beispiele zeigen, dass die aktuellen politischen Konfliktlinien, die mit dem Erstarken des Rechtspopulismus verbunden sind, auch durch die Zivilgesellschaft verlaufen und eine Herausforderung für den demokratischen Basiskonsens der Gesellschaft darstellen.

Diese Aktivitäten sind der Anlass, rechtspopulistische Aktivitäten und Interventionen in der organisierten Zivilgesellschaft sowie deren Reaktionen sellschaft von rechts. Interventionsversuche und Reaktionsmuster «zusammen (Schroeder et al. 2020). Es ist die leicht gekürzte Fassung eines Aufsatzes, der in Heft 4(2020) des Forschungsjournals Soziale Bewegungen erschienen ist. 
systematisch und aus einer vergleichenden Perspektive $\mathrm{zu}$ analysieren. Mit Blick auf Gewerkschaften, Wohlfahrtsverbände, Kirchen sowie Akteure aus dem Kultur- und Sportbereich stellen sich drei zentrale Fragen, die die Resilienz der organisierten Zivilgesellschaft gegenüber rechten Einflussversuchen in den Blick nehmen (vgl. Grande 2018a):

(1) Welche Themen, Handlungsfelder und -formen zeichnen rechtspopulistische Aktivitäten in den fünf Bereichen aus und inwiefern geht daraus eine Infragestellung des bundesrepublikanischen Basiskonsenses hervor?

(2) Welche Reaktionen der jeweiligen Organisationen sind im Umgang mit diesen Aktivitäten erkennbar?

(3) Existieren subsystemspezifische Muster von Interventionen oder Reaktionen?

\section{Rechtspopulismus, organisierte Zivilgesellschaft und Basiskonsens}

Die Frage nach rechtspopulistischen Interventionen macht es notwendig, das eigene Verständnis des uneindeutigen Begriffs »Rechtspopulismus« $\mathrm{zu}$ klären. Wir verstehen Populismus als eine »dünne« Ideologie (Freeden 1998; Mudde 2007) (»Wir« gegen »die da oben« und »Wir« gegen »die anderen«). Das Verhältnis zwischen Populismus und Extremismus ist dabei ambivalent, da der »dünne« ideologische Kern sowohl von etablierten demokratischen als auch von extremistischen Akteuren adaptiert werden kann. Rechtspopulismus eröffnet dabei einen Diskurs, der »nicht rechts genug ist, um ihn als anti-systemisch oder verfassungswidrig auszugrenzen, aber hinlänglich rechts, um jenen als Auffangbecken zu dienen, die sich [...] immer weniger repräsentiert fühlen.« (Priester 2012, S. 109) Rechtspopulismus kann daher als Brücke und Möglichkeitsraum zwischen einer demokratisch konstituierten Öffentlichkeit und rechtsextremistischen Positionen verstanden werden. Diese Brücke reicht bis in die Zivilgesellschaft hinein.

Die organisierte Zivilgesellschaft nimmt für die Akzeptanz der Demokratie eine Schlüsselposition ein, da sie eine zentrale Rolle bei der Strukturierung des öffentlichen Raumes spielt. Verbände und Vereine bearbeiten, beantworten und deuten die Interessen der Bevölkerung. In diesem Sinne ist die organisierten Zivilgesellschaft eng mit dem bundesrepublikanischen Basiskonsens verbunden. Unter diesem wird die weitgehende gesellschaftliche »Anerkennung ökonomischer, politischer und ideologischer Grundlagen« ei- 
ner Gesellschaft verstanden (Weßels 1991, S. 32). Er entsteht im Zuge langfristiger gesellschaftlicher Entwicklungen, bildet einen gemeinsamen Werteund Normenkanon, der als Korridor staatlichen und gesellschaftlichen Handelns verstanden wird und garantiert damit »die Stabilität der politisch-gesellschaftlichen Ordnung (ebd.). Inhaltlich umfasst er Strukturen der politischen Willensbildung und Entscheidungsfindung. Der kometenhafte Aufstieg des Rechtspopulismus stellt diesen Basiskonsens infrage.

Es lohnt also zu reflektieren, welche Bedeutung der Zivilgesellschaft sowohl als Verfechter des Basiskonsens als auch als rechtspopulistisches Einfallstor für dessen Infragestellung zukommt. Wir verstehen Zivilgesellschaft dabei empirisch als Gesamtheit aller gesellschaftlichen Aktivitäten jenseits von Markt und Staat. Sie folgt nicht ausschließlich dem normativen Ideal der gemeinwohlorientierten, demokratiefördernden Selbstorganisation (Grande 2018b, S. 52), sondern weist auch Praktiken der Spaltung und Exklusion - also eine »schmutzige Seite« - auf (Geiges et al. 2015). Insoweit ist die Zivilgesellschaft ein ambivalenter Ort und es ist nicht verwunderlich, wenn rechtspopulistische Akteure "zunehmend zivilgesellschaftlich orientierte Strategien« verfolgen, um diesen Ort für sich zu erschließen (Roth 2010, S. 53).

\section{Systematik rechtspopulistischer Interventionen in die Zivilgesellschaft}

Wie wirkt der Rechtspopulismus in die Zivilgesellschaft hinein? Unsere Analyse zeigt in allen untersuchten Bereichen ähnlich strukturierte Einfallstore für rechtspopulistische Interventionen (vgl. Tabelle 1). Korporatistisch strukturierte institutionelle Arrangements, die zwischen staatlichen und verbandlichen Akteuren in den jeweiligen Arenen bestehen, bilden eine grundlegende Gelegenheitsstruktur. ${ }^{2}$ Zwar gibt es markante Unterschiede zwischen den stärker institutionalisierten Akteuren (Gewerkschaften, Kirchen, Wohlfahrtsverbände) und den weniger institutionalisierten Bereichen (Kultur, Sport). Dennoch sind die grundlegenden Ansatz- und Kritikpunkte von rechts vergleichbar, auch wenn sich die konkreten Interventionen subsystemspezifisch

2 Gelegenheitsstrukturen sind begünstigende oder beschränkende strukturelle Rahmenbedingungen. Das Konzept knüpft an der »political opportunity structure « zur Erklärung für das Entstehen von sozialen Bewegungen an (Kriesi 1991). 
unterschiedlich ausgestalten. Inhaltlich setzen sie an der spezifischen Rolle an, welche die Bereiche für den demokratischen Basiskonsens einnehmen und aus der die zivilgesellschaftlichen Akteure ihr politisches Mandat ableiten.

Tabelle 1: Ebenen rechtspopulistischer Interventionen

\begin{tabular}{|c|c|c|c|}
\hline & $\begin{array}{l}\text { Institutionelles Ar- } \\
\text { rangement }\end{array}$ & Normative Basis & Politisches Mandat \\
\hline Gewerkschaften & $\begin{array}{l}\text { korporatistische } \\
\text { Arbeitsbeziehun- } \\
\text { gen, Monopolan- } \\
\text { spruch }\end{array}$ & Gute Arbeit für alle & $\begin{array}{l}\text { Historisch veranker- } \\
\text { tes Engagement ge- } \\
\text { gen Rechts }\end{array}$ \\
\hline Kirchen & $\begin{array}{l}\text { Kirchenkorporatis- } \\
\text { mus }\end{array}$ & $\begin{array}{l}\text { universelle Nächs- } \\
\text { tenliebe }\end{array}$ & $\begin{array}{l}\text { Engagement für } \\
\text { partnerschaftliche, } \\
\text { multikulturelle } \\
\text { Gesellschaft }\end{array}$ \\
\hline $\begin{array}{l}\text { Wohlfahrts- } \\
\text { verbände }\end{array}$ & $\begin{array}{l}\text { Wohlfahrtskorpo- } \\
\text { ratismus }\end{array}$ & $\begin{array}{l}\text { universelle Sozial- } \\
\text { anwaltschaft }\end{array}$ & $\begin{array}{l}\text { Engagement für } \\
\text { Schwache und } \\
\text { Migranten }\end{array}$ \\
\hline $\begin{array}{l}\text { organisierter } \\
\text { Sport }\end{array}$ & $\begin{array}{l}\text { Sportkorporatis- } \\
\text { mus }\end{array}$ & $\begin{array}{l}\text { Engagement für } \\
\text { Multikulturalis- } \\
\text { mus, Fairness und } \\
\text { Toleranz }\end{array}$ & $\begin{array}{l}\text { Motor für Inte- } \\
\text { gration, Kampf } \\
\text { gegen Rechts und } \\
\text { Rassismus }\end{array}$ \\
\hline $\begin{array}{l}\text { organisierte } \\
\text { Kultur }\end{array}$ & $\begin{array}{l}\text { Kulturkorporatis- } \\
\text { mus (staatliche } \\
\text { Kulturförderung) }\end{array}$ & $\begin{array}{l}\text { Kosmopolitische } \\
\text { Multikulturalität, } \\
\text { Offenheit, Toleranz }\end{array}$ & $\begin{array}{l}\text { kulturelle Vielfalt } \\
\text { (Meinungs- und } \\
\text { Kunstfreiheit) }\end{array}$ \\
\hline
\end{tabular}

Quelle: eigene Darstellung

Die konkreten rechtspopulistischen Interventionen bedienen sich dabei subsystemspezifischer Widersprüche und Konflikte. So werden im Bereich der Arbeitswelt beispielsweise die Unsicherheiten des Lohnarbeitsverhältnisses aufgegriffen. Für die Gewerkschaften steht die Frage im Zentrum, ob es Rechtspopulisten gelingt, aus den gewachsenen Machtbeziehungen zu den Arbeitgebern und den Verunsicherungen der Arbeitnehmer ein Potenzial der Akzeptanz zu schöpfen, um eine salternative Interessenvertretung gegen die Dominanz der DGB-orientierten Betriebsräte zu etablieren. Sowohl die Ergebnisse der Betriebsratswahlen als auch die Tatsache, dass bei der Bun- 
destagswahl 2017 rund $15 \%$ der Gewerkschaftsmitglieder die AfD wählten, zeigt, dass die interessenpolitische Logik des "Entweder-Oder" gesprengt wird und sich "gewerkschaftliches und rechtspopulistisches Engagement nicht von vornherein aus[schließen]« (Sauer et al. 2018, S. 58).

Im Umfeld der christlichen Kirchen dominiert die Instrumentalisierung von christlichen Werten. Zur Disposition steht, ob es dadurch gelingt, diejenigen Christen zu mobilisieren, die den konservativen Positionen rechter Akteure - etwa bei den Themen Islam und gleichgeschlechtlicher Ehe - nahestehen. Allport (1966, S. 447ff.) formulierte bereits in den 1960er Jahren das Paradoxon, dass Religionen Vorurteilsstrukturen und rassistischen Denkmustern durch ihren moralischen Wertekanon zwar entgegenwirken, zugleich aber mit einigen theologischen Elementen (u.a. Auserwähltheit, Wahrheitsanspruch) Einfallstore für Überzeugungen liefern, die mit Selbsterhöhung und antipluralistischen Tendenzen verbunden sein können. Insbesondere der religiöse Exklusivitätsanspruch und die Kirchgangshäufigkeit sind entscheidende Variablen, die mit einer Ablehnung plural-demokratischer Strukturen korrelieren (Ahrens/Rebenstorf 2018, S. 198). Für die Bundestagswahl 2017 zeigt sich, dass katholische sowie protestantische Kirchgänger, die mindestens einmal im Monat einen Gottesdienst besuchen, die AfD unterdurchschnittlich häufig wählten (Weßels 2018).

Wohlfahrtsverbände bieten als zentrale Akteure der Daseinsvorsorge vielfältige Angriffspunkte. Neben Fällen, in denen der Missbrauch staatlicher Mittel öffentlich wurde, wird der Einsatz der Verbände im Sinne einer universellen Sozialanwaltschaft infrage gestellt, worunter auch ihr Engagement im Rahmen der sogenannten Flüchtlingskrise fällt. So wird versucht, die Wohlfahrtsverbände und ihre Einrichtungen als Teil einer >Asylindustrie $\mathrm{zu}$ charakterisieren, die viel Steuergeld koste. Darüber hinaus geht es rechten Akteuren in diesem Feld darum, exklusive Ansprüche für Deutsche zu schaffen, während sie für andere ethnische Gruppen eine restriktivere Konditionierung anstreben (Schroeder et al. 2020, S. 110ff.).

Auch das korporatistische Arrangement im Sport bietet Anknüpfungspunkte für Interventionen, die am multikulturellen, integrativen Gedanken der Sportförderung ansetzen. Den Zielen von Fairness und Toleranz wird die Forderung nach einer stärkeren Förderung deutscher Tugenden und Traditionen gegenübergestellt, die sich wieder stärker an Stolz, Nation, Identität und Patriotismus orientieren müssten. Wettkampf, Männlichkeit und Gemeinschaft ergeben weitere Anknüpfungspunkte für rechtes Gedankengut. So versuchen rechte Akteure im Fußball beispielsweise, das Gemeinschafts- 
gefühl von Vereinen und Fangruppen zur Ausgrenzung gegenüber anderen gesellschaftlichen Gruppen zu nutzen.

Im Bereich Kultur erweisen sich insbesondere die Themen »(partei)politische Neutralität« und »Freiheit der Kunst« als Einfallstore für Rechtspopulisten. Inhaltlich werden die Ideen von Heimat und Nation gegen die Ziele einer multikulturellen Gesellschaft gerichtet. Rechtspopulistische Aktivitäten sind in diesem Sinne häufig mit dem Ziel verbunden, eigene Positionen als Teil der »freien Meinungsäußerung« zu legitimieren.

Insgesamt entsprechen die skizzierten rechten Interventionen den vertikalen und horizontalen Logiken, die dem Populismus inhärent sind. Insbesondere stärker institutionalisierte Subsysteme befördern eine Abgrenzung im Sinne einer »Oben-gegen-Unten«-Logik. Zivilgesellschaftliche Organisationen werden in ihrem Wirken und in ihren (politischen) Haltungen kritisiert und es wird versucht, sie in ihren Funktionen zu delegitimieren. Dabei werden Themen aufgegriffen, welche die inneren Widersprüche der zivilgesellschaftlichen Räume adressieren. Auf horizontaler Ebene wird unter dem Postulat einer kulturellen Hegemonie die Abgrenzung gegen multikulturelle Lebens-, Arbeits-, Freizeit- und Glaubensräume betrieben. Beide Ebenen verbindet die Einforderung eines erweiterten Pluralismus, der die Enttabuisierung von Diskursen vorsieht und die Grenzen des Sagbaren aufweicht.

\section{Systematik zivilgesellschaftlicher Reaktionen}

Die Frage nach dem richtigen Umgang mit rechten Interventionen wird kontrovers diskutiert und ein Königsweg scheint bisher nicht gefunden. Deutlich wird, dass die Reaktionen im Umgang mit rechtspopulistischen Tendenzen in allen Subsystemen aus einem Mix aus präventiven und reaktiven Maßnahmen bestehen. Dies ist der Einsicht geschuldet, dass die Akteure sowohl strukturell (im Sinne langfristiger Konfliktlagen und Widersprüche) als auch situativ (aufgrund konkreter Anlässe) herausgefordert sind.

Da die untersuchten Organisationen aufgrund ihrer normativen Basis und ihres politischen Mandats aktiv für den bundesdeutschen Basiskonsens einstehen und sich in ihrer Werteorientierung diametral $\mathrm{zu}$ rechtspopulistischen Vorstellungen verorten, bleiben zustimmende Positionierungen aus. Auf der kommunikativen Ebene entsprechen die Reaktionen in der Regel einer Distanzierung von rechten Akteuren und Haltungen. Diese fällt umso deutlicher aus, je weiter die Intervention dem rechtsextremen Spektrum 
zugeordnet werden kann. Es überwiegt die Hervorhebung der eigenen Werte und Standpunkte: abgrenzen, ohne auszugrenzen.

Auf der organisationalen Ebene wird versucht, den Dialog offenzuhalten (auseinandersetzen). Es kommt aber auch dazu, dass Interventionen ignoriert werden, was wahrscheinlicher ist, wenn es sich um Mitglieder handelt, die man nicht verlieren will und der Vorfall bisher keine (mediale) Öffentlichkeit erfahren hat. Zu Konfrontationen und Sanktionen kommt es nur in Extremfällen. Einer konfrontativen Logik durch Ausgrenzen folgen beispielsweise Unvereinbarkeitsbeschlüsse, die jedoch - nicht zuletzt aufgrund rechtlicher Unklarheiten - eher selten sind.

Insgesamt sind die Reaktionen stark situativ-reaktiver Natur und nicht von einer belastbaren Strategie geprägt. Sie gleichen Suchbewegungen, in denen die Verunsicherung zivilgesellschaftlicher Akteure und Organisationen in Fragen des richtigen Umgangs mit rechtspopulistischen Interventionen zum Ausdruck kommt. Dazu mag auch die strukturelle Ambivalenz der Reaktionsmöglichkeiten beitragen (vgl. Tabelle 2).

Der Grund dafür, dass die Reaktionen zwischen Chancen und Risiken changieren, liegt in dem inhärenten Dilemma des Populismus: Sowohl bei Nichtbeachtung als auch bei Reaktionen besteht das Risiko, das Phänomen zu stärken. Der Versuch, Rechtspopulisten durch Beteiligung zu sentzaubern<, beschert ihnen Aufmerksamkeit und spricht ihnen möglicherweise Legitimität zu. Nichtbeachtung beinhaltet dagegen die Gefahr, als stillschweigende Zustimmung missverstanden zu werden oder zur Normalisierung rechtspopulistischer Positionen beizutragen.

Öffentliche Nichtbeachtung kann aber nicht ohne weiteres mit Ignoranz gleichgesetzt werden. So kann sie durchaus der sensiblen Beobachtung folgen, zwar öffentlich nicht zu handeln, aber unterhalb der öffentlichen Wahrnehmung zu reagieren. Dafür braucht es ein tiefergehendes Verständnis der Handlungslogik rechter Interventionen. Es gibt keinen `One-size-fitsalk-Ansatz, bei dem eine einzige Reaktionsform die ultimative Antwort auf alle rechten Interventionen darstellt. Vielmehr bedarf es eines Bündels an Reaktionsformen. Diese müssen aufeinander bezogen und abgestimmt sowie nicht nur reaktiv genutzt werden, damit von einer Strategie gesprochen werden kann. Dafür müssen sich die Organisationen aktiv mit den Ursachen für rechtspopulistische Denk- und Handlungsmuster auseinandersetzen. Nur so können sie diese erkennen, verstehen und darauf reagieren. Insbesondere wertebasierte Orientierungspunkte ermöglichen dabei authentische Reaktionen. 
Tabelle 2: Reaktionsmuster: Chancen und Risiken

\begin{tabular}{|l|l|l|}
\hline Reaktion & $\begin{array}{l}\text { Umgang mit Interven- } \\
\text { tion }\end{array}$ & Ambivalenz \\
\hline Ignorieren & nicht darauf eingehen & $\begin{array}{l}\text { Risiko: »stillschweigende Zu- } \\
\text { stimmung«, Normalisierung } \\
\text { Chance: keine Aufmerksam- } \\
\text { keit, keine Opferrolle }\end{array}$ \\
\hline Auseinandersetzen & $\begin{array}{l}\text { eingehende Beschäfti- } \\
\text { gung }\end{array}$ & $\begin{array}{l}\text { Risiko: Aufmerksamkeit } \\
\text { Chance: Aufklärung, Gren- } \\
\text { zen markieren, Profilschär- } \\
\text { fung }\end{array}$ \\
\hline Abgrenzen & distanzieren & $\begin{array}{l}\text { Risiko: Konflikt, Wider- } \\
\text { spruch, Mitgliederverluste } \\
\text { Chance: Klare Orientierung }\end{array}$ \\
\hline Ausschließen & $\begin{array}{l}\text { "Stiller« Ausschluss } \\
\text { ohne öffentliche } \\
\text { Thematisierung }\end{array}$ & $\begin{array}{l}\text { zung, Vorwurf, Probleme } \\
\text { zu verschweigen } \\
\text { Chance: Interne Grenzzie- } \\
\text { hung }\end{array}$ \\
\hline Ausgrenzen & $\begin{array}{l}\text { Risiko: Opfermythos, Mit- } \\
\text { gliederverluste } \\
\text { Chance: Grenzziehung }\end{array}$ \\
\hline
\end{tabular}

Quelle: eigene Darstellung

\section{Fazit}

Bestehende Konfliktlinien innerhalb der zivilgesellschaftlichen Arenen werden von Rechts aufgegriffen. Ihre Interventionen erfolgen damit pfadabhängig. Dabei setzen sie - der populistischen Logik des »Unten gegen Oben« folgend - an den Gelegenheitsstrukturen spezifischer, korporatistisch strukturierter institutioneller Arrangements in den Subsystemen an, um die etablierten Akteure als Teil des Establishments zu diffamieren. Die Interventionen folgen einem Muster von Delegitimierungs- und Skandalisierungsversuchen. In der populistischen Logik »Innen gegen Außen « richten sie sich gegen die werteorientierte Verfasstheit und die normative Basis der organisierten Zivilgesellschaft. 
Für diese eröffnen sie alternative Interpretationsangebote im Sinne einer kulturellen Hegemoniebestrebung. Beide Ebenen verbinden sich in der Kritik am politischen Mandat der zivilgesellschaftlichen Organisationen, die sich als Verfechter des bundesdeutschen Basiskonsenses begreifen. Mit der sogenannten Flüchtlingskrise oder den Betriebsratswahlen 2018 öffneten sich Gelegenheitsfenster für Rechtspopulisten, um an vorhandene Konflikte in den zivilgesellschaftlichen Subsystemen anzudocken.

Die Reaktionen der organisierten Zivilgesellschaft auf diese Interventionen changieren bislang zwischen Abgrenzen und Auseinandersetzen. Dabei kommt der Mitgliederlogik eine wichtige Rolle zu, womit auf der inhaltlichen Ebene das Risiko einer stillschweigenden Zustimmung oder Normalisierung gegeben ist. Sollte diese Perspektive dominieren, könnte die Rolle der organisierten Zivilgesellschaft als Anwalt des demokratischen Basiskonsenses strukturell geschwächt werden und der »schmutzigen Seite« (Geiges et al. 2015) der Zivilgesellschaft eine veränderte politische Bedeutung zukommen. Wie aber kann die Gratwanderung einer eindeutigen normativen Positionierung gelingen, ohne die Tür für rechtsaffine Mitglieder zuzuschlagen?

Zivilgesellschaftliche Organisationen sind zunächst herausgefordert, ihre inneren Widersprüche zu bearbeiten. Organisational verfestigte normative Werte und ein klarer, aus dem institutionellen Arrangement abgeleiteter politischer Auftrag sind die Basis für die Entwicklung einer angemessenen Strategie. Ob ihnen dies gelingt, entscheidet mit darüber, inwiefern sie als Schutzfaktor gegen oder als Einfallstor für Rechtspopulismus wirken können. Dies ist umso notwendiger, je mehr ersichtlich wird, dass die Erschöpfung der organisierten Zivilgesellschaft selbst die Akzeptanz und Legitimität des Basiskonsenses schwächt.

\section{Literaturhinweise}

Ahrens, Petra-Angela/Rebenstorf, Hilke (2018): Rechtspopulismus unter evangelischen Christen - empirische Befunde der Kirchen- und Religionssoziologie. In: ZEE, 62(3), S. 183-199.

Allport, Gordon W. (1966): Religious Context of Prejudice. In: JSSR, 5(5), S. 447457.

Freeden, Michael (1998): Ideologies and Political Theory: A Conceptual Approach. Oxford: Clarendon Press.

Geiges, Lars/Marg, Stine/Walter, Franz (2015): Pegida. Die schmutzige Seite der Zivilgesellschaft? Bielefeld: transcript. 
Grande, Edgar (2018a): Warum auch rechte Bewegungen zur Zivilgesellschaft gehören. In: Süddeutsche Zeitung, 17.08.2018.

Grande, Edgar (2018b): Zivilgesellschaft, politischer Konflikt und soziale Bewegungen. In: Forschungsjournal Soziale Bewegungen, 31(1-2), S. 52-60.

Kriesi, Hanspeter (1991): The Political Opportunity Structure of New Social Movements - Its Impact on Their Mobilization. WZB Discussion Paper FS III, 91-103. Berlin: WZB.

Mudde, Cas (2007): Populist radical right parties in Europe. Cambridge: Cambridge University Press.

Niedermayer, Oskar (2018): Die AfD in den Parlamenten der Länder, des Bundes und der EU. Bipolarität im Selbstverständnis und im Verhalten. In: Zeitschrift für Parlamentsfragen, 49(4), S. 896-908.

Priester, Karin (2012): Rechter und linker Populismus. Annäherung an ein Chamäleon. Frankfurt/New York: Campus.

Roth, Roland (2010): Demokratie braucht Qualität! Beispiele guter Praxis und Handlungsempfehlungen für erfolgreiches Engagement gegen Rechtsextremismus. Berlin: FES.

Sauer, Dieter/Stöger, Ursula/Bischoff, Joachim/Detje, Richard/Müller, Bernhard (2018): Rechtspopulismus und Gewerkschaften. Eine arbeitsweltliche Spurensuche. Hamburg: VSA.

Schroeder, Wolfgang/Greef, Samuel/Ten Elsen, Jennifer/Heller, Lukas (2020): Bedrängte Zivilgesellschaft von rechts. Interventionsversuche und Reaktionsmuster. OBS-Arbeitsheft 102. Frankfurt a.M.: Otto-Brenner-Stiftung.

Schroeder, Wolfgang/Weßels, Bernhard/Neusser, Christian/Berzel, Alexander (2017): Parlamentarische Praxis der AfD in deutschen Landesparlamenten. Berlin: WZB.

Weßels, Bernhard (1991): Erosion des Wachstumsparadigmas: Neue Konfliktstrukturen im politischen System der Bundesrepublik? Wiesbaden: VS Verlag.

Weßels, Bernhard 2018: Wahlverhalten sozialer Gruppen. In: Roßteutscher, Sigrid et al. (Hg.), Zwischen Parlamentarisierung und Beharrung: Die Bundestagswahl 2017. Baden-Baden: Nomos, S. 187-202. 


\section{Entwicklungen und Herausforderungen der Zivilgesellschaft in Deutschland}

Edgar Grande

Die Beiträge dieses Bandes zeigen eindrucksvoll, dass die Zivilgesellschaft in Deutschland sehr vielfältig und - bei aller Widersprüchlichkeit - sehr vital ist. Aber wie ist es um ihre Zukunft bestellt? Welche Zukunftsperspektiven hat die Zivilgesellschaft in Deutschland? Dieser Frage möchte ich mich in diesem Beitrag über einen Umweg nähern. Ausgehend von einigen allgemeinen theoretischen Erwartungen zu den Entwicklungsperspektiven der Zivilgesellschaft werde ich mich mit neueren Entwicklungstendenzen beschäftigen und die Herausforderungen skizzieren, vor denen die Zivilgesellschaft derzeit - und auf absehbare Zeit - in Deutschland steht. Abschließend werde ich darauf eingehen, was getan werden kann und muss, damit sie diese Herausforderungen meistert. Meine Schlussfolgerung lautet, dass die Zukunft der Zivilgesellschaft nicht vorgezeichnet ist - sie ist vielmehr eine vordringliche gesellschaftspolitische Aufgabe.

\section{Wie entwickelt sich die Zivilgesellschaft in Deutschland?}

Nicht nur das Verständnis von Zivilgesellschaft hat sich in den vergangenen Jahrzehnten gewandelt, auch die Zivilgesellschaft selbst. Im Folgenden werde ich die wichtigsten Entwicklungslinien dieses Wandels in Deutschland kurz beschreiben. Diese Entwicklungen stehen im Kontext allgemeiner gesellschaftlicher Wandlungsprozesse. Zu deren Auswirkungen auf die Zivilgesellschaft gab es - und gibt es noch immer - ganz unterschiedliche Erwartungen. Auf der einen Seite steht die insbesondere von Inglehart (1998) formulierte Theorie des gesellschaftlichen Wertewandels, aus der sich eine optimistische Prognose über die Entwicklung des bürgerschaftlichen Engagements ableiten lässt. In der post-industriellen Wohlstandsgesellschaft, so 
die Annahme, gewinnen immaterielle Werte wie die individuelle Selbstverwirklichung an Bedeutung, die unter anderem im Wunsch nach größerer politischer Beteiligung ihren Ausdruck finden. Davon profitieren aber nicht in erster Linie die etablierten Parteien und Großorganisationen, sondern vor allem neue soziale Bewegungen (vgl. dazu den Beitrag von Rucht in diesem Band). Politische Soziologen und Bewegungsforscher wie Neidhart und Rucht haben die Bundesrepublik vor diesem Hintergrund auf dem Weg zur »Bewegungsgesellschaft« gesehen (vgl. Neidhart/Rucht 1993), zu einer »aktiven Gesellschaft« (Etzioni 1975), die sich nicht nur durch ein insgesamt höheres Engagementniveau auszeichnet, sondern auch durch neue, offenere Beteiligungsformen. Die Gegenthese hierzu formulierte Putnam, dessen Arbeiten die Zivilgesellschaftsforschung in den vergangenen fünfzwanzig Jahren stark beeinflusst haben. Er behauptet in einer zuerst 1995 als Aufsatz erschienen Arbeit, dass die amerikanische Gesellschaft auf dem Weg zur Individualisierung sei. Dies zeige sich nicht zuletzt daran, dass die Bürger immer weniger in Gemeinschaft mit anderen aktiv seinen und zunehmend alleine handelten: Das »bowling alone« (Putnam 1995) nehme immer mehr an Bedeutung zu. In diese Richtung argumentieren auch neuere soziologische Theorien, die den »Verlust des Allgemeinen « und die Überbetonung von »Singularitäten« in unserer Gesellschaft behaupten (vgl. Reckwitz 2018). »Bewegungsgesellschaft« oder »bowling alone« - dies scheinen, zugespitzt formuliert, die gegensätzlichen Entwicklungsperspektiven der Zivilgesellschaft auch in Deutschland zu sein.

Diese konträren Erwartungen waren ein wichtiges Motiv dafür, die Zivilgesellschaft und das bürgerschaftliche Engagement in Deutschland kontinuierlich und systematisch zu erfassen und zu vermessen. Ausgehend von der Enquetekommission des Deutschen Bundestages "Zukunft des bürgerschaftlichen Engagements«, die 2002 ihren Abschlussbericht vorlegte (vgl. EnqueteKommission 2002), war das bürgerschaftliche Engagement in Deutschland in den vergangenen zwanzig Jahren Gegenstand zahlreicher Umfragen und Erhebungen, beginnend mit dem ersten Freiwilligen-Survey aus dem Jahr 1999, der seither in regelmäßigen Abständen durchgeführt wird (zuletzt: Simonson et al. 2017). Hinzu kommen die Engagementberichte des Bundesfamilienministeriums (zuletzt: Deutscher Bundestag 2020); die Erhebungen des Stifterverbandes (Priemer et al. 2017), Umfragen wie die des Allensbacher Instituts für Demoskopie (z.B. BMFSFJ 2017) - um nur die wichtigsten zu nennen. Bei allen Unterschieden im Detail zeigen diese Studien einhellig, dass die Zivilgesellschaft in Deutschland sehr aktiv ist, dass das bürgerschaftliche Engagement stark ausgeprägt ist. Etwas vereinfacht kann man sagen, dass in 
Deutschland jeder zweite Bundesbürger auf die eine oder andere Weise aktiv ist. Der letzte Freiwilligensurvey hat daraus den Schluss gezogen, dass sich in Deutschland heute mehr Personen freiwillig oder ehrenamtlich engagieren als jemals zuvor (Simonson et al. 2017, S. 21).

Ist das so? Der Blick in die ältere soziologische Literatur lässt Zweifel an solchen Aussagen aufkommen. Die Bundesrepublik Deutschland war schon in den Nachkriegsjahren eine »organisierte Gesellschaft«. Die Mitgliederstärke der Kirchen und Gewerkschaften, aber auch der großen »Volksparteien « die damals noch beides waren: groß und »Volksparteien « - belegen dies eindrucksvoll. Mayntz kam in ihrem erstmals 1963 erschienen Buch »Soziologie der Organisation«, dem Klassiker der Organisationssoziologie in Deutschland, zu dem Ergebnis, dass in den 1950er Jahren »etwas über die Hälfte der Erwachsenen Mitglieder von freiwilligen Vereinigungen und Verbänden (sind), und zwar nicht selten von mehreren zugleich « (Mayntz 1963, S. 8).

Dies legt die Vermutung nahe, dass es nicht der Gesamtumfang der Beteiligung ist, der sich verändert hat, sondern Form und Intensität des Engagements. Auf drei Aspekte dieses Wandels möchte ich im Folgenden ausführlicher eingehen: Erstens den Strukturwandel, also den Wandel der Organisations- und Engagementformen, in dem sich die Zivilgesellschaft seit geraumer Zeit befindet; zweitens den Aktivierungsschub, den die Zivilgesellschaft in den vergangenen Jahren erfahren hat; und drittens die zunehmende Politisierung von Zivilgesellschaft. Diese drei Aspekte - Strukturwandel, Aktivierung und Politisierung - prägen zusammen die Entwicklung und die Entwicklungsperspektiven der Zivilgesellschaft in Deutschland. Ich werde jeden dieser drei Punkte kurz erläutern.

\section{Die Zivilgesellschaft wandelt sich!}

Die Veränderungen innerhalb der Zivilgesellschaft sind ein zentrales - und höchst kontrovers diskutiertes - Thema der Zivilgesellschaftsforschung. Es gibt zahlreiche Hinweise darauf, dass sich die assoziativen Grundlagen unserer Gesellschaft grundlegend verändern. Dieser Wandel der Zivilgesellschaft hat viele Facetten. Er reicht vom Vereinswesen über die soziale Bewegungslandschaft bis hin zu den politischen Parteien. Am bekanntesten ist der Bedeutungs- und Mitgliederverlust von großen Organisationen. Das betrifft die Volksparteien, die Kirchen und die Gewerkschaften. Für die Gewerkschaften finden sich im Beitrag von Wolfgang Schröder (in diesem Band) die entsprechenden Zahlen. 
Für das bürgerschaftliche Engagement in Deutschland hat die EnqueteKommission »Zukunft des Bürgerschaftlichen Engagements« den Wandel der Engagementformen bereits im Jahr 2002 detailliert aufgezeigt (vgl. EnqueteKommission 2002). Die vorliegenden Befunde zeigen, dass das bürgerschaftliche Engagement zwar insgesamt zugenommen hat, dass sich aber gleichzeitig sein Tätigkeitsspektrum und seine Organisationsformen gewandelt haben. Feste, dauerhafte Bindungen an Vereine, Verbände und Parteien verlieren an Bedeutung, während sich neue, flexiblere Formen des Engagements herausbilden.

Am Beispiel der Vereine und der Veränderung der Vereinslandschaft lässt sich dieser Wandel gut veranschaulichen. Die Vereine sind noch immer die stärkste Säule der Zivilgesellschaft in Deutschland. Die Hälfte des bürgerschaftlichen Engagements in Deutschland findet in Vereinen statt. Es gibt in Deutschland über 600.000 Vereine und der Stifterverband erfasst ihren Bestand und ihre Entwicklung systematisch. In seinem letzten Bericht aus dem Jahr 2017 kommt er zu dem Ergebnis: »Kulturpessimisten zum Trotz: Nach wie vor werden neue Vereine, Stiftungen und andere Organisationen gegründet. Die Zahl der in den Vereinsregistern eingetragenen Vereine ist von 2012 bis 2016 um knapp 23.600 auf rund 604.000 gestiegen« (Priemer et al. 2017, S. 10). Das ist die gute Nachricht. Wenn man sich aber die Entwicklung der Vereinslandschaft genauer anschaut, dann zeigt sich noch ein anderes Bild: Die Zahl der jährlich neu gegründeten Vereine nimmt kontinuierlich ab (von 22.042 im Jahr 1995 auf 15.084 im Jahr 2013), während die Zahl der jährlich aufgelösten Vereine kontinuierlich ansteigt (von 4.448 im Jahr 1995 auf 10.512 im Jahr 2013) (vgl. Priemer et al. 2017, S. 8). Man muss kein »Kulturpessimist « sein, um zu erwarten, dass sich diese beiden Entwicklungslinien bald treffen und überschneiden werden - wenn sie es nicht schon längst getan haben. Kurz gesagt: Die Daten des Stifterverbandes belegen nicht nur die große Vitalität der Zivilgesellschaft, sie lassen auch befürchten, dass uns schon in diesem Jahrzehnt eine Debatte über das Vereinssterben in Deutschland bevorsteht. Hinzu kommt, dass sich auch die Funktionen von Vereinen, insbesondere für ihre Mitglieder, verändert haben. Der Stifterverband hat die Vereine auch nach Organisationstypen unterschieden und ihre relative Bedeutung über Zeit erfasst. Dabei ist auffällig, dass im Zeitverlauf der Anteil von Organisationen, die sich als fördernde Themenanwälte oder als reine Förderorganisationen verstehen, ansteigt, während der Anteil der sogenannten »Integrierer«, also von gemeinschaftsorientierten Vereinen, stark zurückgegangen ist (vgl. Priemer et al. 2017, S. 21). 


\section{Aktivierung der Zivilgesellschaft}

Die Entwicklung der Zivilgesellschaft in Deutschland war in den vergangenen Jahren auch geprägt durch eine Zunahme des bürgerschaftlichen Engagements in den verschiedensten Formen; und wenn man den Umfragen glaubt, besteht auch noch ein erhebliches Aktivierungspotential.

Ein wichtiger Aspekt dieser Aktivierung sind neue Protestbewegungen. In Deutschland ist eine neue Protestlandschaft entstanden, die viele Gesichter, vor allem neue Gesichter, hat. Pegida, der neue Rechtspopulismus und der Protest gegen Einwanderung in Deutschland ist eine Facette dieser neuen Protestbewegungen. Aber: Vor Pegida gab es bereits die »Wutbürger«, das was Gassert (2018) den »Aufstand der Ausgebildeten « nennt und die Proteste gegen »Stuttgart 21《. Ein weiteres Gesicht sind die neuen Umweltproteste. Diese Umweltproteste haben zwei Seiten. $\mathrm{Zu}$ ihnen gehören zum einen die Schülerproteste von »Fridays for Future«, die im Jahr 2019 gerade in Deutschland große mediale Aufmerksamkeit gefunden haben; dazu gehören aber auch die Proteste gegen Dieselfahrverbote und die Demonstrationen von Landwirten gegen stärkere Umweltschutzauflagen. Die Corona-Proteste des Jahres 2020, insbesondere die "Querdenken«-Demonstrationen, sind ein weiteres neues Gesicht in der deutschen Protestlandschaft.

Besonders deutlich hat sich das große Engagementpotential in Deutschland in der sogenannten Flüchtlingskrise gezeigt. Das nach 2015 entstandene bürgerschaftliche Engagement gilt als »Sternstunde für die Zivilgesellschaft« (Schiffauer et al. 2017: 29) in Deutschland. Inzwischen liegen zahlreiche Studien vor, die die große Bedeutung der Zivilgesellschaft bei der Bewältigung der unmittelbaren Herausforderungen durch die Ankunft einer großen Zahl von Geflüchteten, ihre Unterbringung und Betreuung dokumentieren und die die sozialstrukturelle Zusammensetzung der Initiativen, die organisationale Vielfalt lokaler Aktivitäten, die Motivation der Beteiligten und das Zusammenwirken der unterschiedlichen Akteure untersuchen (Schiffauer et al. 2017; BMFSFJ 2017; vgl. dazu auch die Beiträge von Poweleit und van den Berg et al. in diesem Band).

Die sogenannte Flüchtlingskrise 2015 hat der Zivilgesellschaft einen starken Aktivierungsschub gegeben. In der Flüchtlingsbewegung haben 25 Prozent der Bundesbürger aktiv Hilfe geleistet. Schiffauer spricht in diesem Zusammenhang von einer "neuen Bürgerbewegung«. Wie eine vom Bundesfamilienministerium (BMBFSJ) beauftragte und vom Allensbach-Institut durchgeführte Studie zeigt, gehörten 21 Prozent derer, die zwischen 2015 
und 2017 in der Flüchtlingshilfe aktiv waren, vor 2015 weder zu Spendern, noch zu Aktiven in zivilgesellschaftlichem Engagement (BMFSFJ 2017). Das ist enorm viel. Die spannende Frage ist natürlich, was davon bleibt, wie nachhaltig dieses Engagement für die Zivilgesellschaft ist und welche längerfristigen Auswirkungen diese Aktivierung hat. Die Studie von van den Berg et al. (in diesem Band) zeigt, dass das Engagement in diesem Bereich schon vor der Corona-Pandemie vielerorts auf einen harten Kern von Engagierten geschrumpft war. Offensichtlich ist es höchst voraussetzungsvoll, spontane Aktivierung und Engagement für die dauerhafte Bildung von neuem sozialen Kapital zu nutzen.

\section{Politisierung der Zivilgesellschaft}

Wir wissen bereits seit geraumer Zeit, dass in den westlichen Demokratien ein grundlegender Wandel der politischen Konfliktstrukturen stattfindet (vgl. Kriesi et al. 2008). Dieser Wandel wurde ausgelöst durch Prozesse der gesellschaftlichen »Denationalisierung « in ihren verschiedenen Dimensionen: ökonomisch, politisch und sozio-kulturell; konkret: durch die Folgen globaler wirtschaftlicher Verflechtung, supranationaler Integration und transnationaler Migration. Dadurch ist ein neuer struktureller Konflikt zwischen neuen Gruppen von »Gewinnern« und »Verlierern« entstanden. In diesem Konflikt geht es um Integration oder Abgrenzung, um Öffnung oder Schließung von Märkten, von politischen Systemen und von sozialen Gemeinschaften. Für diese Konflikte waren bislang vor allem zwei Themen konstitutiv: Einwanderung und Europa. Diese Themen waren schon in den 1990er Jahren konfliktträchtig, durch die Eurokrise und die Flüchtlingskrise hat ihre politische Sprengkraft jedoch erheblich zugenommen. Durch diese neuen Konflikte ändern sich die Grundkoordinaten der Politik. Mit dem alten Links-RechtsSchema, das überwiegend die sozio-ökonomischen Konflikte der kapitalistischen Industriegesellschaft des 20 . Jahrhunderts abbildet, sind wir nicht in der Lage, die neuen kulturell-identitären Konflikte angemessen politisch zu verorten. Durch diese Konflikte ist ein zweidimensionaler politischer Raum entstanden, in dem die Unterscheidung von links und rechts ihre Aussagekraft verliert. In den vergangenen Jahren waren wir alle Zeugen der politischen Orientierungslosigkeit, die daraus resultiert (vgl. Grande 2018a).

Diese neuen Konflikte wirken sich nicht nur auf das Parteiensystem aus, sondern in die Zivilgesellschaft in ihrer ganzen Breite und Vielfalt hinein. Das hat zu einer Politisierung der Zivilgesellschaft geführt und diese Politisierung ist 
ein wichtiger und in Deutschland bislang unterschätzter Aspekt des Wandels der Zivilgesellschaft. Bei genauerer Betrachtung können wir mehrere Muster und Kanäle der Politisierung der Zivilgesellschaft unterscheiden (vgl. Grande 2018b):

- das Entstehen neuer zivilgesellschaftlicher Vereinigungen mit gesellschaftspolitischen Zielsetzungen (z.B. Menschenrechte, Flüchtlingshilfe). Die zahlreichen Helfervereine, die im Zuge der Flüchtlingskrise in Deutschland entstanden, sind das beste Beispiel hierfür;

- das Entstehen neuer sozialer Bewegungen "von rechts« zu den neuen Konfliktthemen (z.B. Pegida). Es gibt in Deutschland inzwischen zahlreiche Organisationen und Gruppierungen, durch die sich der Rechtspopulismus »als soziale Bewegung« (Rucht 2017) konstituiert und zu den neuen Konfliktthemen in der Zivilgesellschaft mobilisiert;

- die Politisierung bestehender zivilgesellschaftlicher Vereinigungen (z.B. Freizeitvereine) durch das gezielte Hineintragen neuer Konflikte (insb. durch die AfD und deren Bestrebungen um eine stärkere »Verankerung in der Gesellschaft «) in die Zivilgesellschaft, aber auch in Schulen und Betriebe;

- die Gegenmobilisierung gegen radikalen rechten Populismus. Die Aktivitäten rechtspopulistischer Parteien und Bewegungen treffen zunehmend auf politischen Widerstand und folgen dem bekannten Muster von Mobilisierung und Gegenmobilisierung, beispielhaft in den letzten Jahren in Chemnitz und Kandel.

Bei all dem zeigt sich, dass das zivilgesellschaftliche Engagement auch seine Schattenseiten hat. Offensichtlich sind auch die freiwilligen zivilgesellschaftlichen Assoziationen geprägt durch die in einer Gesellschaft dominierenden politischen Konflikte. Die Zivilgesellschaft ist dadurch in zunehmendem Maß der Gefahr von Polarisierungen und Spaltungen ausgesetzt, wie Vorländer und Schroeder et al. in ihren Beiträgen (in diesem Band) zeigen.

\section{Vor welchen Herausforderungen steht die Zivilgesellschaft in Deutschland?}

In der Gesamtschau zeigen die vorliegenden Studien, dass wir in Deutschland eine sehr aktive und vielfältige Zivilgesellschaft besitzen, die ein großes Ak- 
tivierungspotential hat. Das ist die gute Nachricht. Gleichzeitig ist aber auch erkennbar, dass sich die Zivilgesellschaft im Wandel befindet. Ihre Organisation und ihre Handlungsformen haben sich stark verändert. Und daraus folgt, so paradox es klingen mag: Die Zivilgesellschaft muss sich wandeln. Drei Aspekte sind aus meiner Sicht dabei besonders wichtig.

\section{Der Wandel der Zivilgesellschaft und das Problem der Beständigkeit}

Die erste Herausforderung, vor der die Zivilgesellschaft steht, ist das Problem der Beständigkeit, das sich aus dem Wandel ihrer Organisations- und Handlungsformen ergibt. Im Kern geht es um die Frage, wie in einer sich ständig wandelnden Welt von zivilgesellschaftlichen Initiativen Beständigkeit und nachhaltige Wirkung erreicht werden kann? Dieses Problem der Beständigkeit betrifft sowohl alte als auch neue Formen des bürgerschaftlichen Engagements, wenngleich auf unterschiedliche Weise. Besonders offensichtlich ist es bei der nahezu unüberschaubaren Vielzahl neuer Initiativen und Projekte. Die geringere Formalisierung von projektorientierten Engagementformen hat den großen Vorteil der Spontaneität, Flexibilität und Autonomie. Sie trägt ganz wesentlich zur großen Vitalität der Zivilgesellschaft bei. Aber das bringt auch das Problem der fehlenden Beständigkeit mit sich. Viele Projekte und Initiativen sind gar nicht auf längere Zeit ausgelegt, vielen anderen fehlen die Ressourcen dafür. Sie sind stark abhängig vom Engagement Einzelner, den besonders motivierten »Kümmerern « (Ebert et al. 2013), und der zeitlich befristeten Projektförderung. Ein nachhaltiger Aufbau neuen sozialen Kapitals ist auf diese Weise nur schwer, wenn überhaupt möglich.

Vor diesem Hintergrund hat der damalige baden-württembergischen Sozialminister Andreas Renner den Schluss gezogen: »Vereine sind besser als kurzfristiges Engagement. «In der praktischen Arbeit einer Kommune und einer kommunalen Verwaltung sind [...] die Vereine wesentlich wichtigere Ansprech- und Kooperationspartner als eher kurzfristig angelegte Aktionen und Initiativen, da nur Vereine Beständigkeit über längere Zeiträume hinweg garantieren können.« (Renner 2001, S. 185)

Aber das Problem der Beständigkeit betrifft, wie wir gesehen haben, auch die Vereine. In ihrem Fall zeigt es sich an der Schwierigkeit, junge Mitglieder zu rekrutieren und an der abnehmenden Bereitschaft, Ehrenämter zu übernehmen. Wenn sie nicht aussterben wollen, dann müssen sie sich an veränderte Bedingungen anpassen und neu positionieren. Wolfgang Schroeder hat das für die Gewerkschaften in seinem Beitrag (in diesem Band) skizziert. Kon- 
kret heißt das: Zivilgesellschaftliche Organisationen müssen ihre Zielsetzungen überdenken, ihre Organisationsstrukturen, ihre Tätigkeitsschwerpunkte, ihre Kommunikationsformen (Internetpräsenz, soziale Medien) und vieles mehr.

Die Stärkung der Beständigkeit der Zivilgesellschaft muss folglich an beiden Seiten ansetzen. Auf der einen Seite muss sichergestellt werden, dass bestehende Vereine erhalten bleiben. Gleichzeitig müssen aber auch neue Initiativen und Projekte so unterstützt werden, dass ihre Beständigkeit größer wird. Auf diese Weise sollte erreicht werden, dass die neue Welt der Initiativen und Projekte, die ein immer wichtigerer Teil der Zivilgesellschaft geworden ist, auch tatsächlich ein verlässlicher Ansprech- und Kooperationspartner von Kommunen, Verwaltungen usw. ist. Kurz gesagt: In der sich wandelnden Welt der Zivilgesellschaft muss zugleich Beständigkeit gesichert und Beständigkeit geschaffen werden.

\section{Wandel der gesellschaftlichen Handlungsbedingungen}

Die zweite Herausforderung, vor der die Zivilgesellschaft steht, ergibt sich aus dem gesellschaftlichen Wandel. Unsere Gesellschaft wird zunehmend geprägt durch den demographischen Wandel, die größere soziale Ungleichheit und durch Migrationsprozesse. Zugespitzt formuliert: Sie wird älter, ungleicher und diverser. Das ist eine Herausforderung für den gesellschaftlichen Zusammenhalt, es ist aber auch eine Herausforderung für die Zivilgesellschaft. Ich möchte hier nur auf ein Problem eingehen, das sich in diesem Zusammenhang für die Zivilgesellschaft stellt, das Problem der Inklusion und Integration.

Zivilgesellschaft ist ihrem Anspruch nach universell: Jeder kann dazu gehören. In der Realität ist sie aber exklusiv und selektiv (Kocka 2001). Der Freiwilligen-Survey aus dem Jahr 2014 zeigt dies für Deutschland sehr deutlich (vgl. Simonson et al. 2017; zum folgenden vgl. zusammenfassend S. 2127). Er kommt zu dem Ergebnis, dass

- Bürger mit höherer Bildung und höherem Einkommen sich überdurchschnittlich engagieren;

- ein ausgeprägtes Ost-West-Gefälle im Engagement besteht. Die Engagementquote beträgt ist Westdeutschland 44,8 Prozent, in Ostdeutschland nur 38,5 Prozent; 
- es ein deutliches Stadt-Land-Gefälle gibt: Das Engagement ist in ländlichen Kreisen höher als in städtischen Regionen; besonders niedrig ist es in Großstädten;

- es ein regionales Gefälle zwischen Regionen mit hoher und mit niedriger Arbeitslosigkeit gibt;

- Bürger mit Migrationshintergrund sich unterdurchschnittlich engagieren. Das gilt insbesondere für Menschen mit eigener Migrationserfahrung.

Die Zivilgesellschaft ist also alles andere als ein Spiegel der Gesellschaft. Die Frage ist dann: Wie kann die Zivilgesellschaft inklusiver werden? Wie können wir erreichen, dass durch bürgerschaftliches Engagement die vorhandenen Ungleichheiten und Spaltungen in unserer Gesellschaft verringert und nicht vergrößert werden?

Die Frage ist aber auch: Wie kann die Zivilgesellschaft integrativer werden? Wenn Spaltungen und Polarisierungen zunehmen, dann kommt es darauf an, Brücken zu bauen zwischen verschiedenen sozialen Gruppen und Milieus. Deswegen ist eine ganz entscheidende Frage, was die Zivilgesellschaft dazu beitragen kann, um solche Spaltungen und Polarisierungen abzubauen und abzuschwächen. Zugespitzt formuliert: Die Integrationskraft der Zivilgesellschaft muss gestärkt werden.

\section{Veränderte Handlungsräume und Handlungsbedingungen für Zivilgesellschaft}

Die dritte Herausforderung resultiert aus dem Wandel der Handlungsräume von Zivilgesellschaft. Drei Aspekte sind aus meiner Sicht hierbei von besonderer Bedeutung: die rechtlichen und politischen Handlungsbedingungen, die territorialen Handlungsräume und die Veränderungen in der Medienlandschaft.

Zunächst: In der Zivilgesellschaft wird seit einigen Jahren eine intensive Debatte über »shrinking spaces«, über die schrumpfenden Handlungsräume von Zivilgesellschaft geführt. Dabei handelt es sich um einen globalen Trend: Weltweit schrumpfen die Handlungsräume von Zivilgesellschaft, werden die Handlungsbedingungen für Zivilgesellschaft schlechter (vgl. Richter 2018). In Europa ist Ungarn sicherlich das prominenteste Beispiel hierfür. Nun ist Deutschland nicht Ungarn, aber die Entwicklungen dort sind ein wichtiger Hinweis darauf, dass die Zivilgesellschaft abhängig ist von ermöglichenden 
und unterstützenden politischen und rechtlichen Rahmenbedingungen. Diese politischen und rechtlichen Rahmenbedingungen können wir nicht selbstverständlich voraussetzen, auch nicht in Deutschland. In Deutschland hat 2019 das Attac-Urteil des Bundesfinanzhofs große Wellen geschlagen. Mit diesem Urteil wurde einer globalisierungskritischen zivilgesellschaftlichen Organisation der Status der Gemeinnützigkeit entzogen - und damit ihre Handlungsbedingungen erheblich geschwächt. Die Tagesschau fragte nach diesem Urteil: Ist die "Freiheit der Zivilgesellschaft in Gefahr?« (tagesschau.de vom 1.4.2019) Dieses Urteil steht in einer Reihe mit anderen Debatten, die alle in die gleiche Richtung weisen. Die Kontroverse um die Deutsche Umwelthilfe ist ein weiteres Beispiel. Die CDU hat im Dezember 2018 auf ihrem Bundesparteitag beschlossen, dass die Deutsche Umwelthilfe keine öffentlichen Fördermittel mehr bekommen soll. Die Botschaft, die von solchen Entscheidungen ausgeht, ist recht einfach zu verstehen: Wenn die Zivilgesellschaft etwas will, was uns nicht passt, dann drehen wir ihr den Geldhahn zu! Wir sollten also auch in Deutschland sensibilisiert sein für solche Entwicklungen und Möglichkeiten. Wenn es um grundsätzliche gesellschaftliche Konflikte geht, wenn diese Konflikte in der Zivilgesellschaft ausgetragen werden, und wenn die Zivilgesellschaft ein Schlüsselakteur in solchen Konflikten ist, dann ist auch damit zu rechnen, dass die Zivilgesellschaft, ihre Handlungsräume und Handlungsbedingungen, auf die eine oder andere Weise Gegenstand von politischen Angriffen wird.

Gleichzeitig erweitern sich die Handlungsräume von Zivilgesellschaft aber auch. Europa ist ein ganz wichtiger Teil dieser Erweiterung. So wichtig ihre lokale und nationale Verankerung ist, die Zivilgesellschaft hat sich längst auch in diesen neuen transnationalen Handlungsräumen vernetzt und positioniert. Sie ist dadurch zunehmend zu einem Spagat zwischen der Beteiligung an europäischen Politikprozessen einerseits und ihrer lokalen bzw. nationalen Verankerung gezwungen.

Und schließlich verändert sich der kommunikative Handlungsraum von Zivilgesellschaft. Wir befinden uns mitten in einem neuen Strukturwandel von Öffentlichkeit durch soziale Medien, in dessen Zuge die Reichweite der Kommunikation zwar enorm zugenommen hat, die Kommunikation in "sozialen Netzwerken« aber immer weniger über politische und gesellschaftliche Gruppen hinweg erfolgt. Daraus ergibt sich eine ganze Reihe von grundsätzlichen Fragen. Wie sind denn sogenannte "virtuellen Gemeinschaften «, also Formen von Netzwerkbildung, bei denen man lediglich über neue Kommunikationsmedien miteinander verbunden ist, aus Sicht der Zivilgesellschaft 
einzuordnen? Sind das überhaupt »Gemeinschaften«? Und wenn ja, sind sie dann Teil von Zivilgesellschaft? Wir wissen natürlich, dass diese neuen Medien auch Mobilisierungschancen mit sich bringen. Neue Protestbewegungen wie »Fridays for Future« wären ohne diese Mobilisierungs- und Kommunikationsmöglichkeiten schwer denkbar. Aber: Man kann mit den neuen sozialen Medien auch viel »zerstören« - nicht nur die CDU.

\section{Was kann man tun, um die Zivilgesellschaft in Deutschland zu stärken?}

Diese Auflistung erhebt keineswegs den Anspruch auf Vollständigkeit. Sie macht aber deutlich, dass die Zivilgesellschaft in Deutschland vor großen Herausforderungen steht. Die Zivilgesellschaft kann nicht davon ausgehen, dass der Handlungsraum, in dem sie sich bewegt, konstant bleibt. Die Zivilgesellschaft muss sich an diese veränderten Handlungsbedingungen anpassen, auf welche Weise auch immer. Bei näherer Betrachtung ist auch erkennbar geworden, dass die Zivilgesellschaft die Bedingungen für ihre Bestands-, Handlungs- und Leistungsfähigkeit nicht selbst schaffen und garantieren kann. Was für den Staat gilt, das gilt auch für die Zivilgesellschaft. Daraus folgt aus meiner Sicht, dass die Zivilgesellschaft Unterstützung benötigt, um die von mir skizzierten Herausforderungen bewältigen zu können. Eine lebendige Zivilgesellschaft benötigt eine aktive Engagementpolitik zur gezielten Förderung nachhaltigen bürgerschaftlichen Engagements.

Was genau könnte man nun aber tun, um die Zivilgesellschaft bei der Bewältigung der Herausforderungen, vor denen sie steht, zu unterstützen? Ich möchte abschließend einige Vorschläge einer Expertenkommission - der Kommission »Sicherheit im Wandel« - präsentieren, in der ich mitgearbeitet habe. Diese Kommission hat sich mit der Frage beschäftigt, wie man den gesellschaftlichen Zusammenhalt in Deutschland stärken kann. Sie hat sich in diesem Zusammenhang auch ausführlich mit der Zivilgesellschaft beschäftigt, weil sie davon ausgegangen ist, dass die Zivilgesellschaft der "Zement der Gesellschaft« (Diani 2015) ist. Die Kommission diskutierte eine ganze Reihe von Vorschlägen, von denen sich einige in ihrem Abschlussbericht wiederfinden (vgl. Zentrum Liberale Moderne 2019).

Die Kommission war sich einig, dass ein wichtiger Ansatzpunkt für die Stärkung von bürgerschaftlichem Engagement in den Schulen liegt. Auch Engagement kann und muss gelernt werden und Schulen werden immer wich- 
tiger als Orte für das Engagementlernen. Ein erster Vorschlag betrifft deshalb den Ausbau und die stärkere Förderung schulischer Projekte zum sogenannten »Service Learning«. In solchen Projekten geht es um das Erlernen von bürgerschaftlichem Engagement als Teil schulischer Aktivitäten. Eine andere Möglichkeit sind »Kohäsionsprojekte«, in denen Jugendliche aus allen sozialen Schichten schulübergreifend in sozialen Projekten zusammenarbeiten. In beiden Fällen sollte das Engagement in Zusammenarbeit mit lokalen Vereinen, Initiativen und Projekten stattfinden. Auf diese Weise kann zum einen in Zusammenarbeit von Schulen und lokalen zivilgesellschaftlichen Organisation Engagement gelernt werden, zum anderen können aber auch die Brücken geschlagen werden zu den lokalen Vereinen und Initiativen, und so die organisierte Zivilgesellschaft besser vernetzt und gestärkt werden.

Der zweite Vorschlag betrifft den Ausbau von Freiwilligendiensten für Jugendliche zu einer verbindlicheren Form des Engagements. Derzeit wird in Deutschland ja die Einführung eines »sozialen Pflichtjahres« diskutiert, das an die Stelle der abgeschafften Wehrpflicht treten könnte. Die Kommission ist diesem Vorschlag nicht gefolgt. Sie war sich einig, dass Freiwilligkeit ein wichtiger Aspekt des Engagements bleiben sollte. Das schließt nicht aus, dass es eine neue, erweiterte Struktur von freiwilligem Engagement mit größerer Verbindlichkeit für junge Menschen geben könnte. Entscheidend sollte dabei ein hohes Maß an Freiwilligkeit und Flexibilität auf der einen Seite, die Einbindung in bestehende Strukturen des zivilgesellschaftlichen Engagements andererseits sein. Wichtig hierbei ist, dass die Gesellschaft die klare Erwartung an junge Menschen formuliert: Wir wollen, dass Du etwas für die Gesellschaft tust! Du darfst selbst entscheiden, was Du machst und wie Du das machst, aber Nichtstun ist keine akzeptable Option.

Der dritte Vorschlag versucht Antworten auf die Frage zu geben, wie man dem drohenden Vereinssterben entgegenwirken kann. Ein wichtiger Ansatzpunkt hierbei ist die Förderung von professionellen Strukturen in den Gemeinden - nicht als Ersatz für ehrenamtliches Engagement, sondern zur Unterstützung von Vereinen und bürgerschaftlichen Initiativen. In den kommunalen Verwaltungen sollte es eine verlässliche professionelle Unterstützung für die Zivilgesellschaft geben. Zugespitzt formuliert: Wir brauchen auf kommunaler Ebene Stellen für die Förderung und Unterstützung von Zivilgesellschaft und die Stärkung von gesellschaftlichem Zusammenhalt. Das ist genauso wichtig wie die Wirtschafts- und Standortförderung. Hierzu gibt es in zahlreichen Städten und Gemeinden bereits Aktivitäten und Initiativen, aber die Notwendigkeit der Förderung der Zivilgesellschaft ist im öffentlichen Be- 
wusstsein und in den öffentlichen Verwaltungen noch bei weitem nicht so stark verankert, wie dies notwendig wäre. Um das zu erkennen, genügt der Blick auf die Organisationspläne der Gemeinde- und Stadtverwaltungen.

Gleichzeitig muss die nachhaltige Finanzierung von zivilgesellschaftlichen Initiativen und Projekten auf eine neue Basis gestellt werden. Das betrifft insbesondere die neue Form von zivilgesellschaftlichen Initiativen und Projekten, die sich nicht über Mitgliedsbeiträge finanzieren können und die in stärkerem Maße abhängig von staatlichen Zuwendungen sind. Diese staatlichen Zuwendungen kommen vielfach aus zeitlich befristeten Förderprogrammen, es gibt zumeist keine auf Nachhaltigkeit angelegte Finanzierung. Für Projekte und Initiativen, die nur für begrenzte Zeit geplant sind, ist das kein Problem. Am Beispiel der Helferprojekte und -initiativen im Bereich der Geflüchtetenhilfe hat sich aber wieder gezeigt, dass zwei- bis drei-jährige Förderphasen unzureichend sind und dass nicht wenige dieser Initiativen und Projekte nicht wissen, wie es am Ende des Jahres weitergeht. Das ist ein strukturelles Problem dieser Art von Initiativen, die auf der einen Seite großen Wert auf ihre Unabhängigkeit vom Staat legen, die auf der anderen Seite aber eben doch immer wieder abhängig sind von öffentlichen Mitteln. In diesem Zusammenhang könnte eine Engagementstiftung eine wichtige Rolle spielen, nicht als weiteres Füllhorn für Projekte, sondern um so eine dauerhafte Finanzierungsquelle für die Zivilgesellschaft zu schaffen, die unabhängig ist von den jährlichen Haushalten von Ministerien und ihren befristeten Förderprogrammen ist. Die Gründung der Deutschen Stiftung für Engagement und Ehrenamt, die im Juli 2020 ihre Arbeit aufgenommen hat, ist ein erster Schritt in diese Richtung.

Ein weiterer wichtiger Punkt ist die bessere Verzahnung von Erwerbsarbeit und bürgerschaftlichem Engagement. In Deutschland setzte bereits in den 1990er Jahren eine Debatte über die »bezahlte Bürgerarbeit« ein, in der versucht wurde, neue Arbeitskonzepte für die »post-industrielle Gesellschaft« $\mathrm{zu}$ entwickeln (vgl. Kommission für Zukunftsfragen 1997). Inzwischen wurden zahlreiche Gründe gegen die Einführung einer solchen bezahlten Bürgerarbeit vorgebracht, gerade auch aus der Zivilgesellschaft selbst. Aber die Grundfrage dieser Debatte bleibt weiterhin aktuell und wichtig: Wie kann die Durchlässigkeit zwischen der Arbeitswelt auf der einen Seite und dem ehrenamtlichen Engagement auf der anderen Seite verbessert werden, wenn die Arbeitswelt flexibler wird, und wenn gleichzeitig die ehrenamtlichen Tätigkeiten umfangreicher und anspruchsvoller werden. Eine Lösung wäre die Einführung eines bezahlten »Engagementurlaubs«. Auf diese Weise würde es 
berufstätigen Menschen möglich, zeitweilig in größerem Umfang gemeinnützige Aufgaben zu übernehmen. Eine weitere Möglichkeit wäre die Förderung von Pro Bono-Aktivitäten von Mitarbeitern durch die Unternehmen. Davon würde im Übrigen nicht nur die Zivilgesellschaft profitieren; die von Mitarbeitern im Rahmen ihrer sozialen und kulturellen Tätigkeiten gesammelten Erfahrungen könnten auch den Unternehmen zu Gute kommen. Beide Beispiele zeigen auch: Die Förderung von bürgerschaftlichem Engagement ist nicht nur eine Aufgabe des Staates, dabei sind auch die Unternehmen gefordert.

Schließlich kann das bürgerschaftliche Engagement durch die Einrichtung von neuen Dialog- und Beteiligungsformaten, vor allem in den Kommunen, gestärkt werden. Zivilgesellschaftliches Engagement setzt ja nicht nur die Bereitschaft der Bürger zum Engagement voraus, sondern auch geeignete Gelegenheiten und Freiräume für Beteiligung. Inzwischen gibt es auf lokaler Ebene eine Vielzahl von Initiativen, um Bürger zu aktivieren und zu motivieren, und ihre Ideen in Bürgerdialogen, Bürgerforen und anderem mehr zu artikulieren. Die Kommunen haben sich in den letzten Jahren zu spannenden Experimentierfeldern für neue Formen der demokratischen Beteiligung entwickelt. Angesichts der zunehmenden Spaltungen in unserer Gesellschaft sollte bei der Förderung der Engagementbereitschaft der Bürger das Bauen von Brücken zwischen verschiedenen sozialen Gruppen und die Verbesserung der Dialogfähigkeit und -bereitschaft eine zentrale Rolle spielen. Besonders wichtig scheinen mir Projekte, in denen es nicht nur um das »Mitreden « geht, und in deren Mittelpunkt das "gemeinsame Machen « steht, wie dies in der nachbarschaftlichen Selbsthilfe, in Bürgergenossenschaften, Dorfläden etc. der Fall ist. Auch solche Projekte bedürfen vielfach der öffentlichen Förderung, wie sie zum Beispiel das neue »Impulsprogramm gesellschaftlicher $\mathrm{Zu}$ sammenhalt« des Landes Baden-Württemberg zur Verfügung stellt.

Kurz gesagt: Es gibt viele Möglichkeiten, wie man die Zivilgesellschaft fördern und stärken kann. Die Beiträge dieses Bandes haben deutlich gemacht, dass die Zivilgesellschaft in der Geschichte der Bundesrepublik wichtig und notwendig war. Jetzt kommt es darauf an, etwas tun, damit sie auch in $\mathrm{Zu}$ kunft das leisten kann, was von ihr erwartet. Gerade in der Corona-Pandemie ist dies besonders offensichtlich geworden. 


\section{Literaturhinweise}

BMFSFJ (2017): Engagement in der Flüchtlingshilfe - Ergebnisbericht einer Untersuchung des Instituts für Demoskopie Allensbach. Berlin: BMFSFJ.

Diani, Mario (2015): The Cement of Society. Studying Networks in Localities. Cambridge: Cambridge University Press.

Deutscher Bundestag (2020): Dritter Engagementbericht Zukunft Zivilgesellschaft: Junges Engagement im digitalen Zeitalter, 19. Wahlperiode 14.05.2020, Drucksache 19/19320.

Ebert, Olaf/Leseberg, Nina/Pautzke, Andreas/Stuth, Ana-Maria/Quednau, Tobias (2013): Kümmerer - Motoren der Bürgergesellschaft. In: Forschungsjournal Soziale Bewegungen, 26 (4), S. 88ff.

Enquete-Kommission (2002): Bericht der Enquete-Kommission $\gg Z u k u n f t$ des Bürgerschaftlichen Engagements«: Bürgerschaftliches Engagement: auf dem Weg in eine zukunftsfähige Bürgergesellschaft. Deutscher Bundestag, 14. Wahlperiode, Drucksache 14/8900.

Etzioni, Amitai (1975): Die aktive Gesellschaft. Wiesbaden: VS Verlag.

Gassert, Philipp (2018): Bewegte Gesellschaft. Deutsche Protestgeschichte seit 1945. Stuttgart: Kohlhammer.

Grande, Edgar (2018a): Der Wandel politischer Konfliktlinien - Strategische Herausforderungen und Handlungsoptionen für Volksparteien. In: Mack, Winfried (Hg.), Zwischen Offenheit und Abschottung. Wie die Politik zurück in die Mitte findet. Freiburg: Herder, S. 17-43.

Grande, Edgar (2018b): Zivilgesellschaft, politischer Konflikt und soziale Bewegungen. In: Forschungsjournal Soziale Bewegungen, 31(1-2), S. 52-59.

Inglehart, Ronald (1998): Modernisierung und Postmodernisierung. Frankfurt a.M.: Campus.

Klie, Thomas/Klie, Anne Wiebke (Hg.) (2018): Engagement und Zivilgesellschaft. Expertisen und Debatten zum zweiten Engagementbericht. Wiesbaden: Springer VS.

Kocka, Jürgen (2001): Zivilgesellschaft. Zum Konzept und seiner sozialgeschichtlichen Verwendung. In: Kocka, Jürgen/Nolte, Paul/Randeria, Shalini/Reichardt, Sven, Neues über Zivilgesellschaft. Aus historisch-sozialwissenschaftlichem Blickwinkel. WZB Discussion Papers 01(801). Berlin: WZB, S. 4-21.

Kommission für Zukunftsfragen der Freistaaten Bayern und Sachsen (1997): Erwerbstätigkeit und Arbeitslosigkeit in Deutschland: Entwicklung, Ursachen, Maßnahmen, München. 
Kriesi, Hanspeter/Grande, Edgar/Lachat, Romain/Dolezal, Martin/Bornschier, Simon/Frey, Timotheus (2008): West European Politics in the Age of Globalization. Cambridge: Cambridge University Press.

Mayntz, Renate (1963): Soziologie der Organisation. Reinbek bei Hamburg: Rowohlt.

Neidhart, Friedhelm/Rucht, Dieter (1993): Auf dem Weg in die Bewegungsgesellschaft. In: Soziale Welt, 44(3), S. 305-326.

Priemer, Jana/Krimmer, Holger/Labigne, Anaël (2017): ZiviZ-Survey 2017: Vielfalt verstehen. Zusammenhalt stärken. Berlin: Stifterverband.

Putnam, Robert D. (1995): Bowling Alone: America's Declining Social Capital. In: Journal of Democracy, 6(1), 65-78.

Reckwitz, Andreas (2018). Die Gesellschaft der Singularitäten: Zum Strukturwandel der Moderne. Berlin: Suhrkamp.

Renner, Andreas, 2001: Vereine sind besser als kurzfristiges Engagement. In: Teufel, Erwin (Hg.), Von der Risikogesellschaft zur Chancengesellschaft. Frankfurt a.M.: Suhrkamp.

Richter, Thomas (2018): Weltweit verringerte Handlungsspielräume von Zivilgesellschaft. In: GIGA FOCUS GLOBAL, Nr. 5, Dezember 2018, S. 1-13.

Rucht, Dieter (2017): Rechtspopulismus als soziale Bewegung. In: Forschungsjournal Soziale Bewegungen, 30(2), S. 34-50.

Schiffauer, Werner/Eilert, Anne/Rudloff, Marlene (Hg.) 2017: So schaffen wir das - eine Zivilgesellschaft im Aufbruch. 90 wegweisende Projekte mit Geflüchteten. Bielefeld: transcript.

Simonson, Julia/Vogel, Claudia/Tesch-Römer, Clemens (Hg.) (2017): Freiwilliges Engagement in Deutschland. Der Deutsche Freiwilligensurvey 2014. Wiesbaden: Springer VS.

Zentrum Liberale Moderne (Hg.) (2019): Abschlussbericht der Kommission »Sicherheit im Wandel - Gesellschaftlicher Zusammenhalt in Zeiten stürmischer Veränderung«. Berlin: Zentrum Liberale Moderne. 



\section{Autorinnen und Autoren}

Grande, Brigitte, M.A., Vorsitzende des Freundeskreises der Evangelischen Akademie Tutzing

Grande, Edgar, Prof. Dr., Gründungsdirektor des Zentrums für Zivilgesellschaftsforschung am Wissenschaftszentrum für Sozialforschung Berlin (WZB)

Greef, Samuel, Dr., Wissenschaftlicher Mitarbeiter am Fachgebiet »Politisches System der BRD - Staatlichkeit im Wandel« an der Universität Kassel

Hahn, Udo, Pfr., Direktor der Evangelischen Akademie Tutzing

Heller, Lukas, Wissenschaftlicher Mitarbeiter am Fachgebiet »Politisches System der BRD - Staatlichkeit im Wandel« an der Universität Kassel

Hutter, Swen, Prof. Dr., Lichtenberg-Professor für Politische Soziologie an der Freien Universität (FU) Berlin; stellvertretender Direktor des Zentrums für Zivilgesellschaftsforschung am Wissenschaftszentrum für Sozialforschung Berlin (WZB)

Poweleit, Julia, Ehrenamtliche, Asyl im Oberland

Röbke, Thomas, Dr., Geschäftsführender Vorstand des Landesnetzwerks Bürgerschaftliches Engagement Bayern e. V. und Vorsitzender des BBESprecher*innenrates 
Rucht, Dieter, Prof. Dr., Protestforscher; Fellow am Wissenschaftszentrum für Sozialforschung Berlin (WZB); bis 2011 Ko-Leiter der Forschungsgruppe »Zivilgesellschaft, Citizenship und politische Mobilisierung in Europa« am WZB

Scheel, Christine, MdB a.D., Vorsitzende des Kuratoriums der Evangelischen Akademie Tutzing

Schmidt, Manfred G., Prof. Dr. Dr. h.c., Professor em. für Politikwissenschaft an der Universität Heidelberg

Schroeder, Wolfgang, Prof. Dr., Leiter des Fachgebiets »Politisches System der BRD - Staatlichkeit im Wandel« an der Universität Kassel und Fellow am Wissenschaftszentrum für Sozialforschung Berlin (WZB)

Ten Elsen, Jennifer, Wissenschaftliche Mitarbeiterin am Fachgebiet »Politisches System der BRD - Staatlichkeit im Wandel« an der Universität Kassel

Thierse, Wolfgang, Dr., Bundestagspräsident a.D., Leiter des Politischen Clubs der Evangelischen Akademie Tutzing

Van den Berg, Clara, M.A., Wissenschaftliche Mitarbeiterin im Zentrum für Zivilgesellschaftsforschung am Wissenschaftszentrum für Sozialforschung Berlin (WZB)

Vorländer, Hans, Prof. Dr., Professor für Politische Theorie und Ideengeschichte am Institut für Politikwissenschaft/Direktor am Zentrum für Verfassungs- und Demokratieforschung und Mercator Forum Migration und Demokratie an der TU Dresden 


\section{Politikwissenschaft}
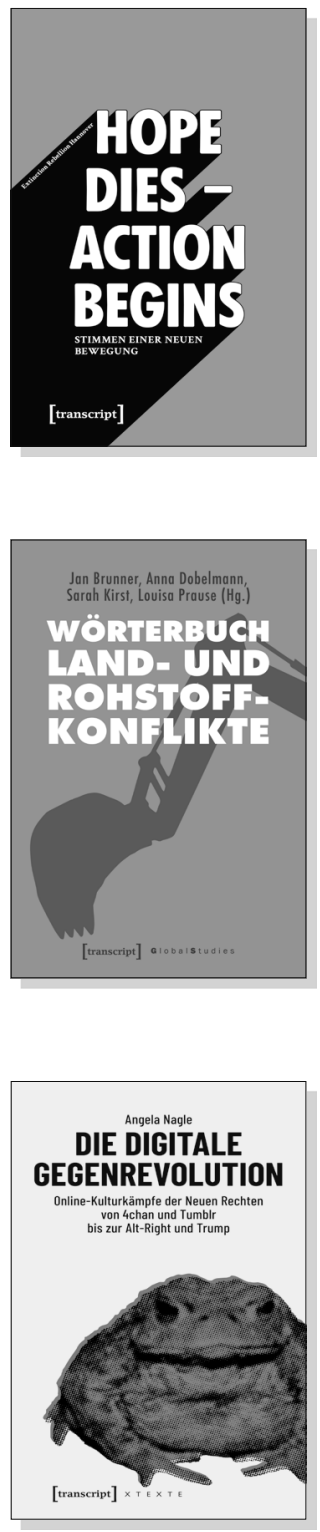

Extinction Rebellion Hannover

"Hope dies - Action begins":

\section{Stimmen einer neuen Bewegung}

2019, 96 S., kart.

7,99 € (DE), 978-3-8376-5070-9

E-Book: kostenlos erhältlich als Open-Access-Publikation, ISBN 978-3-8394-5070-3

EPUB: kostenlos erhältlich als Open-Access-Publikation, ISBN 978-3-7328-5070-9

Jan Brunner, Anna Dobelmann,

Sarah Kirst, Louisa Prause (Hg.)

\section{Wörterbuch Land- und Rohstoffkonflikte}

2019, 326 S., kart., Dispersionsbindung, 1 SW-Abbildung 24,99€ (DE), 978-3-8376-4433-3

E-Book: 21,99 € (DE), ISBN 978-3-8394-4433-7

Angela Nagle

Die digitale Gegenrevolution

Online-Kulturkämpfe der Neuen Rechten

von 4chan und Tumblr bis zur Alt-Right und Trump

2018, 148 S., kart.

$19,99 €(D E), 978-3-8376-4397-8$

E-Book: 17,99 € (DE), ISBN 978-3-8394-4397-2

EPUB: $17,99 €$ (DE), ISBN 978-3-7328-4397-8 


\section{Politikwissenschaft}

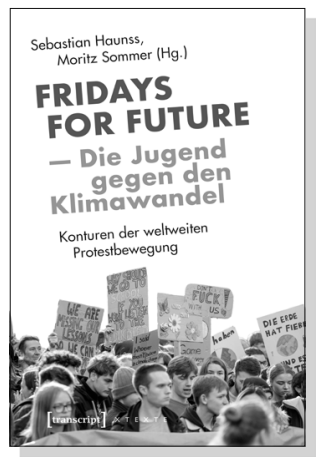

Sebastian Haunss, Moritz Sommer (Hg.)

Fridays for Future -

Die Jugend gegen den Klimawandel

Konturen der weltweiten Protestbewegung

Oktober 2020, 264 S., kart.

22,00€ (DE), 978-3-8376-5347-2

E-Book: kostenlos erhältlich als Open-Access-Publikation

PDF: ISBN 978-3-8394-5347-6

ISBN 978-3-7328-5347-2

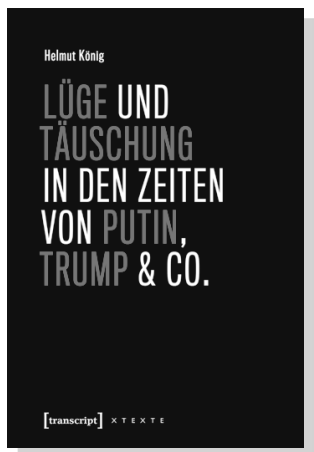

Helmut König

Lüge und Täuschung in den Zeiten von Putin, Trump \& Co.

September 2020, 360 S., kart.

29,50€ (DE), 978-3-8376-5515-5

E-Book:

PDF: $26,99 €$ (DE), ISBN 978-3-8394-5515-9

EPUB: $26,99 €$ (DE), ISBN 978-3-7328-5515-5

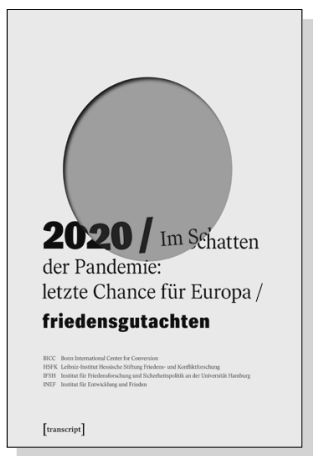

BICC Bonn International Center for Conversion, HSFK Leibniz-Institut Hessische Stiftung Friedens- und Konfliktforschung, IFSH Institut für Friedensforschung und Sicherheitspolitik an der Universität Hamburg, INEF Institut für Entwicklung und Frieden

\section{Friedensgutachten 2020}

Im Schatten der Pandemie: Ietzte Chance für Europa

Juni 2020, 160 S., kart., 33 Farbabbildungen 15,00€ (DE), 978-3-8376-5381-6

E-Book: kostenlos erhältlich als Open-Access-Publikation PDF: ISBN 978-3-8394-5381-0 